\author{
Universidade de São Paulo \\ Instituto de Física
}

\title{
Estudos estruturais de sistemas biológicos utilizando métodos de espalhamento
}

\author{
Renata Naporano Bicev
}

Orientador: Prof. Dr. Cristiano Luis Pinto de Oliveira

Dissertação de mestrado apresentada ao Instituto de Física para a obtenção do título de Mestre em Ciências

Banca Examinadora:

Prof. Dr. Cristiano Luis Pinto de Oliveira (IFUSP)

Prof. Dr. Leandro Barbosa (IFUSP)

Prof. Dr. Roberto Kopke Salinas (IQUSP) 


\section{FICHA CATALOGRÁFICA \\ Preparada pelo Serviço de Biblioteca e Informação do Instituto de Física da Universidade de São Paulo}

Bicev, Renata Naporano

Estudos estruturais de sistemas biológicos utilizando métodos de espalhamento São Paulo, 2015.

Dissertação (Mestrado) - Universidade de São Paulo. Instituto de Física. Depto. de Física Experimental

Orientador: Prof. Dr. Cristiano Luis Pinto de Oliveira.

Área de Concentração: Física.

Unitermos: 1. SAXS; 2. Proteínas; 3.Proteassomo. 
À minha avó Angelina, com saudades... 



\section{Agradecimentos}

Acima de tudo agradeço a Deus.

Agradeço ao Prof. Cristiano Luis Pinto de Oliveira pela confiança, dedicação e paciência na orientação. Além de todas as oportunidades e apoio para minha formação.

À Capes, Inctfcx pelo apoio financeiro.

Agradeço à Prof. Marilene Demasi, do Instituto Butantan, por toda a orientação e discussão bioquímica, e pela oportunidade de usar o laboratório de Bioquímica. Essa colaboração me proporcionou uma visão de mundo multidiscplinar. Agradeço também ao Adrian por me ensinar e me acompanhar nos experimentos de síntese e purificação do Proteassomo e à Janaína pelas discussões sobre esse sistema.

Agradeço à Prof. Elisabeth Andreoli de Oliveira, por ter me mostrado os caminhos desse mundo da pesquisa, me incetivado e diversas vezes me escutado e aconselhado.

Agradeço ao Hélio José Araújo Brandão, por ter literalmente dado o sangue á esta pesquisa. Peço-lhe também desculpas, por não termos conseguido atingir todos os objetivos que queríamos.

Agradeço meus grandes amigos, que tive o prazer de dividir sala Rafael Rubim, 
Vivian Vieira, Emerson Rodrigo e as agregadas da sala, Talita Fujimoto e Maria Melo. Tenho certeza que pude crescer muito,não só em relação à pesquisa científica, mas em relação a vida. Foram muitos os momentos de discussão sobre ciência e sobre a vida. Ali nós rimos, choramos e assim, sempre tivemos a certeza de que o "Futuro é lindo!". Agradeço também ao Cassio Alves, o amigo que nunca mediu esforços para ajudar. E a Priscila Santos pelo apoio e diversas discussões.

Aos colegas do grupo, Alexander Duarte, André Luiz, Barbara Gerbelli, Celso Risi, Eduardo Gonçalves, Eraldo de Sales, Erol,Luis Henrique, Pedro Leonidas, pela convivência nos laboratórios, principalmente na 108, que rendeu discussões e sugestões.

Aos técnicos do grupo, principalmente ao Társis e ao Dennys por toda ajuda na coleta dos dados de SAXS.

Ao Laboratório de Cristalografia pelo uso de suas dependências.

As minhas amigas de longa data, Barbara Bentivoglio, Bruna Capuzo, Bruna Leonardi, Juliana Galati, Gabriela Zago, Marília de Almeida, Melina Nonomura, Nathalia Gouveia, pela companhia e incentivo.

À querida família Serafim por todo o carinho sempre!

Ao Rafael Serafim, pessoa especial com quem compartilho muitos momentos, e ao Zeca, meu companheiro de quatro patas, por sempre estarem ao meu lado.

E por fim, agradeço a minha família, a base de tudo. Minha mãe Anabela, meu pai João, meu irmão Renato, minhas sobrinhas Júlia e Angelina, e minha cunhada Luciana. Por nunca deixarem faltar nada, por todo apoio e compreensão.

Muito obrigada a todos! 
"Vá até onde sua vista alcançar e, ao chegar lá, você sempre conseguirá enxergar mais longe"

(Autor Desconhecido) 



\section{Resumo}

Neste trabalho serão apresentados resultados sobre três sistemas proteícos diferentes: Lisozima, Crioglobulina e Proteassomo, analisados a partir, principalmente, da técnica de espalhamento de Raios X a baixos ângulos. Técnicas como microscopia eletrônica de transmissão e espalhamento de luz dinâmico foram utilizadas como técnicas complementares.

Os resultados apresentados demonstram o potencial único que a técnica de espalhamento a baixos ângulos possui no estudo de sistemas em solução. Os dados correspondem a um estudo em um grande intervalo de tamanhos para as proteínas estudadas ( $15 \mathrm{kDa}$ to $750 \mathrm{kDa})$, requerendo diferentes abordagens em cada caso. Como será mostrado, para casos onde se tem um meio monodisperso, diversas metodologias de modelagem podem ser utilizadas.

Para o sistema composto de Lisozima, por se tratar de uma proteína amplamente estudada na literatura, é interesante poder comparar os resultados encontrados com os já publicados e observar sua estabilidade em solução. O peso molecular calculado a partir dos dados de espalhamento foi $15 k D a$, que está em bom acordo com a esperado para esta proteina $(14,6 k D a)$. Além disso, ao variar-se a concentração da proteína em solução, é possível observar um fator de interação entre as partículas para maiores concentrações. Esse fator de interação pode ser considerado próximo ao de esferas rígidas.

Para o sistema de Crioglobulinas, houve uma dificuldade na purificação da amostra, mas ainda assim apresentaremos alguns resultados interessantes, em que a técnica de SAXS fornece informações sobre a flexibilidade de proteínas e as análises para as amostras de um pool de imunoglobulinas indicou que com a diminuição da temperatura a dispersão de raios de giro aumenta, indicando a formação de agregados.

Para o sistema do Proteassomo, diversas análises se mostraram possível e resultados novos puderam ser obtidos e publicados. Dos estudos utilizando MET, com as micrografias obtidas tem-se a indicação de diferenças na estrutura, quando a molécula está em condições diferentes. Das análises feitas por SAXS, é possível utilizar duas modelagens diferentes, uma simples, outra mais avançada, em que se pode concluir que a redução do Cys-PT glutatiolado induz mudanças conformacionais. Além disso, resultados de SAXS e MET estão em concordância e fornecem informações complementares.

Palavras-chaves: SAXS, Proteínas, Proteassomo 



\section{Abstract}

In this work results will be presented on three different protein system: Lysozime, Cryoglobulin and Proteasome, analyzed mainly by Small Angle X-ray scattering technique. Techniques such as transmission electron microscopy and dynamic light scattering were used as complementary techniques.

The results show that an unic potential Small Angle X-ray scattering technique around the study of systems in solution. The data correspond to a study of a wide range of sizes for the studied proteins $(15 \mathrm{kDa}$ to $750 \mathrm{kDa})$, requiring different approaches in each case. As will be shown for cases where there is a monodisperse system, different modeling methodologies may be used.

For the system composed of Lysozyme, because it is a protein widely studied in the literature, it is interesting to compare the results with those already published and observe its stability in solution. The molecular weight calculated from the scattering data was $15 k D a$, which is in good agreement with the expected for this protein $(14.6 \mathrm{kDa})$. Futhermore by varying the concentration of the protein in solution, it is possible to observe a factor of interaction between the particles for higher concentrations. This interaction factor can be considered close to the rigid spheres.

For Cryoglobulins system, there was a difficulty in the sample purification, but still present some interesting results, where the SAXS technique provides information on the flexibility of proteins and the analysis for the samples from a pool of immunoglobulin indicated that with decreasing temperature, the dispersion of radius of gyration increases, indicating the formation of aggregates.

For the proteasome system, various analyzes have proved possible and new results could be obtained and published. From studies using TEM, with the micrographs we have the indication of differences in the structure, when the molecule is in different conditions. From the analyzes made by SAXS, it is possible to use two different modeling, a simple one, and other more advanced, where it can be concluded that the reduction of the Cys-PT glutathiolated induces conformational changes. Moreover, SAXS and TEM results are in agreement and provide additional information.

Key-words:SAXS, Proteins, Proteasome 



\section{Lista de ilustrações}

Figura 1 - Representação esquemática de um experimento de SAXS em solução $[23]$.

Figura 2 - Intensidades de espalhamento e funções distribuição de pares de distância p(r) calculadas para tipicas formas geométricas. Adaptada de $[23]$

Figura 3 - Exemplo de gráficos do Tipo Kratky Plot. Em (a) temos uma proteína compacta, enquanto em (b) uma proteína flexivel (figura adaptada da tese de doutorado de Cristiano Luis Pinto de Oliveira). . . . . . . . . . 36

Figura 4 - Os 20 aminoácidos formadores de proteínas (Retirada de: $[=[\ldots \ldots$

Figura 5 - Estrutura Geral dos Aminoácidos . . . . . . . . . . . . . . 38

Figura 6 - Representação da ligação peptídica (Retirado de: $[=[\ldots \ldots$. . . . . . 38

Figura 7 - Representação dos níveis de estrutura de uma proteína (Adaptada de:

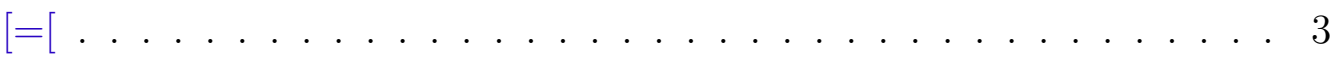

Figura 8 - Sequência primária e predição da estrutura secundária da Lisozima [6]

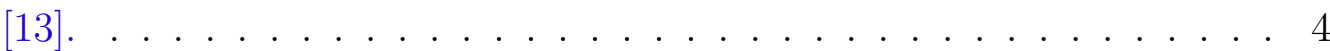

Figura 9 - Representação da estrutura cristalográfica da Lisozima em cartoon, entrada no PDB: $2 \mathrm{LYZ}[6] \ldots \ldots \ldots \ldots$. . . . . . . . . . . . 41

Figura 10 -Modelo antígeno-anticorpo (Adaptada de: $[=[\ldots \ldots$. . . . . . . . . 42

Figura 11 -Representação do proteassomo (Adaptado de [11]) . . . . . . . . . . . . 44

Figura 12 -Legenda da predição das estruturas secundárias apresentadas nas figu$\operatorname{ras} 13$ a 26 
Figura 13 - Predição da estrutura secundária das subunidades 1 e 2 do proteassomo $20 \mathrm{~S}[13] \ldots \ldots \ldots \ldots \ldots \ldots \ldots \ldots$

Figura 14 - Predição da estrutura secundária das subunidades 3 e 4 do proteassomo

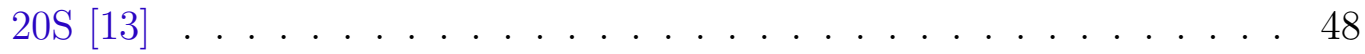

Figura 15 - Predição da estrutura secundária das subunidades 5 e 6 do proteassomo $20 \mathrm{~S}[13] \ldots \ldots \ldots \ldots$

Figura 16 - Predição da estrutura secundária das subunidades 7 e 8 do proteassomo

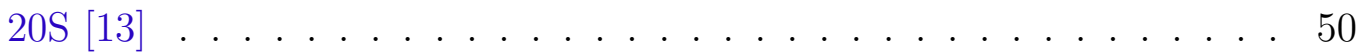

Figura 17 - Predição da estrutura secundária das subunidades 9 e 10 do proteas-

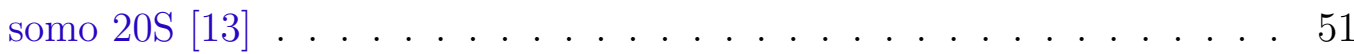

Figura 18 - Predição da estrutura secundária das subunidades 11 e 12 do proteas-

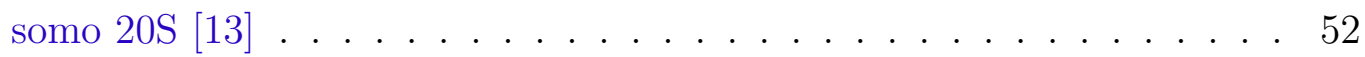

Figura 19 - Predição da estrutura secundária das subunidades 13 e 14 do proteassomo $20 \mathrm{~S}[13] \ldots \ldots \ldots \ldots \ldots \ldots \ldots$

Figura 20 - Predição da estrutura secundária das subunidades 15 e 16 do proteassomo $20 \mathrm{~S}[13] \ldots \ldots \ldots \ldots \ldots \ldots \ldots$

Figura 21 - Predição da estrutura secundária das subunidades 17 e 18 do proteassomo $20 \mathrm{~S}[13] \ldots \ldots \ldots \ldots \ldots \ldots \ldots$

Figura 22 - Predição da estrutura secundária das subunidades 19 e 20 do proteassomo $20 \mathrm{~S}[13] \ldots \ldots \ldots \ldots \ldots \ldots$

Figura 23 - Predição da estrutura secundária das subunidades 21 e 22 do proteassomo $20 \mathrm{~S}[13] \ldots \ldots \ldots \ldots$

Figura 24 - Predição da estrutura secundária das subunidades 23 e 24 do proteassomo $20 \mathrm{~S}[13] \ldots \ldots \ldots \ldots \ldots$ 
Figura 25 - Predição da estrutura secundária das subunidades 25 e 26 do proteassomo $20 \mathrm{~S}[13] \ldots \ldots \ldots \ldots \ldots \ldots$

Figura 26 -Predição da estrutura secundária das subunidades 27 e 28 do proteassomo $20 \mathrm{~S}[13] \ldots \ldots \ldots \ldots$

Figura 27 -Vista superior e vista lateral da representação da estrutura tridimensional do proteassomo. Entrada no PDB:3d29 [12]. . . . . . . . . . . . . 60

Figura 28 -Esquema do processo de purificação da Crioglobulina . . . . . . . . . . 63

Figura 29 -Esquema do processo de purificação através da técnica de cromatografia por afinidade. Retirada de $[17] \ldots \ldots$. . . . . . . . . . . 64

Figura 30 -Esquema do processo de obtenção e purificação do proteassomo . . . . 65

Figura 31 -Esquema do processo de eletroforese . . . . . . . . . . . . . . 66

Figura 32 -Representação do processo de espalhamento por uma partícula fixa. (Figura retirada de $[23]) \ldots \ldots . \ldots . \ldots 68$

Figura 33 -Representação da técnica de DLS. Figura adaptada de $[=[\ldots \ldots 71$

Figura 34 -Representação do processo de interação do feixe de elétrons com a amostra. (Figura Retirada de $[33]$ ) . . . . . . . . . . . . . . . . 74

Figura 35 - Controle do processo de cromatografia. Em (a) temos a purificação do soro de paciente sadio. Em (b) do soro de paciente com crioglobulemia

Figura 36 -Em (a) temos as pérolas de vidro. Em (b) as células com as pérolas de vidro. Em (c) o extrato celular já separado das pérolas de vidro. Em (d) a coluna carregada por níquel utilizada para a purificação por afinidade. . . . . . . . . . . . . . . . . . 78

Figura 37 -Foto do equipamento utilizado, Nanostar Bruker, no laboratório de Cristalografia ...................... . . 79 
Figura 38 -Foto do equipamento de DLS do Laboratório do Grupo de Fluidos

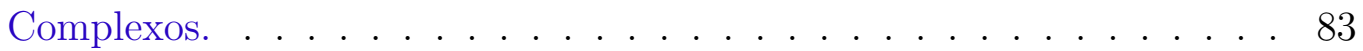

Figura 39 -Em (a) temos uma figura esquemática de um Microscópio Eletrônico, funcionando no modo imagem (adaptada de $[=[\ldots \ldots$. . . . . . . 84

Figura 40 - Intensidades de espalhamento, cálculo IFT (linha sólida) e função distribuição de pares de distância. Em (a) tem-se as intensidades para amostras de Lisozima em PBS (Cículos vazados representam os pontos experiemntais utilizados para o ajuste IFT, X representam pontos experimentais que não foram considerados para o ajuste IFT); em (b) as p(r) para Lisozima em PBS, em (c) a intensidade para as amostras em TRIS (Cículos vazados representam os pontos experiemntais utilizados para o ajuste IFT, X representam pontos experimentais que não foram considerados para o ajuste IFT) e em d para as $\mathrm{p}(\mathrm{r})$ para as amostras em TRIS . . . . . . . . . . . . . . . . . . . . 88

Figura 41 - Intensidades de espalhamento, Ajuste (linha sólida) utilizando fator de forma de esfera e fator de estrutura de esferas rígidas para as amostras em $\mathrm{PBS} \ldots \ldots \ldots \ldots \ldots \ldots$

Figura 42 - Intensidades de espalhamento, Ajuste (linha sólida) utilizando estrutura cristalográfica resolvida (2LYZ) através do programa Crysol . . . 90

Figura 43 - Intensidades de espalhamento, Ajuste (linha sólida) utilizando o modelo gerado pelo DAMMIN [26]. Insert: sobreposição do modelo ab initio e a estrutura cristlográfica . . . . . . . . . . . . . . . . . . . 991

Figura 44 - Gráfico de Log I X q, para uma temperatura de $38^{\circ} \mathrm{C}$ (círculos abertos) e o ajuste teórico (linha contínua). . . . . . . . . . . . . . . 92 
Figura 45 - Gráfico do Raio de Giro em função da temperatura . . . . . . . . . . . 92

Figura 46 -Evolução da curva $p(r)$ em função da temperatura . . . . . . . . . . . . 93

Figura 47 - Modelo Estático da proteína em duas temperaturas diferentes. Em (a)

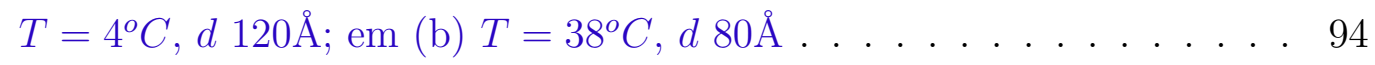

Figura 48 - Gráfico do tipo Kratky plot da crioglobulina a uma temepratura de $38^{\circ} \mathrm{C} 94$

Figura 49 -Em (a) temos a distribuição do Raio de Giro obtido pelo EOM para $38^{\circ} \mathrm{C}$ e $4^{\circ} \mathrm{C}$ em (b) possíveis modelos para ambas as temperaturas . . . 95

Figura 50 -Curva de autocorrelação para cada uma das temperaturas estudadas. . 96

Figura 51 -Gráfico de diâmetro hidrodinâmico médio em função da temperatura. 97

Figura 52 -Em a temos: círculo dados experimentais da linhagem selvagem do Proteassomo. Triângulos dados experimentais do Protassomo com a adição de DTT. As linhas continuas representam o ajuste IFT dos dados de espalhamento. Em b temos a $p(r)$ para cada uma dos sitemas. A linha continua representa o Proteassomo e a Pontilhada o Proteassomo com a adição de DTT. . . . . . . . . . . . . . . . . . . . . . . 98

Figura 53 -Círculos representam os dados experimentais da linhagem selvagem do Proteassomo. Triângulos, os dados experimentais do Protassomo com a adição de DTT. As linhas continuas representam o ajuste com o modelo teórico analítico para cilindros. . . . . . . . . . . . . . . . 100

Figura 54 -Modelagem ab initio. Em (a) 20S PT. Em (b) 20S PT+DTT . . . . . . 101 Figura 55 -Em (a) temos: Intensidade de espalhamento do proteassomo, Ajuste (linha sólida) utilizando estrutura cristalográfica resolvida (3d39) através do programa Crysol. Em (b) temos: Intensidade de espalhamento do proteassomo+DTT, Ajuste (linha sólida) utilizando estrutura cristalográfica resolvida (3d39) através do programa Crysol . . . . . . . . . 102 
Figura 56 - Modelo Cristalográfico do Proteassomo, em que é possível observar as 4 camadas de que é composto. . . . . . . . . . . . . . . . . 103

Figura 57 - Modelo Cristalográfico do Proteassomo, em que é possível observar as 2 subunidades utilizadas para cálculo dos modelos. . . . . . . . . . . 103

Figura 58 -A esquerda temos o gráfico que mostra o ajuste da curva de espalhamento. A direita temos em esferas cinzas a média de 10 simulações independentes. Em azul e vermelho a estrutura mais provável. . . . . . 104

Figura 59 - Projeções criadas através dos modelos gerados. Em (a) apenas o proteassomo. Em (b) o Proteassomo com DTT . . . . . . . . . . . 105

Figura 60 -Micrografias, em (a) apenas do proteassomo e em (b), do proteassomo com DTT. . . . . . . . . . . . . . . . . 105

Figura 61 -Ajuste dos dados de SAXS utilizando método IFT. Esquerda: Os dados experimentais. Círculos: proteassomo. Quadrados: Proteassomo + GSH. Triângulos: Proteassomo + GSSG.Estrelas: Proteassomo + DTT. As linhas sólidas: ajuste IFT. Direita: Função Pares de Distribuição de Distância. Círculos: proteassomo. Quadrados: Proteassomo + GSH. Triângulos: Proteassomo + GSSG. Estrelas: Proteassomo + DTT. . . . 106

Figura 62 -Ajuste dos dados de SAXS utilizando método IFT para $q>0.015 \AA^{-} 1$. Esquerda: Os dados experimentais. Círculos: proteassomo. Quadrados: Proteassomo + GSH. Triângulos: Proteassomo + GSSG.Estrelas: Proteassomo + DTT. As linhas sólidas: ajuste IFT. Direita: Função Pares de Distribuição de Distância. Círculos: proteassomo. Quadrados: Proteassomo + GSH. Triângulos: Proteassomo + GSSG. Estrelas: Proteassomo + DTT. . . . . . . . . . . . . . . 107 
Figura 63 -Em a temos a micrografia do Proteassomo crescido em meio rico em Glicose em que $67 \%$ das estruturas se apresentam abertas. Em b o Proteassomo crescido em meio rico em Glicerol, em que apenas 11\% das estruturas se apresentam abertas . . . . . . . . . . . 109 



\section{Lista de tabelas}

Tabela 1 - Dimensões máximas e Raios de Giro . . . . . . . . . . . . . . . . . . 99

Tabela $2-$ Resumo dos resultados obtidos . . . . . . . . . . . . 100 



\section{Lista de abreviaturas e siglas}

$\begin{array}{ll}\text { NMR } & \text { Ressonânica Magnética Nuclear } \\ \text { SAXS } & \text { Espalhamento de Raios X a baixos ângulos } \\ \text { IFT } & \text { Transformada Indireta de Fourier } \\ \text { Ig } & \text { Imunoglobulina } \\ \text { PT20S } & \text { Proteassomo 20S } \\ \text { Cys } & \text { Cisteína } \\ \text { MET } & \text { Microscopia Eletrônica de Transmissão } \\ \text { Tris } & \text { tris(hidroximetil)aminometano ((HOCH2)3CNH2) } \\ \text { PBS } & \text { Tampão fosfato-salino } \\ \text { DTT } & \text { Ditiotreitol } \\ & \\ & \\ \text { Max } & \text { Dimensão máxima } \\ & \end{array}$


GSH

Glutationa na forma reduzida

GSSG Glutationa na forma oxidada 


\section{Sumário}

1 Introdução . . . . . . . . . . . . . . . . 29

1.1 Motivação e Objetivos . . . . . . . . . . . . . . . . . . . . . . 29

1.2 Breve introdução a técnica de SAXS . . . . . . . . . . . . 30

1.3 Introdução aos sistemas . . . . . . . . . . . . . . 36

1.3.1 Lisozima . . . . . . . . . . . . . . . . . 39

1.3.2 Crioglobulinas . . . . . . . . . . . . . . . . 40

1.3.3 Proteassomo . . . . . . . . . . . . . . . . 43

2 Fundamentos .......................... 61

2.1 Extração/Obtenção das proteínas e processos de purificação . . . . . . . . 61

2.1 .1 Lisozima . . . . . . . . . . . . . . . . . 61

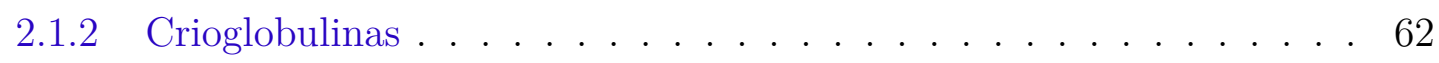

2.1.3 Proteassomo ....................... 64

2.2 Primeiras caracterizações das amostras . . . . . . . . . . . . . . 65

2.3 Métodos de Espalhamento . . . . . . . . . . . . . . . 67

2.3.1 Espalhamento de Raios X a Baixos Angulos . . . . . . . . . . . . 67

2.4 Espalhamento de Luz Dinâmico . . . . . . . . . . . . . . . . . 70

2.5 Microscopia Eletrônica de Transmissão . . . . . . . . . . . . . . . . . 73

3 Materiais e Métodos . . . . . . . . . . . . . . . 75

3.1 Preparação das Amostras . . . . . . . . . . . . . . . . . . 75

3.1 .1 Lisozima . . . . . . . . . . . . . . . . . 75

3.1 .2 Crioglobulinas . . . . . . . . . . . . . . 75 
3.1.3 Proteassomo . . . . . . . . . . . . . . . . . . . . . 77

3.2 SAXS (Espalhamento de Raios X a baixos ângulos) . . . . . . . . . . . . 78

3.2.1 Aquisição dos Dados . . . . . . . . . . . . . . . . . . . . . . 78

3.2 .2 Análise dos Dados . . . . . . . . . . . . . . . . . . . . 79

3.2.2.1 Lisozima . . . . . . . . . . . . . . . . . 80

3.2.2.2 Crioglobulinas .................. . . 81

3.2.2.3 Proteassomo . . . . . . . . . . . . . . . . 81

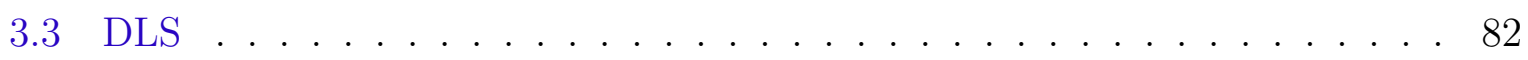

3.3.1 Aquisição dos Dados . . . . . . . . . . . . . . . . . . . . . 82

3.3 .2 Análise dos Dados . . . . . . . . . . . . . . . . . . . . 82

3.3.2.1 Crioglobulinas . . . . . . . . . . . . . . 82

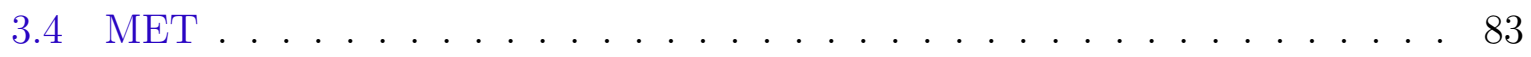

3.4.1 Aquisição dos Dados . . . . . . . . . . . . . . . . . . . 83

3.4.2 Análise dos Dados . . . . . . . . . . . . . . . 85

3.4.2.1 Proteassomo . . . . . . . . . . . . . 85

4 Resultados e Discussões . . . . . . . . . . . . . . . . . . . . 87

4.1 Lisozima . . . . . . . . . . . . . . . . . . . . . . . . 87

4.2 Crioglobulina . . . . . . . . . . . . . . . . . . . 91

4.2.1 Amostra não caracterizada / Pool de Imunoglobulinas . . . . . . . . 91

4.2.2 Amostra caracterizada $-\mathrm{Ig} G \ldots \ldots . \ldots 96$

4.3 Proteassomo . . . . . . . . . . . . . . . . . . . . . . . 98

5 Conclusões e Perspectivas . . . . . . . . . . . . . . . . . . . 111 
A Artigos publicados . . . . . . . . . . . . . . . 123

A.1 Redox Control of 20S Proteasome Gating . . . . . . . . . . . . . 123

A.2 Redox regulation of the proteasome via S-glutathionylation . . . . . . . . 137

A.3 20S proteasome activity is modified via S-glutathionylation based on intracellular redox status of the yeast Saccharomyces cerevisiae: Implications for the degradation of oxidized proteins . . . . . . . . . . . . . 147 



\section{Introdução}

\subsection{Motivação e Objetivos}

O campo moderno da biologia estrutural é dominado por uma abordagem sistemática em que o foco é definido no estudo estrutural de sistemas complexos correlacionados com suas funções. Para tanto, dentre inúmeras técnicas de caracterização estrutural, como Ressônancia Magnética Nuclear (NMR), métodos cristalográficos, etc., a técnica de espalhamento de Raios X a baixos ângulos (SAXS), pode apresentar diversas vantagens, muito em decorrência de novas metodologias de análises, que serão exploradas a seguir. O presente trabalho tem como objetivo descrever, em linhas gerais, estas diversas metodologias, bem como utilizá-las na descrição sistemas biológicos diferentes. Diversos detalhes de preparação destas amostras e procedimentos experimentais serão discutidos. Como resultados, informações inéditas sobre os sistemas puderam ser obtidos, bem como procedimentos de preparação de amostras, coleta de dados experimentais, análise e modelagem de dados [16] [20] [23]. 


\subsection{Breve introdução a técnica de SAXS}

Proteínas são macromoléculas que constituem um importante componente celular e participam de vários processos biológicos como, por exemplo, transportar e armazenar moléculas como o oxigênio, transmitir impulsos nervosos, realizar a defesa do organismo e atuar em mecanismos de regulação dos processos fisiológicos [17]. Seu arranjo estrutural está diretamente relacionado com sua função no organismo. Para estudos relacionados à estrutura proteíca é amplamente utilizado a técnica de cristalografia de Raios X, porém pode ser difícil obter um cristal que difrate adequadamente. Assim, é crescente o uso da técnica de espalhamento de Raios X a baixos ângulos em sistemas de biomoléculas, uma vez que é possível realizar o estudo do sistema em solução. Essa técnica, de maneira geral, permite obter informações como tamanho, forma, estado de agregação, grau de flexibilidade, entre diversas outras propriedades. [16] [20] [23].

Em um experimento de SAXS, um feixe monocromático e colimado de Raio X ilumina as macromoléculas que estão randomicamente orientadas em solução e seu espalhamento é coletado em um detector. Para soluções, com partículas randomicamente orientadas, a intensidade de espalhamento $I$ é isotrópica e depende apenas do ângulo de espalhamento $2 \theta$ (figura 1) [23].

O perfil do espalhamento resultante pode ser expresso em função do vetor de tranferência de momento do espaço recíproco, $q$, definido como $q=4 \pi \sin \theta / \lambda$, sendo $\lambda$ o comprimentos de onda da radiação incidente e $2 \theta$ o ângulo de espalhamento. Como será mostrado posteriormente, o perfil de espalhamento é proporcional ao espalhamento de uma única partícula, promediada sobre todas as orientações. Esta propriedade notável dos experimentos de SAXS permite obter dados estruturais sobre as partículas em solução $[23]$. 


\section{Detector}

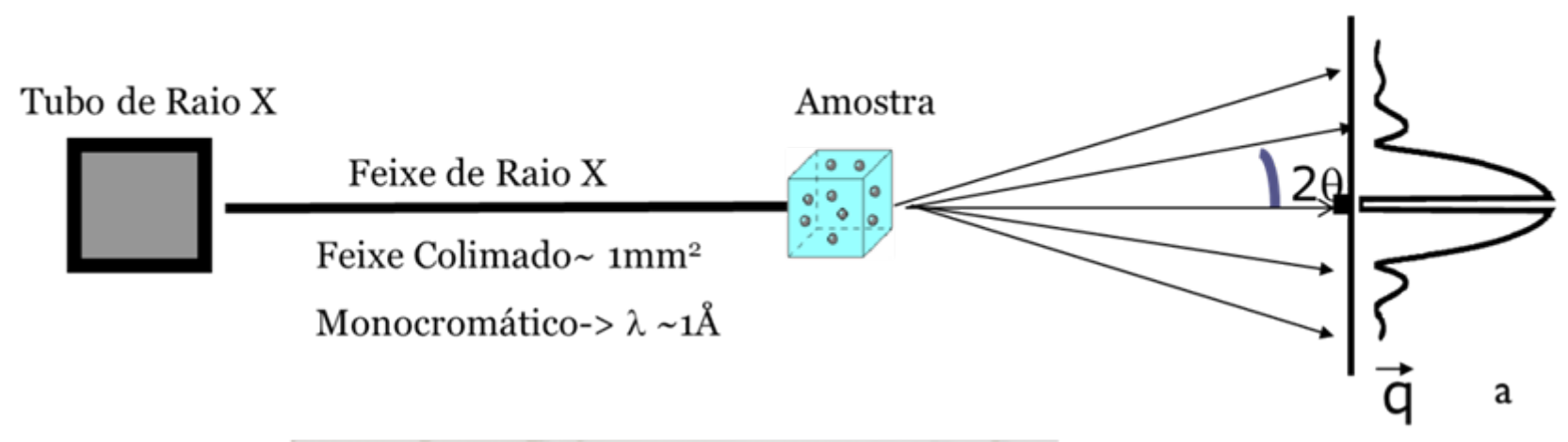

Figura 1: Representação esquemática de um experimento de SAXS em solução [23].

Com a técnica de SAXS é possível estudar estruturas num grande intervalo de tamanho molecular, desde pequenas proteínas e polipeptideos de $1 \mathrm{kDa}$ a $10 \mathrm{kDa}$ até complexos macromoleculares e partículas virais grandes, de algumas centenas de MDa. Além disso, uma das vantagens da técnica é usar relativamente pouco material, com $1 \mathrm{mg}$ ou 2mg de proteína é possível realizar o estudo [20].

É possível obter, diretamente das curvas de espalhamento, informações de forma e parâmetros como: peso molecular, raio de giro, dimensão máxima, etc. Isso permite caracterizar o sistema rapidamente. Essa caracterização estrutural rápida da amostra sob condições próximas da nativa é uma das maiores vantagens do SAXS sobre outras técnicas estruturais. Ao utilizar-se métodos computacionais mais avançados é possível extrair, não apenas esses parâmetros simples, mas também modelos tridimensionais. Modelos de baixa resolução (1-2nm), podem ser determinados utilizando modelagem ab initio, bem como a partir do refinamento de estruturas de alta resolução e/ou modelos homólogos [16] [20] $[23]$.

A análise desenvolvida por Guinier nos anos 30, é um dos métodos mais utilizados até hoje para obter a intensidade na origem $\mathrm{I}(0)$ e o raio de giro $(\mathrm{Rg})$ [9]. Para uma solução 
monodispersa de macromoléculas globulares. A equação de Guinier é definida como:

$$
I(q)=I(0) \exp \left(\frac{-1}{3} R_{g}^{2} q^{2}\right)
$$

Em principio, I(0) e Rg podem ser extraídos do intercepto do eixo y e da inclinação da região linear em um gráfico de Guinier $\left(\ln [I(q)] v s . q^{2}\right)[9]$. É necessário ressaltar que, para partículas esféricas, a Análise de Guinier é válida para $q<1,3 R_{g}$ e que um gráfico de Guinier não linear indica uma amostra não monodispersa [9]. Tendo em vista as limitações da aproximação de Guinier, a extração do $I(0)$ e $R_{g}$ dos dados de espalhamento, também podem ser feitos através do método da Transformada Indireta de Fourier (IFT)[9]. A transformada de Fourier dos dados de espalhamento fornece a função distribuição de pares de distância, $p(r)$ :

$$
p(r)=\frac{r^{2}}{2 \pi^{2}} \int_{0}^{\infty} q^{2} I(q) \frac{s e n q r}{q r} d q
$$

A função distribuição de pares de distância é a representação no espaço real dos dados de espalhamento, e permite graficamente mostrar peculiaridades da forma da partícula, como é exemplificado na figura 2[23].

Recentes avanços computacionais e metodológicos permitem a reconstrução de baixa resolução de modelos tridimensionais através apenas dos dados de espalhamento, sendo considerado como um procedimento padrão e uma maneira rápida de caracterização do sistema. A primeira abordagem ab initio, descrevia a forma das partículas por funções envelope angulares [7]. Mas uma reconstrução ab initio mais detalhada, começou a ser possível através do desenvolvimento da modelagem automática do tipo bead models [2]. Um programa muito citado na literatura, que utiliza a modelagem ab initio com bead models, é o DAMMIN (Dummy Atom Model Minimisation) [26]. O algoritmo representa 

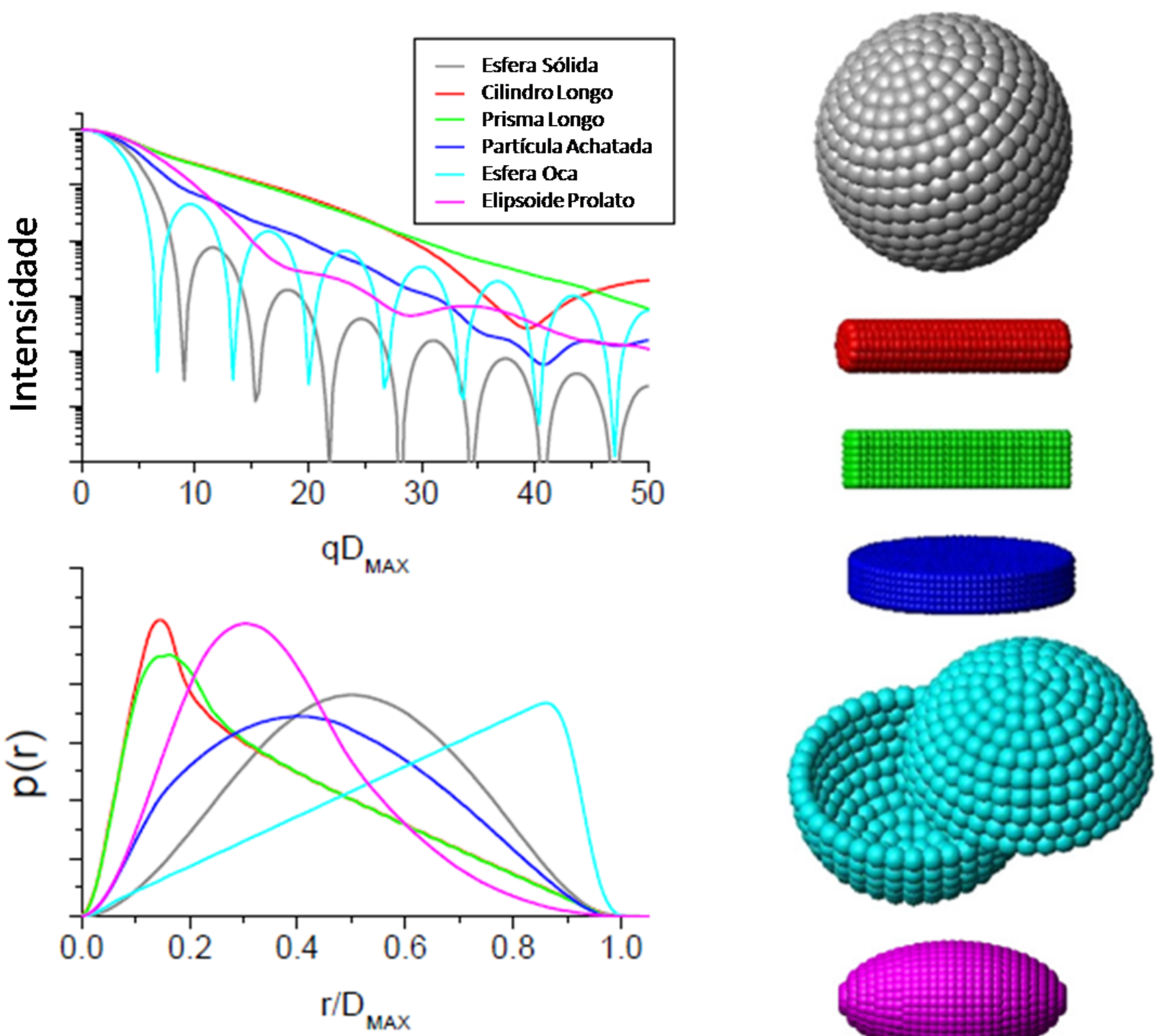

Figura 2: Intensidades de espalhamento e funções distribuição de pares de distância p(r) calculadas para tipicas formas geométricas. Adaptada de [23]

uma partícula como uma coleção de M "grânulos"densamente empacotados dentro de um volume de busca limitado (geralmente esférico), com diâmetro máximo definido através do $D_{\text {máx }}$ determinado através da Transformada Indireta de Fourier dos dados experimentais de espalhamento. Utilizando uma otimização por simulated annealing, o programa encontra o sub conjunto de beads que melhor ajusta os dados experimentais[26].

A resolução da forma determinada pelo modelo tipo bead model ou pelas fun- 
ções envelope são limitadas [7] [2] uma vez que assume-se uma distribuição uniforme da densidade eletrônica dentro da partícula. Uma abordagem alternativa para proteínas, é representar a molécula, não como uma coleção de "grânulos"uniformemente distribuídos, mas como uma montagem de Dummy Residues (DR)[27] [22]. Neste caso usa-se o fato de uma proteína ser composta por uma sequencia de aminoácidos (backbone). Deste modo, cada aminoácido é representado por uma esfera e, sendo assim, a proteína é representada por uma sequência de esferas interconectadas. O número de esferas é idêntico ao o número de aminoácidos da proteína. Esta abordagem pode ser encontrada no programa GASBOR, e novamente se usa uma otimização por simulated annealing.[27] [22]

Vale ressaltar que os métodos ab initio que buscam a reconstrução tridimensional a partir do espalhamento unidimensional, não fornecem uma única solução ou seja, quando rodamos os programas várias vezes, os modelos gerados podem apresentar diferenças [29]. Uma forma de tentar obter o modelo mais provável, bem como avaliar a estabilidade do resultado obtido consiste em obter um conjunto de modelos (tipicamente de 10 a 20) e fazer uma comparação por pares. Desta comparação pode-se listar os modelos com maior similaridade, bem como pinçar um modelo como melhor representante do grupo. Isto pode ser feito no programa DAMAVER [31].

Quando se conhece a estrutura de alta resolução ou modelos homólogos da proteína inteira ou de partes da mesma, pode-se fazer o cálculo da curva de espalhamento teórica do modelo atômico e a comparação com a curva experimental. Portanto, um modelo que fornece um bom ajuste dos dados, valida a descrição da estrutura sob as condições da solução usadas no experimento. Um programa que pode ser utilizado para esta função é o CRYSOL [28].

O arranjo de partes em alta resolução conhecidas para uma proteína bem como a 
composição de estruturas quartenárias (grupos de proteínas) também podem ser obtidos pelo uso de dados de SAXS. O espalhamento teórico do complexo pode ser calculado utilizando o programa CRYSOL, que descreve a amplitude de espalhamento das estruturas conhecidas como uma soma de harmônicos esféricos [28]. Esse formalismo é aplicado no método automático da modelagem de corpo rígido presente em programas como o SASREF e BUNCH. Existem vários algoritimos disponíveis para os diferentes cenários de modelagem, desde o refinamento local de homo e heterodímeros até a otimização automática global de complexos de multisubunidades (SASREF) [21], proteínas com multidomínios (BUNCH)[21] e suas combinações (CORAL) [22]. No SASREF é necessário ter o modelo completo de alta resolução de todas as subunidades. Quando não se conhece a estrutura dos linkers ou de um domínio completo, um método alternativo pode ser aplicado, combinando modelagem de corpo rigido e métodos ab initio, presentes no programa BUNCH, que utiliza os Dummy Residues para modelar as regiões faltantes. O programa CORAL [22] permite a otimização de corpo rígido e modelagem dos linkers para sistemas de mais de uma proteína.

Para estudar proteínas com partes móveis ou flexíveis, existe o Ensemble Optimization Method (EOM) [30] [1]. Nesse método uma grande população de configurações randômicas são geradas e um conjunto dessa população é selecionado utilizando algoritmo genético, de tal modo que a média do espalhamento computado sobre o conjunto se ajusta na curva experimental[30] [1]. Um possível programa a ser utilizado é o RANCH, em que uma população de até 15000 configurações possíveis para a conformação da proteína é gerado e através do ajuste da curva experimental obtêm-se quais dessas configurações são mais adequadas [30] [1]. Um sistema pode ser caracterizado como flexível através do gráfico de Kratky $\left(I . q^{2} v s q\right)$ [8]. Estes gráficos fornecem indicativos do grau de compacidade 
de uma estrutura, onde partículas compactas fornecerão gráficos com formato tipo "sino", com um máximo bem definido e caindo para zero a altos valores de q. Para partículas com partes flexíveis teremos gráficos onde a curva tem a tendência de não ir mais para zero a altos ângulos. Para partículas com altos graus de flexibilidade (como polímeros, por exemplo) teremos uma curva que pode atingir um platô bem como crescer monotonicamente. Exemplos desse tipo de curva podem ser vistos na figura 3 [8].

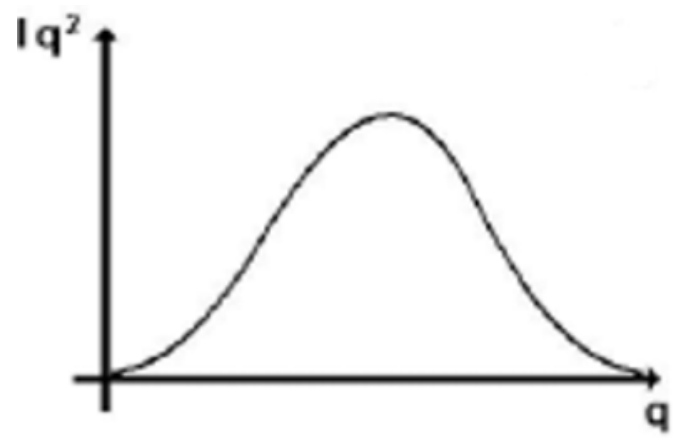

a

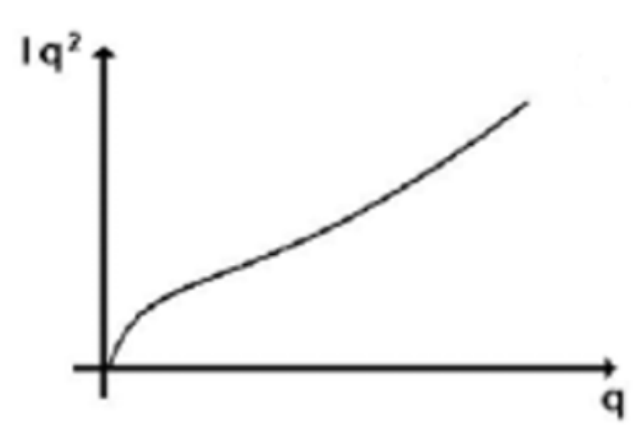

b

Figura 3: Exemplo de gráficos do Tipo Kratky Plot. Em (a) temos uma proteína compacta, enquanto em (b) uma proteína flexivel (figura adaptada da tese de doutorado de Cristiano Luis Pinto de Oliveira).

\subsection{Introdução aos sistemas}

Neste trabalho foram estudados três sistemas proteícos distintos, a Lisozima, a Crioglobulina e o Proteassomo. Por se tratar de sistemas biológicos diferentes, as seções serão subdivididas, para que a abordagem de cada sistema fique mais clara. Inicialmente, é necessário uma discussão geral sobre propriedades estruturais de proteínas.

Proteínas são constituídas por combinações de 20 aminoácidos (figura 4) diferentes suscitando a formação de estruturas diversas. Esses aminoácidos têm uma característica estrutural comum, pois têm um grupo carboxila e um grupo amino ligados ao mesmo 
átomo de carbono, diferindo-se entre si pela cadeia lateral (ou grupo R) (figura 5), a qual varia em estrutura, tamanho e carga elétrica que influenciam a solubilidade do aminoácido na água [17].

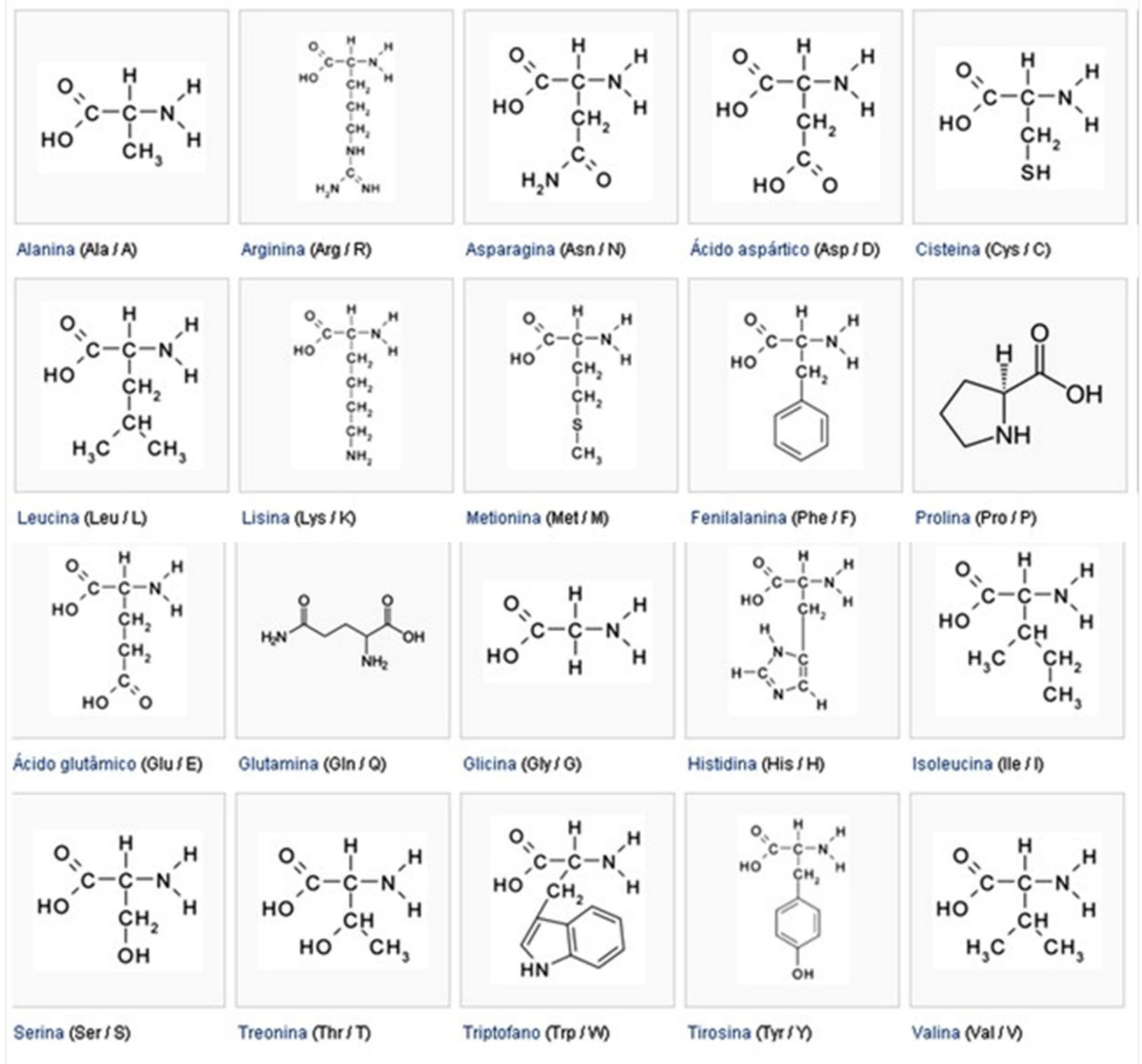

Figura 4: Os 20 aminoácidos formadores de proteínas (Retirada de:http://educacao.globo.com/quimica/assunto/quimica-organica/proteinas-aminoacidos-eenzimas.html)

Para formar as diversas sequências de proteínas, cada aminoácido une-se a seu vizinho através da ligação peptídica, uma ligação covalente, como representado na figura 6 [17]. 


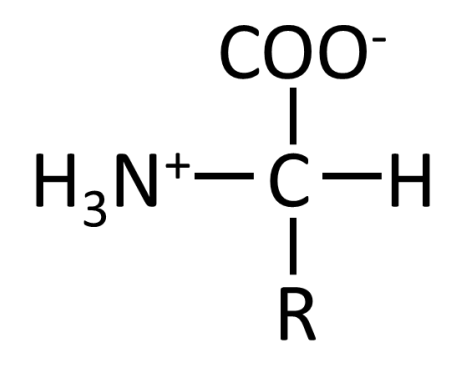

Figura 5: Estrutura Geral dos Aminoácidos

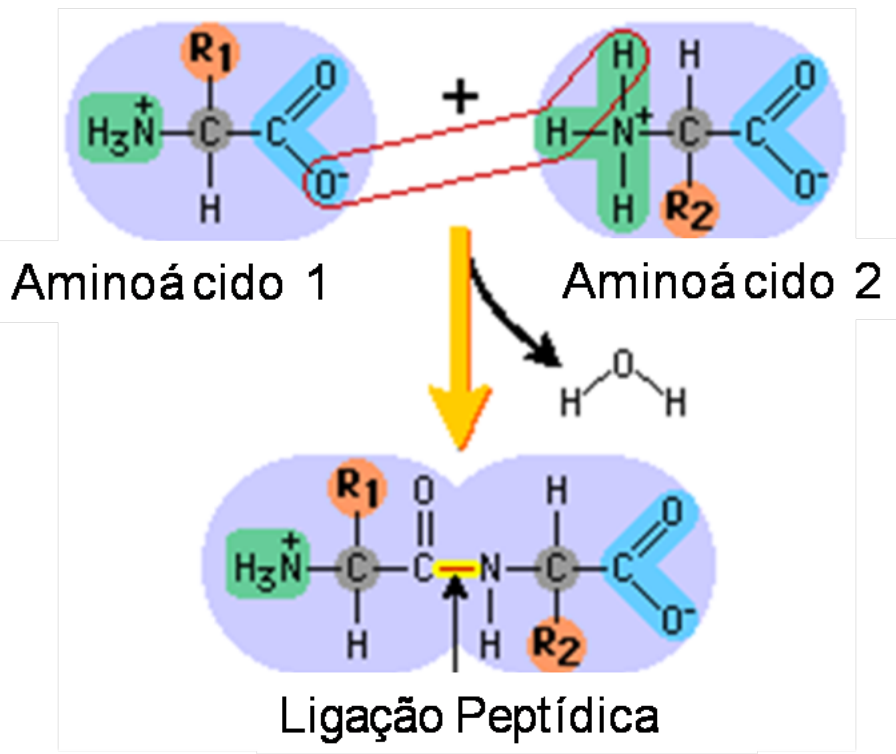

Figura 6: Representação da ligação peptídica (Retirado de: www.phschool.com/science/biolog_place/biocoach/translation/pepb.html)

Outras ligações ocorrem entre o restante da cadeia carbonada dos aminoácidos, como por exemplo, ligações covalentes entre os grupamentos -SH de dois aminoácidos cisteína, formando uma ponte dissulfeto, ou ligações de hidrogênio entre grupamentos polares da cadeia carbonada, ou até ligações fracas do tipo de van der Waals, mas que garantem estabilidade e conformação tridimensional única às proteínas, relacionada diretamente com sua função [17]. Comumente são definidos quatro níveis de estrutura de uma proteína: estrutura primária, a sequência de aminoácidos que forma a cadeia polipeptídica através das ligações covalentes; estrutura secundária, resultante de ligações de 
Hidrôgenio entre aminoácidos distintos; estrutura terciária, o arranjo tridimensional, ou seja, o dobramento tridimensional de um polipeptídio; estrutura quaternária, quando uma proteína possuí duas ou mais subunidades polipeptidicas, ou seja, a formação de dímeros, trímeros, etc. Uma representação dessas estruturas pode ser visto na figura 7 [17].

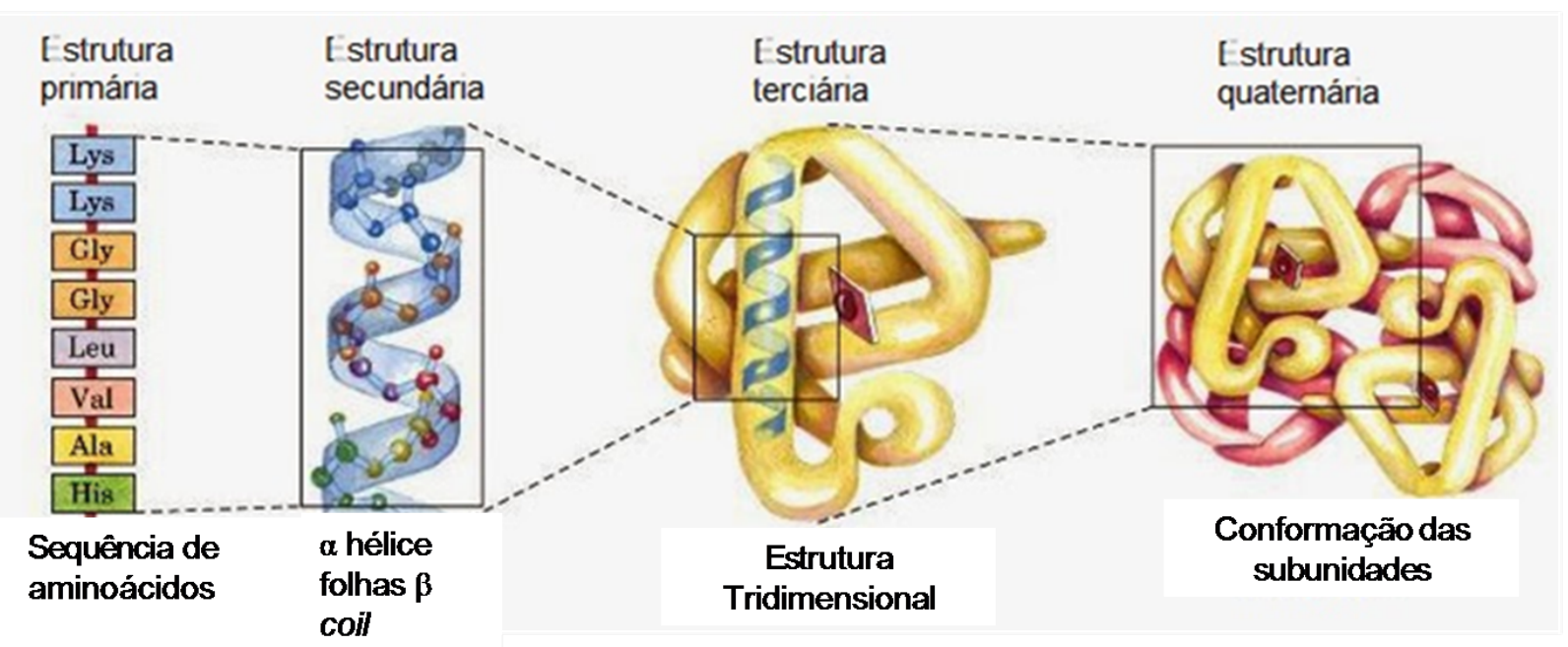

Figura 7: Representação dos níveis de estrutura de uma proteína (Adaptada de: http://lucindamorais.blogspot.com.br/p/proteinas-estrutura-e-funcao.html).

\subsubsection{Lisozima}

A Lisozima, descoberta em 1922 pelo médico escocês Alexander Fleming, é uma proteína pequena, de $\approx 14 k D a$ (129 resíduos) e teve sua estrutura tridimensional definida em 1965 por David Chilton e colaboradores. Trata-se de uma molécula estável, responsável por proteger o organismo contra infecções bacterianas [17].

A sequência da Lisozima e sua estrutura secundária são representadas na figura 8.

A predição usando bioinformática da estrutura secundária é gerada pelo programa PSIPRED [13], em que é necessário fornecer a sequência da proteína (estrutura primária) para o cálculo da estrutura secundária. 

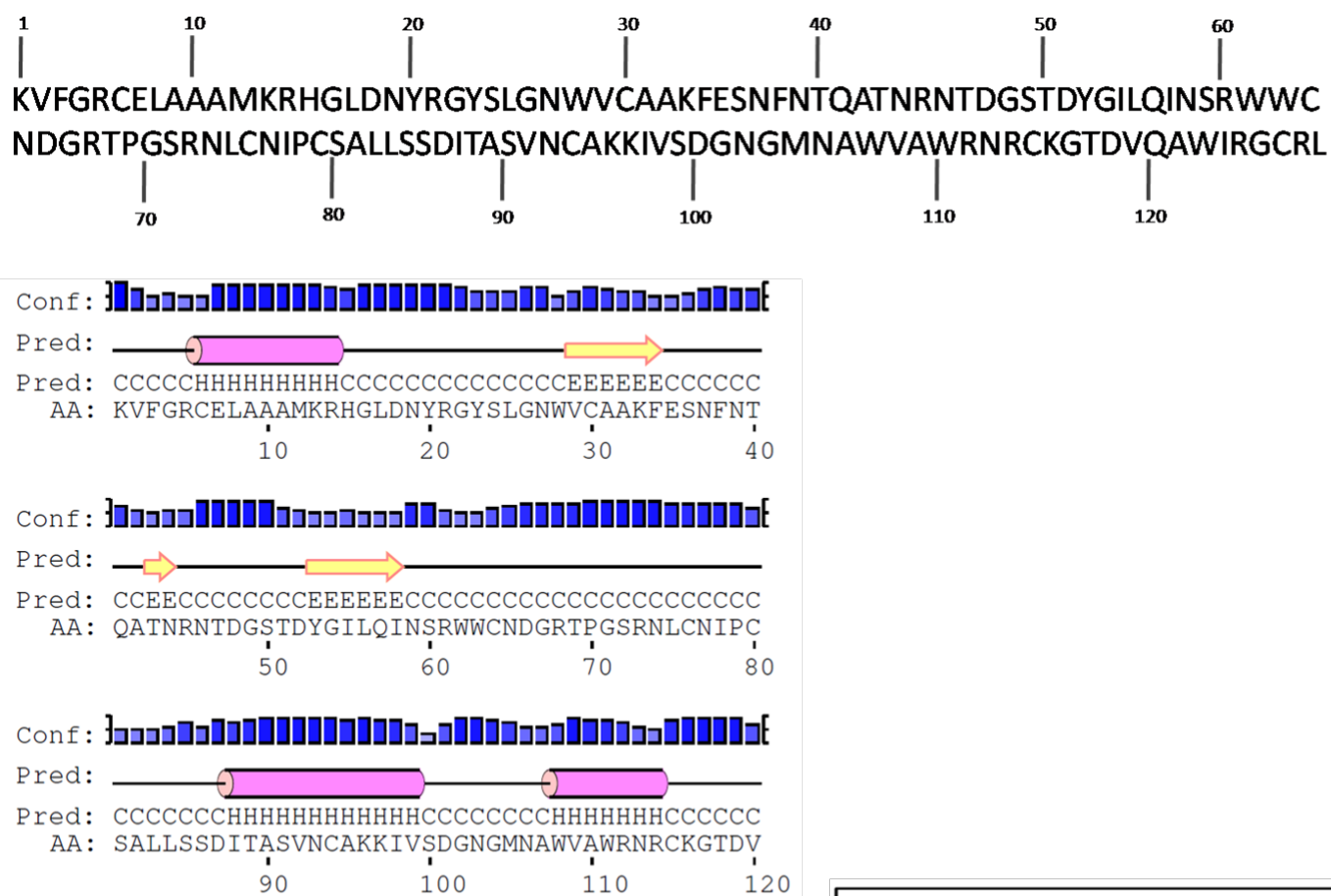

Conf : ] ]

Pred:

Pred: CCCCCCCCC

AA : QAWIRGCRI

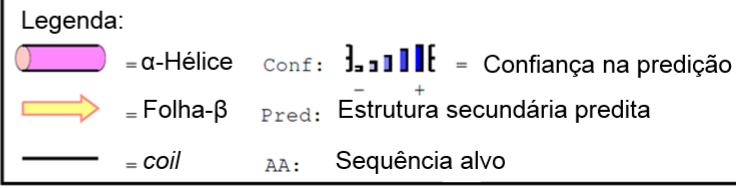

Figura 8: Sequência primária e predição da estrutura secundária da Lisozima [6] [13].

Na figura 9 tem-se sua estrutura terciária no formato de cartoon, o que evidencia a estrutura secundária.

Por se tratar de uma proteína amplamente estudada na literatura, ser estável e ter a estrutura tridimensional resolvida, pode ser utilizada como um sistema modelo para o aprendizado e teste dos programas de análise de SAXS. Para tanto, variou-se a concentração de Lisozima em duas soluções salinas diferentes, a fim de observar os possíveis efeitos de concentração no sistema.

\subsubsection{Crioglobulinas}

As crioglobulinas são proteínas do tipo imunoglobulinas (Ig), ou seja, estão relacionadas ao sistema imunológico e portanto atacam proteínas estranhas ao corpo, os 


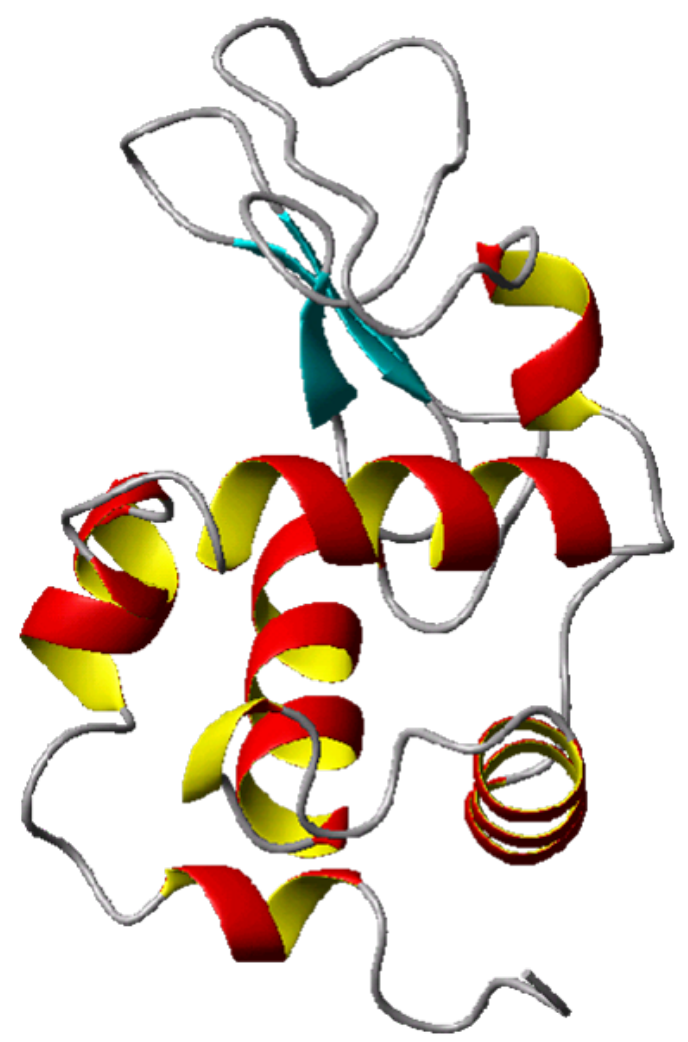

Figura 9: Representação da estrutura cristalográfica da Lisozima em cartoon, entrada no PDB: 2LYZ[6]

antígenos, realizando assim a defesa do organismo. A figura 10, ilustra um modelo de interação entre antígeno e anticorpo [17].

As crioglobulinas, normalmente, à temperatura abaixo de $37^{\circ} \mathrm{C}$, quando em concentrações acima do valor considerado de referência, $80 \mu \mathrm{g} / \mathrm{mL}$ [3], podem aglomerar e precipitar, causando danos em vasos de pequeno e médio calibre, resultando em infecções, doenças autoimunes e desordens neoplásicas. No entanto, trata-se de um processo reversível, torna-se solúvel ao aquecermos o criopreciptado [3] [5].

São classificadas em três tipos: tipo I, formada apenas por imunoglobulinas monoclonais; tipo II, formada por uma mistura de imunoglobulinas monoclonais e policlonais; tipo III, formada por uma mistura de imunoglobulinas policlonais. As imunoglobulinas monoclonais são sintetizadas por uma população de células B idênticas, já as policlo- 


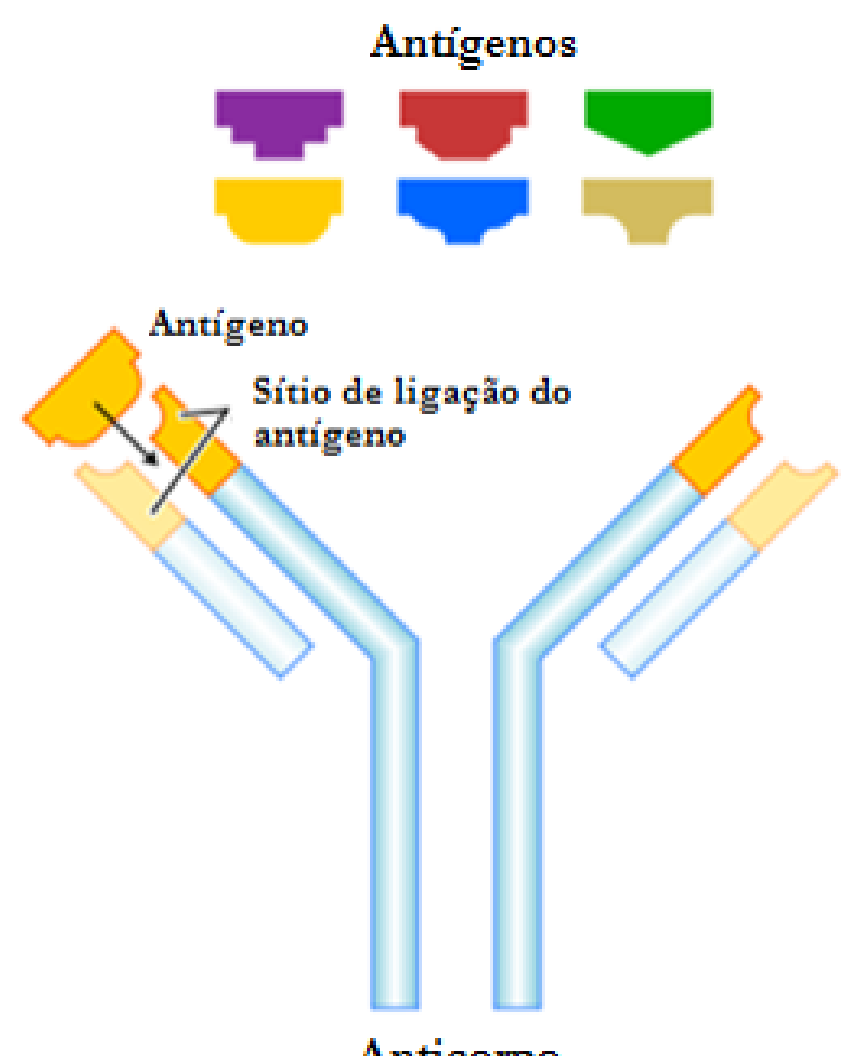

Anticorpo

Figura 10: Modelo antígeno-anticorpo (Adaptada de: http://pt.wikipedia.org/wiki/Ficheiro:Antibody.svg).

nais são produzidas por linfócitos B diferentes, o que corresponde respectivamente a um anticorpo homogêneo e a uma mistura de anticorpos [3].

Além disso, existem cinco classes de imunoglobulina, IgA, IgD, IgE, IgG e IgM. Os diferentes tipos se diferenciam por suas propriedades biológicas, localizações funcionais e habilidade para lidar com diferentes antígenos. A IgA é encontrada principalmente em secreções, prevenindo as mucosas de colonização por patógenos; a IgD é produzida nas células B, mas sua função ainda não é suficientemente clara; a IgE tem um papel importante na atuação com alérgenos; a IgG é uma das proteínas mais abundantes no soro sanguíneo e proporcionam a principal imunidade contra os patógenos que invadem o corpo;a IgM é o anticorpo produzido primeiro quando o organismo precisa reagir contra um antígeno[17]. 
Os mecanismos que levam a agregação dessas proteínas não são bem definidos. Na literatura, encontra-se indícios de que estudos de propriedades química e termodinâmica sugerem que forças eletrostática e de dispersão são responsáveis pela insolubilidade da crioglobulina[5]. Portanto, estudos variando a concentração de sais, como por exemplo de íons cloro, na solução podem regular o processo de agregação. Esses estudos foram realizados utilizando, principalmente, técnicas de fluorescência e de espalhamento dinâmico de luz. Estudos utilizando a técnica de SAXS são pouco descritos na literatura. Essa técnica, que nos permite estudar a proteína em solução, em condições próximas à fisiológica, pode ser utilizada para estudarmos as possíveis mudanças na conformação da crioglobulina, o que permite explorar os mecanismos que levam à agregação.

Entender o mecanismo de agregação pode auxiliar na busca de novas propostas de tratamento de pacientes com crioglobulemia.

\subsubsection{Proteassomo}

O processo de proteólise (degradação de proteínas) intracelular é tido como um mecanismo de regulação da homeostase celular tão importante quanto expressão gênica[32].

O proteassomo é um complexo proteolítico responsável pela degradação de proteínas previamente marcadas para degradação por uma cauda de poli-ubiquitina. As proteínas intracelulares poli-ubiquitináveis estão envolvidas na regulação do ciclo e sinalização celular. Esse sistema de degradação de proteínas intracelulares é altamente conservado ao longo da escala evolutiva em todos os organismos eucarióticos: da levedura (eucarioto unicelular) aos seres humanos [14].

O proteassomo, esquematicamente mostrado na figura 11 consiste de uma unidade catalítica central denominada 20S (PT 20S), onde se localizam os sítios que possuem 
atividade catalítica, acoplado em uma ou ambas as extremidades por unidades regulatórias, denominadas de 19S. Essa unidade regulatória é responsável pelo reconhecimento das proteínas poli-ubiquitinadas, pela desubiquitinação dessas proteínas, desdobramento e translocação delas para a câmera catalítica 20S, onde ocorre a hidrólise.

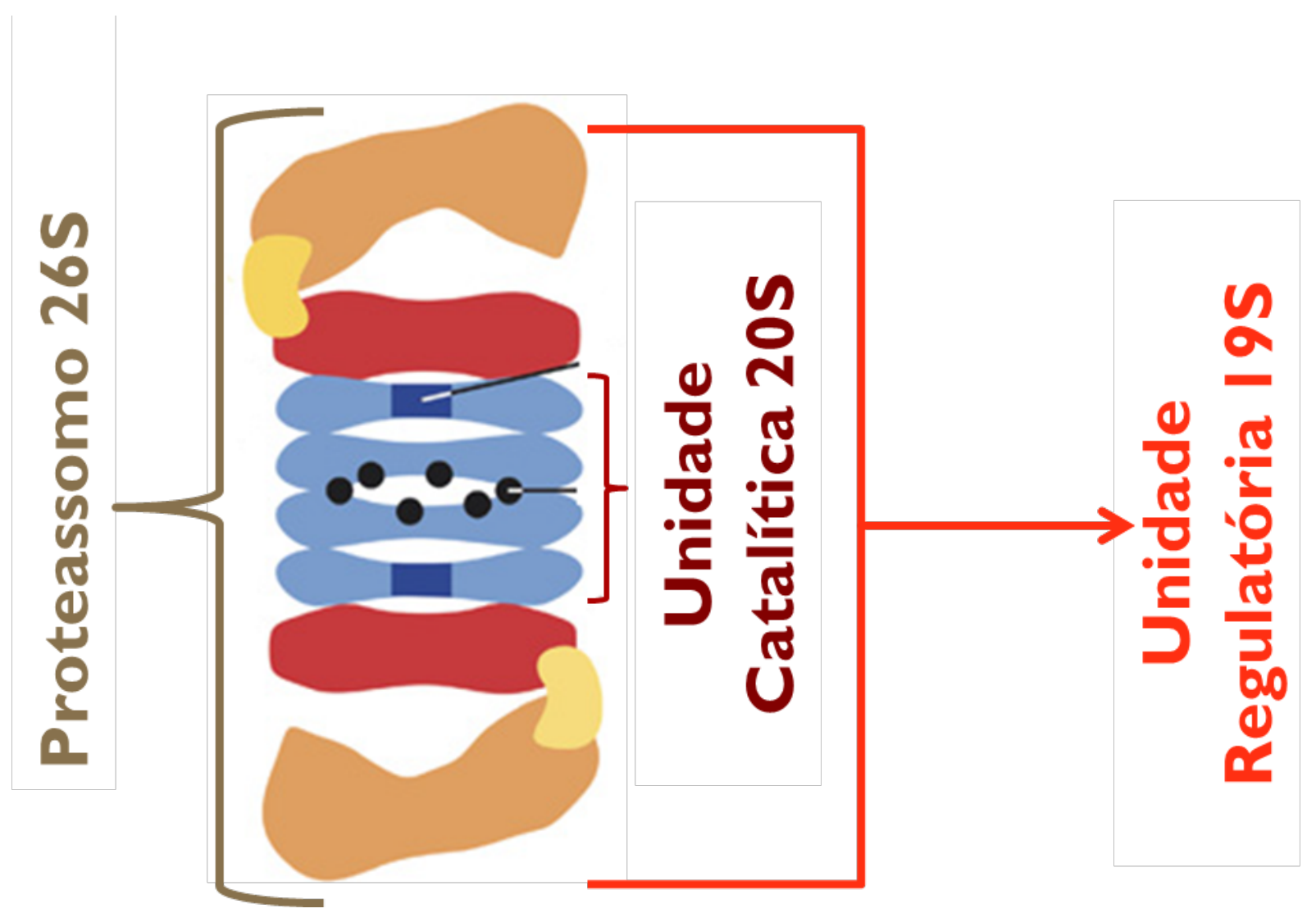

Figura 11: Representação do proteassomo (Adaptado de [11])

No entanto, a unidade catalítica (PT 20S) é capaz de degradar proteínas não marcadas por cauda de poli-ubiquitina, como no caso de proteínas oxidadas. As células possuem aproximadamente $1 / 3$ do proteassomo destituído de unidades regulatórias, ou seja, apenas a unidade catalítica 20S.

A remoção de proteínas oxidadas pelo 20S PT é considerada defesa antioxidante, uma vez que, proteínas não são reparadas após dano oxidativo como no caso de nucleotídeos (DNA, RNA) e lipídeos. Proteínas oxidadas têm tendência à agregação (fenômeno 
que subjaz patologias neurodegenerativas humanas), sendo assim elas devem ser eficazmente removidas por processo de degradação.

O PT 20S é constituído por uma unidade central formada por dois anéis heptaméricos denominados de $\beta$, flanqueados por outros dois denominados $\alpha$. Os sítios catalíticos se localizam nos anéis $\beta$ sendo que os $\alpha$ regulam a abertura / fechamento da câmera catalítica. Portanto, os anéis $\alpha$ controlam a entrada de substratos no PT 20S. O PT 20S em sua forma dita latente apresenta-se fechado impedindo a entrada de proteínas. No entanto, existem formas intracelulares abertas do PT 20S. Ou a abertura ocorre pelo acoplamento de unidades regulatórias 19S, ou, no caso do PT 20S destituído de unidades regulatórias, por processos de modificação pós-traducionais ainda pouco explorados. Em trabalho recente [24], foi demonstrado que um dos mecanismos de abertura da câmera catalítica é a oxidação de resíduos de cisteína (Cys) do PT 20S. Nesse estudo, além da demonstração da modificação dos resíduos de Cys por espectrometria de massas, foi demonstrada, a modificação estrutural, a abertura da câmera, por técnicas de Microscopia Eletrônica de Transmissão (MET) e SAXS. Técnicas para a análise estrutural do PT 20S descritas até o momento se restringem à cristalografia seguida de difração de Raios X, microscopia eletrônica de transmissão e microscopia de força atômica. Da figura 13 a 26 tem-se a representação da estrutura secudánria, das 28 subunidades que compõe o Proteassomo 20S. Para a predição da estrutura secundária utilizou-se o program PSIPRED [13], e a legenda da representação dessa estrutura pode ser vista na figura 12. Na figura 27, tem-se a estrutura terciária no formato de cartoon, o que evidencia a estrutura secundária.

A resolução estrutural 3D do proteassomo, PT 20S, tem grande importância para a melhor compreensão de seu mecanismo de ação na degradação de proteínas, principalmente as oxidadas. Trata-se de um passo importante para a compreensão de sua interação 
com moduladores catalíticos e conseqüente modelagem desses compostos.

A técnica de SAXS tem vantagens importantes uma vez que as amostras são analisadas em solução (estado 'natural' do PT 20S). Devido a seu caráter quantitativo, a análise das dimensões proteicas somente comparáveis à difração de raios-X do cristal proteico.

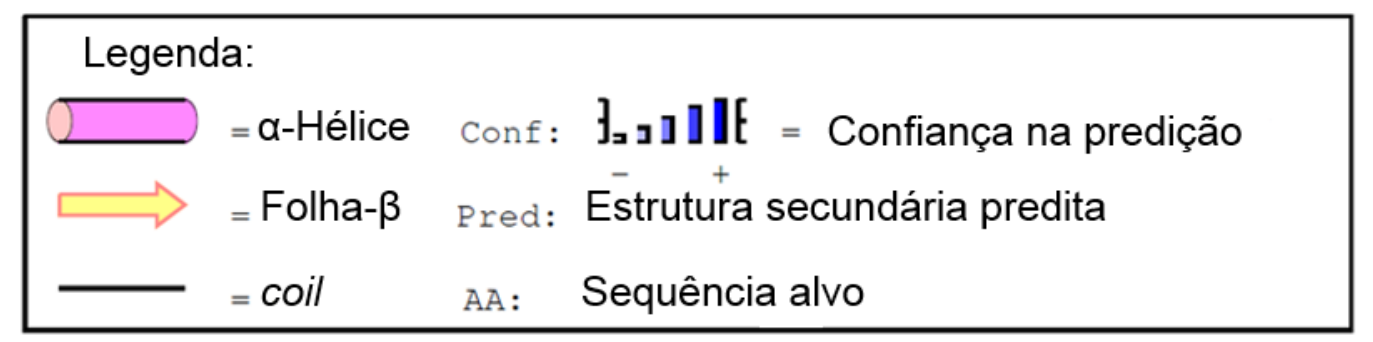

Figura 12: Legenda da predição das estruturas secundárias apresentadas nas figuras 13 a 26 


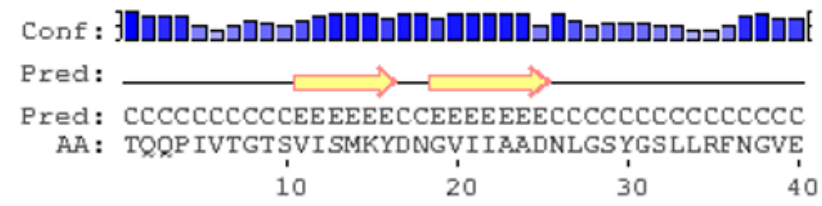

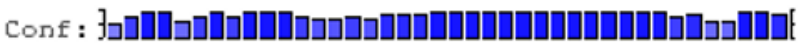

Pred: $\square-\longrightarrow \longrightarrow 0$

Pred: EEEEECCEEEEE ECCCHHHHHHHHHHHHHHHHHHHHCCCC

AA: RLIPVGDNTVVGISGDI SD $\$$ IERLLKD LVTENAYDNPL

50 $60 \quad$ io $\quad 80$

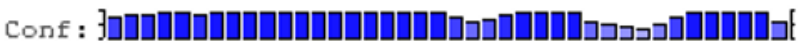

Pred: $\longrightarrow$

Pred: CCCCCCCCHHHHHHHHHHHHCCCCCCCCCCCCEEEEEEE

AA: ADAEEALEP SYIFE YLATVMYQRRSKANP LYNAI IVAGVQ $90 \quad 100 \quad 110 \quad 120$

Conf : \}all| Pred: $\longrightarrow \longrightarrow \longrightarrow \longrightarrow$

Pred: CCCCEEEEEECCCCCEEECCEEEECCCHHHHHHHHHHHCC

AA: SNGDQELRYVNLLGVTYSSPTLXTGEGAHMANPLLRKVVD $130 \quad 140 \quad 150 \quad 160$

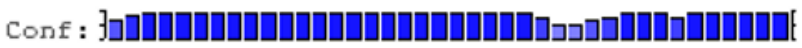

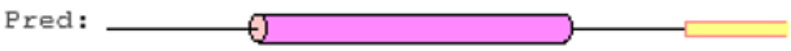

Pred: CCCCCCCCCHHHHHHHHHHHHHHHHHHCCCCCCCEEEEEE

AA: RESDIPKTTVQVAEEAIVNAMRVL YYRDARSSRNESLAI I

$\begin{array}{llll}170 & 180 & 190 & 200\end{array}$

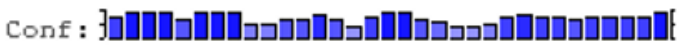

Pred: $>\longrightarrow$

Pred: ECCCCEEECCCEEECCCCCCCCCCCCCCCCCCC

AA: DKNTGLTFKKNLQVENIKWDFAKD IKGYGTQKI

$210 \quad 220 \quad 230$

Subunidade 1

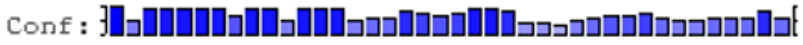

Pred: $\longrightarrow \longrightarrow \longrightarrow \longrightarrow \longrightarrow$

Pred: CCEEEEEECCEEEEEECCCCCCCCEEECCCCCCCCEEECCC

AA: TS IMAVTFKDGVILGAD SRTTTGA YIANRVTD KL TRVHDK

$10 \quad 20 \quad 30$

40

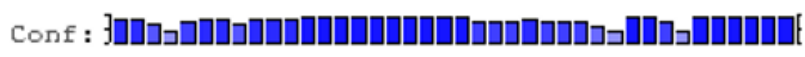

Pred: $\Longrightarrow \longrightarrow$

Pred: EEECCCCCHHHHHHHHHHHHHHHHHHHHHHCCCCHHHHHH

AA: IWCCRSGSA.ADTQR.IAD IVQYHLELYTSOYGTPSTETRAS

$\begin{array}{lll}50 & 60 & 70\end{array}$

80

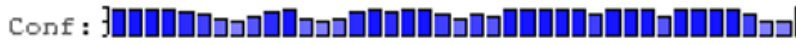

Pred:

Pred: HHHHHHCCCCCEEEEEEEEEEECCCCCEEEEECCCCCCC

AA: VF KELCYENKDNLTAGI IVAGYDDKNKGEVYT IPLGGSVH

$90 \quad 100 \quad 110$

Conf : ל ל ל

Pred: $\longrightarrow \longrightarrow$

Pred: CCCEEECCCHHHHHHHHHHCCCCCCCCHHHHHHHHHHHH AA: KLPYAIAGSGSTF I YGYCDKNE RENMSSEETVDF IKHSLS

$130 \quad 140 \quad 150 \quad 160$

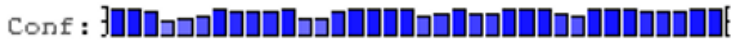

Pred:

Pred: HHHHCCCCCCCCEEEEEECCCCEEEEEECCCCCCCC AA: QAIKWDGSSGGVIRIVVLTAAGVERLIFYPDEYEQL

$\begin{array}{lll}170 & 180 & 190\end{array}$

\section{Subunidade 2}

Figura 13: Predição da estrutura secundária das subunidades 1 e 2 do proteassomo 20S [13] 


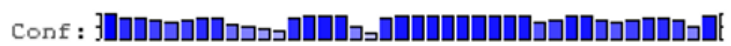

Pred: $\longrightarrow$ Pred: CCCCCCCCCCCCCCCCCHНHНHНHНHНHНCCCCEEEE EEC AA : MTDRYSE SLTTE SPSGKLGQIDYALTAVKOGVTSLGIKRT 10

20

40

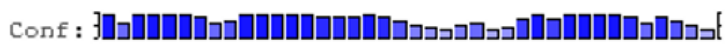

Pred:

Pred: CEEEEEEECCCCCCCCCCCCCCCEEECCCCEEEEECCCCC AA: NGVVIATEKKSSSPLAMSETLSKVSLLTPDIGAVYSGMGP $\begin{array}{lll}50 & 60 & 70\end{array}$

Conf : ל

Pred: $\square$

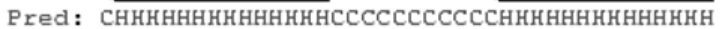
AA: DYRVLVDKSRKVRHTSYKRIYGEYPPTKLLVSEVAKIMQE $\begin{array}{llll}90 & 100 & 110 & 120\end{array}$

Conf : \} ל Pred:

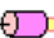

Pred: HHHCCCCCCHHEEEEEEEECCCCCEEEEEECCCCCCCCCC AA: ATQSGGVRPFGVSLLIAGHDEF NGF SLYQVDP SGSYF PWK $\begin{array}{llll}130 & 140 & 150 & 160\end{array}$

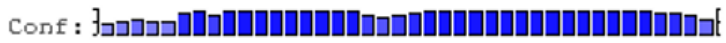

Pred: $\longrightarrow \longrightarrow$

Pred: CEEECCCCHHHHHHHHHHCCCCCCHHHHHHHHHHHHHHHH AA: ATAIGKGSVAAKTF LEKRWNDE LELEDA IHIALL TLKESV $\begin{array}{llll}170 & 180 & 190 & 200\end{array}$

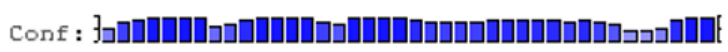

Pred: $\rightarrow-0$

Pred: CCCCCCCCEEEEEEECCCCCCCCCCCCCCCCCCCCEECCH AA: EGEFNGDTIELAIIGDENPDLLGYTGIPTDKGPRFRKLTS $\begin{array}{llll}210 & 220 & \dot{2} 30 & 240\end{array}$

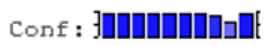

Pred:

Pred: HHHHHHHHHC

AA: QEINDRLEAI

250

\section{Subunidade 3}

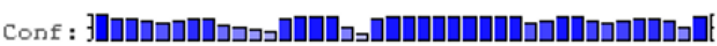

Pred: $\longrightarrow$

Pred: cCCCCCCCCCCCCCCCCCHHHHHHHHHHHCCCCEEEE EEC AA: MTDRYSESLTTE SPSGKLGQIDYALTAVKO GVTSLGIKR.T $10 \quad 20 \quad 30$

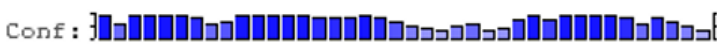

Pred:

Pred: CEEEEEEECCCCCCCCCCCCCCCEEECCCCEEEEECCCCC AA: NGVVIATEKKSSSP LAMSETLSKVSLLTPDIGRVYSGMGP

$50 \quad 60 \quad 70$

80

Conf : ל ל

Pred: 0

Pred: CHHHHHHHHHHHHHHCCCCCCCCCCCHHHHHHHHHHHHHH AA: DYRVLVDKSRKVAHTSYKRIYGEYPPTKLLVSEVAKIMQE $90 \quad 100 \quad$ i10

Conf : \}

Pred: $\longrightarrow \longrightarrow \longrightarrow$

Pred: HHHCCCCCCHHEEEEEEEECCCCCEEEEEECCCCCCCCCC AA: ATQSGGVRPEGVSLLIAGHDEF NGF SLYQVDP SGS YF PWK $130 \quad 140 \quad 150 \quad 160$

Conf : ל ל ל

Pred: $\longrightarrow \longrightarrow 0$

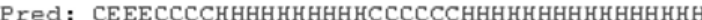
AA: ATAIGKGSVAAKTF LEKRWNDE LELEDA IHIALLTLKESV $\begin{array}{llll}170 & 180 & 190 & 200\end{array}$

Conf : ל ל

Pred:

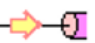

Pred: CCCCCCCCEEEEEEECCCCCCCCCCCCCCCCCCCCEECCH AA: EGEFNGDTIELAIIGDENPDLLGYTGIPTDKGPRFRKLTS $\begin{array}{llll}\dot{2} 10 & 220 & \dot{1} & 1\end{array}$

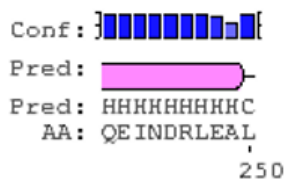

Subunidade 4

Figura 14: Predição da estrutura secundária das subunidades 3 e 4 do proteassomo 20S [13] 


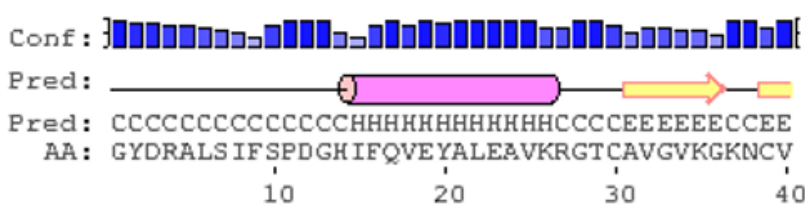

Conf : 30100 :

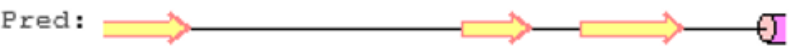

Pred: EEEEECCCCCCCCCCCCCCCCEEEECCCEEEEEECCCCCH AA : VLGCERRSTLKLQDTRITPSKVSKIDSHVVLSFSGLNADS $50 \quad 60 \quad 70 \quad 80$

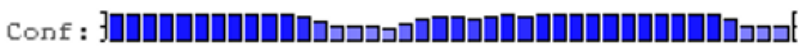

Pred:

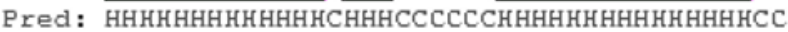
AA: RILIEKARVEAQSHRLTLEDPVTVEYLTRYVAGVQORYTQ

9่0 100 ílo

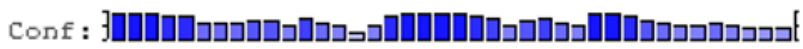

Pred: $\longrightarrow-$

Pred: CCCCCCHHHHHHHHCCCCCCCCCCEEE ECCCCCCCCCEEC AA: SGGVRPEGVSTLIAGEDPRDDEPKLYQTEPSGIYSSWSAQ

$130 \quad 140 \quad 150 \quad 160$

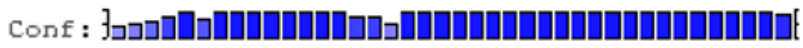

Pred: $\Rightarrow 00$ O AA: TIGRNSKTVREF LEKNYDRKEP PATVEECVKLTVRSLLEV $\begin{array}{llll}170 & 180 & 190 & 200\end{array}$

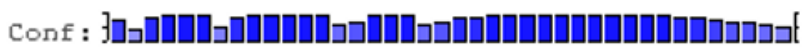

Pred: $\longrightarrow \longrightarrow \longrightarrow$

Pred: HCCCCCCEEEEEEECCCCEEECCHHHHHHHHHHHHHHHHC AA: VQTGAKN IEITVVKPDSDIVALSSEE INQYVTQIEQE KQE $\begin{array}{llll}210 & 220 & 230 & 240\end{array}$

Conf : ]][

Pred:

Pred: C

$A A: Q$

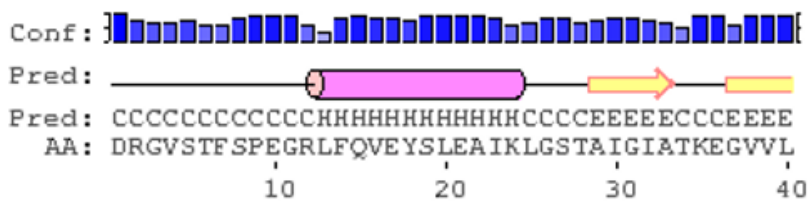

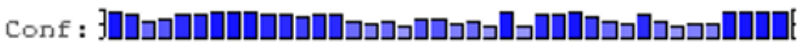
Pred: $\Rightarrow \longrightarrow 000$

Pred: EEECCCCCCCCCCCCCHHHHEECCCEE EEECCCHHCHHHH

AA: GVEKRATSPLLESDSIEKIVEIDRHIGCXMSGLTADARSM

50 60 7'0

80

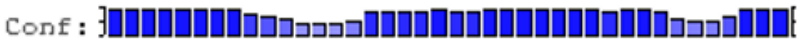

Pred: $\longrightarrow 0$

Pred: НHНHНHHНHНCHHCCCCCC CHHНHНHНHНHНHНHCCCCCC

AA: IEHARTAAVTHNLYYDEDINVE SL TQSVCDLALRE GEGAS

90 $100 \quad 110 \quad 120$

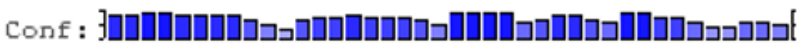

Pred:

Pred: CCCCCCCCCCCEEEEEE EEECCCCCEEEEECCCCCCCCCC

AA: GEERLMSRPF GVALLIAGHDADDG YQLFHAEP SGTF YRYN

$130 \quad 140 \quad 150$

160

Conf : \} \}

Pred : $\square \longrightarrow 0$

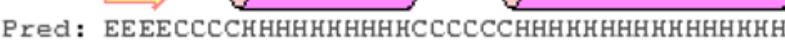

AA: AKAIGSGSEGAQA.E LLNEWHSSLTLKEAELLVLKILKQVM

$170 \quad 180 \quad 190$

200

Conf : \}

Pred: $\longrightarrow \longrightarrow$

Pred: CCCCCCCCEEEEEEECCCCEEECCHHHHHHHHHHHHHHHH

AA: EEKLDENNAQLSCITKQDGFKIYDNEKTAELIKELKEKEA

\begin{tabular}{llll}
210 & \multicolumn{2}{l}{220} &
\end{tabular}

Conf : J]

Pred: -

Pred: $\mathrm{CC}$

$A A$ : $A E$

\section{Subunidade 5}

\section{Subunidade 6}

Figura 15: Predição da estrutura secundária das subunidades 5 e 6 do proteassomo 20S [13] 


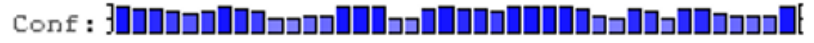

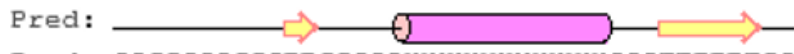

Pred: CCCCCCCCCCEECCCCCHHHHHHHHHHHHCCCEEEEEECC AA: FRNNYDGDTVTE SP TGRLFQVEYZLEA IKQ্, GSVTVGLRSN io $20 \quad 30 \quad 40$

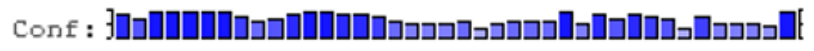

Pred: $\longrightarrow \longrightarrow \longrightarrow \longrightarrow$

Pred: CEEEEEEEECCCCCCCCCCCCCEEECCEEEEEEECCHHCH AA: THAVLVALKRNADELSSYQKKI IKCDE HMGLSLAGLAPDA $50 \quad 60 \quad 70$

80

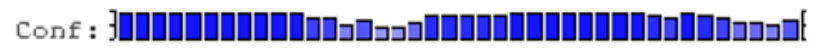

Pred : Pred: HHHA RVLSNYLRQQCNYSSLVFNRKLAVERAGH LLCDKAQKNTQ

$$
\text { 9ै } 100 \quad 110 \quad 120
$$

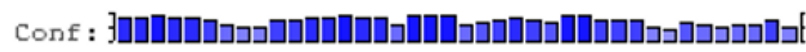

Pred:

Pred: CCCCCCCCEEEEEEEEECCCCEEEEECCCCCCCCCEEEE AA: SYGGRPYGVGLLIIGYDKSGAHLLEEQPSGNVTELYGTZI

$$
130 \quad 140 \quad 150 \quad 160
$$

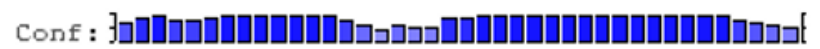

Pred: 000

Pred: CCCCHHHHHHHHHHHCHHCCCCCCHHHHHHHHHHHHHHHC
AA: GARSQGAKTYLERTLDTFIKIDGNPDELIKAGVEAISQSL

$$
\text { i70 } 180 \quad \text { iso }
$$

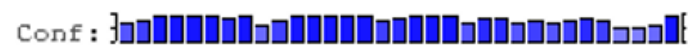

Pred:
Pred: CCCCCCCCCEEEEEEECCCCEEECCHHHHHCCC
AA: RDESLTVDNLSIAIVGKDTPETIYDGEAVAKYI 210

220

230

\section{Subunidade 7}

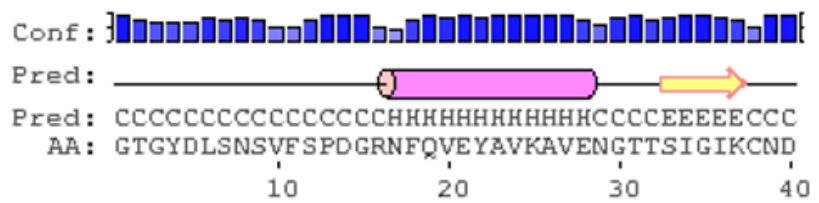

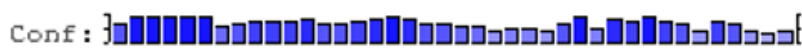
Pred: $\longrightarrow \longrightarrow \longrightarrow$

Pred: EEEEEEECCCCCCCCCCCCCCCCEECCCEEEEEECCCCCC AA : GVVFAVEKL ITSKL LVPQKNVK IQVVDRH IGCVY SGLIPD $5060 \quad 70$ 80

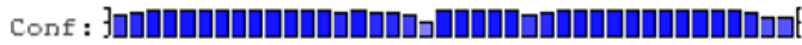
Pred: 0

Pred: НHНHНHНHННННННННННССССС СНHННННННННННННН AA: GRHLVNRGREEA.S.SF KKLYKTP IP IPAFADRLGQYVQAH T 9่0 100 ín

Conf : \} כ ל

Pred: $\supset \longrightarrow \longrightarrow$

Pred: HCCCCCCCCEEEEEEEEECCCCEEEEECCCCCCCCCCEEE AA: LYNSVRPFGVSTIFGGVDKNGAHL MILEP SGSYWGYKGA.A $\begin{array}{llll}130 & 140 & 150 & 160\end{array}$

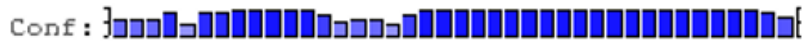

Pred: $>0$

Pred: ECCCCHНHНHНHНHНHCCCCCCCCHНHНHНHНHНННHНHН AA: TGKGRQSAKAELEKLVD HHPEGLSAREZVKQA.XKI I YLA.H $\begin{array}{llll}170 & 180 & 190 & 200\end{array}$

Conf : \} \}

Pred: $\longrightarrow \longrightarrow \longrightarrow$

Pred: CCCCCCCCEEEEEEEEECCCCCEEEECCHHHHHHHHHHHH AA: EDNKEKDFELEISWCSLSETNGLHKEVKGDLLQEAIDFAQ $\begin{array}{llll}210 & 220 & 230 & \end{array}$

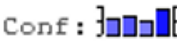

Pred :

Pred: $\mathrm{HHHC}$

AA: KEIN

\section{Subunidade 8}

Figura 16: Predição da estrutura secundária das subunidades 7 e 8 do proteassomo 20S [13] 
Conf : 1 :

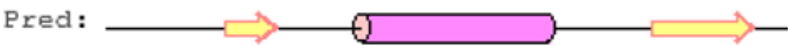

Pred: CCCCCCCEEECCCCCHHHHHHHHHHHCCCCCCEEEEEECC AA: AGYDRHITIFSPEGRLYQVEYAFKATNQTNINSLAVRGKD

io $\quad$ í $\quad 30 \quad$ í

Conf : \} \}

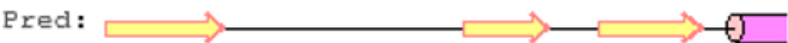

Pred: EEEEEEECCCCCCCCCCCCCCEEEEECCCEEEEEECCHHH

AA: CTVVISQKKVPDKLLDPTTVSYIFCISRT IGMVVNGP IPD

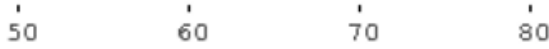

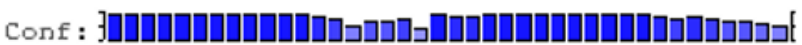
Pred: $\longrightarrow-0$

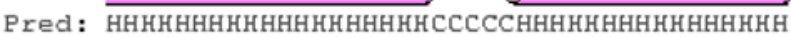
AA: ARNA.ALRA.KAEA.AEFRYKYGYDMPCDVLA.KRMANLSQIYT
90
100
110
120

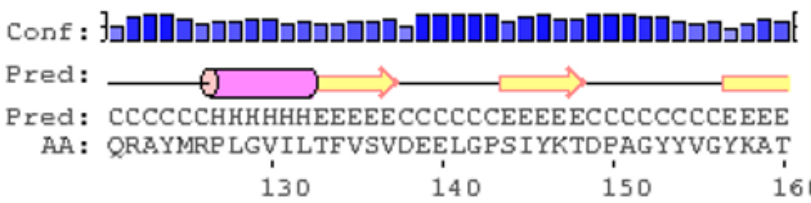

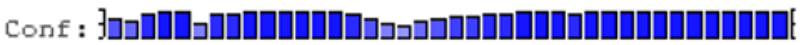

Pred: $\Rightarrow 0$

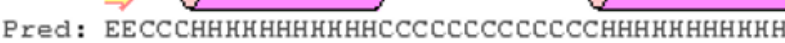

AA: ATGPKQQEI TTNLENHE KKSKIDH INE ESWEKVVEFA ITH $170 \quad 180 \quad 190 \quad 200$

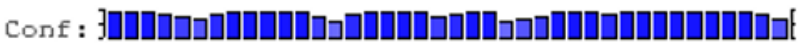

Pred : $\longrightarrow \longrightarrow \longrightarrow$

Pred: HHHHHCCCCCCCCEEEEEEECCCCEECCHHHHHHHHHHHH

AA: MIDALGTEF SKNDLEVGVATKDKFF TLSAENIEERLVAIA

$\begin{array}{llll}210 & 220 & 230 & 240\end{array}$

Conf : \}all

Pred:

Pred: CCC

$A A$ : $E Q D$

\section{Subunidade 9}

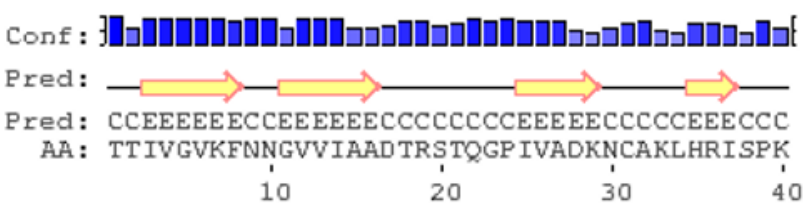

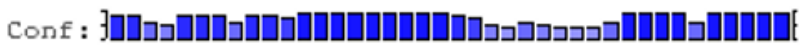

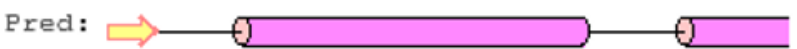

Pred: EEECCCCCHНHHHНHНHНHНHНHНHНHНCCCCCCHНHНHH AA: IWCAGAGTZADTEAVTQLIGSNIELHSLYTSREPRVVSAL

60

70

80

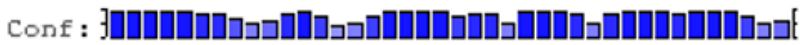

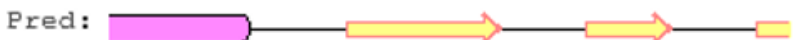

Pred: HНHHHHHHCCCCCCEEE EEEEE ECCCCCEEEE ECCCCCEE

AA : QMLKQHLFKYQGHIGAYLIVAGVDPTGSHLE S IHAHGSTD

90 $100 \quad 110$

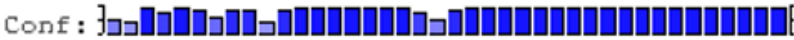

Pred: $\Rightarrow-\longrightarrow \rightarrow 0$

Pred: EECEEEECCHHHHHHHHHHCCCCCCCCHНHHHHHHHHHHH AA: VGYYLSLGSGSLR.MAMLESHWKQDLTKEEAIKLASDAIQ

$\begin{array}{llll}130 & 140 & 150 & 160\end{array}$

\section{Conf : :}

Pred:

Pred: HHHHCCCCCCCCEEEEEEECCCCEEEECCCCCCCCCCCCC

AA: AG IWNDLGSGSNVDVCVME IGKDAEYLRNYLTPNVREEKQ

$\begin{array}{llll}170 & 180 & 190 & 200\end{array}$

\section{Conf : \} 3}

Pred:

Pred: CCCCCCCCCEEEEEEEEEECCC

AA: KSYKFPRGT TAVLKESIVNICD

$210 \quad 220$

\section{Subunidade 10}

Figura 17: Predição da estrutura secundária das subunidades 9 e 10 do proteassomo 20S [13] 


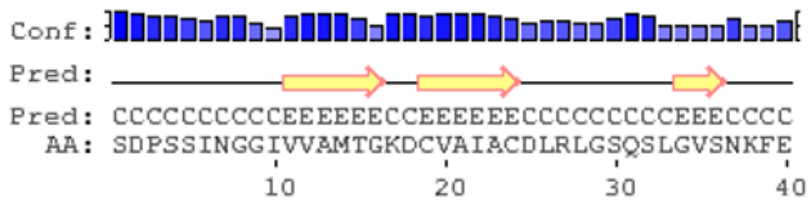

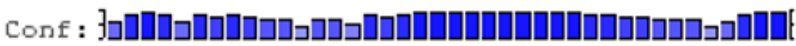

Pred: $\longrightarrow-\longrightarrow \longrightarrow 0$

Pred: EEEEECCEEEEECCCHHHHHHHHHHHHHHHHHHHHCCCCC AA: KIFH YGHVF LGITGLATDVTTLNEMERYKTNLYKLKEERA

50 60 10

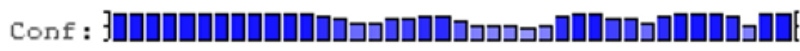

Pred: $\longrightarrow \longrightarrow$

Pred: CCHHHHHHHHHHHHCCCCCCCCCCCEEEEEECCCCCEEE

AA: IEPETE TQLVSSSL YERRF GPYFVGPVVAGINSKSGKPFI

$$
\text { 90 } 100 \quad 110 \quad 120
$$

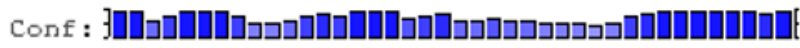

Pred : $\Rightarrow \longrightarrow 0$

Pred: EEECCCCCCCCCCCEEE ECCCHHHHHHHCCCCCCCCCHH

AA: AGFDLIGCIDEAKDF IVSGTASDQLEGMCESLYEPNLEPE

$130 \quad 140 \quad 150 \quad 160$

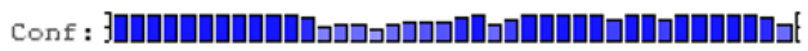

Pred: $\longrightarrow \longrightarrow$

Pred: HHHHHHHHHHHHHHCCCCCCCEEEEE EEECCCEEEEEEE

AA: DLFETISQALLNAADRDALSGWGAVVYIIKKDEVVKRYLK

$$
170 \quad 180 \quad 190 \quad 200
$$

Conf : $\mathrm{J}] \mathrm{an}$

Pred:

Pred: CCCC

AA: $M R Q D$

Subunidade 11

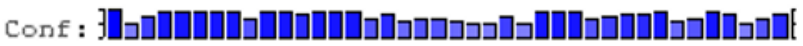 \\ Pred: $\longrightarrow \longrightarrow \longrightarrow \longrightarrow \longrightarrow$ \\ Pred: CEEEEEEEECCEEEEEEECCCCCCEEEEECCCCCEEECCC AA : MDIILGIRVQDSVILASSKAVTRGISVLKDSDDKTRQLSP \\ 10 $20 \quad 30$ \\ 40}

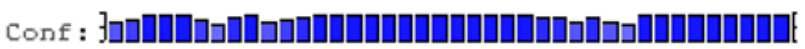

Pred: $\longrightarrow-\square$

Pred: CEEEEEECCHHHHHHHHHHHHHHHHHHHHCCCCCCHHHH

AA: HTLMSFAGEAGD TVQEAEY IQANIQLYSIREDYELSPQRV

50 60 'ं0

80

\section{Conf : Зण :}

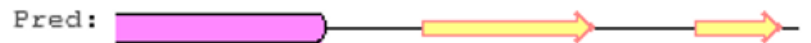

Pred: HHHHHHHHHHHHCCCCCCEEEE EEEEE ECCCCCCEEEEEC

AA: SSFVRQELAKSIRSRRPYQVNVL IGGYDKKKNKPE LYQID

$$
\text { 90 } 100 \quad 110 \quad 120
$$

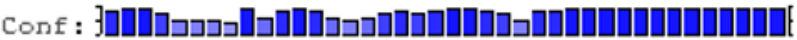

Pred: $\longrightarrow-\longrightarrow-0$

Pred: CCCCCEECCEEE ECCHHHHHHHHHHCCCCCCCCHHHHHHH

AA: YLGTKVELP YGAHGYSGFYTESLLDHHYRPDMTTEEGLDL

$$
130 \quad 140 \quad 150 \quad 160
$$

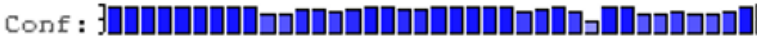

Pred:

Pred: HHHHHHHHHHHCCCCCCCEEEE EECCCCEEECCCCCCC

AA: LKLCVQELEKRMPMDFKGVIVK IVDKDGIRQVDDFQAQ $170 \quad 180 \quad 190$

Subunidade 12

Figura 18: Predição da estrutura secundária das subunidades 11 e 12 do proteassomo 20S [13] 


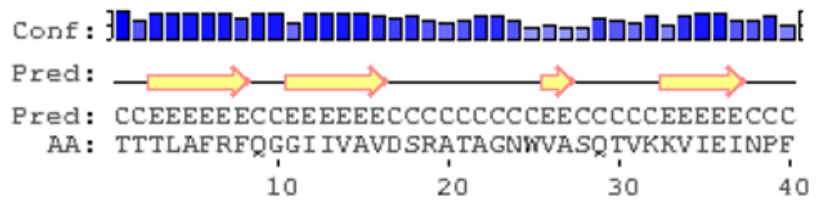

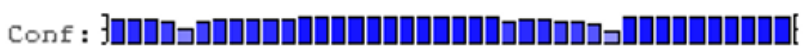

Pred: $\square-0$

Pred: EEEECCCCHHHHHHHHHHHHHHHHHHHHHCCCCCCHHHHH

AA: LLGTMAGGAADCQFWETWL GSQCRLHE LREKERISVA.A.S $\begin{array}{llll}50 & 60 & 70 & 80\end{array}$

Conf : 3

Pred: $\longrightarrow \longrightarrow \longrightarrow$

Pred: HHHHHHHCCCCCCCEEEEEEEEEECCCCCEEEEECCCCC

AA: KILSNLVYQYKGAGLSNGTMICGYTRKEGPTIYYVDSDGT

90 $100 \quad 110 \quad 120$

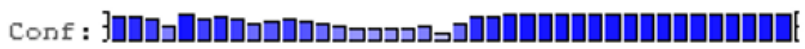

Pred: $\Rightarrow-\square \longrightarrow 0$

Pred: EEECCEEEECCCCCCHHHHCCCCCCCCCCHHHHHHHHHH

AA: RLKGDIFCVGSGQTFAYGVLDSNYKWDLSVEDAL YLGKRS $130 \quad 140 \quad 150 \quad 160$

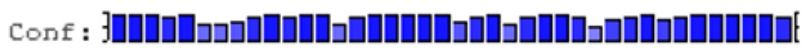

Pred: $\square-\square \longrightarrow 0$

Pred: HHHHHHCCCCCCCCEEEEEECCCCEEEECCCCHHHHHHH

AA: ILA.AAHRDA YSGGSVNL YHVTEDGWI YHGNHDVGELEWKV $170 \quad 180 \quad 190 \quad 200$

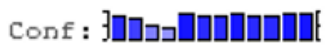

Pred:

Pred: HHHCCCCCCCCC

AA: KEEEGSFNNVIG

$$
210
$$

Subunidade 13

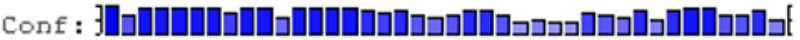

Pred: $\longrightarrow-\longrightarrow \longrightarrow$

Pred: CCEEEEEECCEEEEEECCCCCCCCCEECCCCCEEEEECCC

AA: TTTLAFRFQGGI IVAVDSRATAGNWVASQTVKKVIEINPF,

$10 \quad 20 \quad 30$

40

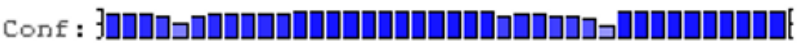

Pred: $\square \longrightarrow 0$

Pred: EEEECCCCHHHHHHHHHHHHHHHHHHHHHCCCCCCHHHHH

AA: LLGTMAGGA.ADCQFWETWLGSQCRLHE LREKERISVA.A.S

$50 \quad 60 \quad 70$

80

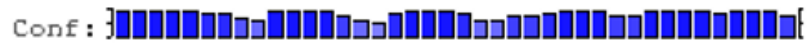

Pred:

Pred: НHHHHHHHCCCCCCCEEEEEEEEEECCCCCEEEEECCCCC

AA: KILSNLVYQYKGAGLSMGTMICGYTRKEGPTIYYVDSDGT

90 $100 \quad 110 \quad 120$

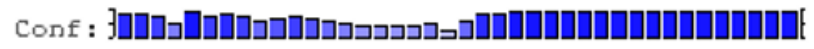

Pred: $\Rightarrow-\longrightarrow-0$

Pred: EEECCEEEECCCCCCHHHHCCCCCCCCCCHHHHHHHHHH AA: RLKGDIF CVGSGQTFAYGVLDSNYKWDLSVEDALYLGKRS

i30 ín iso

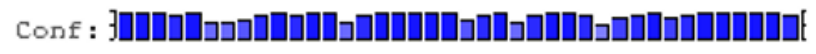

Pred: $\longrightarrow \longrightarrow \longrightarrow$

Pred: HHHHHHCCCCCCCCEEEEEECCCCEEE ECCCCHHHHHHHH

AA: ILA,AHRDA YSGGSVNLYHVTEDGWI YHGNHDVGELFWKV

$\begin{array}{llll}170 & 180 & 190 & 200\end{array}$

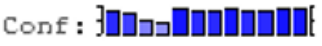 \\ Pred: \\ Pred: $\mathrm{HHHCCCCCCCCC}$ \\ AA: KEEEGSENNVIG \\ 210}

\section{Subunidade 14}

Figura 19: Predição da estrutura secundária das subunidades 13 e 14 do proteassomo 20S [13] 


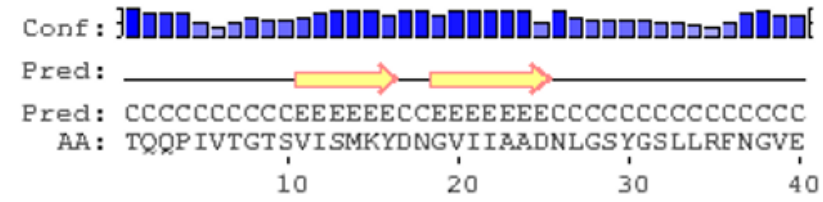

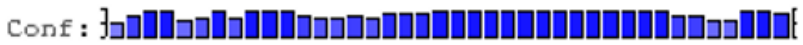

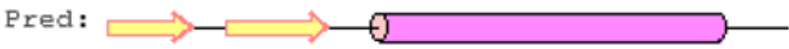

Pred: EEEEECCEEEEE ECCCHНHНHНHНHНHHHНHHHHHHCCCC AA: RLIPVGDNTVVG ISGD ISDWOH IERLLKDLVTENAYDNPL $\begin{array}{lll}50 & 60 & 70\end{array}$

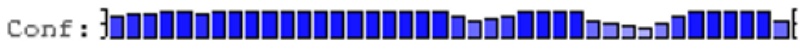
Pred: $\longrightarrow$

Pred: CCCCCCCCHHHHHHHHHHHHHCCCCCCCCCCCCEEEEEEE AA: ADAEEALEP SYIFEYLATVMYQRRSKANP LWNAI IVAGVQ 90 $100 \quad 110 \quad 120$

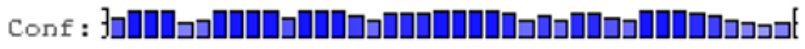

Pred: $\longrightarrow \longrightarrow \longrightarrow \longrightarrow$

Pred: CCCCEEEEEECCCCCEEECCEEEECCCHHHHHHHHHHHHC AA: SNGDQFLRYVNLLGVTYSSPTLATGEGR.HMANPLLRKVVD $130 \quad 140 \quad 150 \quad 160$

\section{Conf : \} :}

Pred:

Pred: CCCCCCCCCHНHНHНHНННННHНHНHНCCCCCCCEEEEE AA: RESD IPKTTVQVAEEAIVNAMRVL $Y$ YRDARSSRNE SLAI I

$\begin{array}{llll}170 & 180 & 190 & \text { 'ं00 }\end{array}$

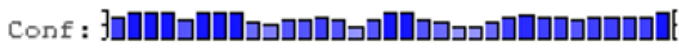

Pred: $>\longrightarrow$

Pred: ECCCCEEECCCEEECCCCCCCCCCCCCCCCCCC AA: DKNTGLTFKKNLQVENAKWDFAKD IKGYGTQKI 210 220 230

\section{Subunidade 15}

Conf : $3 \mid \mathrm{A}$

Pred: $\longrightarrow \longrightarrow \longrightarrow \longrightarrow$

Pred: CCEEEEEECCEEEEEECCCCCCCCEECCCCCCCCEEECCC AA: TS IMAVTFKDGVILGADSRTTTGR YIANRVTDKL TRVHDK $10 \quad 20 \quad 30$ 40

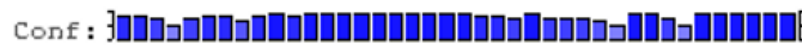

Pred: $\square-0$

Pred: EEEECCCCHНHНHНHНHНHНHНHНHНHНHНCCCCHНHНHН AA: IWCCRSGSAADTQA.IAD IVQYHLELYTSQYGTPSTETA.S $5060 \quad 70 \quad 80$

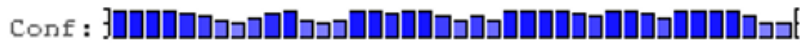

Pred:

Pred: HHHHHHHCCCCCEEEEEEEEEE ECCCCCEEEEECCCCCCC AA: VF KELCYENKDNLTAGI IVAGYDDKNKGEVYT IP LGGSVH 9o $100 \quad$ ín

Conf : $\}_{7}$;

Pred: $\longrightarrow-0$

Pred: CCCEEECCCHНHНHНHНHНССССCСССНHНHНHНHНHНH AA: KLPYAIAGSGSTFIYGYCDKNE RENMSKEETVDF IKHSLS i30 ín

\section{Conf : 3010 : \\ Pred: \\ Pred: HHHHCCCCCCCCEEEEEECCCCEEEEEECCCCCCCC AA : QA IKWDGSSGGVIRIVVLTAAGVERLIFYPDEYEQL 170 180 190}

\section{Subunidade 16}

Figura 20: Predição da estrutura secundária das subunidades 15 e 16 do proteassomo 20S [13] 
Conf : 3

Pred: $\longrightarrow$ Pred: CCCCCCCCCCCCCCCCCHHHHHHHHHHHCCCCEEEEECC AA: MTDRYSE SLTTESPSGKLGIDYALTAVKO,GVTSLGIKRT $\begin{array}{llll}10 & 20 & 30 & 40\end{array}$

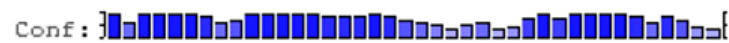

Pred:

Pred: CEEEEEEECCCCCCCCCCCCCCCEEECCCCEEEEECCCCC AA: NGVVIATEKKSSSPLAMSETLSKVSLLTPDIGAVYSGMGP

$\begin{array}{llll}50 & 60 & 70 & 80\end{array}$

Conf : ל ל :

Pred: 0

Pred: CHHHHHHHHHHHHHHCCCCCCCCCCCHHH HHHHHHHHHH AA: DYRVLVDKSRKVAHTSYKRIYGEYPPTKL LVSEVAKIMQE $90100 \quad 110 \quad 120$

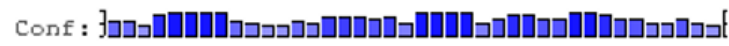
Pred:

Pred: HHHCCCCCCHHHEEEEEEECCCCCEEEEEECCCCCCCCCC AA: ATOSGGVRPFGVSLLIAGHDEF NGE SLYOVDP SGSYF PWK $\begin{array}{llll}130 & 140 & 150 & 160\end{array}$

Conf : ל ל :

Pred: $\square 0$

Pred: EEEECCCCHHHHHHHHHHCCCCCCHHHHH HHHHHHHHHH AA: ATRIGKGSVAAKTF LEKRWNDELELEDR.IHIALL TLKESV i70 iso í

Conf : ל ל : Pred: $\longrightarrow \longrightarrow-(T$

Pred: CCCCCCCCEEEEEEECCCCCCCCCCCCCCCCCCCEEECCH AA: EGEFNGDTIELAIIGDENPDLLGYTGIPTDKGPRERKLTS $\begin{array}{llll}210 & 220 & 230 & 240\end{array}$

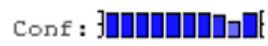

Pred:

Pred: НHнHНHнHНC

AA: QE INDRLER L

250

\section{Subunidade 17}

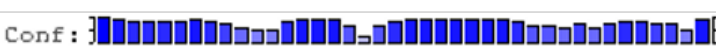

Pred: $\longrightarrow$

Pred: CCCCCCCCCCCCCCCCCCCHHHHHHHHHHHCCCCEEEEECC

AA: GSRRYDSRTTIF SPEGRLYQVEYRLES ISHAGTAIGIMAS

$10 \quad 20 \quad 30$

40

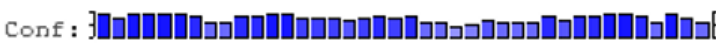

Pred:

Pred: CEEEEEEECCCCCCCCCCCCCCCCEEEECCCEEEEECCCC AA: DGIVLAAERKVTSTLLEQDTSTEKLYKLNDKIZVAVAGL T $\begin{array}{lll}50 & 60 & 70\end{array}$ 80

Conf : \} ל ב

Pred: 0

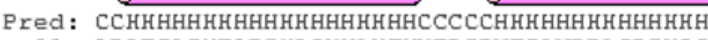
AA: ADZEILINTARI HZONYLKTYNED IPVEI LVRRL SD IKQG

$90 \quad 100 \quad 110$

120

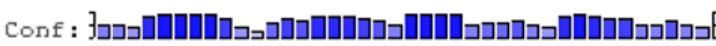

Pred:

Pred: HHHCCCCCCCCEEEEEEEEECCCCCEEEECCCCCCCCCCC AA : YTQHGGLRPFGVSF I YAGYDDRYGYQLYTSNP SGNYTGWK i30 $140 \quad 150 \quad 160$

Conf : \}

Pred: $\square-0$

Pred: EEEECCCCHHHHHHHHHHCCCCCCHHHHHНHНHНHНHНHH AA: AISVGANTSAAQTLLQNDYKDDMKVDDAIELALKTLSKT T 170 $180 \quad$ i90

Conf : 3

Pred: $\longrightarrow \longrightarrow-0$

Pred: CCCCCCCCCEEEEEEEECCCCCCCEEE ECCHHHHHHHHHH AA: DSSALTYDRLEF AT IRKGANDGEVYQKIFKPQEIKDILVK $\begin{array}{lll}210 & \dot{2} 20 & 230\end{array}$

Conf : $\mathrm{J}] \mathrm{Du}$

Pred:

Pred: $\operatorname{CCCC}$

$A A$ : TGIT

\section{Subunidade 18}

Figura 21: Predição da estrutura secundária das subunidades 17 e 18 do proteassomo 20S [13] 


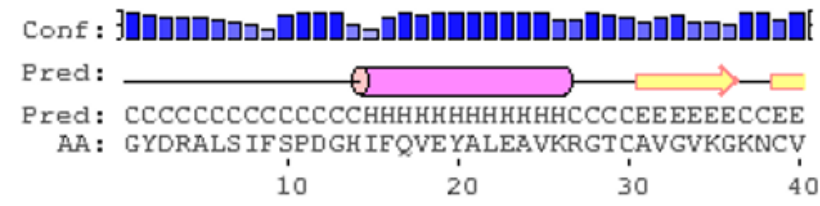

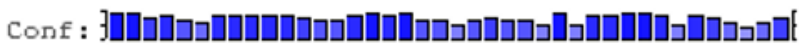

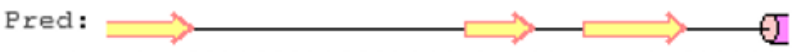

Pred: EEEEECCCCCCCCCCCCCCCCEEEECCCEEEEEECCCCCH

AA: VLGCERRSTLKLQDTRITPSKVSKIDSHVVLSFSGLNADS

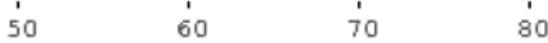

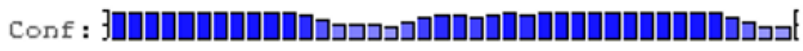

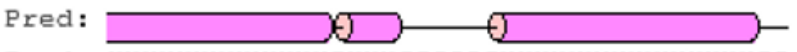

Pred: HHHHHHHHHHHHHCHHHCCCCCCHНHHHHНHНHНHHHHCC

AA: RILIEKARVEAQSHRLTLEDPVTVEYLTR YVAGVQORYTQ

$$
\text { 90 } 100 \quad 110 \quad 120
$$

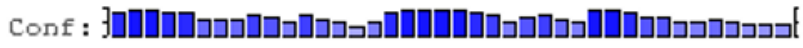

Pred: $\longrightarrow \longrightarrow$

Pred: CCCCCCHHHHHHHHCCCCCCCCCCEEEECCCCCCCCCEEC AA: SGGVRPF GVSTLIIZGEDPRDDEPKLYQTEPSGIYSSWSAO

$\begin{array}{llll}130 & 140 & 150 & 160\end{array}$

Conf : \} \}

Pred: $\Rightarrow \longrightarrow 0$

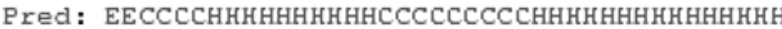
AA: TIGRNSKTVREF LEKNYDRKEP PZ TVEECVKLTVRSLLEV $\begin{array}{llll}170 & 180 & 190 & 200\end{array}$

Conf : \}ด :

Pred: $\bigcirc$ AA: VQTGAKN IEI TVVKPDSD IVALSSEE INQYVTQIEQE KQE

$$
\begin{array}{llll}
210 & 220 & 230 & 240
\end{array}
$$

Conf : ] ]

Pred:

Pred: C

$A A: Q$

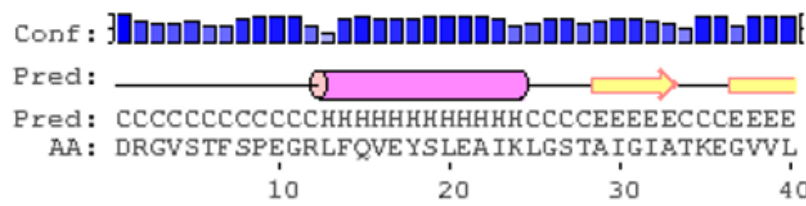

Conf : \}

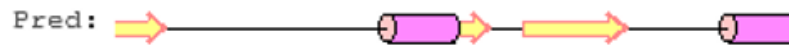

Pred: EEECCCCCCCCCCCCCHHHHEECCEEEEEECCCCCCHHHH AA: GVEKRATSPLLESD SIEKIVEIDRHIGCRMSGLTADARSM
50
60
70
80

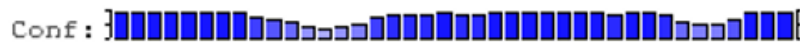

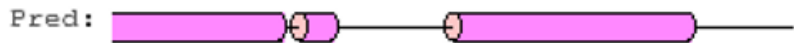

Pred: HHHHHHHHHHCHHCCCCCCCHHHHHHHHHHHHHHCCCCCC AA: IE H.RTA.RVTHNLY YDED INVE SL TQSVCDLALRE GE GAS
90
100
110
120

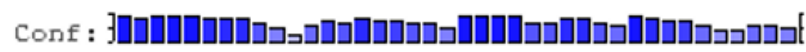

Pred:

Pred: CCCCCCCCCCCEEEEEEEECCCCCCEEEEECCCCCCCCCC AA: GEERLISRPFGVRLLIAGHDADDG YQLFHAEP SGTF YRYN

$$
130 \quad 140 \quad 150 \quad 160
$$

Conf :

Pred: $\square-0$

Pred: EEEECCCCHHHHHHHHHHCCCCCCHHHHHHHHHHHHHHH AA: AKAIGSGSEGAQRELLNEWHSSLTLKE. BELLVLKILKQVM
170
180
190
200

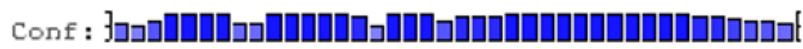

Pred: $\longrightarrow \longrightarrow$

Pred: CCCCCCCCEEEEEEECCCCEEECCHHHHHHHHHHHHHHH AA: EEKLDENNAOLSCITKQDGEKIYDNEKTAELIKELKEKEA
210
220
230
240

\section{Subunidade 19}

Figura 22: Predição da estrutura secundária das subunidades 19 e 20 do proteassomo 20S [13] 


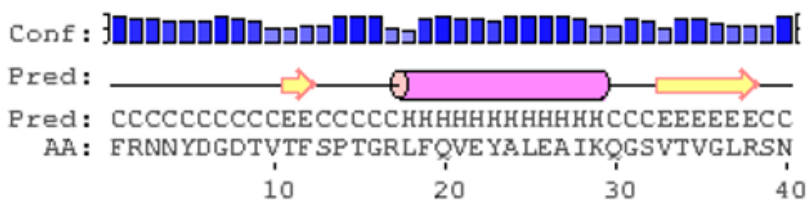

Subunidade 21
Conf : 3|

Pred:

()

Pred: CCCCCCCCCCCCCCCCHHHHHHHHHHHHCCCCEEEEECCC

AA: GTGYDLSNSVESPDGRNFQVEYAVKAVENGTTSIGIKCND

$$
\begin{array}{lll}
10 & 20 & 30
\end{array}
$$

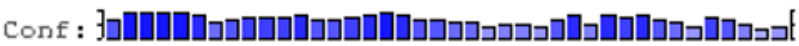

Pred:

Pred: EEEEEEECCCCCCCCCCCCCCCCEECCCEEEEEECCCCCC

AA: GVVFAVEKL ITSKL LVPQKNVKIQVVDRH IGCVYSGLIPD

$$
50 \quad 60 \quad 70
$$

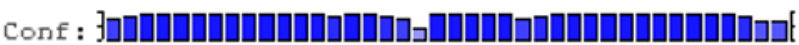

Pred: 0

Pred: HНHHHHHHHHHHHHHHHHHCCCCCHHHHHHHHHHНHHHHH

AA: GRHLVNRGREEA.X.SFKKLYKTP IP IPAFR.DRLGQYVQR.H T

$$
\text { 90 } 100 \quad 110 \quad 120
$$

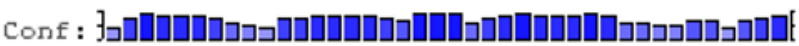

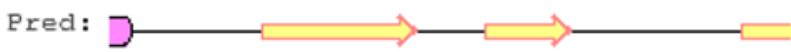

Pred: HCCCCCCCCEEEEEEEEECCCCEEEEECCCCCCCCCCEEE

AA: LYNSVRP FGVSTIFGGVDKNGAHL MLEPSTSYWGYKGA.A.

$$
\begin{array}{llll}
130 & 140 & 150 & 160
\end{array}
$$

Conf : \} ל

Pred : $\longrightarrow 0$

Pred: ECCCCHHHHHHHHHHHCCCCCCCCHHHHHHHHHHHHHHH

AA: TGKGRQSAKAELEKLVDHHPEGLSARERVKOA.RKIIYLA.H

$$
\text { 170 } 180 \quad 190 \quad 200
$$

\section{Conf : \}}

Pred: $\longrightarrow \longrightarrow$

Pred: CCCCCCCCEEEEEEEEECCCCCEEEECCHHHHHHHHHH AA: EDNKEKDFELEISWCSLSE TNGLHKFVKGDLLQEAIDFBO

$$
\begin{array}{llll}
\dot{2} 10 & 220 & 230 & 240
\end{array}
$$

Conf : ]

Pred:

Pred: $\overrightarrow{\mathrm{HHHC}}$

$A A: K E I N$

Subunidade 22

Figura 23: Predição da estrutura secundária das subunidades 21 e 22 do proteassomo 20S [13] 


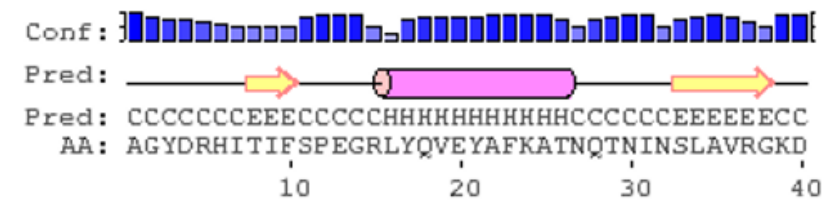

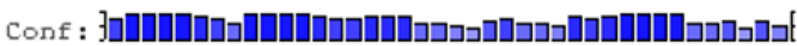

Pred: $\square \longrightarrow \longrightarrow$

Pred: EEEEEEECCCCCCCCCCCCCCEEEEECCCEEEEEECCHHH

AA: CTVVISQKKVPDKLLDPTTVSYIFCISRT IGMVVNGP IPD $\begin{array}{llll}50 & 60 & 70 & 80\end{array}$

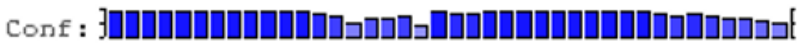

Pred: $\longrightarrow-0$

Pred: НHНHНHНHНHНHНHНHНHНССС СНHНHНHНHНHНHНH

AA: ARNA.ALRAKAEA.AEFRYKYGYDMP CDVLAKRMANLSQIYT 9० $100 \quad 110 \quad 120$

Conf : ל :

Pred: $\longrightarrow \longrightarrow \longrightarrow$

Pred: CCCCCCHHHHHHEEEEECCCCCCEEEEECCCCCCCCEEEE

AA: QRAYMRPLGVILTFVSVDEELGPSIYKTDPAGYYVGYKA.T $130 \quad 140 \quad 150 \quad 160$

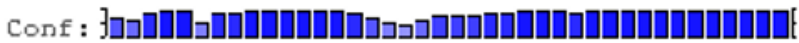

Pred: $\Rightarrow 0$

Pred: EECCCHHHHHHHHHHHCCCCCCCCCCCCCHHHHHHHHHHH

AA: ATGPKQQEITTNLENHE KKSKIDH INE ESWEKVVEFAITH $170 \quad 180 \quad 190 \quad 200$

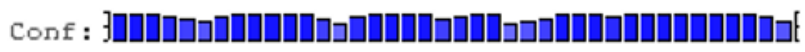

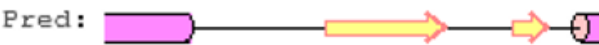

Pred: HHHHHCCCCCCCCEEEEEEECCCCEECCHHHHHHHHHHH

AA: MIDALGTEF SKNDLEVGVATKDKFFTLSAENIEERLVAIA $\begin{array}{llll}210 & 220 & 230 & 240\end{array}$

Conf : Jall

Pred:

Pred: CCC

$A A: E Q D$

Subunidade 23
Conf : 3 |f

Pred: $\longrightarrow \longrightarrow \longrightarrow \longrightarrow$

Pred: CCEEEEEECCEEEEEECCCCCCCCEEEECCCCCCEEECCC

AA: TTIVGVKFNNGVVIAADTRSTQGP IVADKNCAKLHRISPK

io $20 \quad 30 \quad 40$

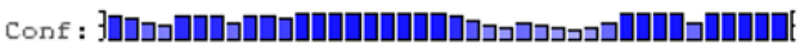

Pred: $\Rightarrow 000$ O

Pred: EEECCCCCHHHHHHHHHHHHHHHCHHCCCCCCCCHHHHHH

AA: IWCXGAGTRADTEXVTQLIGSN IELHSLYTSREPRVVSAL

$50 \quad 60 \quad 70$

80

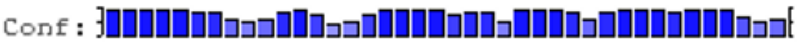

Pred: $\longrightarrow \longrightarrow$

Pred: HHHHHHHHCCCCCCEEEEEEEEECCCCCEEEEECCCCCEE

AA: QNLKQHLFKY YGHIGAYLIVAGVDPTGSHLF IHAHGSTD

$$
90100 \quad 110 \quad 120
$$

Conf : ל ๖ :

Pred: $\Rightarrow-\longrightarrow-0$

Pred: EECEEEECCHHHHHHHHHCCCCCCCCHHHHHHHHHHHH

AA: VGYYLLGSGSLA.MAMLESHWKDLTKEEAIKLASDAIQ $130 \quad 140 \quad 150 \quad 160$

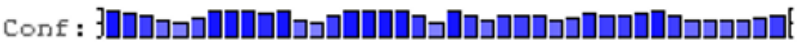

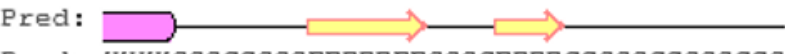

Pred: HHHHCCCCCCCCEEEEE EECCCCEEEECCCCCCCCCCCCC AA: AGIWNDLGSGSNVDVCVMEIGKDAEYLRNYLTPNVREEKQ

170 $180 \quad 190 \quad 200$

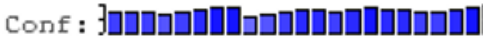

Pred: $\longrightarrow$

Pred: CCCCCCCCCEEEEEEEEEECCC

AA: KSYKFPRGTTAVLKESIVNICD

$210 \quad 220$

\section{Subunidade 24}

Figura 24: Predição da estrutura secundária das subunidades 23 e 24 do proteassomo 20S [13] 


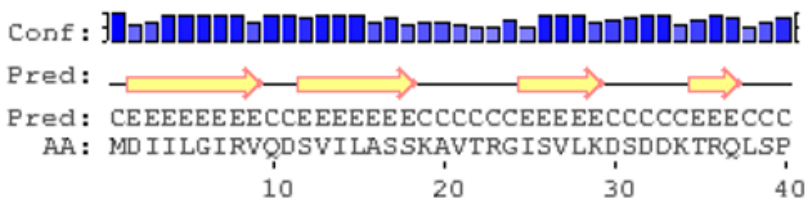

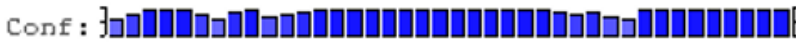

Pred: $\longrightarrow-\longrightarrow$

Pred: CEEEEEECCHHHHHHHHHHHHHHHHHHHCCCCCCHHH AA: HTLMSEAGEAGD TVQEAEY IQANIQLYSIRED YELSPQRV $\begin{array}{llll}50 & 60 & 70 & 80\end{array}$

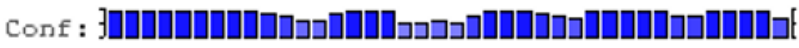

Pred: $\longrightarrow-$

Pred: HHHHHHHHHHHCCCCCCEEEEEEEEE ECCCCCCEEEEEC

AA: SSFVRQELAKSIRSRRP YQVNVL I GGYDKKKNKPELYQID

9่ 100 i10 120

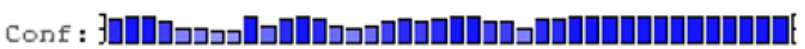

Pred: $\longrightarrow \longrightarrow$

Pred: CCCCCCCCCEEEECCHHHHHHHHHHCCCCCCCCHHHHHH

AA: YLGTKVELP YGAHGYSGFYTESLLDHHYRPDMTTEEGLDL
130
140
150
160

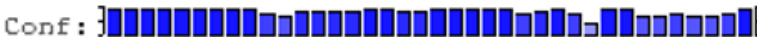

Pred:

Pred: HHHHHHHHHHHCCCCCCCEEEE EECCCCEEECCCCCCC

AA: LKLCVQELEKRMPMDEKGVIVK IVDKDGIRQVDDFQAQ 170 180 190

\section{Subunidade 25}

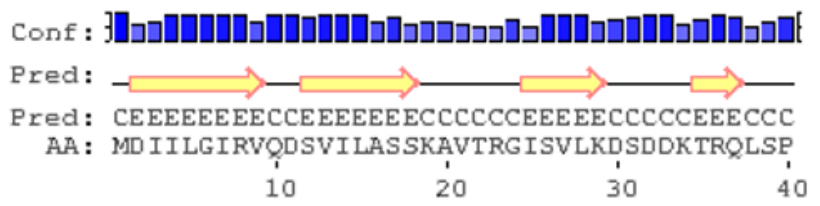

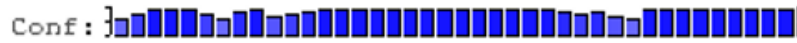

Pred: $\longrightarrow \longrightarrow$

Pred: CEEEEEECCHHHHHHHHHHHHHHHHHHHHHCCCCCCHHHH AA: HTLMSEAGEAGDTVQEAEY IQANIQLYSIREDYELSPQAV

$50 \quad 60 \quad 70$

80

Conf : \}

Pred: $\longrightarrow \longrightarrow$

Pred: HHHHHHHHHHHCCCCCCEEEEEEEEE ECCCCCCEEEEEC AA: SSFVRQELAKSIRSRRPYQVNVLIGGYDKKKNKPELYQID 90 $100 \quad 110 \quad 120$

Conf : \}

Pred: $\longrightarrow-0$

Pred: CCCCCCCCCEEEECCHHHHHHHHHCCCCCCCCHHHHHH AA: YLGTKVELPYGAHGYSGFYTESLLDHHYRPDMTTEEGLDL $130 \quad 140 \quad 150$ 160

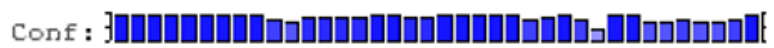

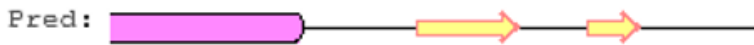

Pred: HHHHHHHHHHHCCCCCCCEEEEEECCCCEEECCCCCCC AA : LKLCVQELEKRMPMDFKGVIVK IVDKD GIRQVDDFQAQ $170 \quad 180$ 190

\section{Subunidade 26}

Figura 25: Predição da estrutura secundária das subunidades 25 e 26 do proteassomo 20S [13] 


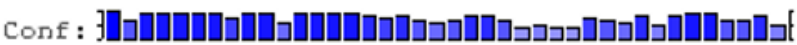

Pred: $\longrightarrow \longrightarrow-\longrightarrow \longrightarrow$

Pred: CCEEEEEECCEEEEEECCCCCCCCCEECCCCCEEEEECCC

AA: TTTLAFRFQGGI IVAVD SRATAGNWVASQTVKKVIE INPE,

$\begin{array}{llll}10 & 20 & 30 & 40\end{array}$

Conf : \} З

Pred: $\longrightarrow$ Pred: EE EECCCCHHHHHHHHHHHHHHHHHHHHHCCCCCCHHHHH

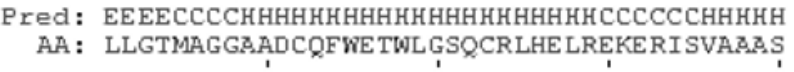

$50 \quad 60 \quad 70 \quad 80$

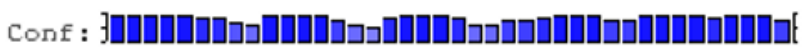

Pred: $\longrightarrow$

$\begin{aligned} & \\ \text { AA : KILSNLVYQYKG } & \text { HHGLSMGTMICGYTRKEGPTIYYVDSDGT }\end{aligned}$

90 $100 \quad$ ín 120

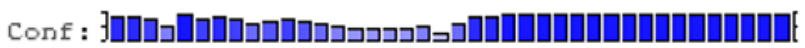

Pred: $\rightarrow-\longrightarrow-\underset{\text { PEECCEE EECCCCCCHHHHCCCCCCCCCCHHHHHHHHHHH }}{\longrightarrow}$

Pred: EEECCEEEECCCCCCHHHHCCCCCCCCCCHHHHHHHHHHH
AA: RLKGDIFCVGSGQTFAYGVLDSNYKWDLSVEDAL YLGKRS

$$
\begin{array}{llll}
130 & 140 & 150 & 160
\end{array}
$$

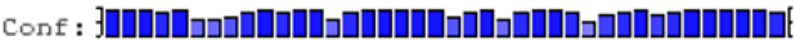

Pred : $\longrightarrow$

red: HHHHHHCCCCCCCCEEE EEECCCCEEE ECCCCHHHHHHHH
AA: ILA.A.AHRDAYSGGSVNLYHVTEDGWIYHGNHDVGE LFWKV

$$
\begin{array}{llll}
170 & 180 & 190 & 200
\end{array}
$$

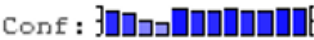

Pred:

Pred: HHHCCCCCCCCC

AA: KEEEGSENNVIG

$$
210
$$

\section{Subunidade 27}

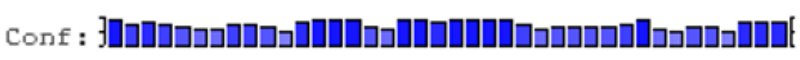

Pred:

Pred: CCCCCCCCCCCEEEEEECCEEEEEECCCCCCCCEEEECCC

AA: QENPYGDNGGTILGIAGEDFAVLAGDTRNITDYSINSRYE

$10 \quad 20 \quad 30$

40

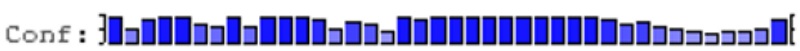

Pred: $\longrightarrow \longrightarrow \longrightarrow$

Pred: CEEEEECCCEEEEECCCHНHHHHHНHНHНHHHHНHHHCCC

AA: PKVFDCGDNIVMSANGE R.D.DGDZLLVKRFKNSVKWYHEDHN

$5060 \quad 70$

80

Conf : 30 :

Pred: $\longrightarrow$

Pred: CCCCCHHHHНHНHНHНHНCCCCCCCEE EEEEE EECCCCCE

AA: DKKLSINSA, , IRN IQHLLYGKRE FP Y YVHT I IAGLDEDGKG

9ैo 100 1ं0 120

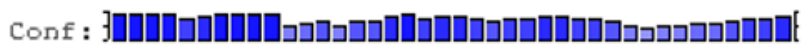

Pred: $\Longrightarrow \longrightarrow \longrightarrow \longrightarrow$

Pred: EEEEECCCCCEEEECEEEECCCHHHHHHHHHHCCCCCCCC

AA: AVYSFDPVGS YEREQCRAGGAAZSLIMPF LDNQVNEKNQY

$\begin{array}{llll}130 & 140 & 150 & 160\end{array}$

\section{Conf :}

Pred:

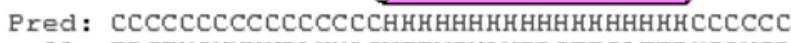
AA: EPGTNGKVKKPLKYLSVEEVIKLVRDSFT SATERHIQVGD

$\begin{array}{llll}170 & 180 & 190 & 200\end{array}$

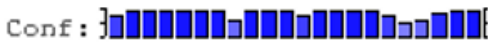

Pred:

Pred: EEEEEEEECCCEEEEEEECCCC

AA: GLEILIVTKDGVRKEFYELKRD

$210 \quad 220$

\section{Subunidade 28}

Figura 26: Predição da estrutura secundária das subunidades 27 e 28 do proteassomo 20S [13]
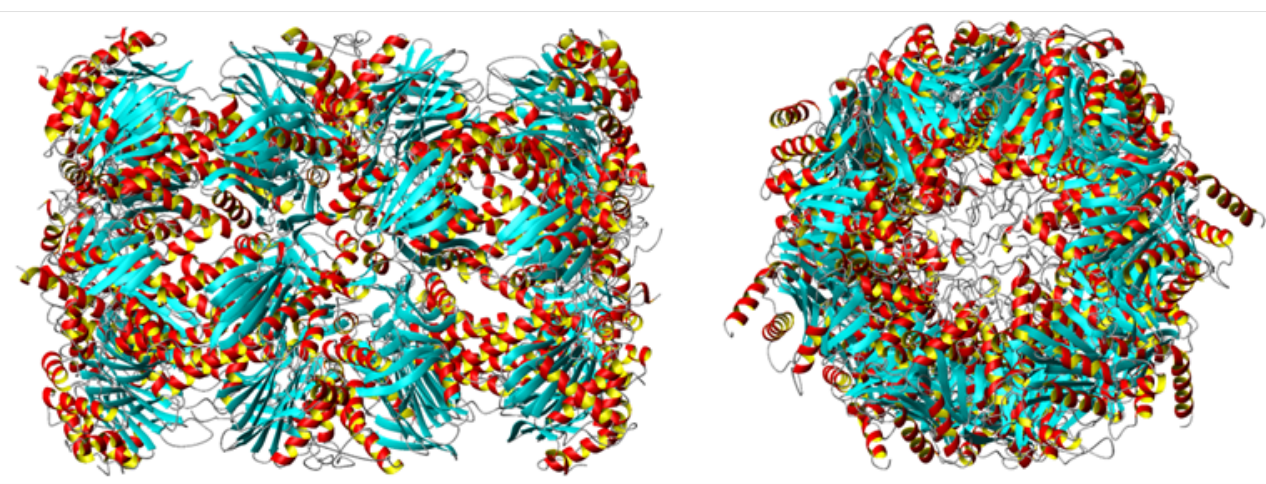

Figura 27: Vista superior e vista lateral da representação da estrutura tridimensional do proteassomo.

Entrada no PDB:3d29 [12]. 
Fundamentos

\subsection{Extração/Obtenção das proteínas e processos de purificação}

Dentro de uma célula humana estima-se que é possível encontrar entre 3000 e 5000 proteínas diferentes. No plasma sanguíneo é encontrada por volta de 300 proteínas [17] [15]. Por isso, para estudarmos uma proteína, em detalhe, é necessário que tenhamos apenas a proteína de interesse, separada das demais. Para isso utilizam-se técnicas de purificação.

\subsubsection{Lisozima}

As amostras de Lisozima foram preparadas variando a concentração, a partir de uma solução estoque de $20 \mathrm{mg} / \mathrm{mL}$ em duas soluções tampões diferentes, uma em tampão PBS $10 m M p H \approx 7,0$ e outra em TRIS $20 m M p H \approx 7,5$ e diluídas nas concentrações de $15 \mathrm{mg} / \mathrm{mL}, 10 \mathrm{mg} / \mathrm{mL}, 5 \mathrm{mg} / \mathrm{mL}$ e $2,5 \mathrm{mg} / \mathrm{mL}$. A proteína, Lisozima, foi obtida da Sigma (Lysozyme from chicken egg white) em pó e utilizada sem nenhuma purificação adicional. 


\subsubsection{Crioglobulinas}

Como existem 5 classes de imunoglobulinas, que podem ser mono ou policlonais, tem-se muitas variáveis a serem consideradas no sistema.

Uma das amostras estudadas, purificada pelo Laboratório de Reumatologia da UNIFESP, liderado pelo professor Luís Eduardo Coelho Andrade, tratava-se de um sistema misto, composto por mais de um tipo (pool de imunoglobulina). A polidispersidade intrínseca dessas amostras, dificultou estudos estruturais. Sendo assim, na tentativa de ter-se amostras mais puras, utilizou-se amostras do tipo IgG monoclonal, tanto de pacientes com crioglobulemia como de pacientes com soro considerado normais. Trabalhou-se apenas com amostra de 1 paciente com crioglobulemia.

O plasma do paciente com crioglobulemia foi coletado no momento da plasmaferese, um procedimento que realiza a "limpeza" do sangue. Esse processo é semelhante a hemodiálise. Porém, na hemodiálise o processo de filtragem remove as toxinas acumaladas devido à insuficiência renal, enquanto que na plasmaferese o filtro é capaz de remover o plasma do sangue levando consigo substâncias, por exemplo as crioglobulinas, que estão causando a doença [17] [15].

O plasma de paciente normal é obtido de doador, no banco de sangue com garantia de sorologia negativa. Como o paciente com crioglobulemia tem sangue tipo $\mathrm{O}$ e fator $\mathrm{RH}$ positivo, o plasma de paciente normal é do mesmo tipo com mesmo fator RH.

Para a purificação das crioglobulinas utilizou-se procedimentos descritos na literatura. Um esquema desse processo de purificação pode ser visto na figura 28. Em resumo, o soro é estocado a $4^{\circ} \mathrm{C}$ entre dois a sete dias. Assim é possível observar a presença do criopreciptado. O sobrenadante é retirado e substituído pelo mesmo volume de solução 
salina com o pH próximo ao fisiológico. Utilizou-se solução fosfato em $\mathrm{pH}=7,4[5]$.

Na tentativa de garantir maior pureza das amostras, realizou-se um procedimento de lavagem, em que essa solução é aquecida até aproximadamente $40^{\circ} \mathrm{C}$ para ressuspender a crioglobulina e então levado a $4^{\circ} \mathrm{C}$ novamente para ocorrer a preciptação e realizar-se a troca da solução salina (Figura 28).

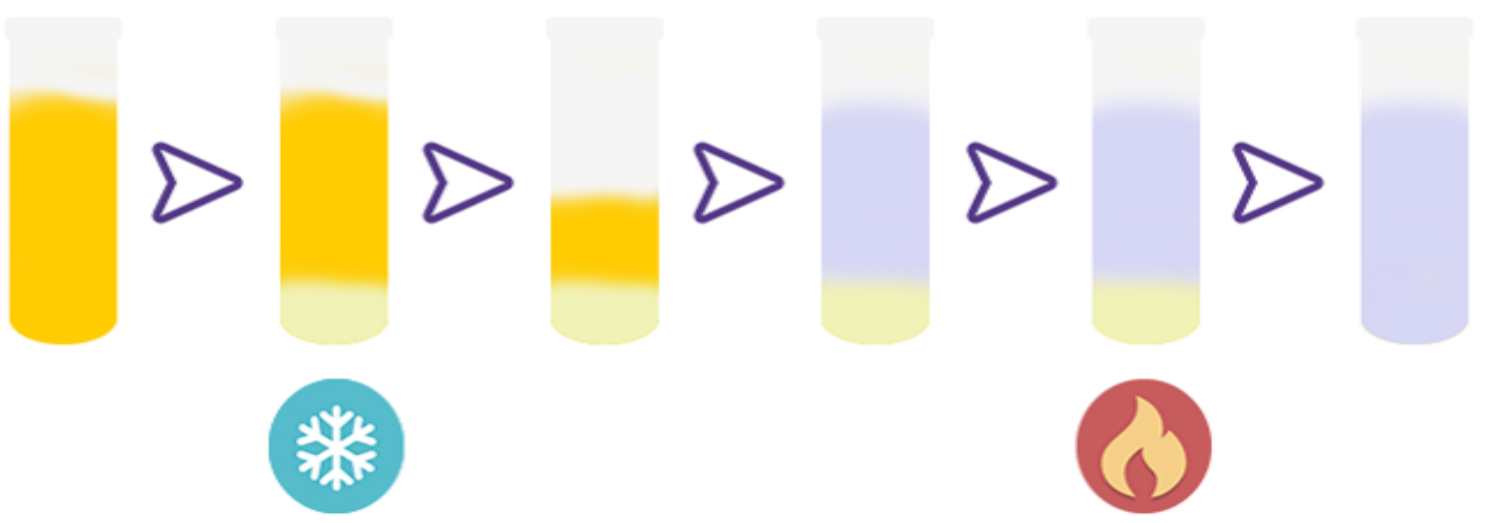

Figura 28: Esquema do processo de purificação da Crioglobulina

No caso do soro normal, como o interesse é trabalhar com a imunoglobulina do tipo IgG, para o processo de purificação, utilizou-se, dentre as técnicas de cromatografia, a cromatografia por afinidade em coluna de proteína G. Um procedimento já bem descrito na literatura para purificação da IgG. Um esquema desse procedimento de purificação pode ser visto na figura 29. A Proteína-G é um polipeptídeo que se acopla ao anticorpo e liga-se a um suporte estacionário. Esta ligação é reversível com mudança de pH, permitindo a eluição da $\operatorname{IgG}$. 

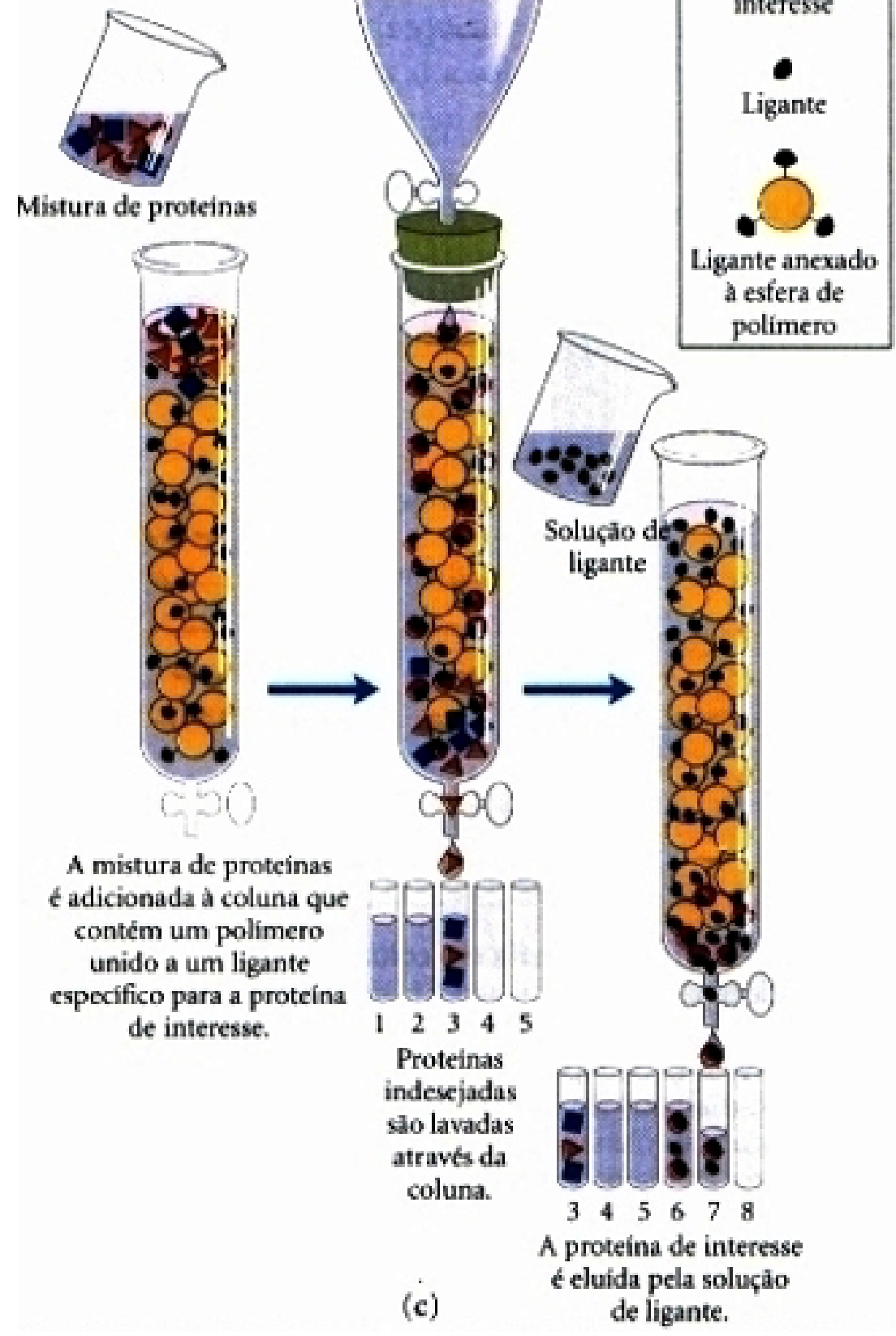

Figura 29: Esquema do processo de purificação através da técnica de cromatografia por afinidade. Retirada de $[17]$

\subsubsection{Proteassomo}

O proteassomo $20 \mathrm{~S}$ de levedura, é obtido através das células da levedura ressupendidas em solução tampão Tris. As células são rompidas por agitação com pérolas de 
vidro a $4^{\circ} \mathrm{C}$ e o extrato celular resultante é centrifugado para separar das pérolas de vidro. O proteassomo contido no extrato é purificado em coluna de afinidade a níquel e eluído em gradiente linear de imidazol. Um esquema desse processo pode ser visto na figura 30. Esse procedimento foi realizado no Laboratório de Bioquímica e Biofísica do Instituto Butantan, sob a supervisão da professora Marilene Demasi.

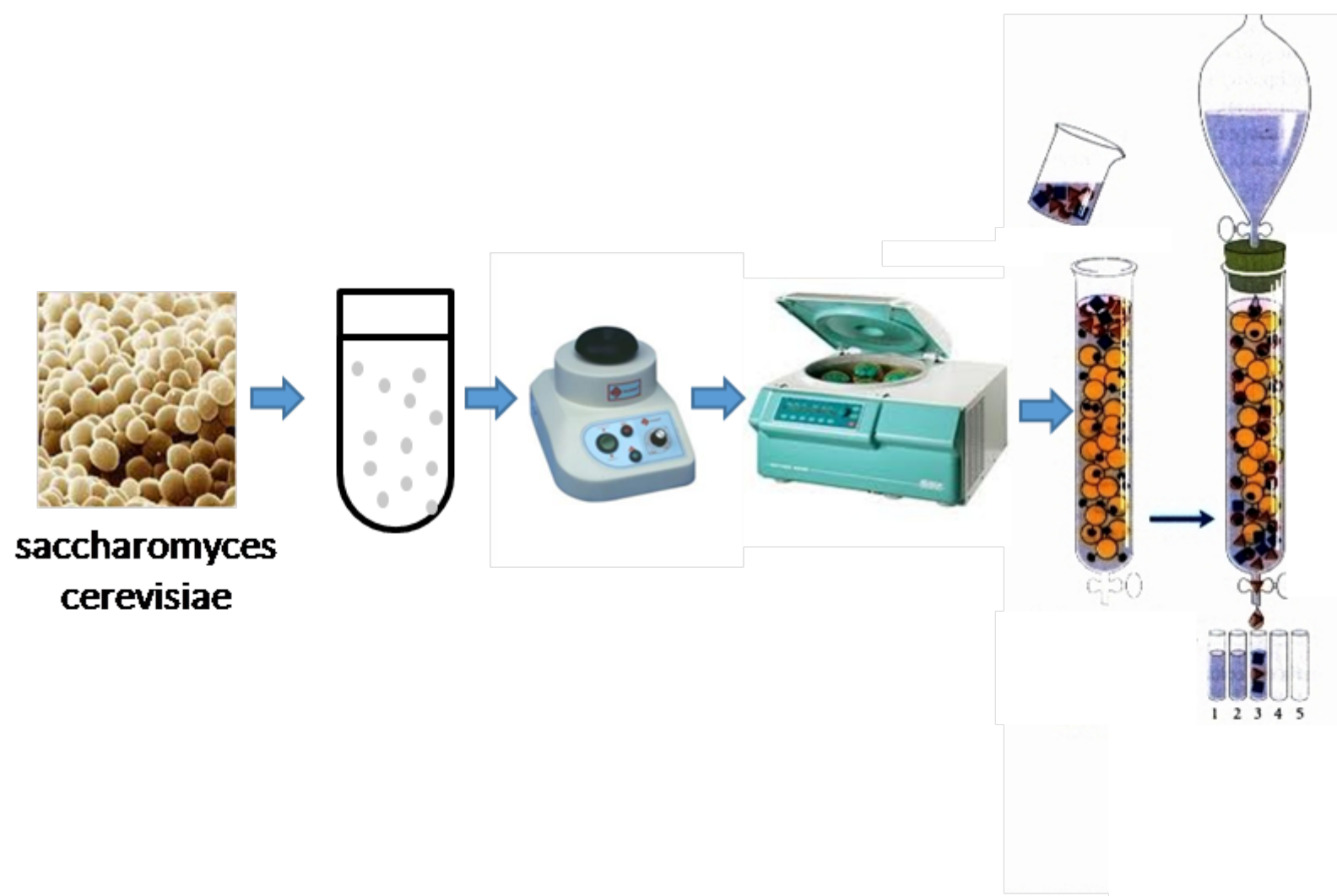

Figura 30: Esquema do processo de obtenção e purificação do proteassomo

\subsection{Primeiras caracterizações das amostras}

Uma caracterização "padrão"inicial das amostras de Crioglobulina e do Proteassomo, consiste na técnica de eletroforese (normalmente em géis de agarose e poliacrilamida - SDS-PAGE) [17] [15]. A eletroforese consiste na separação de moléculas, conforme o tamanho, a forma ou carga, através da migração das partículas carregadas num determinado 
meio, sob a influência de uma diferença de potencial[17] [15].

Diferentes suportes podem ser utilizados na forma de géis poliméricos. Como por exemplo, gel de poliacrilamida.

Na eletroforese em gel de poliacrilamida (PAGE) as proteínas migram através dos poros do gel em resposta a um campo elétrico. O procedimento pode incluir a separação em condições nativas e desnaturantes. Por exemplo, as proteínas são tratadas previamente com um detergente aniônico (Dodecil Sulfato de Sódio-SDS) que rompe quase todas as interações não-covalentes nas proteínas nativas, conferindo-lhes densidade de carga uniforme. Os complexos SDS com proteínas desnaturadas são submetidos a eletroforese em gel de poliacrilamida, tipicamente na forma de placa final vertical. A direção da eletroforese é de cima para baixo. As proteínas pequenas movem-se rapidamente no gel, enquanto as grandes ficam em cima, perto do ponto de aplicação da mistura. Finalmente, pode-se visualizar as proteínas no gel corando-as com prata ou com algum outro corante (figura 31) $[17][15]$.

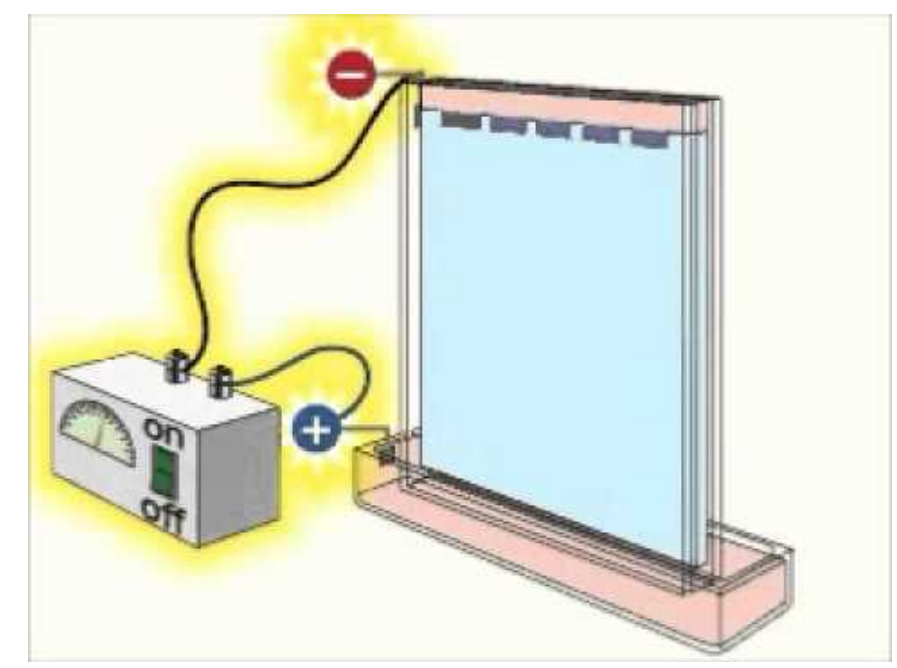

Figura 31: Esquema do processo de eletroforese

Além disso, no caso do proteassomo é necessário realizar ensaios de atividade, que consiste em utilizar peptídeos fluorogênicos como substrato e captar a emissão de flurores- 
cência a 440nm (excitação a 365nm) em um fluorímetro. Estas medidas foram realizadas no Laboratório de Bioquímica e Biofísica do Instituto Butantan, sob a supervisão da professora Marilene Demasi e com o auxilio do técnico de laboratório Adrian Hand.

\subsection{Métodos de Espalhamento}

Segundo o modelo clássico, uma onda eletromagnética consiste em um campo elétrico oscilante. Ao atingir um meio, ela induz uma polarização nas partículas do mesmo. Os elétrons dessas partículas que constituem o meio, passam a oscilar e emitir radiação, fazendo com que cada uma das partículas funcione como "antenas", dispersando parte da energia da radiação incidente em diferentes direções, chamada de radiação espalhada [23] [16].

A forma, tamanho e interações entre as partículas influenciarão nas propriedades dessa radiação espalhada, como freqüência, polarização e, sobretudo, a intensidade. Esse processo constitui a base de todos os fenômenos de espalhamento[23] [16].

Com base nessas alterações da radiação espalhada, obtêm-se informações sobre a estrutura e dinâmica do meio que está sendo irradiado[23] [16].

\subsubsection{Espalhamento de Raios X a Baixos Angulos}

A técnica de Espalhamento de Raios X à baixos ângulos (SAXS - Small Angle Xray Scattering) foi a principal técnica utilizada para o estudo desses sistemas. Podendo-se obter informações como tamanho, forma, estado de agregação, flexibilidade de partículas em solução, entre diversas outras informações. Além disso, uma vez que a técnica permite que façamos experimentos com amostras em solução, podemos nos aproximar das condições fisiológicas[23] [16]. 
A técnica de SAXS, que utiliza um comprimento de onda da ordem de $1 \AA$, nos permite estudar a forma de complexos com dimensões que variam desde $10 \AA ̊$ até aproximadamente $1000 \AA$, dependendo do arranjo experimental[23] [16].

Consideramos uma onda plana monocromática incidente sobre o centro de espalhamento O. Parte dessa radiação interage, no caso do uso de Raios X, com a nuvem eletrônica, o que gera um onda esférica secundária (radiação espalhada). Esse espalhamento é descrito pela primeira aproximação de Born, que considera que não haverá espalhamentos múltiplos. Desse modo, a onda incidente possui mesma energia que a onda espalhada (figura 32)[23] [16].

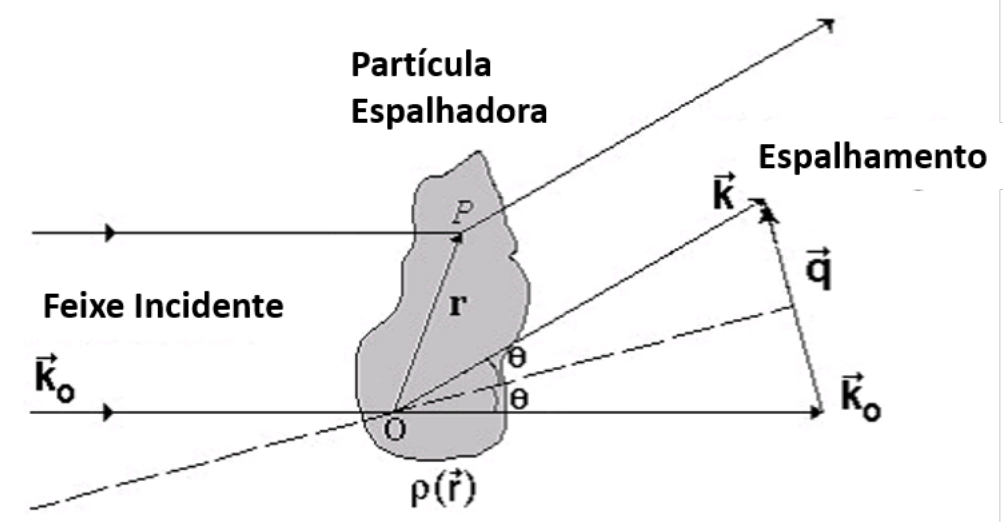

Figura 32: Representação do processo de espalhamento por uma partícula fixa. (Figura retirada de [23] )

Considerando uma partícula fixa, sendo $\overrightarrow{k_{0}}$ o vetor que representa a onda incidente, podemos definir o módulo vetor de transferencia de momento $\vec{q}$ no espaço recíproco como sendo[23]:

$$
q=\frac{4 \pi}{\lambda} \sin \theta
$$

Pois 


$$
\begin{gathered}
\vec{q}=\vec{k}-\overrightarrow{k_{0}} \\
q=2 k \sin \theta \\
k=\frac{2 \pi}{\lambda}
\end{gathered}
$$

Considerando uma partícula fixa no espaço, com densidade eletrônica definida por $\rho(r)$, a amplitude de espalhamento será dada por [23] :

$$
A(\vec{q})=\frac{1}{4 \pi} \int_{V} \rho(\vec{r}) e^{-i \vec{q} \vec{r}} d r
$$

Assim a intensidade espalhada para uma única partícula $\left(I_{1}\right)$ será dada por:

$$
I_{1}(\vec{q})=A(\vec{q}) A(\vec{q})^{*}
$$

No estudo de um sistema real, as partículas não estão fixas no espaço, mas randomicamente orientadas. Desta forma pode-se tomar a média orientacional da equação 2.6 e obter a expressão 2.7

$$
I_{1}(q)=4 \pi \int_{0}^{\infty} \gamma(r) \frac{\sin (q r)}{q r} r^{2} d r
$$

onde $\gamma(r)$ é a função de auto-correlação da partícula. Definindo a função distribuição de pares $p(r)$, como $p(r)=r^{2} \gamma(r)$ então podemos escrever [23]:

$$
I_{1}=4 \pi \int_{0}^{\infty} p(r) \frac{\sin (q r)}{q r} d r
$$


Ressaltando, que as definições acima foram feitas para uma única partícula, podemos agora pensar num sistema de partículas. Podemos escrever[23]:

$$
I(q)=N<f^{2}(\vec{q})><S(\vec{q})>
$$

onde $<f^{2}(\vec{q})>$ é o fator de forma e $<S(q)>$ é o fator de estrutura, promediadas para o sistema de partículas. Para um sistema bem diluído, como os que serão utilizados neste trabalho, o fator de estrutura assume valor 1. Portanto para um sistema diluído e monodisperso podemos escrever:

$$
I(q)=N I_{1}(q)
$$

A função $p(r)$ está relacionada com a intensidade espalhada através de uma Transformada de Fourier. Ela representa uma função no espaço real. Portanto através da função $p(r)$ pode-se obter informações estruturais da partícula como dimensão máxima, indicações sobre a forma, entre outros parâmetros [23] [16].

Visto que existem diversas formas de análise e modelagem dos sistemas como descrito no capítulo anterior, para cada uma das proteínas estudadas, utilizou-se métodos de análises específicos, que serão abordados no capítulo de resultados.

\subsection{Espalhamento de Luz Dinâmico}

A técnica de Espalhamento de Luz Dinâmico (DLS - Dynamic Light Scattering) permite investigar a difusão de partículas em um meio. Desta difusão consegue-se, por exemplo, o tamanho médio das partículas [19]. A técnica é também conhecida como Espectroscopia de Correlação de fótons[19]. 
O detector capta a intensidade de luz espalhada em função do tempo, convertendo os fótons que atingem em sinais elétricos. Um esquema da técnica pode ser vista na figura 33.

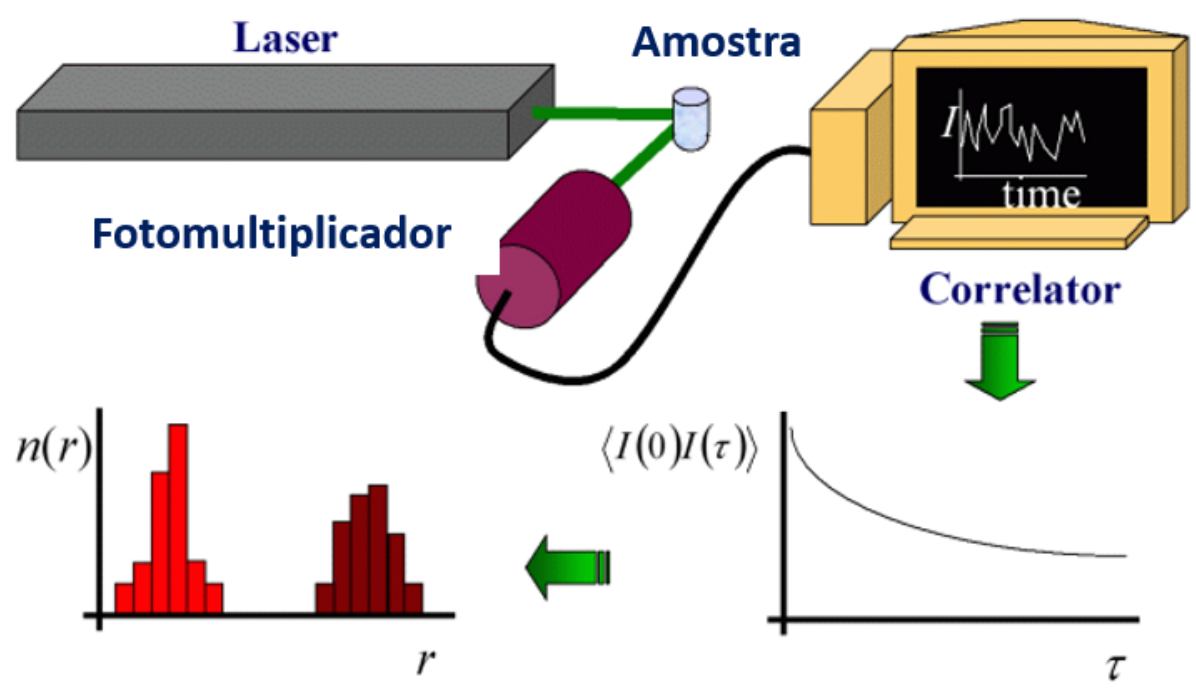

Figura 33: Representação da técnica de DLS. Figura adaptada de http://www.ecs.umass.edu/che/henson ${ }_{g}$ roup/research/emul.html.

O correlator registra os pulsos elétricos em intervalos de tempo discretos. Como as partículas estão em movimento (Movimento Browniano), faz-se uma correlação entre a intensidade da luz espalhada em um instante $t_{0}$ e a intensidade da luz espalhada no instante seguinte $t_{0}+\tau$; no instante $t_{0}+2 \tau$, e assim, sucessivamente, até chegar ao instante final de medida (T), onde $\tau$ é o tempo de correlação. Para amostras monodispersas, escrevemos uma expressão conhecida como função de auto-correlação, definida por[19]:

$$
C(\tau)=\lim _{\tau \rightarrow \infty} \frac{1}{T} \int_{0}^{T} I(t) I(t+\tau) d t
$$

Caso não haja interações entre as partículas, pode-se demonstrar que a função de correlação tem um comportamento descrito pela seguinte expressão[19]: 


$$
C(\tau)=A+B \exp (-2 \Gamma \tau)
$$

onde $\Gamma$ é a taxa de decaimento. Observa-se que a correlação deve tender a zero para tempos de correlação muito altos. E, quanto maior a taxa de decaimento, menos correlacionado é o sistema. A taxa de decaimento da função de correlação está diretamente relacionada ao produto do coeficiente de difusão translacional das partículas $\left(D_{t}\right)$ pelo quadrado do módulo do vetor de espalhamento[19]:

$$
\Gamma=D_{t} q^{2}
$$

onde o vetor de espalhamento é redefinido da seguinte maneira para o espalhamento de $\operatorname{luz}[19]$ :

$$
q=\frac{4 \pi n}{\lambda_{0}} \sin (\theta)
$$

onde $\lambda_{0}$ é o comprimento de onda da luz laser $(0,635 \mu m), n$ é o índice de refração da suspensão líquida e $2 \theta$ é o ângulo de espalhamento $\left(90^{\circ}\right)$.

O coeficiente de difusão translacional pode ser influenciado pelas forças de interação entre as partículas. Porém, trabalhando com sistemas muito diluídos, não há interações entre as mesmas. Realiza-se uma aproximação do coeficiente de difusão translacional $\left(D_{t}\right)$ pelo coeficiente de difusão no regime de diluição infinita $\left(D_{0}\right)$, que está relacionado ao diâmetro hidrodinâmico $\left(d_{h}\right)$ da partícula pela expressão de Stokes-Einstein[19]:

$$
D_{0}=\frac{k_{B} T}{6 \pi \eta R}
$$




\subsection{Microscopia Eletrônica de Transmissão}

Historicamente, os equipamentos de Microscopia Eletrônica de Transmissão foram desenvolvidos diante do limite da resolução dos microscópios de luz, dado o comprimento de onda da luz visível [33].

Devido ao caráter dual do elétron, foi possível utilizar seu comprimento de onda que é muito menor que o da luz, para observar estruturas nanométricas. O comprimento de onda do elétron pode ser obtido da seguinte forma[33]:

$$
\lambda=\frac{h}{m_{e} v}
$$

onde $\lambda$ é o comprimento de onda de de Broglie para o elétron, $m_{e}$ é a massa de repouso e $v$ a velocidade. Essa equação, pode ser reescrita, em função da tensão de aceleração $\Phi[33]$ :

$$
\lambda=\frac{12,3}{\sqrt{\Phi}}
$$

Assim para uma tensão de $80 k V$ temos $\lambda$ de $0,04 \AA$.[33]

No Microcópio Eletrônico, um feixe de elétrons é produzido e focalizado na amostra através das lentes magnéticas. Esse feixe pode interagir de diferentes formas com a amostra, como visto na figura 34[33].

Muitos desses sinais são utilizados para análises químicas de amostra no Microscópio Eletrônico Analítico. Porém, para um Microscópio Eletrônico de Transmissão, operando no modo imagem, o sinal de interesse é devido à interação elástica do elétron com a matéria[33]. Essa interação com a amostra produz uma imagem de projeção em um anteparo. Esse anteparo pode ser uma tela fosforescente e aquisição em filme fotográfico, ou uma câmera CCD e aquisição digital. 


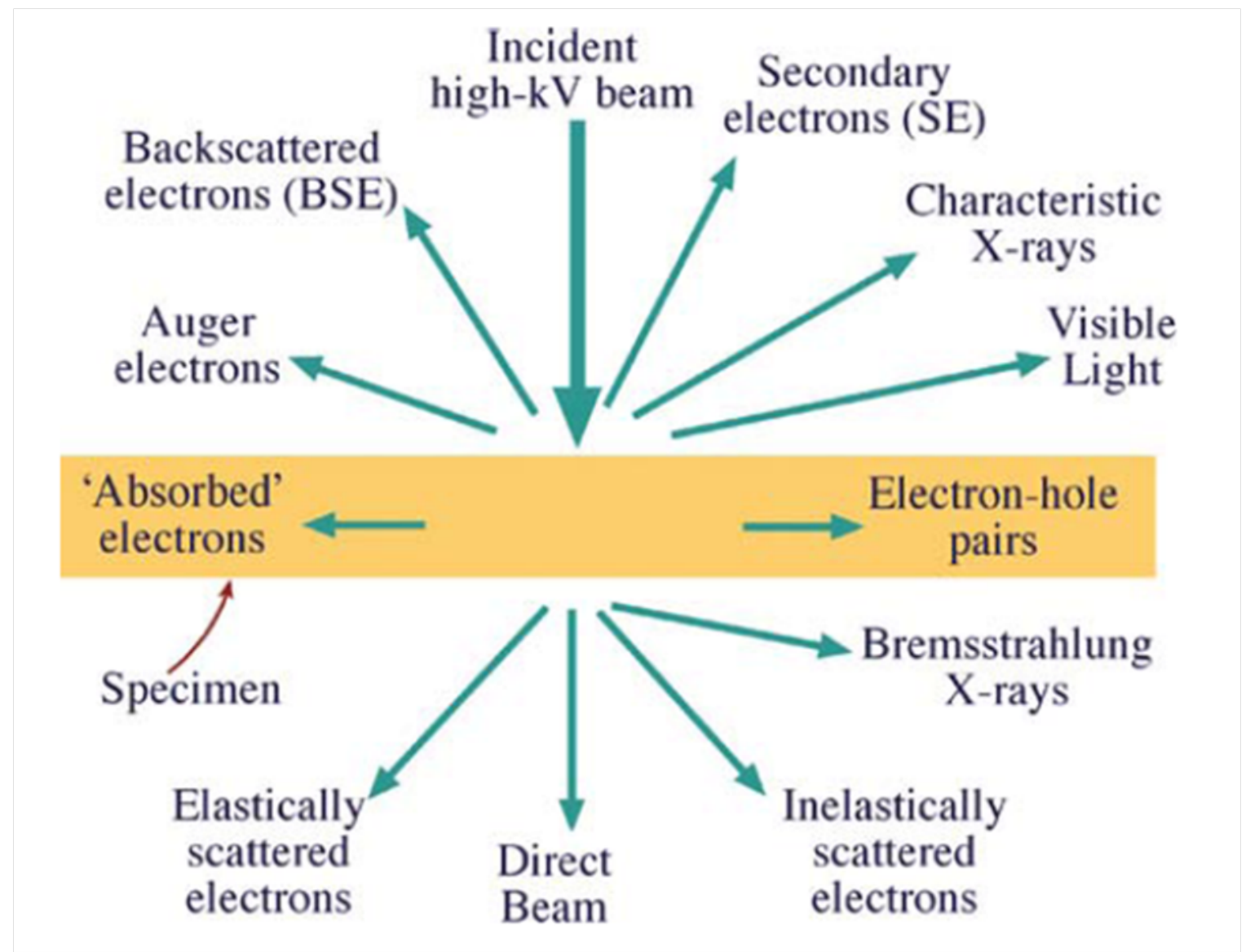

Figura 34: Representação do processo de interação do feixe de elétrons com a amostra. (Figura Retirada de $[33]$ ) 


\section{Materiais e Métodos}

\subsection{Preparação das Amostras}

\subsubsection{Lisozima}

A proteína é adquirida da Sigma em pó, pesada em balança analítica e ressuspensa em uma solução estoque de $20 \mathrm{mg} / \mathrm{mL}$ em duas soluções tampões diferentes, uma em tampão PBS $10 m M p H \approx 7,0$ e outra em TRIS $20 m M p H \approx 7,5$. A partir da solução estoque, diluiu-se nas concentrações de $15 \mathrm{mg} / \mathrm{mL}, 10 \mathrm{mg} / \mathrm{mL}, 5 \mathrm{mg} / \mathrm{mL}$ e $2,5 \mathrm{mg} / \mathrm{mL}$.

\subsubsection{Crioglobulinas}

Utilizou-se soro de um paciente com crioglobulemia e o soro de um paciente sadio, ou seja, com sorologia negativa. Os dois soros são do tipo O, com fator Rh positivo.

Em teste clínico, a crioglobulina, presente no soro do paciente com crioglobulemia, foi caracterizada como uma imunoglobulina monoclonal da classe IgG. Ressalta-se o interesse em trabalhar com amostras do tipo $\operatorname{IgG}$, para tanto é necessário realizar o processo de purificação. No contexto do projeto foi proposto utilizar a técnica de cromatografia, neste caso cromatografia por afinidade em coluna de proteína A - Sepharose. 
Este é um procedimento já bem descrito na literatura para purificação da IgG. Tentou-se utilizar uma coluna de proteína $\mathrm{G}$ que, em relação a proteína A, pode se mostrar mais eficaz, uma vez que purifica todos os tipos de IgGs, enquanto a proteína A não é capaz de purificar IgG3 [17] [15].

Dois procedimentos diferentes para a purificação da crioglobulina foram utilizados, uma como o descrito na seção 2.1.2, em que se realza uma espécie de lavagem do soro. Porém esse método se mostrou ineficaz de acordo com os resultados de DLS que serão tratados no capítulo seguinte. Como havíamos proposto para a purificação do soro sadio, o uso da técnica de cromatografia em coluna G, tentou-se utilizar esse método também para a crioglobulina.

Para realizar-se esse procedimento de purificação por cromatografia, em uma etapa anterior, o soro, tanto de paciente normal, quanto com crioglobulemia, passa pelo processo de deslipidação, ou seja, a retirada de lipídeos do soro. Em seguida realiza-se o processo de cromatografia, em que o controle é feito espectrofotometricamente. Na figura 35 é possível observar o momento que ocorre a eluição da IgG (a proteína de interesse).
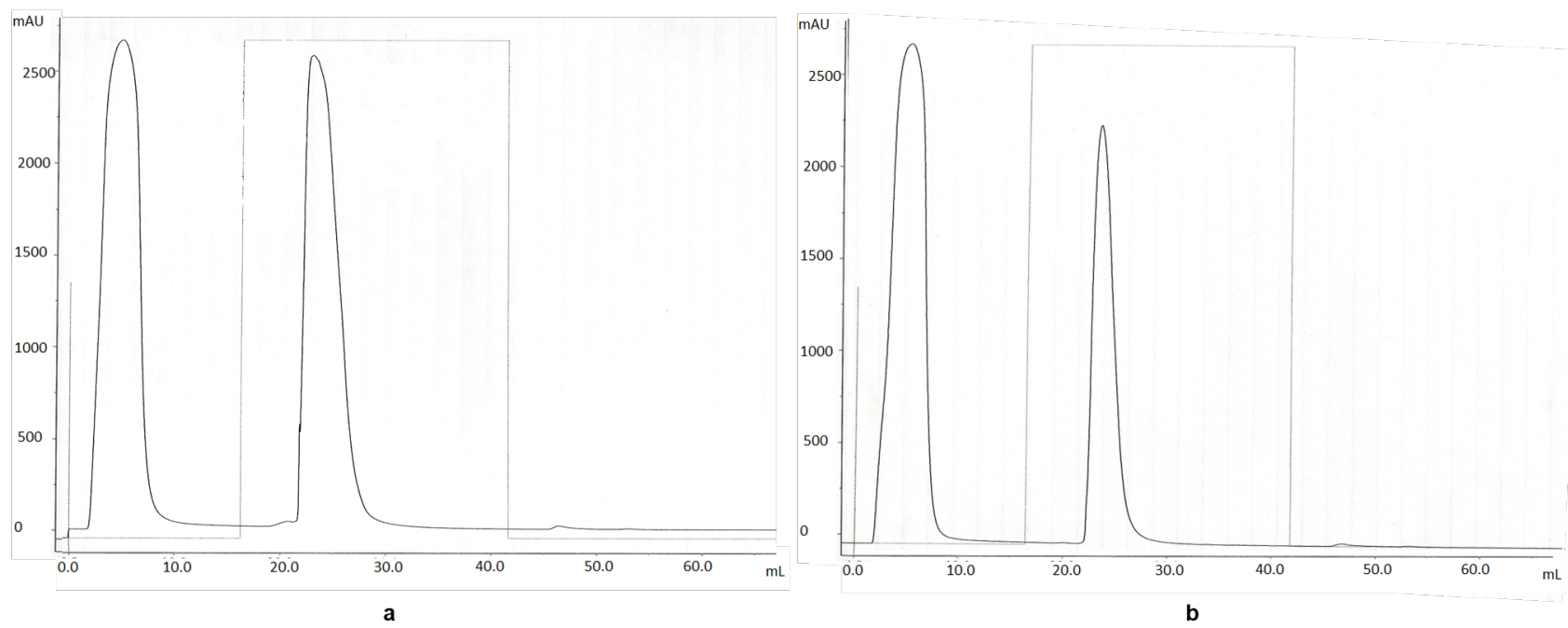

Figura 35: Controle do processo de cromatografia. Em (a) temos a purificação do soro de paciente sadio. Em (b) do soro de paciente com crioglobulemia 
Do controle mostrado na figura 35, observa-se que o máximo na curva para o soro de paciente normal está maior do que o do paciente com crioglobulemia. Isso indica que há uma concentração maior de IgG no soro do paciente normal. Conclui-se que ocorreu uma possível perda da crioglobulina, pois é característica da doença uma concentração muito maior de $\operatorname{IgG}$ que em pacientes sadios.

Além disso, ao final de todo o processo, não foi possível observar a presença do crioprecipitado, inviabilizando a realização de experimentos posteriores.

Uma possível causa da perda da crioglobulina, pode ser da impossibilidade de realizar-se um controle de temperatura no procedimento de cromatografia.

\subsubsection{Proteassomo}

O proteassomo 20S de levedura, é obtido através das células obtidas da levedura, que são ressupendidas em solução tampão Tris. As células são rompidas por agitação com pérolas de vidro a $4^{\circ} \mathrm{C}$ e o extrato celular obtido é centrifugado para separar das pérolas de vidro. O proteassomo contido no extrato é purificado em coluna de afinidade a níquel, e eluído em gradiente linear de imidazol (figura 36) [17] [15][24]. O controle é feito espectrofotometricamente a 280nm. A amostra é dessalinizada em coluna de dessalting.

Além disso, realiza-se ensaios de atividade, que consiste em utilizar peptídeos fluorogênicos como substrato e captar a emissão de flurorescência a 440nm (excitação a 365nm) em um fluorímetro. Todo esse procedimento foi realizado em colaboração com o laboratório de bioquímica do Instituto Butantan, liderado pela professora Marilene Demasi. 

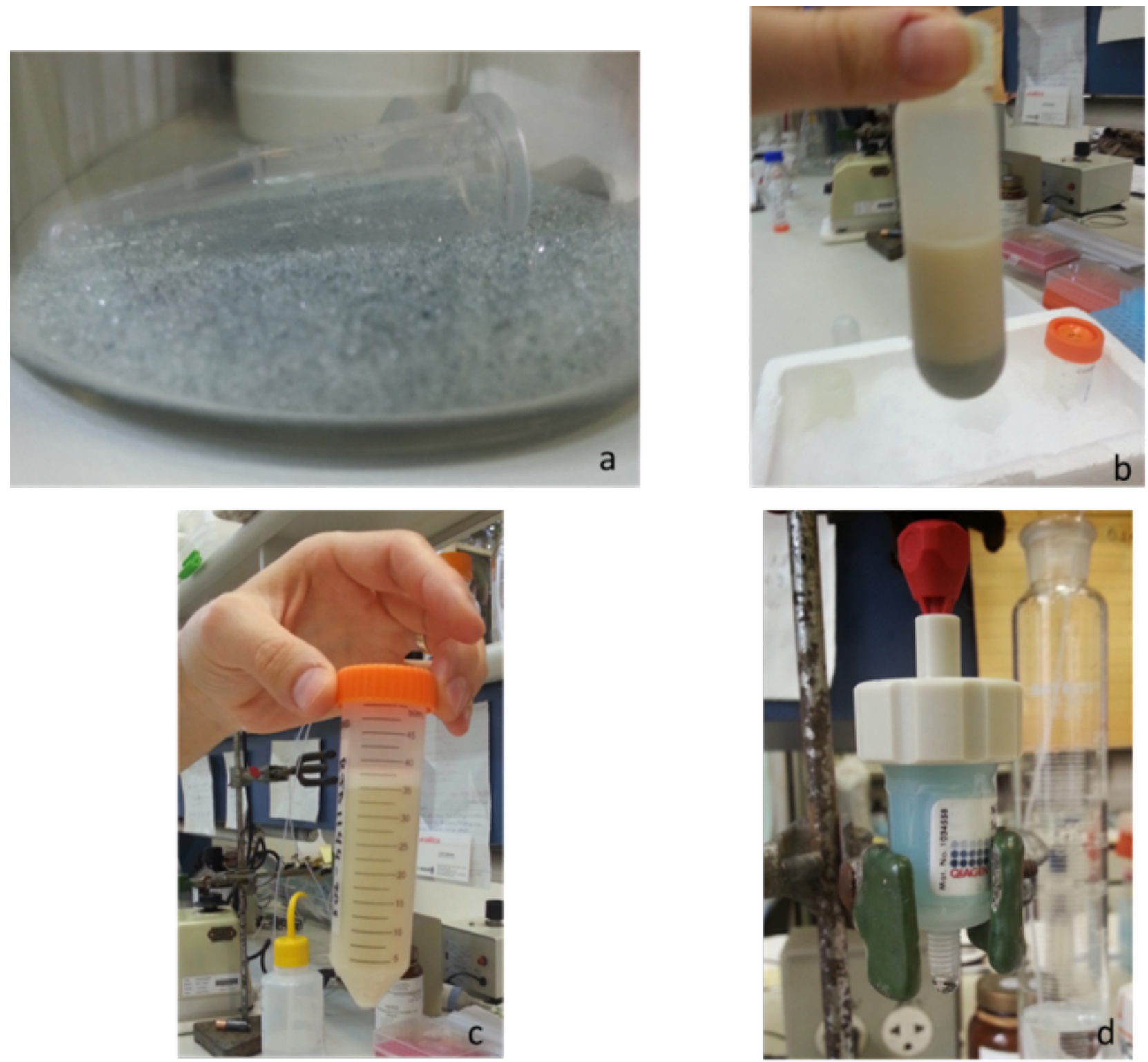

Figura 36: Em (a) temos as pérolas de vidro. Em (b) as células com as pérolas de vidro. Em (c) o extrato celular já separado das pérolas de vidro. Em (d) a coluna carregada por níquel utilizada para a purificação por afinidade

\subsection{SAXS (Espalhamento de Raios $\mathrm{X}$ a baixos ângulos)}

\subsubsection{Aquisição dos Dados}

Realizou-se os experimentos de SAXS no equipamento Nanostar da Bruker, localizado no Laboratório de Cristalografia do Instituto de Física da Universidades de São Paulo. Na figura 37 tem-se uma foto do equipamento utilizado. A distância amostra- 
detector estabelecida em $66,7 \mathrm{~cm}$ e o comprimento de onda do Raio X de $\lambda=1,54 \AA$. As medidas foram realizadas em um porta amostra para líquidos que consiste em capilares de quartzo colados em suportes de aço inoxidável. Esses capilares podem ser lavados e reutilizados, o que permite uma subtração de fundo confiável. Para obter-se uma melhor estatística dos dados coleta-se mais de 5 exposições de 1800s de cada amostra e realiza-se uma média.

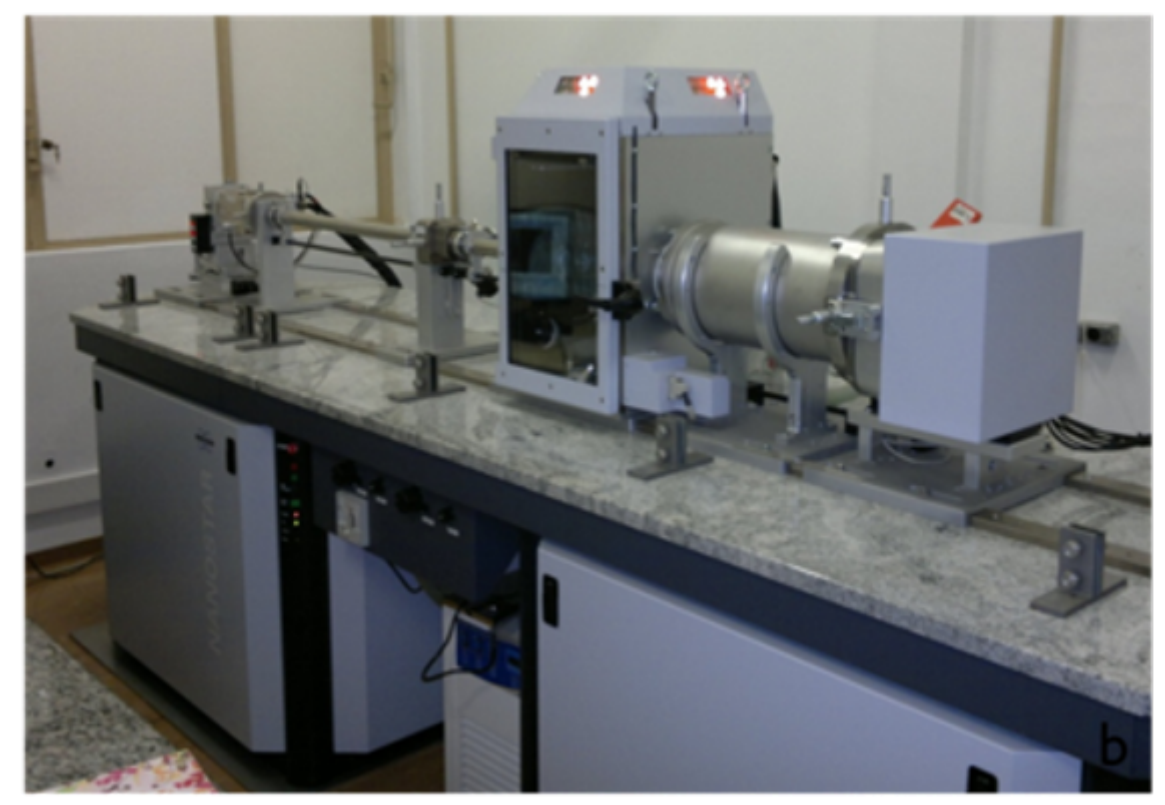

Figura 37: Foto do equipamento utilizado, Nanostar Bruker, no laboratório de Cristalografia

\subsubsection{Análise dos Dados}

A primeira etapa para análise dos dados obtidos, é realizar as correções padrões para obter os dados em escala absoluta e calcular os erros. Para isso, utiliza-se o programa SUPERSAXS (Oliveira and Pedersen, unpublished) . Nessa etapa, a primeira coisa a se fazer é subtrair o tampão dos dados de espalhamento, para obter-se apenas o espalhamento das proteínas. Depois os dados são normalizados para escala absoluta utilizando-se o espalhamento da água, que para uma dada temperatura tem um valor teórico bem 
definido.

Com os dados já em escala absoluta, na etapa seguinte realiza-se a Transformada Indireta de Fourier IFT dos dados de espalhamento e o cálculo da função distribuição de pares de distância $p(r)$. Neste trabalho utilizou-se, diversos programas para o cálculo de IFT, GNOM [25] e WIFT [18]. Ambos os programas realizam a Transformada Indireta de Fourier dos dados de espalhamento. Do ajuste, obtém-se a curva de distribuição de pares de distâncias $p(r)$. Desta curva é possível obter-se indicações sobre a forma da partícula bem como obter-se o valor extrapolado da intensidade na origem $\mathrm{I}(0)$ e, também o raio de giro da partícula [9].

A partir disso, estratégias diferentes de análise foram aplicadas para cada um dos sistemas e são tratados separadamente nas seções a seguir.

\subsubsection{Lisozima}

A Transformada Indireta de Fourier IFT dos dados de espalhamento e o cálculo da função Distribuição de Pares de Distância $p(r)$ foram feitas através do program WIFT[18]. Para as amotras mais diluídas, 2,5mg/mL e $5,0 \mathrm{mg} / \mathrm{mL}$, pode-se considerar a presença apenas do fator de forma da partícula na Intensidade de Espalhamento. Para o cálculo teórico da curva de SAXS do modelo cristalográfico da Lisozima (entrada no pdb 2LYZ) utiliza-se o programa CRYSOL[28]. Permitindo o ajuste das curvas experimentais de espalhamento. Ademais, uma modelagem ab initio foi aplicada ao sistema para baixa concentração através do programa DAMMIN [26]. Já para as amostras mais concentradas, $20 \mathrm{mg} / \mathrm{mL}, 15 \mathrm{mg} / \mathrm{mL}, 10 \mathrm{mg} / \mathrm{mL}$, em que é possível observar a ocorrência de interação no sistema, utilizou-se o programa WBODIES [18] para modelagem, indicando efeitos de concentração. 


\subsubsection{Crioglobulinas}

Medidas sistemáticas variando a temperatura foram realizadas para o estudo de dinâmica de agregação. Além do tratamento inicial dos dados de espalhamento para obterse os dados em escala absoluta, a p(r), I(0) e Raio de Giro, pode-se obter informações sobre a flexibilidade da proteína, utilizando gráficos do tipo Kratky (I.q $\left.q^{2} v s q\right)$ [23] . Estes gráficos, como já comentado anteriormente, fornecem indicativos do grau de compacidade de uma estrutura. Partículas compactas fornecerão gráficos com formato tipo "sino", com um máximo bem definido e caindo para zero a altos valores de q [8].

Para partículas com partes flexíveis teremos gráficos onde a curva tem a tendência de não ir mais para zero a altos ângulos. Para partículas com altos graus de flexibilidade (como polímeros, por exemplo) teremos uma curva com um platô ou monotonicamente crescente.

Para o caso de uma amostra monodispersa e uma proteína compacta é possível utilizar modelagem ab initio de modo a construir um modelo tridimensional para a forma da partícula, a partir dos resultados da análise de IFT. Para o caso de uma proteína flexível, uma das metodologias empregadas é o ensemble optimization method (EOM)[30], em que é gerado um pool de 10000 configurações possíveis para a conformação da proteína e, através do ajuste da curva experimental é possível obter um subconjunto dessas configurações que melhor descrevem o sistema.

\subsubsection{Proteassomo}

Para estudar este sistema, analisou-se o complexo selvagem e com algumas modificações adivindas da interação com inibidores e ativadores. Para análise dos dados de SAXS várias metodologias podem ser aplicadas. Inicialmente análise de IFT podem 
ser feitas, fornecendo informações gerais do sistema [23]. Como mostrado a seguir, como a forma do proteassomo 20S é semelhante à um cilindro vazado, foi possível obter informações importantes com um modelo semi-analítico [16] [18]. Posteriormente também realizou-se uma modelagem mais avançada, utilizando a estrutura homóloga conhecida para o proteassomo. Tal modelagem foi realizada com o programa CORAL [22]. Como será apresentado, nas três abordagens foi possível identificar mudanças estruturais na proteína em decorrência da interação com os inibidores/ativadores.

\subsection{DLS}

\subsubsection{Aquisição dos Dados}

Os experimentos de DLS foram realizados no laboratório do Grupo de Fluidos Complexos. O equipamento utilizado foi o 90 Plus da Brookhaven Instruments. Na figura 38, temos uma representação esquemática do funcionamento do equipamento e uma foto do mesmo.

As análises de DLS foram feitas apenas para o sistema de Crioglobulina. O interesse era de variar a temperatura da amostra e observar o que ocorre com o diâmetro hidrodinâmico das partículas. Em geral foram adquiridos 5 exposições de 2 minutos cada, para cada temperatura estudada (que variou de $38^{\circ} \mathrm{C}$ até $9^{\circ} \mathrm{C}$ )

\subsubsection{Análise dos Dados}

\subsubsection{Crioglobulinas}

As análises foram feitas através do software da Brookhaven em que é possível ajustar a curva de correlação e obter-se uma distribuição de tamanhos. Dessa distribuição 


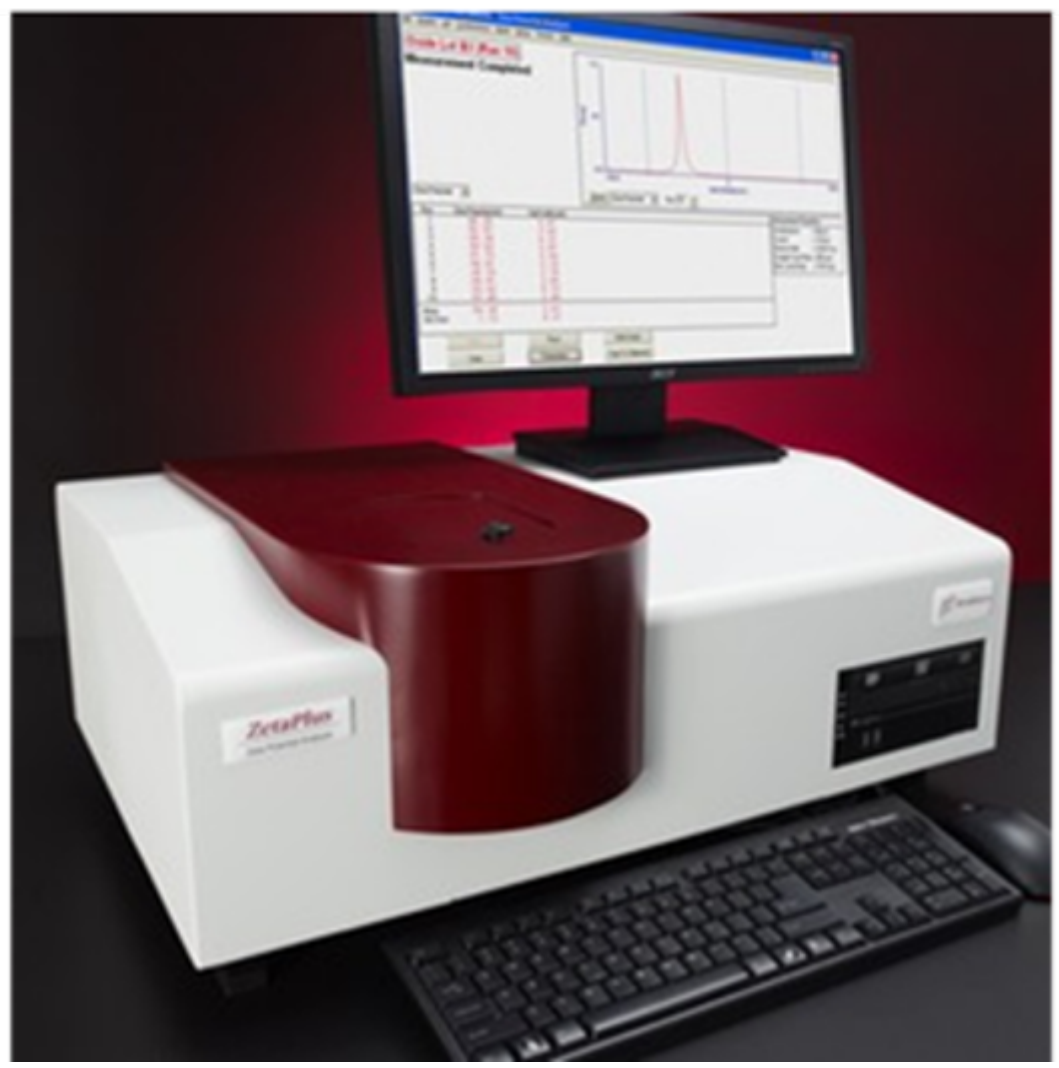

Figura 38: Foto do equipamento de DLS do Laboratório do Grupo de Fluidos Complexos.

de tamanhos pode ser obtido um diâmetro hidrodinâmico médio, bem como a dispersão, para cada temperatura estudada.

\subsection{MET}

\subsubsection{Aquisição dos Dados}

Os experimentos de Microscopia Elterônica de transmissão foram realizados no Laboratório de Biologia Celular do Instituto Butantan. O microscópio eletrônico utilizado foi o LEO906E, da marca Carl Zeiss, mostrado na figura 39. Essa técnica foi utilizada apenas para o sistema do Proteassomo, por se tratar de uma proteína relativamente grande. 


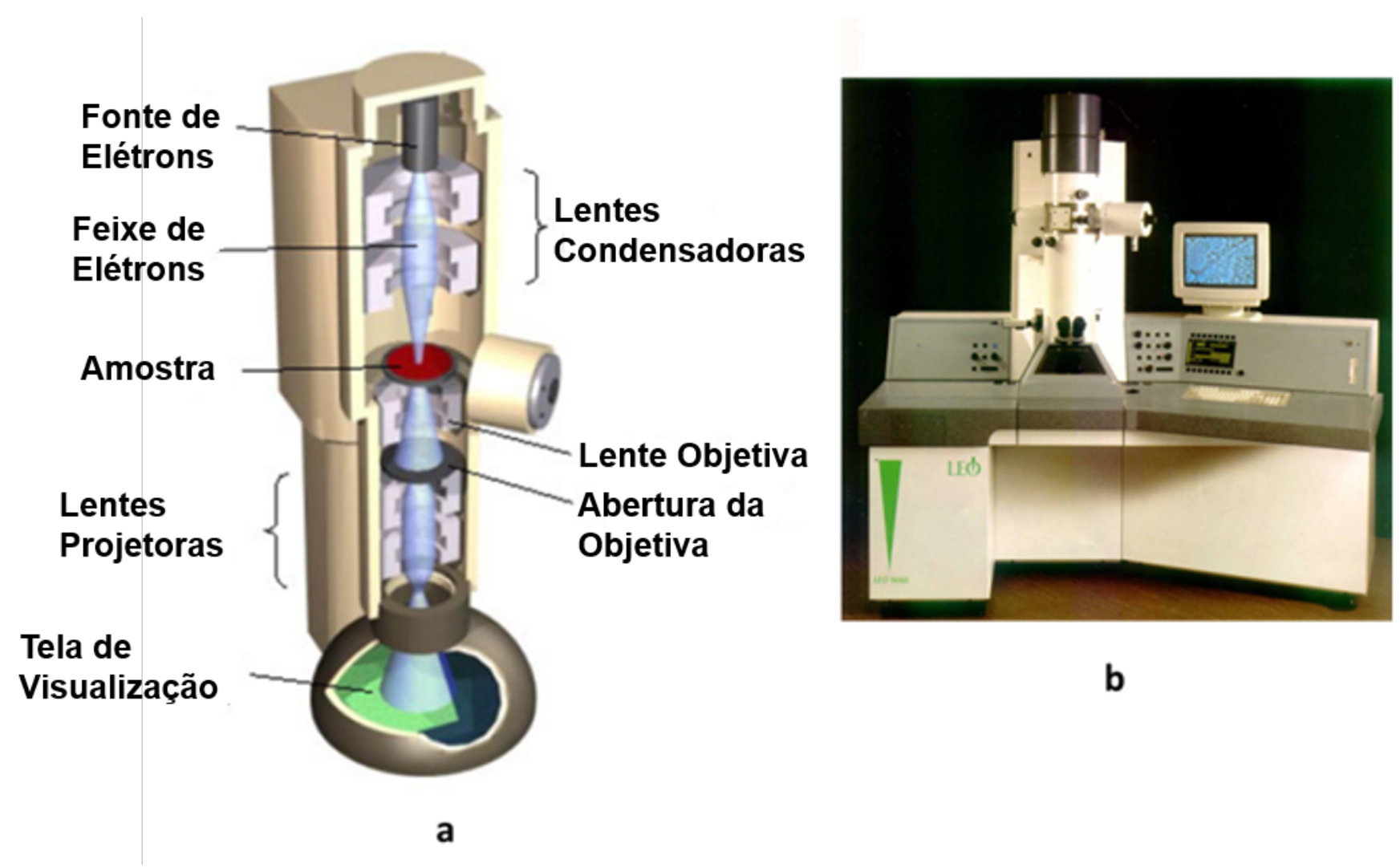

Figura 39: Em (a) temos uma figura esquemática de um Microscópio Eletrônico, funcionando no modo imagem (adaptada dehttp://barrett-group.mcgill.ca/tutorials/nanotechnology/nano02.htm). Em (b) o Microscópio Eletrônico Utilizado Laboratório de Biologia Celular do Instituto Butantan .

Os experimentos foram realizados com uma tensão de $80 \mathrm{kV}$ e uma corrente $10 u \mathrm{~A}$.

As amostras tinham uma concentração de $1 \mathrm{mg} / \mathrm{ml}$. Para observação das partículas, é necessário que haja um contraste entre sua amostra e o feixe. Para obter-se esse contraste, utilizou-se a técnica de Contrastação Negativa (Negative Stain), que consiste no envolvimento das partículas por uma meio eletrodenso. Assim, as imagens se apresentam como em um negativo, em que o elemento biológico fica claro, ou seja, ele é mais transparente aos eletróns [10]. Neste estudo, utilizou-se o ácido fosfotúngstico PTA 2 para recobrir a partícula[10]. 


\subsubsection{Análise dos Dados}

\subsubsection{Proteassomo}

Para análise dos dados de MET, o ideal é que as imagens apresentem um bom contraste, para que se possa observar com detalhes a amostra. Esse contraste é ajustado tanto no momento de aquisição da imagem, quanto, em alguns casos em que seja necessário melhorar esse contraste, utiliza-se programas de tratamento de imagem, como Image $J^{T M}$ ou mesmo o Photoshop ${ }^{T M}$.

O principal interesse, no caso do Proteassomo, é observar se há alguma mudança estrutural na molécula, ao tratar-se de diferentes formas. Como em geral obteve-se imagens de top view da proteína pois, ao depositar a amostra sobre a tela de cobre com suporte de carbono, a interação da partícula com o carbono, induziu essa orientação na molécula, é possível observar o que ocorre com o diâmetro da mesma.

Para cada amostra analisada, pelo menos 5 micrografias de regiões diferentes da amostra, foram obtidas. Com isso, faz-se uma análise estatítica de estruturas abertas e fechadas.

Como será mostrado, foi possível correlacionar a imagem obtida com o modelo gerado através da análise de SAXS. 

Resultados e Discussões

\subsection{Lisozima}

As intensidades de espalhamento, o ajuste IFT e a função distribuição de pares de distância são apresentadas na figura 40. Da análise dos dados obtém-se a dimensão máxima (Dmax), o Raio de Giro (Rg) e o peso Molecular (Mw) da Proteína, apresentados na tabela a seguir.

Conforme aumenta-se a concentração observa-se que existe consistência entre os dados apresentados. Apesar disso, observa-se, na figura 40(a) e 40(c), um pior ajuste para baixos valores de $q$. Isso demonstra que ao aumentar a concentração, ocorre a interação entre as partículas, ou seja o fator de estrutura passa a ter importância no sistema [23]. Por isso ao fazer o ajutse IFT dos dados para maiores concentrações, desconsideram-se pontos do início da curva (desconsiderar o fator de estrutura). Porém, com isso perde-se a precisão do diâmetro máximo na $p(r)$.

Identifica-se uma interação repulsiva, uma vez que, para as maiores concentrações, ocorre um desvio para menores valores de intensidade, nos menores valores de q. Foi utilizado o modelo de esferas rígidas implementadas no programa wbodies[18] para modelagem do sistema. Sendo possível observar a presença da interação, isto para as amostras com 

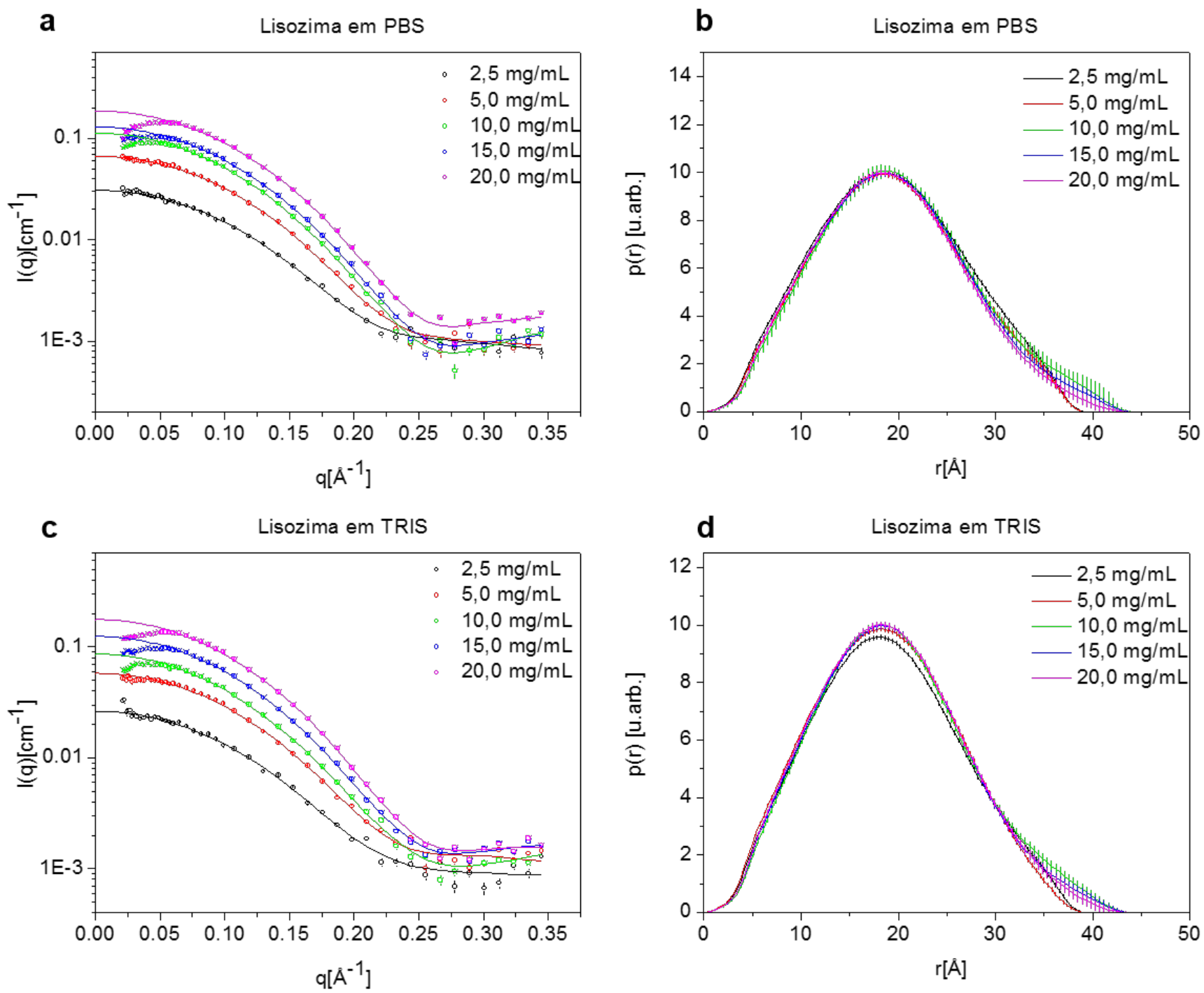

Figura 40: Intensidades de espalhamento, cálculo IFT (linha sólida) e função distribuição de pares de distância. Em (a) tem-se as intensidades para amostras de Lisozima em PBS (Cículos vazados representam os pontos experiemntais utilizados para o ajuste IFT, $\mathrm{X}$ representam pontos experimentais que não foram considerados para o ajuste IFT); em (b) as p(r) para Lisozima em PBS, em (c) a intensidade para as amostras em TRIS (Cículos vazados representam os pontos experiemntais utilizados para o ajuste IFT, $\mathrm{X}$ representam pontos experimentais que não foram considerados para o ajuste IFT) e em d para as p(r) para as amostras em TRIS

concentração de $10 \mathrm{mg} / \mathrm{mL}$ a $20 \mathrm{mg} / \mathrm{mL}$, em ambos tampões. O ajuste pode ser visto na figura 41, apresentado apenas para o tampão PBS por se tratar de resultados que não diferiram entre si.

Observa-se na figura 41 um bom ajuste a baixo ângulo. No qual o modelo de esferas rígidas é um fator de estrutura razoável. Como fator de forma, utlizou-se um elipsóde de 

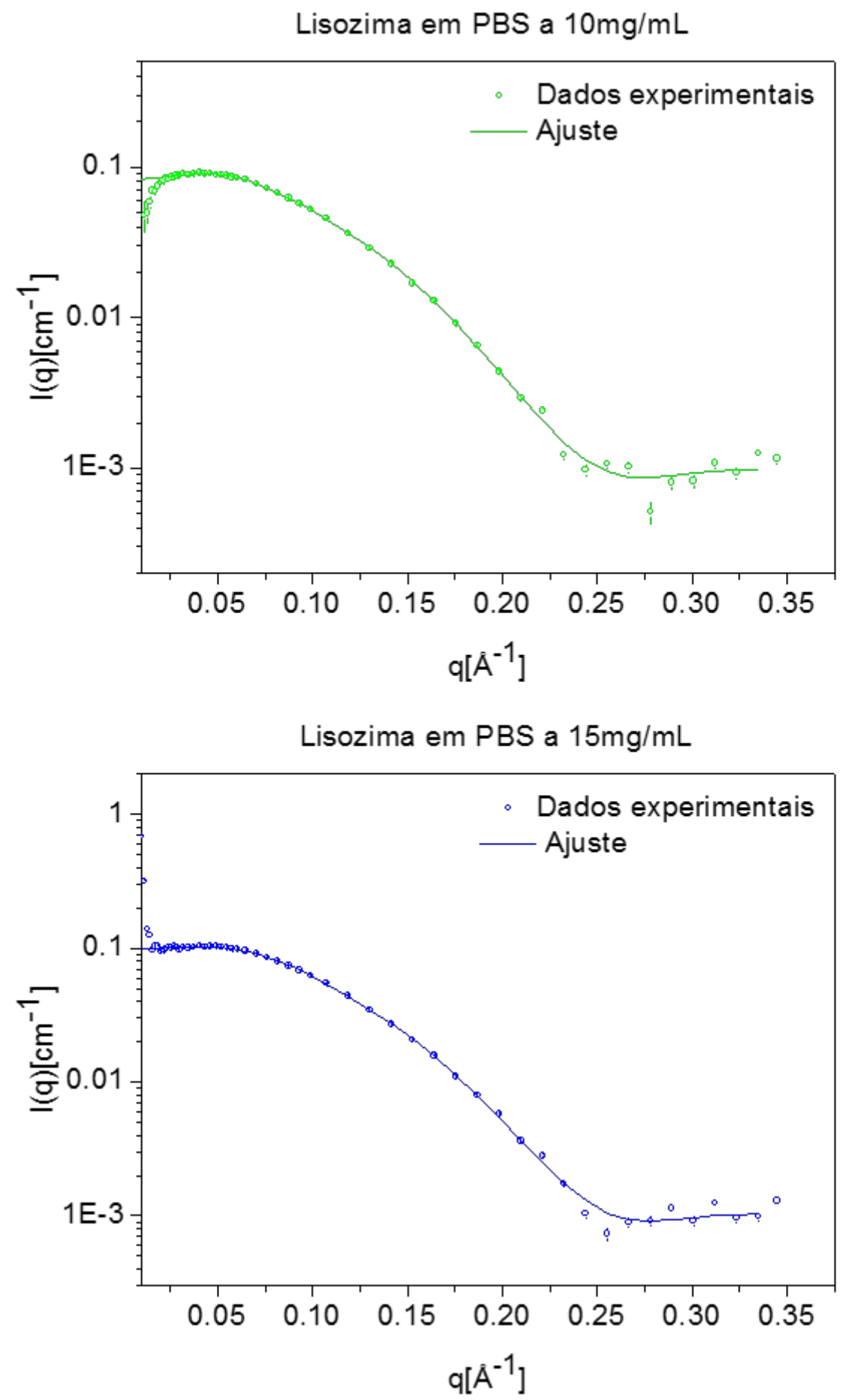

Figura 41: Intensidades de espalhamento, Ajuste (linha sólida) utilizando fator de forma de esfera e fator de estrutura de esferas rígidas para as amostras em PBS

revolução.

Do ajuste do fator de estrutura, é possível obter o parâmetro que indica o raio da esfera rígida de $\approx 50 \AA$. 
Foi possível utilizar o modelo cristalográfico, para ajustar a curva experimental.

Esse procedimento foi realizado para as amostras de menor concentração, $2,5 \mathrm{mg} / \mathrm{mL}$ e $5,0 \mathrm{mg} / \mathrm{mL}$, para garantir que não havia influência das interações das partículas no sistema. O resultado é apresentado na figura 42, apenas para o tampão PBS por se tratar de resultados que não diferiram entre si, utilizou-se o programa CRYSOL [28]. Observase um bom acordo da curva experimental com a curva teórica calculada para o modelo cristalográfico. Quando em solução, isso indica que a proteína tem estrutura semelhante ao cristal. A modelagem ab initio (programa DAMMIN [26]) foi aplicada para o cálculo
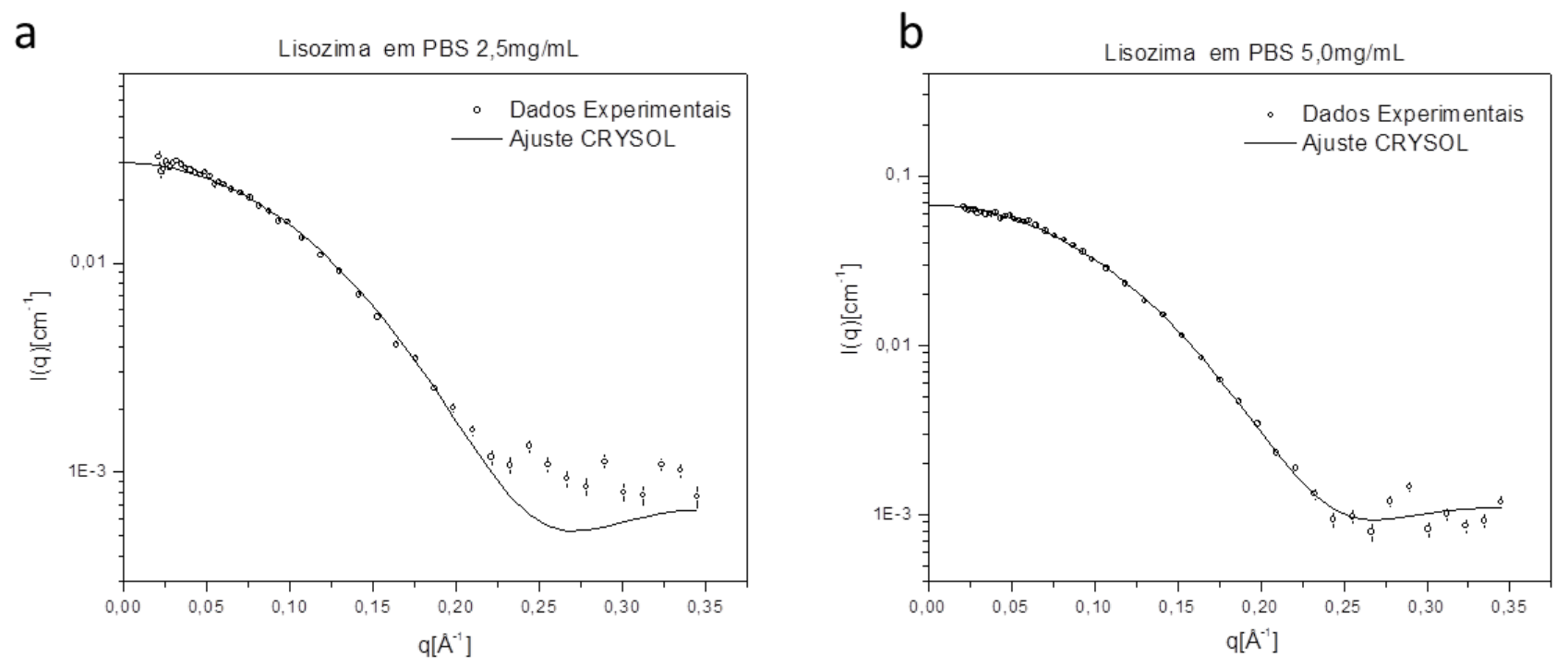

Figura 42: Intensidades de espalhamento, Ajuste (linha sólida) utilizando estrutura cristalográfica resolvida (2LYZ) através do programa Crysol

do envelope da proteína em 2,5mg/mL em tampão PBS. E é mostrado na figura 43.

Observa-se que o ajuste da curva experimental é bom. Além disso, o envelope gerado está em bom acordo com a estrutura cristalina. 


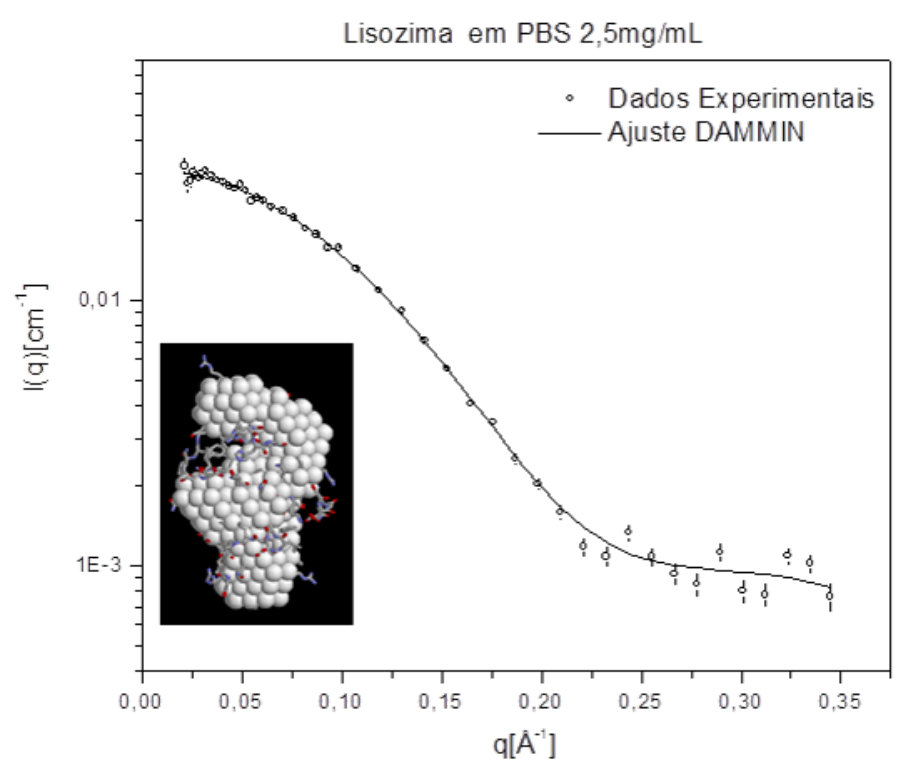

Figura 43: Intensidades de espalhamento, Ajuste (linha sólida) utilizando o modelo gerado pelo DAMMIN [26]. Insert: sobreposição do modelo ab initio e a estrutura cristlográfica

\subsection{Crioglobulina}

Em relação as amostras de crioglobulina, como citado no item de preparação de amostras, havia dois tipos diferentes: uma delas não caracterizada (ou seja, o tipo de Imunoglobulina é indeterminada) e a outra caracterizada como IgG por exame clínico. Os resultados serão apresentados em subseções distintas para melhor visualização.

\subsubsection{Amostra não caracterizada / Pool de Imunoglobulinas}

A primeira análise realizada foi para a amostra não caracterizada. Variou-se a temperatura do sistema desde $38,5^{\circ} \mathrm{C}$ até $4^{\circ} \mathrm{C}$ para a realização das medidas de SAXS. A concentração utilizada foi de $10 \mathrm{mg} / \mathrm{mL}$. Na figura 44 é mostrado um dos resultados obtidos com o respectivo ajuste utilizando o programa GNOM.

Para cada uma das temperaturas estudadas, foi obtido um gráfico, como o da figura 44. Obtém-se o raio de giro da partícula, para cada uma das temperaturas. É mostrado 


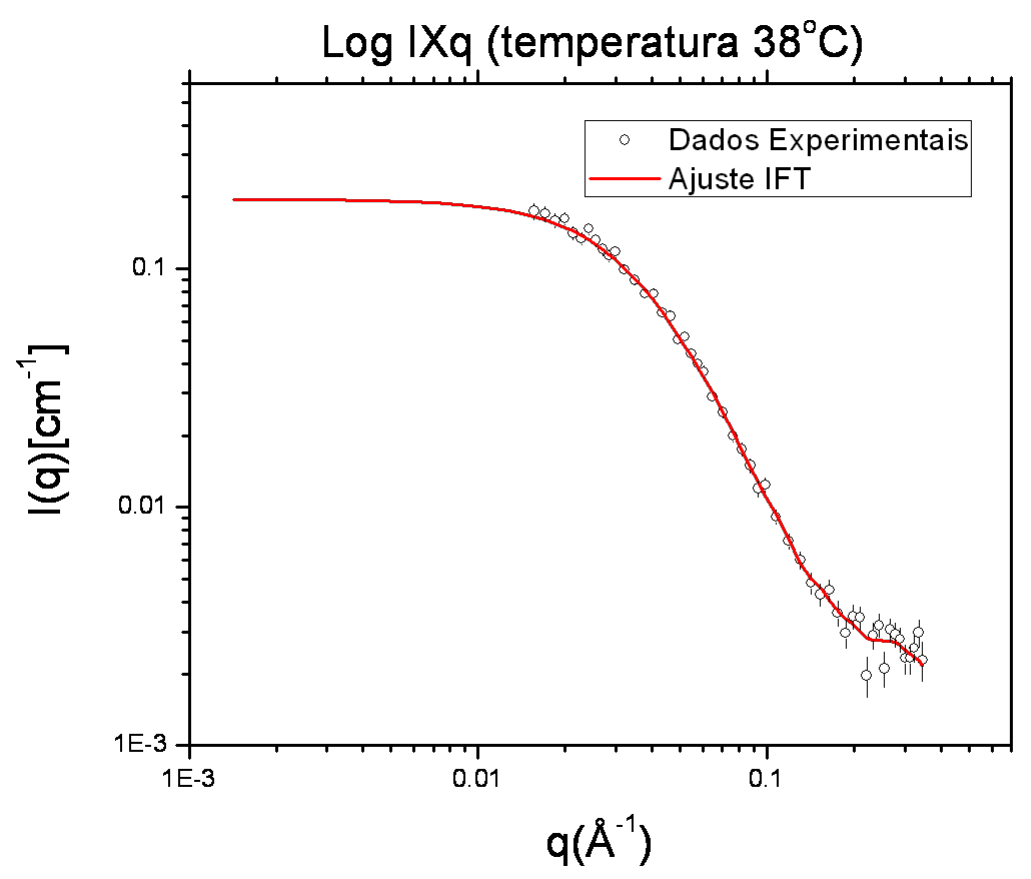

Figura 44: Gráfico de Log I X q, para uma temperatura de $38^{\circ} \mathrm{C}$ (círculos abertos) e o ajuste teórico (linha contínua).

na figura 45, um gráfico que apresenta os raios de giro em função da temperatura.

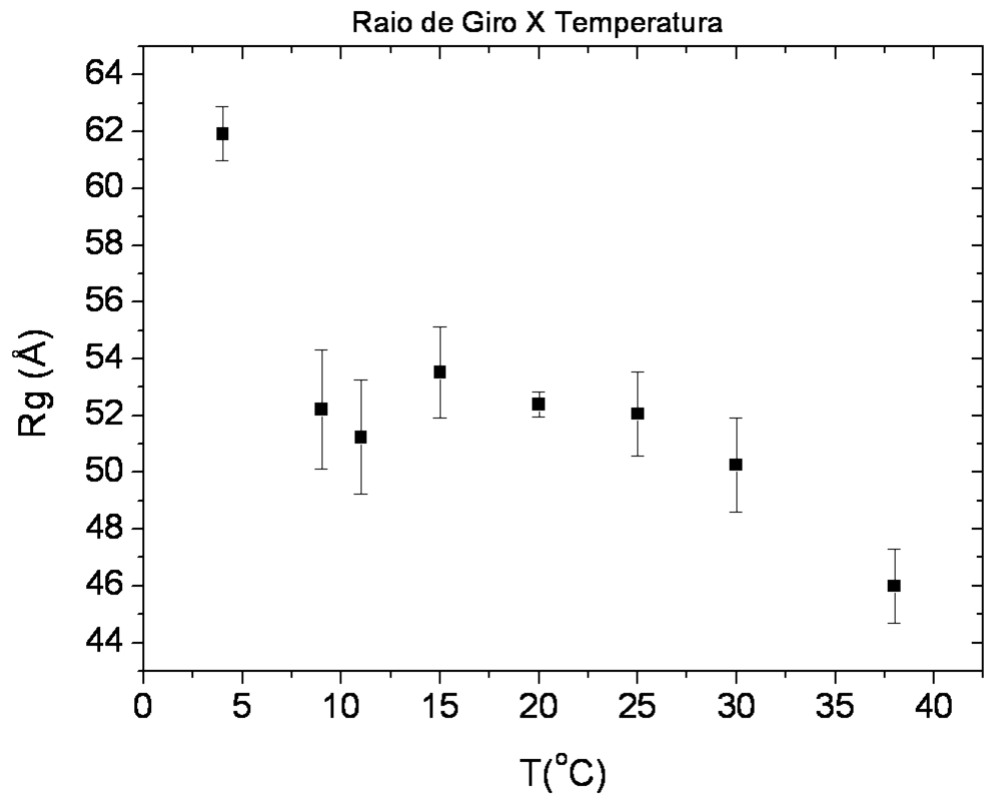

Figura 45: Gráfico do Raio de Giro em função da temperatura 
baixa-se a tempertura, indicando a formação de aglomerados. Ademais, é possível observar que tratam-se de agregados com forma prolata, ao serem estudadas as curvas $p(r)$ obtidas para cada temperatura conforme apresentadas na Figura 46.

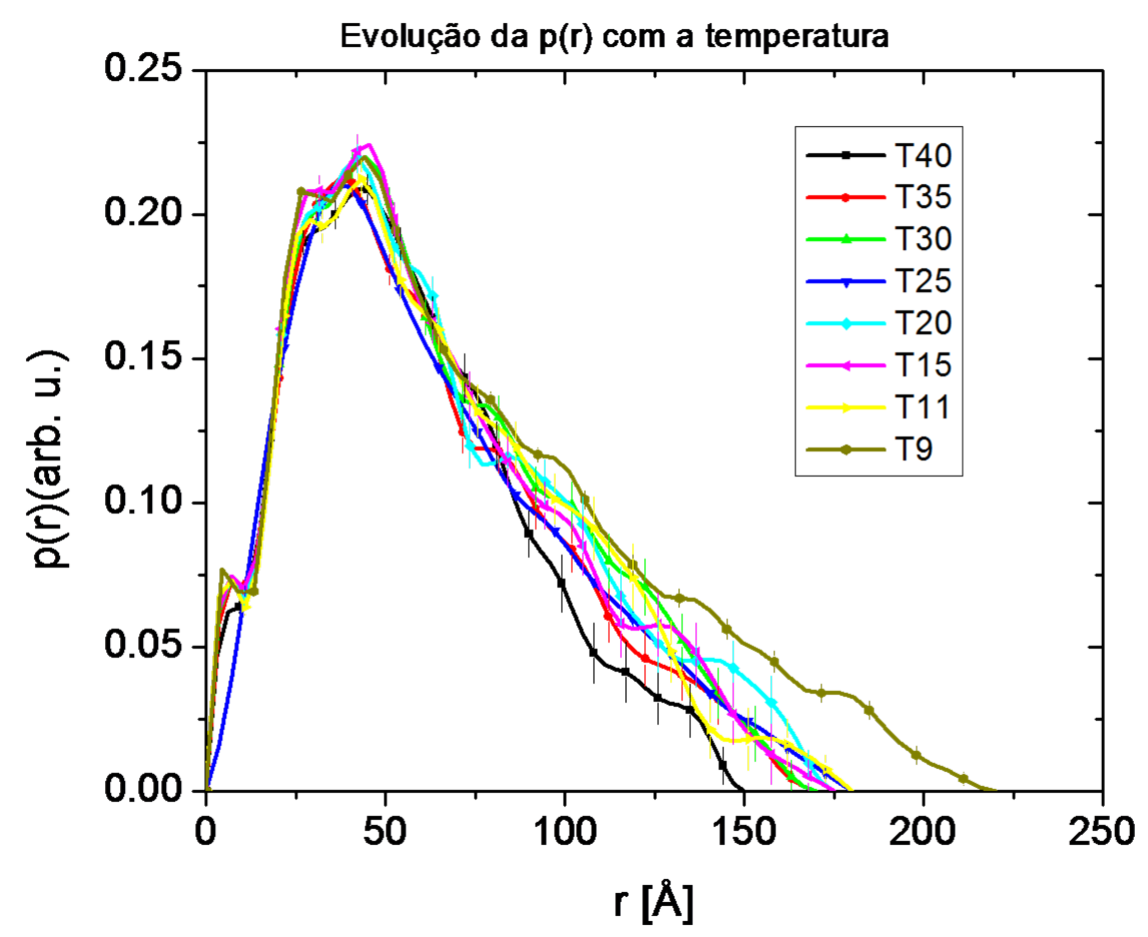

Figura 46: Evolução da curva $p(r)$ em função da temperatura

Similarmente, ao caso dos raios de giro, as curvas $p(r)$ também indicam ao baixar-se a temperatura, uma tendência à formação de agregados com diâmetros máximos, maiores. A forma das partículas é prolata.

Dos resultados da análise de IFT pode-se utilizar a modelagem ab initio para contruir um modelo tridimensional para a forma da partícula. Este modelo foi calculado com o programa DAMMIN [26] e é mostrado na figura 47.

Esta modelagem foi uma tentativa de obter uma representação em espaço real para as partículas do sistema. Apesar de ser possível verificar uma diferença nos diâmetros das partículas, os modelos indicados na Figura 47 forneceram estruturas ramificadas o que é 


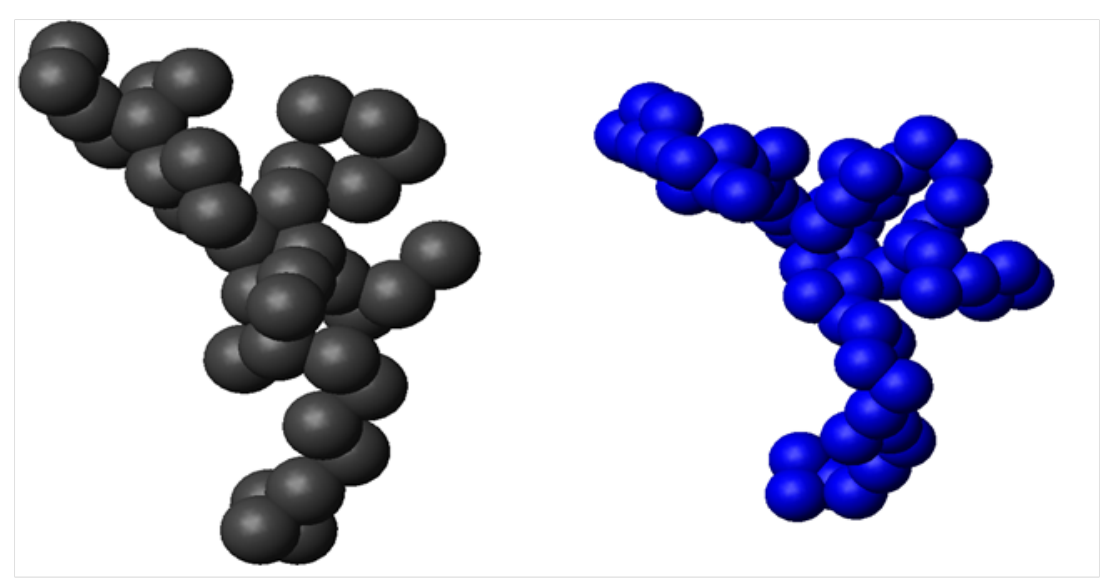

Figura 47: Modelo Estático da proteína em duas temperaturas diferentes. Em (a) $T=4^{\circ} C, d 120 \AA$; em (b) $T=38^{\circ} C, d 80 \AA$

um indicativo de que se pode ter uma polidispersidade de formas/tamanhos bem como estruturas flexíveis [31].

Para a averiguação de ter-se ou não estruturas flexíveis, construiu-se os chamados Kratky Plots, (I.q $\left.q^{2} v s q\right)$. Interessantemente, ao construir-se este gráfico para o sistema em estudo obteve-se o gráfico indicado na Figura 48.

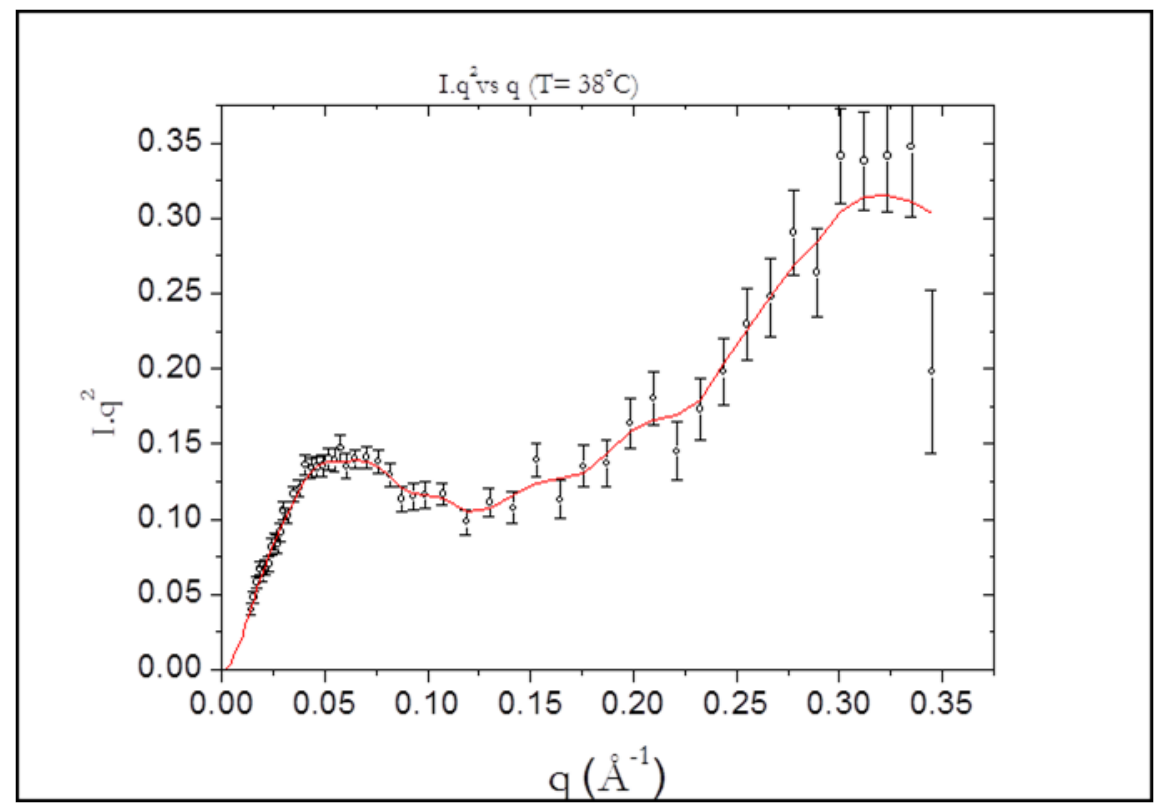

Figura 48: Gráfico do tipo Kratky plot da crioglobulina a uma temepratura de $38^{\circ} \mathrm{C}$ 
Este gráfico indica claramente que a estrutura possui alto grau de flexibilidade, indicando que a modelagem $a b$ initio, aplicada anteriormente, não é a mais adequada uma vez que, não leva em conta, esta propriedade. Assim, utilizou-se o Ensemble Optimization Method para gerar os possíveis modelos e o resultado é apresentado na figura 49.

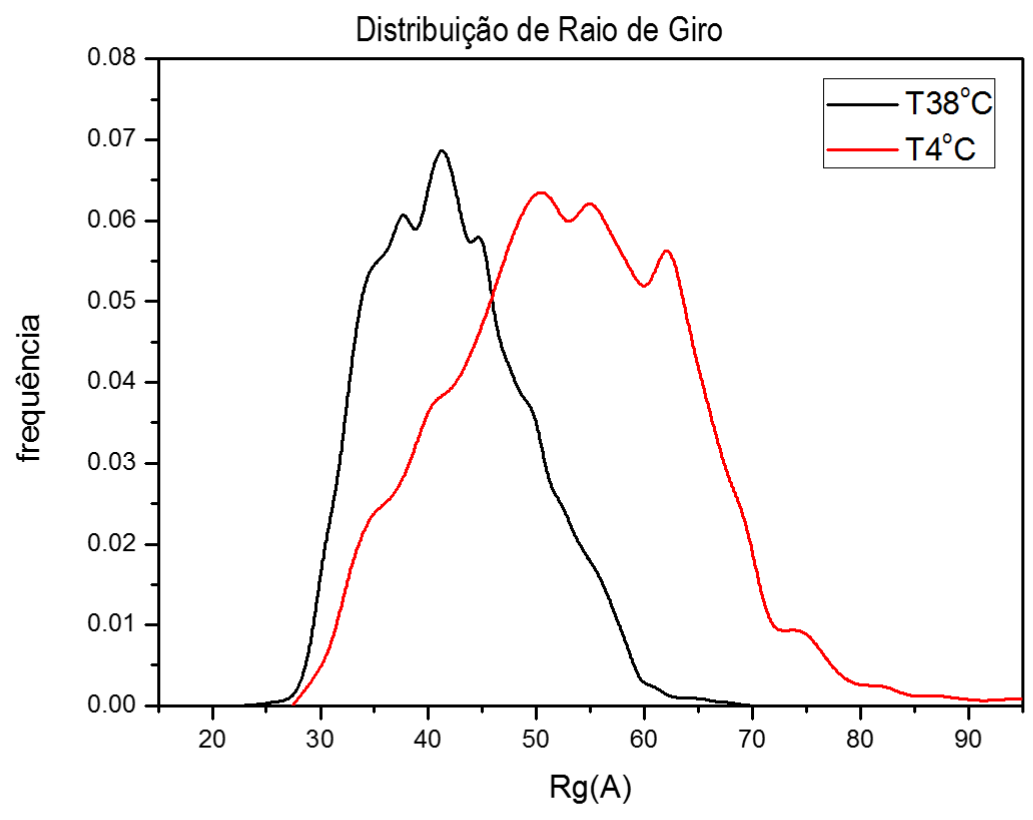

(a)

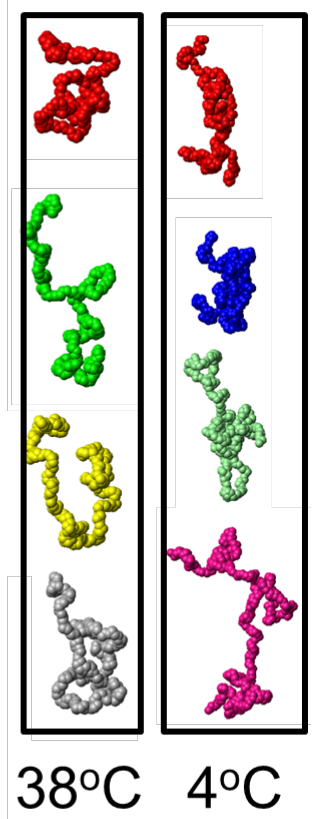

(b)

Figura 49: Em (a) temos a distribuição do Raio de Giro obtido pelo EOM para $38^{\circ} \mathrm{C}$ e $4^{\circ} \mathrm{C}$ em (b) possíveis modelos para ambas as temperaturas

Em relação a essa amostra, por se tratar de um sistema não caracterizado, inúmeras váriaveis estão presentes, como por exemplo se é uma amostra monoclonal ou policlonal.

Apesar de terem sido aplicadas as metodologias de análises propostas, não se obteve conclusões finais acerca desse sistema. Esta provável polidispersidade do sistema dificulta a obtenção de resultados mais confiáveis. No entanto os resultados indicam que a diminuição de temperatura causou um aumento sistemático do tamanho médio das partículas. Os dados indicam que as estruturas formadas são bastante flexíveis e até possíveis conformações puderam ser estimadas. 


\subsubsection{Amostra caracterizada - $\lg G$}

$\mathrm{Na}$ tentativa de ter-se um controle da purificação das amostras de crioglobulina realizou-se as medidas de DLS para a proteína caracterizada, IgG, em solução salina (PBS) com pH 7,4 e variando a temperatura do sistema desde $40^{\circ} \mathrm{C}$ até $9^{\circ} \mathrm{C}$. A concentração utilizada foi de $2 \mathrm{mg} / \mathrm{mL}$.

Com a técnica de DLS é possível obter a curva de auto-correlação. E, a partir do ajuste dessa curva, para uma amostra polidispersa, obtém-se uma distribuição de diâmetros.

Para cada uma das temperaturas estudadas obteve-se o diâmetro hidrodinâmico médio das partículas. Na figura 50 tem-se a curva de correlação para cada uma das temperaturas e na figura 51 o gráfico de diâmetro médio em função da temperatura.

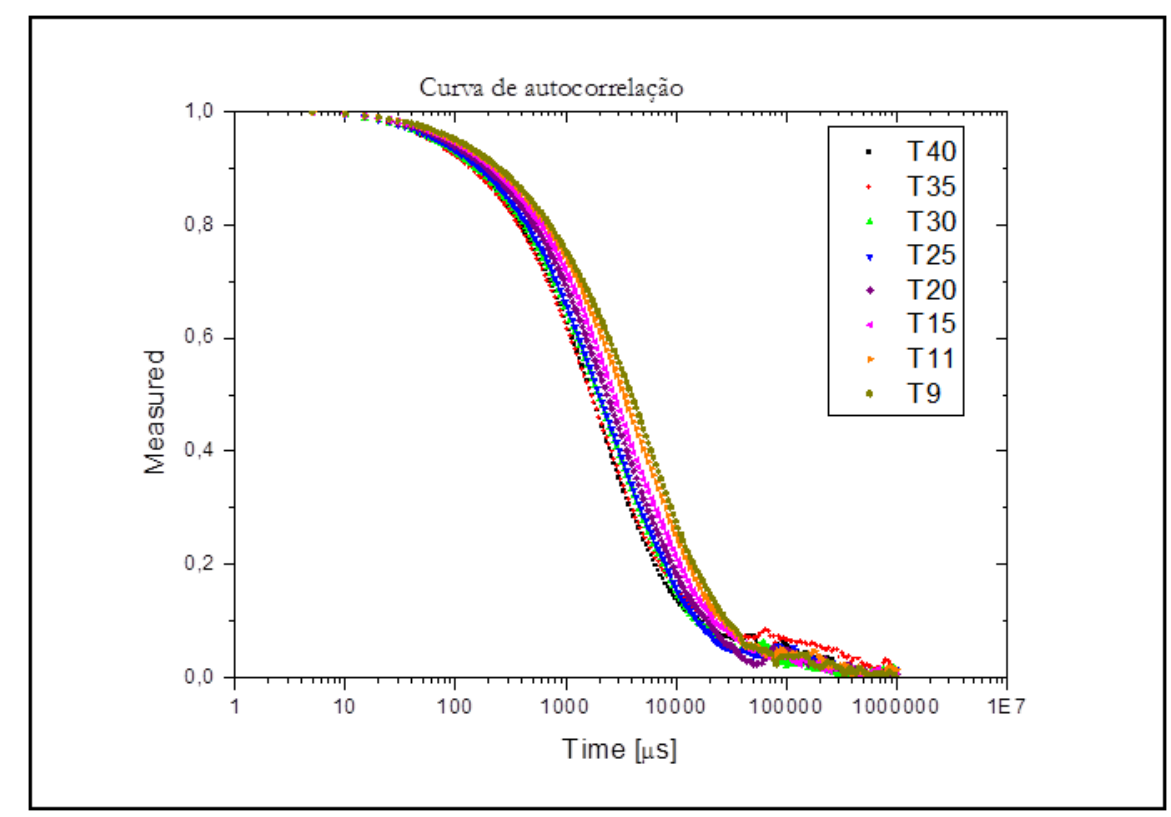

Figura 50: Curva de autocorrelação para cada uma das temperaturas estudadas.

É possível observar na figura 50 uma tendência a um decaimento para tempos maiores, conforme baixou-se a temperatura. Isso ocorre pois o movimento das partículas é governado, basicamente, pelo movimento browniano e sabe-se que, quanto maior o diâme- 


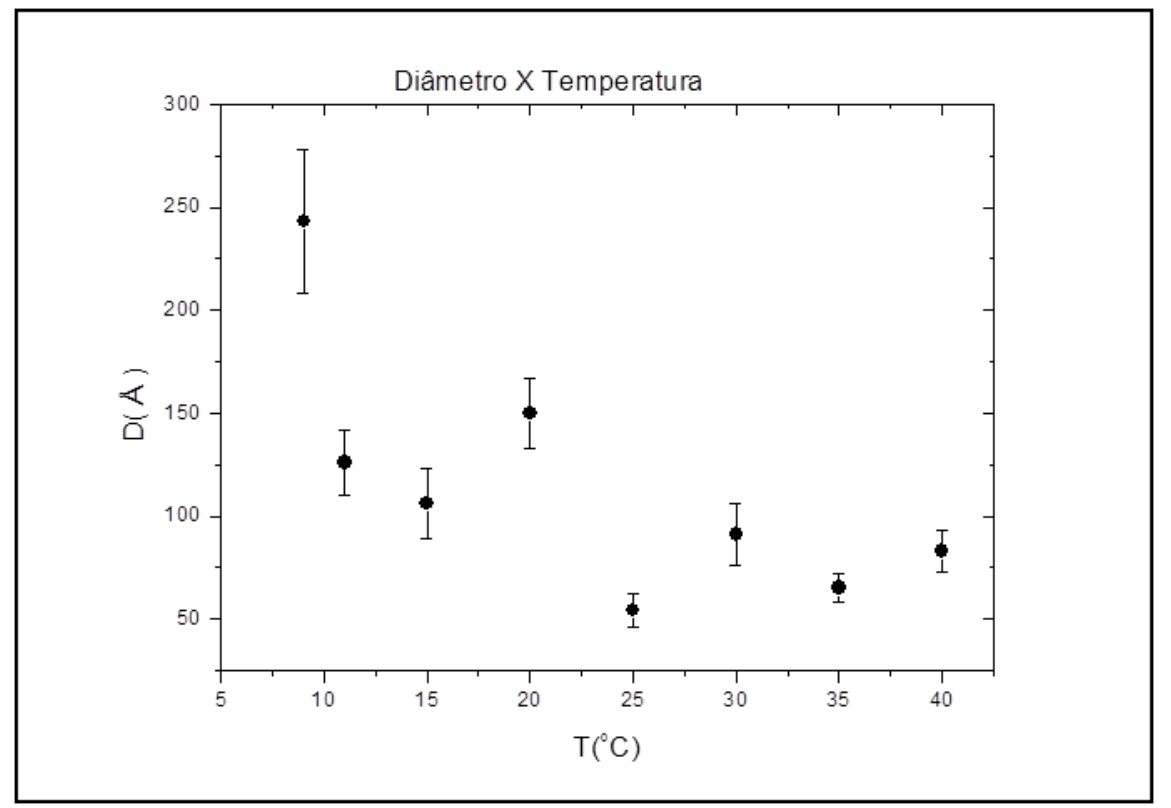

Figura 51: Gráfico de diâmetro hidrodinâmico médio em função da temperatura.

tro da partícula, mais lentamente ela se move. Assim tem-se partículas maiores conforme baixamos a temperatura. Quando observamos a figura 36, vê-se que apesar das flutuações, os diâmetros hidrodinâmico médio apresentam um aumento.Vale ressaltar que este resultado é bastante semelhante ao obtido pelos dados de SAXS: diminuindo a temperatura aumentou-se o tamanho médio das partículas do meio.

Já os resultados apresentados na literatura [5] para amostras mais puras, mostram uma dinâmica de agregação muito mais rápida do que a obtida e, diâmetros hidrodinâmicos médio, também maiores. Por exemplo, para uma temperatura de $25^{\circ} \mathrm{C}$, na literaura, é descrito um diâmetro de $370 \AA ̊$, enquanto, foi obtido para $4^{\circ} C$, um diâmetro hidrodinâmico médio de $250 \AA ̊$. Assim, possivelmente, a metodologia de purificação aplicada mostrou-se ineficiente para alcançar altos índices de pureza. No entanto, os resultados de espalhamento de Raios X e Luz Dinâmico demonstraram a tendência do sistema a formar agregados com a diminuição da temperatura, fato também visto na literatura. Interessantemente, os dados indicam que a presença de outras proteínas no meio provavelmente 
diminuem a dinâmica de agregação. Além disso, seria necessário um estudo sistemático em função da concentração para avaliar potenciais efeitos. Tal estudo não foi realizado neste trabalho. Logo, um procedimento otimizado de purificação é necessário. Apesar dos experimentos com as crioglobulinas apresentarem problemas quanto a purificação da amostra, os dados de SAXS e DLS permitiram a obtenção de informações úteis quanto a estrutura do sistema.

\subsection{Proteassomo}

Os experimentos de SAXS foram feitos com uma linhagem selvagem do Proteassomo, tanto em solução salina simples, como com a adição de DTT ( $2 \mu \mathrm{M})$. Na figura 52 estão os dados de espalhamento, bem como a $p(r)$ obtida.
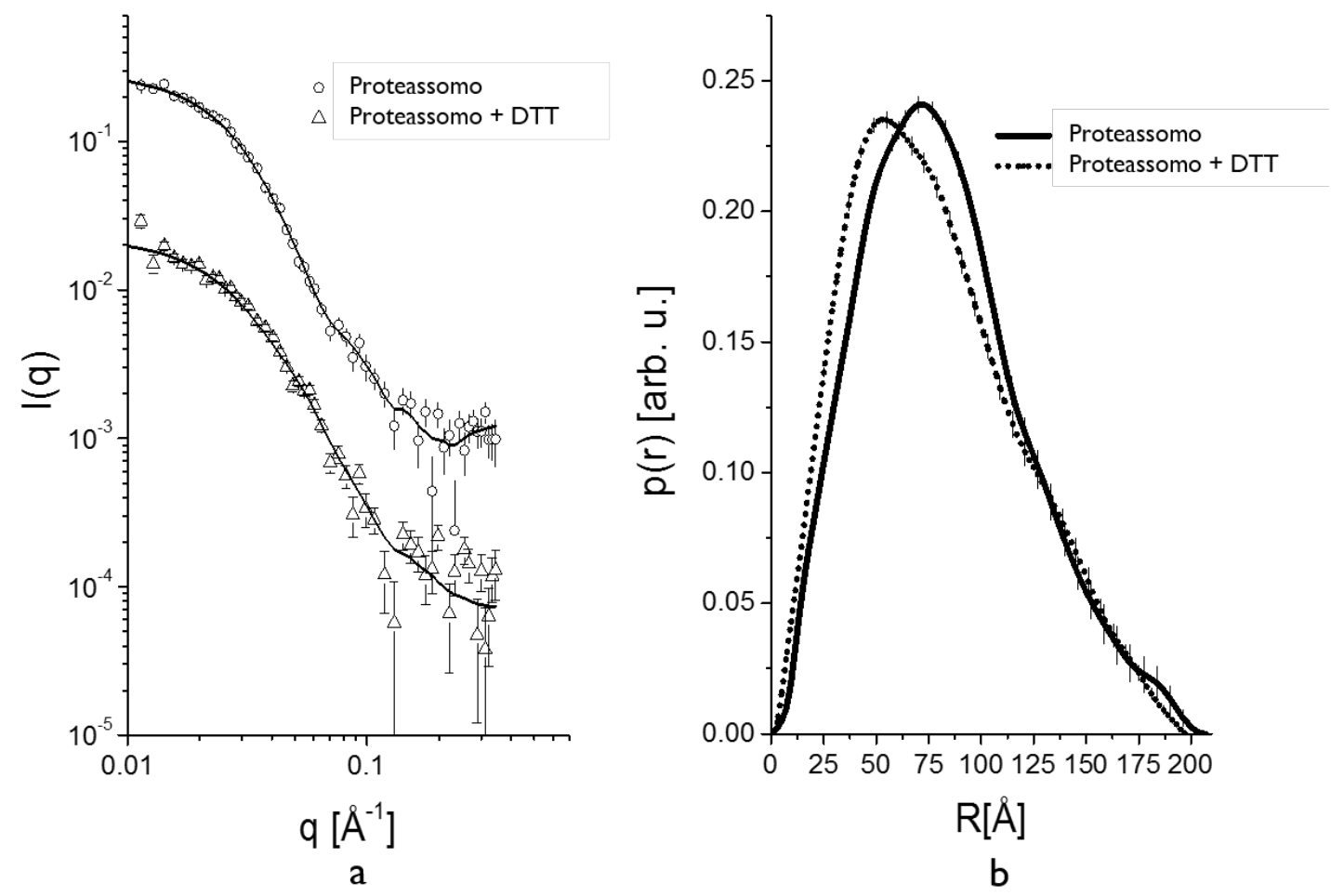

Figura 52: Em a temos: círculo dados experimentais da linhagem selvagem do Proteassomo. Triângulos dados experimentais do Protassomo com a adição de DTT. As linhas continuas representam o ajuste IFT dos dados de espalhamento. Em b temos a $p(r)$ para cada uma dos sitemas. A linha continua representa o Proteassomo e a Pontilhada o Proteassomo com a adição de DTT. 
Do formato da curva $p(r)$ conluiu-se que a forma da proteína é de fato um cilindro. Além disso, obteve-se a dimensão máxima da partícula e o raio de giro, apresentados na tabela 1.

Tabela 1: Dimensões máximas e Raios de Giro

\begin{tabular}{r|c|c} 
Amostra & Dimensão Máxima $(\AA)$ & Raio de Giro $(\AA)$ \\
Proteassomo & $\approx 210$ & $65(2)$ \\
Proteassomo+DTT & $\approx 200$ & $62(1)$
\end{tabular}

Os resultados de IFT já fornecem dados muito interessantes. A forma da curva $\mathrm{p}(\mathrm{r})$ indica que nos dois casos temos partículas ligeramente elongadas, por exemplo, como cilindros curtos, o que está em concordância com a estrutura do proteassomo. Outro aspecto muito interessante são as análises por IFT. O ponto de inflexão da curva p(r) para um cilindro é proporcional ao raio do cilindro [23]. Deste modo a adição de DTT ao sistema promove a diminuição do diâmetro externo do proteassomo, o que pode indicar o fechamento do canal. Para obtermos mais detalhes sobre a estrutura outras abordagens de modelagem foram utilizadas.

Na primeira abordagem, mais simplificada, se utilizou um modelo teórico analítico. Considerou-se cilindros vazados para realizar-se o ajuste dos dados e obter-se informações como: comprimento do cilindro, raio interno e externo. Abaixo a expressão utilizada, bem como na figura 53 o gráfico que mostra o ajuste. Na tabela 2 são mostrados os parâmetros obtidos em cada caso.

$$
I_{1}(q)=\int \frac{V\left(R_{\text {out }}\right) F_{\text {cyl }}\left(q, R_{\text {out }}\right) \exp \left(-\frac{q^{2} \sigma^{2}}{2}\right)-V\left(R_{\text {in }}\right) F_{\text {cyl }}\left(q, R_{\text {in }}\right)}{V\left(R_{\text {out }}\right)-V\left(R_{\text {in }}\right)} \sin \alpha d \alpha
$$

Onde:

$$
F_{c y l}(R, L, \alpha)=\frac{2 J_{1}(q R \sin \alpha) \sin \left(q L \cos \frac{\alpha}{2}\right)}{q R \sin \alpha q L \cos \frac{\alpha}{2}}
$$


e

$$
V(R)=\pi R^{2} L
$$

sendo $R_{\text {in }}$ o raio interno do cilindro, $R_{\text {out }}$ o raio externo, $L$ o seu comprimento.

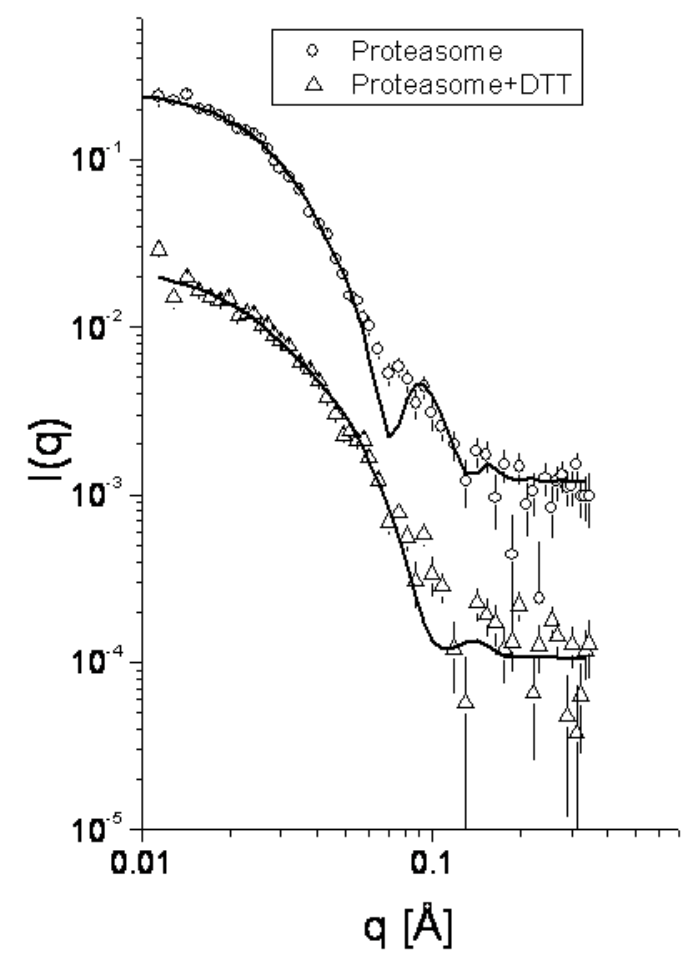

Figura 53: Círculos representam os dados experimentais da linhagem selvagem do Proteassomo. Triângulos, os dados experimentais do Protassomo com a adição de DTT. As linhas continuas representam o ajuste com o modelo teórico analítico para cilindros.

Tabela 2: Resumo dos resultados obtidos

\begin{tabular}{r|c|c} 
Parâmetro & Proteassomo & Proteassomo+DTT \\
Raio Externo $(\AA)$ & $53(2)$ & $36(2)$ \\
Raio Interno $(\AA)$ & $39(2)$ & $\approx 0$ \\
$\sigma(\AA)$ & $\approx 5$ & $\approx 5$ \\
Comprimento $(\AA)$ & $188(10)$ & $210(20)$ \\
$\chi^{2}$ & 2,5 & 3,5
\end{tabular}

As análises dos dados de SAXS indicaram que o proteassomo em solução em solução salina simples ou com DTT pode ser bem descrito como cilindro oco curto. No 

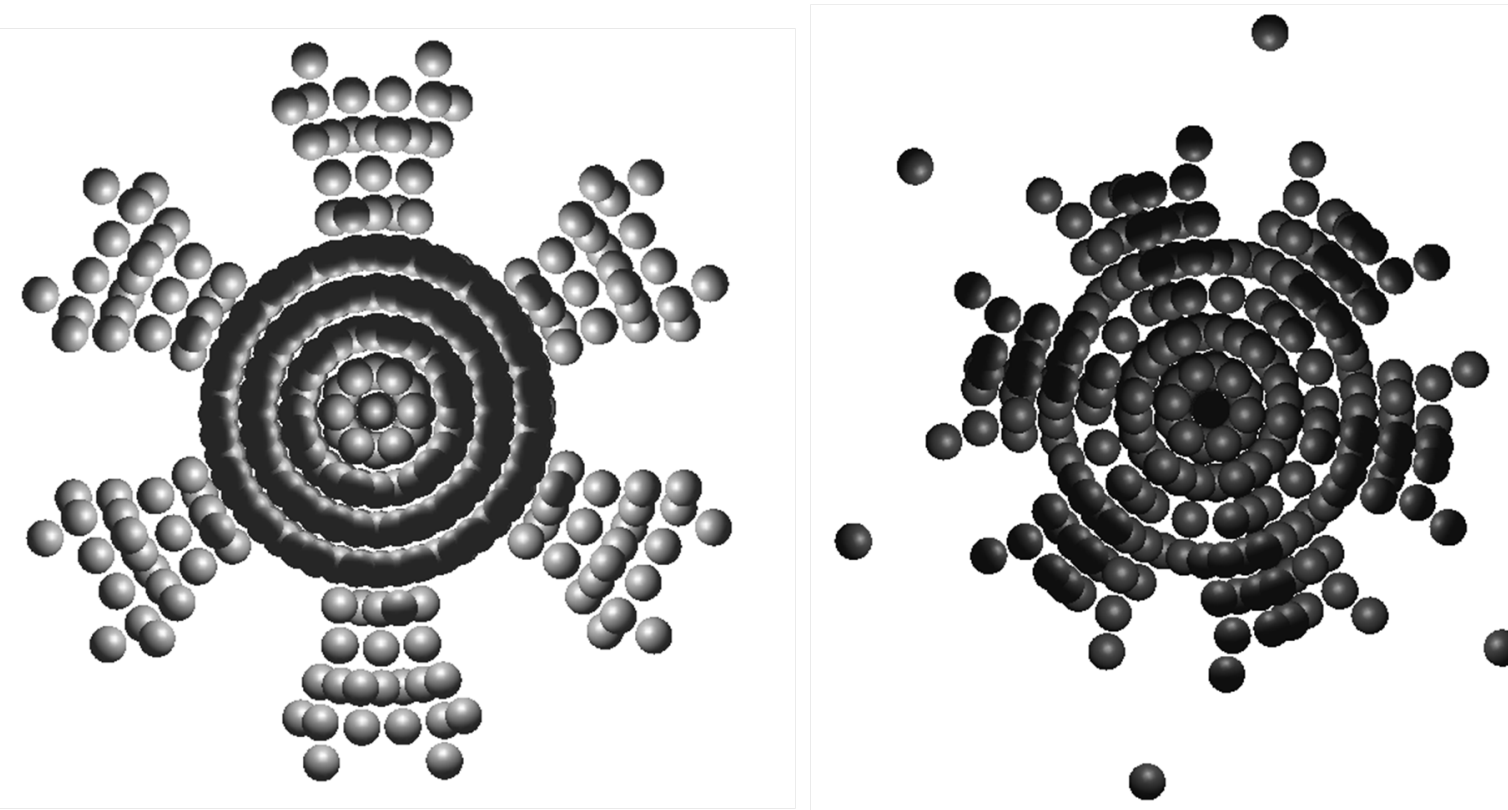

Figura 54: Modelagem ab initio. Em (a) 20S PT. Em (b) 20S PT+DTT

entanto, as dimensões e as características da partícula, com ou sem DTT são notavelmente diferentes. O proteassomo puro pode ser entendido como um cilindro oco em uma boa concordância com a estrutura conhecida do proteassomo. Por outro lado, o proteassomo com DTT, mostrou uma secção transversal menor, indicando uma diminuição no raio exterior, como indicado pelo resultado de IFT. Além disso, a modelagem indicou que o raio interno é quase fechado pela alteração na estrutura.

Tentou-se realizar cálculos utilizando métodos ab initio mas os resultados não forneceram modelos estáveis, mesmo impondo-se uma simetria P72, que é intrinseca ao proteassomo. A forma geral obtida foi de um cilindro, mas modelagens independentes forneciam resultados substancialmente diferentes (Figura54). De toda maneira, a modelagem ab initio indica uma mudança no raio externo, como indicado nas otras análises.

Esta variabilidade de resultado é consequencia da quantidade limitada de informação das curvas de espalhamento. Têm-se parâmetros estruturais gerais mas não detalhados da estrutura. 
Para diminuir a ambiguidade dos resultados, deve-se introduzir, se possível, informações adicionais na modelagem [22]. No caso do proteassomo tem-se o modelo em resolução atômica [12]. Quando usa-se essa estrutura para ajustar os dados de espalhamento (figura 55) (programa CRYSOL [28]), é posível observar que a intesidade de esplhamento teórica, baseada na estrutura cristalográfica está em desacordo com os dados de espalhamento. Isso indica que existem diferenças de conformação, entre as amostras estudadas e o modelo cristalográfico. Sendo assim, pode-se utilizar modelagem por corpo rígido para gerar alteração na estrutura. Neste caso usa-se uma parte da molécula como base. Na figura 56 temos que a estrutura é composta de 4 camadas com simetria 7 :

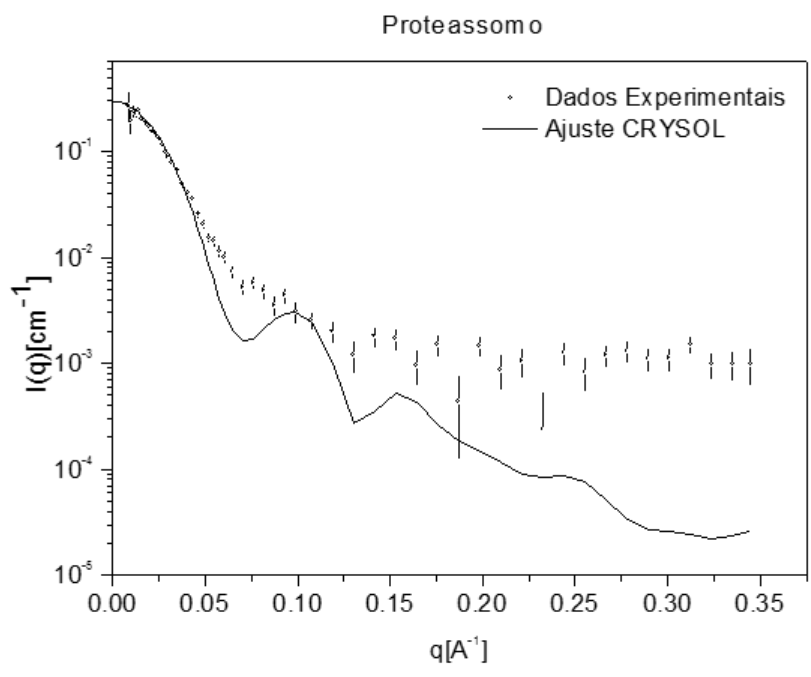

a

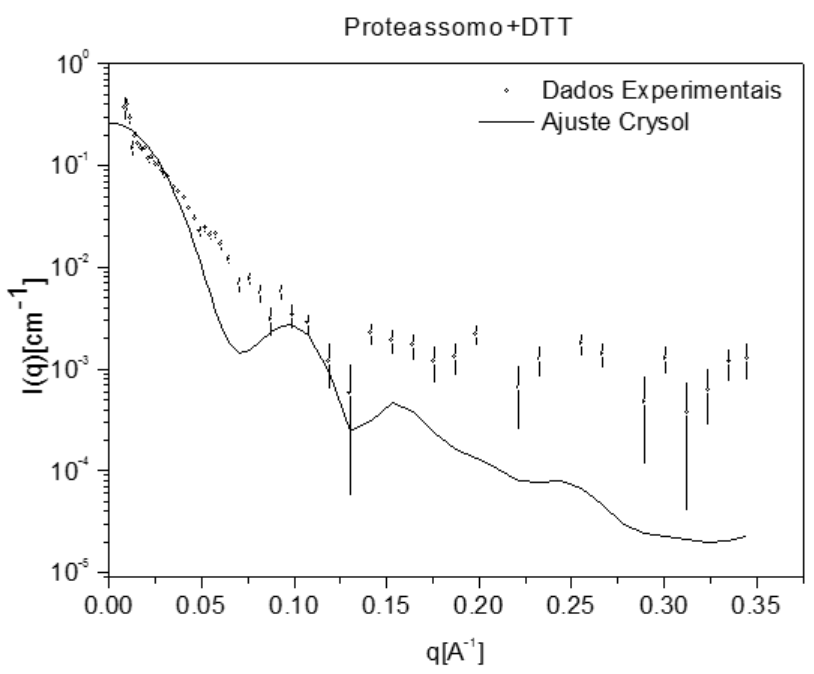

b

Figura 55: Em (a) temos: Intensidade de espalhamento do proteassomo, Ajuste (linha sólida) utilizando estrutura cristalográfica resolvida (3d39) através do programa Crysol. Em (b) temos: Intensidade de espalhamento do proteassomo+DTT, Ajuste (linha sólida) utilizando estrutura cristalográfica resolvida (3d39) através do programa Crysol

Uma possibilidade de modelagem seria tomar uma molécula em cada camada e impor uma simetria 7. Mas, como a molécula possui uma simetria 2 perpendicular ao eixo longitudinal, pode-se tomar 2 moléculas e impor uma simetria P72 para construir a estrutura toda. 

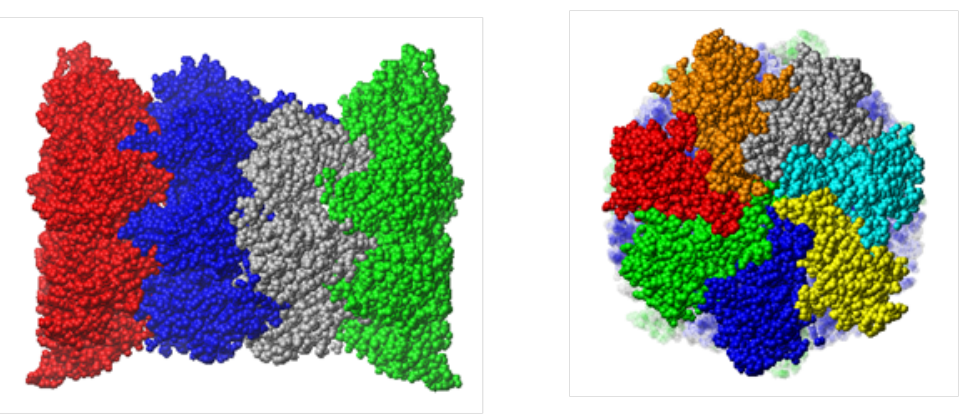

Figura 56: Modelo Cristalográfico do Proteassomo, em que é possível observar as 4 camadas de que é composto.

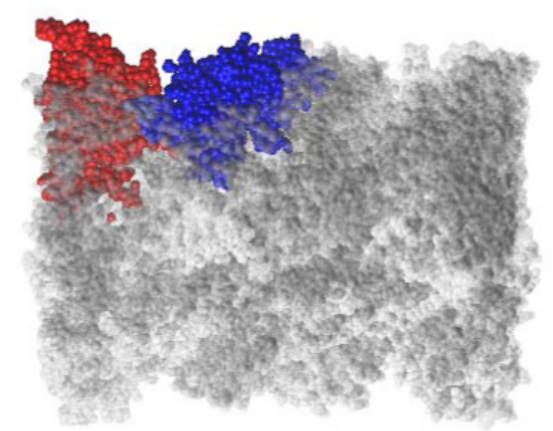

Figura 57: Modelo Cristalográfico do Proteassomo, em que é possível observar as 2 subunidades utilizadas para cálculo dos modelos.

Desta forma, utilizou-se as duas moléculas mostradas na figura 57, impondo a simetria P72 para construir a estrutura. Além disso, tomando como base a estrutura do proteassomo, vínculos são impostos de modo que a estrutura obtida esteja em concordância com a estrutura inicial, por exemplo, as faces das proteínas devem manter o mesmo tipo de interação, podendo variar um pouco sua posição espacial.

A modelagem foi feita utilizando o programa CORAL. Na modelagem, realizou-se 10 simulações independentes para cada sistema (PT e PT+DTT) e os resultados foram promediados para obter a estrutura mais provável, mostrada na figura 58, juntamente com o gráfico que mostra o ajuste dos dados de espalhamento.

A simulação é bastante estável e os modelos obtidos, para cada amostra, são muito parecidos. Diferentemente do caso da modelagem ab initio, os modelos gerados foram 

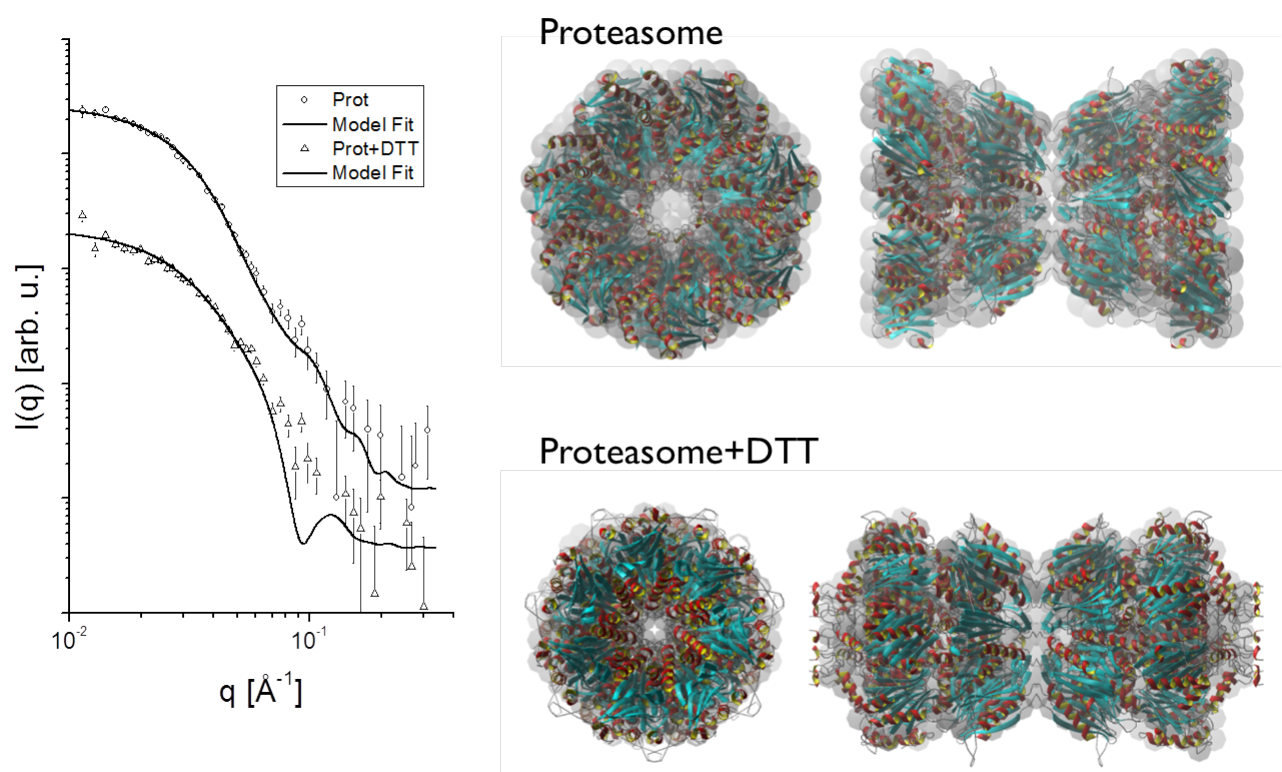

Figura 58: A esquerda temos o gráfico que mostra o ajuste da curva de espalhamento. A direita temos em esferas cinzas a média de 10 simulações independentes. Em azul e vermelho a estrutura mais provável.

muito semelhantes. O fato de usarmos o dímero de proteínas em uma simetria P72 impõe um espaço de busca limitado, de modo que os resultados devem satisfazer os vínculos. Além disso, os resultados corroboram muito bem ao que havia sido obtido anteriormente na modelagem com o cilindro oco: 1) o proteassomo nativo possui um diâmetro maior do que tratado com DTT; 2) o proteassomo com DTT assume uma conformação mais elongada; 3) é possível ver que o proteassomo nativo é mais aberto do que com DTT, o que suporta a idéia de fechamento da estrutura.

Além disso, o modelo do complexo proteíco nativo, apresenta uma parte côncava em seu topo, o que faz com que, em uma micrografia, quando tem-se uma visão do topo, a parte central da imagem fique escura e as bordas claras. Como o proteassomo com DTT não possui esta concavidade, ela fica totalmente clara. Utilizando os modelos obtidos, foram criadas as projeções mostradas na figura 59, para exemplificar a situação vista por Microscopia Eletrônica de Transmissão (as imagens estão na mesma escala): 


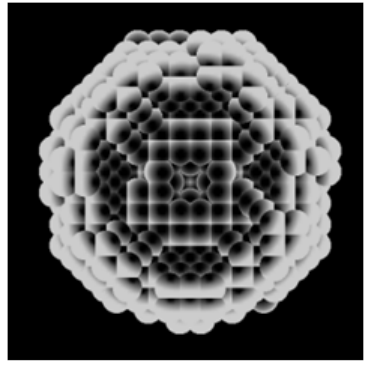

a

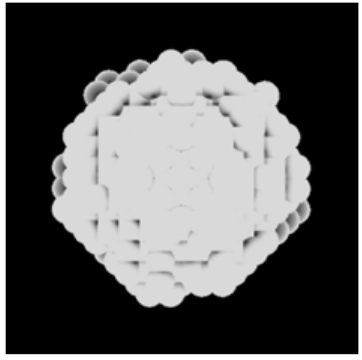

b

Figura 59: Projeções criadas através dos modelos gerados. Em (a) apenas o proteassomo. Em (b) o Proteassomo com DTT

Para as medidas de microscopia eletrônica dessas amostras (Proteassomo e Proteassomo+DTT) obteve-se as medidas apresentadas na figura 60 .
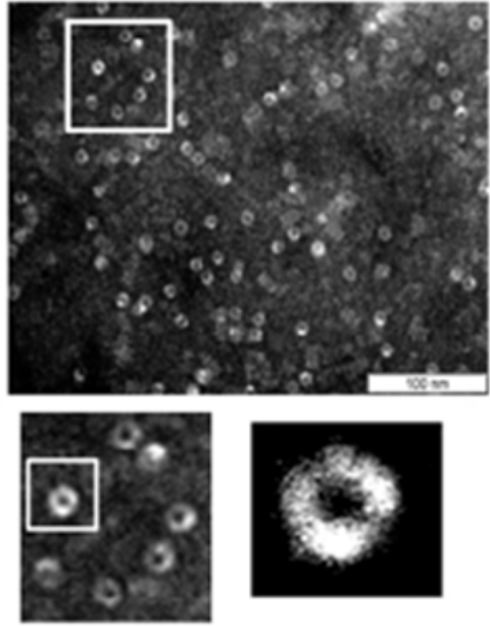

a
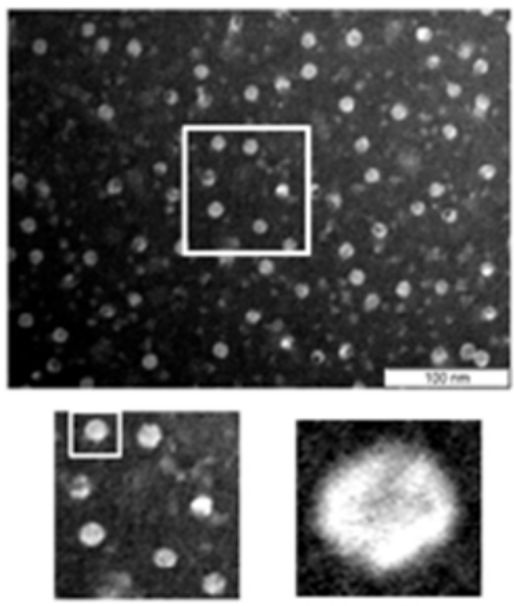

b

Figura 60: Micrografias, em (a) apenas do proteassomo e em (b), do proteassomo com DTT.

Os resultados de IFT, modelagem por modelo semi-analítico e modelagem por corpo rígido, demonstraram que a proteína sofre alterações estruturais importantes quando sujeita à ação do DTT. A principal vantagem dos estudos realizados é o fato de estudarmos o sistema diretamente em solução, o que aumenta a confiabilidade dos resultados.

Medidas de SAXS também foram realizadas para uma linhagem mutante do proteassomo. Nesse mutante, a passagem interna permanece aberta. Após tratar a molécula 
de diferentes formas, buscou-se confirmar essa permanência através da técnica de SAXS.

As experiências foram realizadas à temperatura ambiente e as amostras tinham concentrações em torno de $1,0 \mathrm{mg} / \mathrm{mL}$.

Estudou-se o proteassomo em quatro condições diferentes: 1)em tampão simples, 2)com a adição de GSH, 3)com a adição de GSSG e 4) com adição de DTT.

Os dados de espalhamento são mostrados na figura 61. Aplicando a abordagem IFT, é possível obter a função de distribuição de pares de distâncias (p(r)) para cada caso.
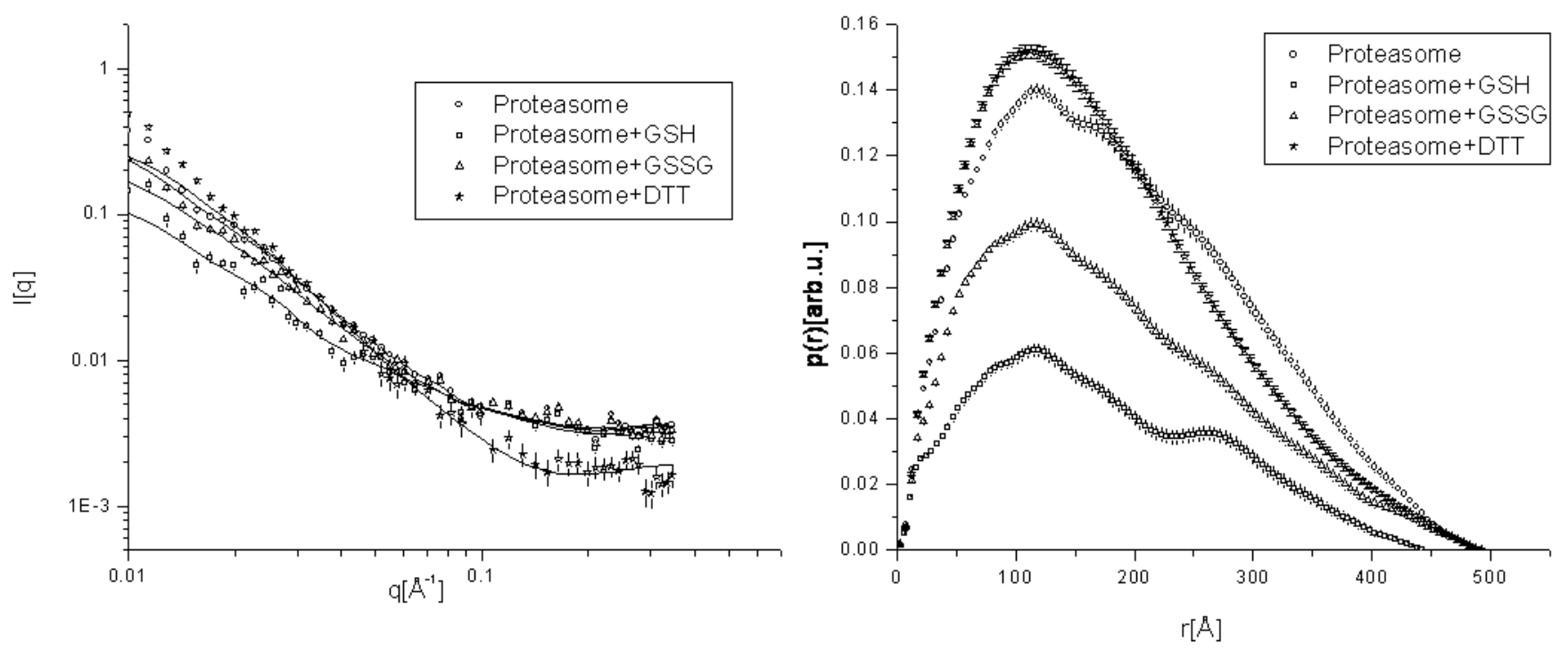

Figura 61: Ajuste dos dados de SAXS utilizando método IFT. Esquerda: Os dados experimentais. Círculos: proteassomo. Quadrados: Proteassomo + GSH. Triângulos: Proteassomo + GSSG.Estrelas: Proteassomo + DTT. As linhas sólidas: ajuste IFT. Direita: Função Pares de Distribuição de Distância. Círculos: proteassomo. Quadrados: Proteassomo + GSH. Triângulos: Proteassomo + GSSG. Estrelas: Proteassomo + DTT.

É possível observar que há uma contribuição de agregados na curva de espalhamento, que podem ser detectados, principalmente, na região de baixo ângulo, $(q<$ $\left.0,015 \AA^{-} 1\right)$, correspondente ao início da curva.

Nos casos em que uma subida abrupta na curva de SAXS é claramente visível, 
pode-se tentar desconsiderar os primeiros pontos a fim de observar apenas a contribuição do "monômero"no sistema. Os resultados IFT para este caso são mostrados na figura 62. Para a curva completa, verificaram-se agregados com dimensão máxima de cerca de $500 \AA$. Enquanto que, após desconsiderar-se alguns pontos, a dimensão máxima permanece perto de $230 \AA$.
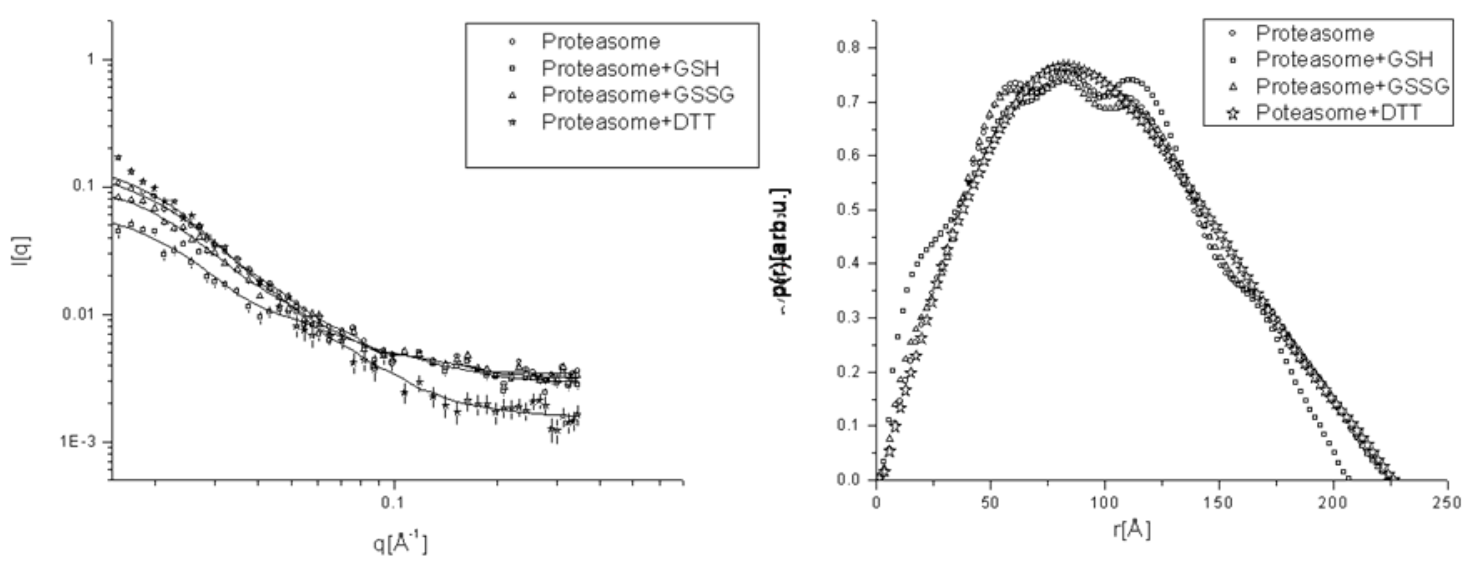

Figura 62: Ajuste dos dados de SAXS utilizando método IFT para $q>0.015 \AA^{-} 1$. Esquerda: Os dados experimentais. Círculos: proteassomo. Quadrados: Proteassomo + GSH. Triângulos: Proteassomo + GSSG.Estrelas: Proteassomo + DTT. As linhas sólidas: ajuste IFT. Direita: Função Pares de Distribuição de Distância. Círculos: proteassomo. Quadrados: Proteassomo + GSH. Triângulos: Proteassomo + GSSG. Estrelas: Proteassomo + DTT.

O ajuste IFT fornece a indicação de que as partículas têm: uma conformação alongada com dimensão máxima de $230 \AA ̊$ para o proteassomo em solução salina simples, com GSSG e com DTT, e $210 \AA ̊$ para o proteassomo tratado com GSH. Além disso, o raio de giração obtido para proteassomo é de $78 \pm 1 \AA$. Para a proteína com GSH $R g=74 \pm 2 \AA$, para a proteína com GSSG, $R g=78 \pm 1 \AA$ e, para a proteína com DTT, $R g=78 \pm 1 \AA$.

Para os dados com DTT, mesmo desconsiderando os pontos iniciais, não foi possível excluir a influência dos agregados, o que não permite a obtenção de informações referentes à estrutura da partícula unicamente. Além disso, nessa tentativa de excluir a influência dos agregados no sistema, tentou-se excluir os primeiros pontos das curvas 
experimentais. Todavia, esse procedimento torna mais impreciso o método de IFT, dificultando a obtenção de valores precisos de dimensão máxima. No entanto, há uma indicação de que a adição de GSH diminui o tamanho máximo enquanto que a secção transversal é semelhante em todos os casos.

Tentou-se realizar a análise utilizando o fator de forma de cilindros, como no estudo anterior, mas a presença de agregados, e as baixas concentrações dos dados de espalhamento não permitiu a obtenção de valores confiáveis com o ajuste, tanto para o raio interior ou exterior e também para o comprimento. Deste modo, os dados indicaram que os aditivos utilizados induziram agregação do sistema, dificultando a interpretação e impedindo a utilização de abordagem mais avançadas na análise dos dados de SAXS. Nestes casos, os dados de MET são cruciais pois podem permitir a visualização de eventuais estruturas "monoméricas"no sistema.

Micrografias da molécula do Proteassomo também foram estudadas em duas outras condições diferentes, em que as células de levedura foram crescidas em meios diferentes: 1) um contendo Glicerol (Gly), que leva ao metabolismo respiratório e o outro 2) contendo Glicose (Glu) associado ao metabolismo fermentativo.

As diferenças estruturais das moléculas foram estudadas através de MET. O interesse principal é observar se o meio de crescimento da levedura afetou a abertura da molécula. Assim, diversas micrografias foram obtidas e para cada uma delas realizou-se a contagem manual de estruturas abertas. A figura 63 representa uma micrografia de cada meio estudado com o valor da respectiva porcentagem de estruturas abertas.

Das micrografias apresentadas acima observou-se ter majoritariamente a presença de top view das moléculas, o auxilia na contagem de estruturas abertas. Para o Proteassomo extraído das células crescidas em meio de Glicose tem-se uma presença maior de 

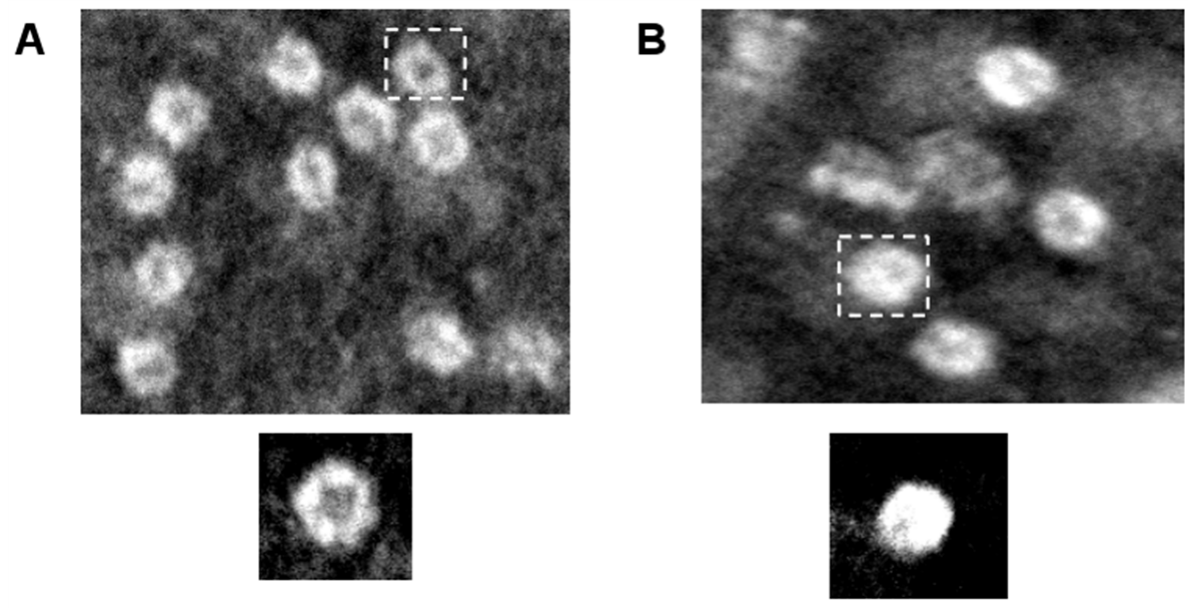

Figura 63: Em a temos a micrografia do Proteassomo crescido em meio rico em Glicose em que $67 \%$ das estruturas se apresentam abertas. Em b o Proteassomo crescido em meio rico em Glicerol, em que apenas $11 \%$ das estruturas se apresentam abertas

estruturas abertas, meio no qual favorece, portanto, a degradação de proteínas oxidadas.

Todos estes resultados demonstraram a aplicabilidade do uso de método de espalhamento e microscopia (quando possível) ao estudos dos sistemas. No caso do proteassomo, por ser uma proteína grande, MET pode ser utilizado para a visualização, em conjunção com os dados de SAXS pode permitir uma caracterização detalhada da estrutura do sistema. 



\section{Conclusões e Perspectivas}

Diversos estudos estruturais foram realizadas para diferentes tipos de proteínas, em que se utilizou variadas técnicas experimentais.

A proteína Lisozima foi estudada em duas soluções tampões diferentes e não houve diferenças nos resultados. Porém ao variarmos a concentração da proteína na solução, é possível observar que para as amostras mais concentradas existe um fator de interação entre as partículas, próximo ao de esferas rígidas. Além disso, tem-se a indicação de que a proteína em solução tem estrutura semelhante à apresentada pelo cristal, mostrado tanto pelo ajuste com o programa CRYSOL [28], quanto pelo modelo ab initio. O peso molecular calculado é $\approx 15 k D a$, que está em bom acordo com a literatura.

Em relação ao sistema de crioglobulinas: não foi possível obter resultados confiáveis para a amostra não caracterizada. Haja vista serem inúmeras as variáveis presente no sistema.

Não foi possível purificar a amostra de paciente com crioglobulemia. Mesmo tentando-se duas maneiras de purificação distintas. No processo de cromatografia, não é possível controlar a temperatura. Sendo assim, a agregação e a precipitação, podem ter impedido a ligação na coluna. Portanto, para purificação do sistema de crioglobulinas é 
necessário utilizar-se metodologias mais elaboradas para a extração das imunoglobulinas do soro humano.

Em relação ao sistema do Proteassomo, para o estudo na condição selvagem e tratado com DTT, obteve-se informações estruturais relevantes dos dados de espalhamento a baixos ângulos através da utilização de metodologias avançadas de modelagem. Além dos resultados da modelagem mais avançada apresentou-se em plena concordância com a modelagem simples utilizando o modelo analítico para cilindro vazado, mas a utilização da estrutura do proteassomo na modelagem forneceu informações adicionais. A mudança que ocorre na estrutura do proteassomo, indicada como abertura e fechamento no modelo analítico [24] [4], pôde ser compreendida através das mudanças ocorridas nos modelos. Os modelos também fornecem subsídios para a compreensão das micrografias vistas nos experimentos de MET[24] [4].

Para os dados de SAXS da amostra mutante os resultados apresentados mostraram que houve a formação de agregados. Isso torna difícil a análise dos dados.

Há indicações de que as seções transversais para PT / PT + GSSG / PT + GSH são semelhantes, sinalizando que os aditivos não acionam o fechamento do canal interno. Por outro lado, o proteassomo estudado com a adição de DTT apresentou muita agregação. Como consequência, não foi possível recuperar conclusões confiáveis.

Diferentemente da amostra do proteassomo selvagem, as amostras do proteassomo mutante apresentaram, em todos os casos, a tendência de agregação. Esta formação de agregados, impede uma análise mais detalhada dos dados de SAXS.

Para o estudo realizado com o crescimento do Proteassomo em meios distintos, observou-se com as micrografias que o meio de crescimento rico em Glicose pode favorecer a abertura da molécula. 
Como mostrado nesta dissertação, dependendo do tipo de sistema e da quantidade de informação conhecida, diversas metodologias de análise podem ser aplicados.

Indicações sobre flexibilidade das partículas do meio podem ser obtidos dos dados de SAXS, sendo possível utilizar métodos de modelagem também nestes casos.

Quando possivel, modelos simples podem ser utilizados na análise dos dados. O uso de modelos simples têm a principal vantagem da utilização de um baixo número de parâmetros, o que facilita a interpretação dos dados. Por outro lado, modelagem avançadas, guiadas por informações e vínculos estruturais podem fornecer resultados únicos sobre o sistema.

Os resultados desta dissertação além de fornecerem dados inéditos sobre os sistemas estudados, pode servir de guia para o uso da técnica no estudo de proteínas em solução. 



\section{Bibliografia}

[1] Pau Bernadó et al. "Structural characterization of flexible proteins using small-angle X-ray scattering". eng. Em: J. Am. Chem. Soc. 129.17 (maio de 2007), pp. 56565664. ISSN: 0002-7863. DOI: $10.1021 / \mathrm{ja} 069124 \mathrm{n}$.

[2] P. Chacón et al. "Low-Resolution Structures of Proteins in Solution Retrieved from X-Ray Scattering with a Genetic Algorithm". Em: Biophysical Journal 74.6 (jun. de 1998), pp. 2760-2775. ISSN: 0006-3495. DOI: 10 . 1016/S0006-3495(98) 77984-6. (Acesso em 16/06/2015).

[3] F. Dammacco et al. "The cryoglobulins: an overview". eng. Em: Eur. J. Clin. Invest. 31.7 (jul. de 2001), pp. 628-638. ISSN: 0014-2972.

[4] Marilene Demasi et al. "Redox regulation of the proteasome via S-glutathionylation". Em: Redox Biology 2 (2014), pp. 44-51. ISSN: 2213-2317. DOI: $10.1016 /$ j.redox. 2013.12.003. URL: http://www. sciencedirect.com/science/article/pii/ S2213231713000918 (acesso em 16/06/2015).

[5] Enrico Di Stasio et al. "Analysis of the dynamics of cryoaggregation by lightscattering spectrometry". eng. Em: Clin. Chem. Lab. Med. 41.2 (fev. de 2003), pp. 152-158. ISSN: 1434-6621. DOI: 10.1515/CCLM. 2003.025. 
[6] R. Diamond. "Real-space refinement of the structure of hen egg-white lysozyme". Em: Journal of Molecular Biology 82.3 (jan. de 1974), pp. 371-391. ISSN: 0022-2836. DOI: $10.1016 / 0022-2836(74) 90598-1$. (Acesso em 16/06/2015).

[7] Ein neues Verfahren zur Bestimmung der Oberflächenform und der inneren Struktur von gelösten globulären Proteinen aus Röntgenkleinwinkelmessungen : Zeitschrift für Physikalische Chemie. URL: http://www.degruyter.com/view/j/zpch.1970.72. issue-4_6/zpch.1970.72.4_6.177/zpch.1970.72.4_6.177.xml (acesso em $16 / 06 / 2015)$

[8] G. Fagherazzi. "Small angle X-ray scattering edited by O. Glatter and O. Kratky". Em: Acta Crystallographica Section A Foundations of Crystallography 39.3 (maio de 1983), pp. 500-500. ISSN: 0108-7673. DOI: 10 . 1107 / S0108767383000926. URL: http: / / scripts . iucr . org/cgi-bin/paper? S0108767383000926 (acesso em $16 / 06 / 2015)$

[9] André Guinier e Gérard Fournet. Small-angle scattering of X-rays. en. Wiley, 1955.

[10] Antonio Haddad et al. Técnicas básicas de microscopia eletrônica aplicadas às ciências biológicas. Portuguese. Rio de Janeiro: Sociedade Brasileira de Microscopia, 1998.

[11] John Hanna e Daniel Finley. "A proteasome for all occasions". eng. Em: FEBS Lett. 581.15 (jun. de 2007), pp. 2854-2861. ISSN: 0014-5793. DOI: 10.1016/j.febslet. 2007.03 .053$.

[12] J. Hines et al. "Proteasome Inhibition by Fellutamide B Induces Nerve Growth Factor Synthesis". Em: Chem.Biol. 15 (maio de 2008), pp. 501-512. ISSN: 10745521. DOI: $10.1016 /$ j.chembiol.2008.03.020. (Acesso em 16/06/2015). 
[13] D. T. Jones. "Protein secondary structure prediction based on position-specific scoring matrices". eng. Em: J. Mol. Biol. 292.2 (set. de 1999), pp. 195-202. ISSN: 0022-2836. DOI: 10.1006/jmbi.1999.3091.

[14] Tobias Jung, Betül Catalgol e Tilman Grune. "The proteasomal system". eng. Em: Mol. Aspects Med. 30.4 (ago. de 2009), pp. 191-296. ISSN: 1872-9452. DOI: 10.1016/ j.mam.2009.04.001.

[15] Anita Marzzoco e Bayardo Baptista Torres. Bioquímica básica. 3. ed. Rio de Janeiro: Guanabara Koogan, 2007. ISBN: 9788527712842.

[16] Haydyn D. T. Mertens e Dmitri I. Svergun. "Structural characterization of proteins and complexes using small-angle X-ray solution scattering". eng. Em: J. Struct. Biol. 172.1 (out. de 2010), pp. 128-141. ISSN: 1095-8657. DOI: $10.1016 / \mathrm{j} \cdot \mathrm{j}$ sb . 2010.06 .012$.

[17] David L. Nelson e Michael M. Cox. Lehninger Principles of Biochemistry. English. 5th edition. New York: W. H. Freeman, fev. de 2008. ISBN: 9780716771081.

[18] Cristiano Luis Pinto Oliveira et al. "A SAXS Study of Glucagon Fibrillation". Em: Journal of Molecular Biology 387.1 (mar. de 2009), pp. 147-161. ISSN: 0022-2836. DOI: $10.1016 / j \cdot j m b .2009 .01$.020. URL: http: //wWw . sciencedirect . com/ science/article/pii/S0022283609000527 (acesso em 16/06/2015).

[19] R. Pecora. Dynamic Light Scattering: Applications of Photon Correlation Spectroscopy. en. Springer Science \& Business Media, nov. de 2013. ISBN: 9781461323891.

[20] Maxim V. Petoukhov e Dmitri I. Svergun. "Applications of small-angle X-ray scattering to biomacromolecular solutions". Em: The International Journal of Biochemistry 8 Cell Biology 45.2 (fev. de 2013), pp. 429-437. ISSN: 1357-2725. DOI: 10. 1016/j.biocel.2012.10.017. (Acesso em 16/06/2015). 
[21] Maxim V. Petoukhov e Dmitri I. Svergun. "Global rigid body modeling of macromolecular complexes against small-angle scattering data". eng. Em: Biophys. J. 89.2 (ago. de 2005), pp. 1237-1250. ISSN: 0006-3495. DOI: 10.1529/biophysj . 105. 064154.

[22] Maxim V. Petoukhov et al. "New developments in the ATSAS program package for small-angle scattering data analysis". Em: Journal of Applied Crystallography 45.2 (abr. de 2012), pp. 342-350. ISSN: 0021-8898. DOI: 10.1107/S0021889812007662. (Acesso em 16/06/2015).

[23] Cristiano Luis Pinto Oliveira. "Investigating Macromolecular Complexes in Solution by Small Angle X-Ray Scattering”. en. Em: Current Trends in X-Ray Crystallography. Ed. por Annamalai Chandrasekaran. InTech, dez. de 2011. ISBN: 978-953307-754-3. (Acesso em 16/06/2015).

[24] Gustavo M. Silva et al. "Redox Control of 20S Proteasome Gating". Em: Antioxidants 83 Redox Signaling 16.11 (jun. de 2012), pp. 1183-1194. ISSN: 1523-0864. DOI: 10.1089/ars . 2011.4210. URL: http://online. liebertpub.com/doi/abs/10. 1089/ars.2011.4210 (acesso em 03/02/2015).

[25] D. I. Svergun. "Determination of the regularization parameter in indirect-transform methods using perceptual criteria". Em: Journal of Applied Crystallography 25.4 (ago. de 1992), pp. 495-503. ISSN: 00218898. DOI: 10.1107/S0021889892001663. (Acesso em 16/06/2015).

[26] D. I. Svergun. "Restoring Low Resolution Structure of Biological Macromolecules from Solution Scattering Using Simulated Annealing". Em: Biophysical Journal 76.6 (jun. de 1999), pp. 2879-2886. ISSN: 0006-3495. DOI: 10.1016/S0006-3495(99) 77443-6. (Acesso em 16/06/2015). 
[27] D I Svergun, M V Petoukhov e M H Koch. "Determination of domain structure of proteins from X-ray solution scattering." Em: Biophys J 80.6 (jun. de 2001), pp. 2946-2953. ISSN: 0006-3495. (Acesso em 16/06/2015).

[28] D. Svergun, C. Barberato e M. H. J. Koch. "CRYSOL - a Program to Evaluate X-ray Solution Scattering of Biological Macromolecules from Atomic Coordinates". Em: Journal of Applied Crystallography 28.6 (dez. de 1995), pp. 768-773. ISSN: 00218898. DOI: $10.1107 /$ S0021889895007047. URL: http://scripts.iucr.org/cgibin/paper?S0021889895007047 (acesso em 16/06/2015).

[29] Dmitri I. Svergun e Michel H. J. Koch. "Small-angle scattering studies of biological macromolecules in solution". en. Em: Rep. Prog. Phys. 66.10 (out. de 2003), p. 1735. ISSN: 0034-4885. DOI: 10.1088/0034-4885/66/10/R05. (Acesso em 16/06/2015).

[30] Giancarlo Tria et al. "Advanced ensemble modelling of flexible macromolecules using X-ray solution scattering”. Em: IUCrJ 2.2 (mar. de 2015), pp. 207-217. ISSN: 20522525. DOI: $10.1107 /$ S205225251500202X. URL: http://scripts.iucr.org/cgibin/paper?S205225251500202X (acesso em 16/06/2015).

[31] Vladimir V. Volkov e Dmitri I. Svergun. "Uniqueness of ab initio shape determination in small-angle scattering". Em: Journal of Applied Crystallography 36.3 (jun. de 2003), pp. 860-864. ISSN: 0021-8898. DOI: 10.1107/S0021889803000268. (Acesso em 16/06/2015).

[32] Allan M. Weissman, Nitzan Shabek e Aaron Ciechanover. "The predator becomes the prey: regulating the ubiquitin system by ubiquitylation and degradation". en. Em: Nat Rev Mol Cell Biol 12.9 (set. de 2011), pp. 605-620. ISSN: 1471-0072. DOI: 10.1038/nrm3173. (Acesso em 16/06/2015). 
[33] David B. Williams e C. Barry Carter. Transmission Electron Microscopy: A Textbook for Materials Science. en. Springer Science \& Business Media, mar. de 2013. ISBN: 9781475725193. 
Anexos 



\section{Artigos publicados}

\section{A.1 Redox Control of 20S Proteasome Gating}

\section{Controle Redox de ativação do proteassomo 20S}

Resumo: O proteassomo é o principal contribuinte na proteólise intracelular. Proteínas oxidadas ou desestruturadas podem ser degradadas via processos independentes de ubitinação e ATP , pelo proteassomo 20S livre (20SPT). O mecanismo pelo qual essas proteínas entram na câmara catalítica, não é bem entendido até o momento, porém mudanças na conformação do 20SPT em sua ativação são considerados uma barreira importante para e livre entrada de proteínas. Apresentamos anteriormente que a S-Glutationilação do 20SPT é uma modificação pós traducional que afeta as atividades proteassomal. Objetivos: A meta deste trabalho foi investigar o mecanismo de regulação da atividade do 20SPT, que inclui a identificação dos residuos de Cys disponíveis para S-Glutationilação. Resultados: A modulação da atividade do 20SPT pela sua ativação é pelo menos parcialmente devido à S-Glutationilação dos resíduos específicos de Cys. A passagem estava aberta quando o 20SPT estava glutatiolado, enquanto após tratamento com altas concentrações de dithiothreitol, a passagem estava fechada. 20SPT S-Glutationilado estava mais efetivo 
na degradação tanto de proteínas oxidadas quanto de proteínas parcialmente desdobradas, do que na forma reduzida. Apenas 2 de 28 Cys foram observados estar S-Glutatioladas na subunidade $\alpha 5$ proteassomal em células de levedura crescidas em fase estacionária em meio contendo Glucose. Inovação:Nós demonstramos um mecanismo redox pós traducional regulatório que controla a atividade de 20SPT. Conclusão: S-Glutationilação é uma modificação pós traducional que desencadeia a abertura da passagem e, assim, ativa as atividades proteolíticas do 20SPT livre. Este processo parece ser um mecanismo regulador importante para intensificar a remoção de proteínas oxidadas ou desestruturadas em situações de stress, por um processo independente de ubiquitinação e consumo de ATP. 


\title{
Redox Control of 20S Proteasome Gating
}

\author{
Gustavo M. Silva, ${ }^{1,2}$ Luis E.S. Netto, ${ }^{2}$ Vanessa Simões, ${ }^{1}$ Luiz F.A. Santos, ${ }^{3}$ Fabio C. Gozzo, ${ }^{3}$ \\ Marcos A.A. Demasi, ${ }^{4}$ Cristiano L.P. Oliveira, ${ }^{5}$ Renata N. Bicev, ${ }^{5}$ Clécio F. Klitzke, ${ }^{6}$ \\ Mari C. Sogayar, ${ }^{4}$ and Marilene Demasi ${ }^{1}$
}

\begin{abstract}
The proteasome is the primary contributor in intracellular proteolysis. Oxidized or unstructured proteins can be degraded via a ubiquitin- and ATP-independent process by the free $20 \mathrm{~S}$ proteasome (20SPT). The mechanism by which these proteins enter the catalytic chamber is not understood thus far, although the 20SPT gating conformation is considered to be an important barrier to allowing proteins free entrance. We have previously shown that S-glutathiolation of the 20SPT is a post-translational modification affecting the proteasomal activities. Aims: The goal of this work was to investigate the mechanism that regulates 20SPT activity, which includes the identification of the Cys residues prone to S-glutathiolation. Results: Modulation of 20SPT activity by proteasome gating is at least partially due to the S-glutathiolation of specific Cys residues. The gate was open when the 20SPT was S-glutathiolated, whereas following treatment with high concentrations of dithiothreitol, the gate was closed. S-glutathiolated 20SPT was more effective at degrading both oxidized and partially unfolded proteins than its reduced form. Only 2 out of 28 Cys were observed to be S-glutathiolated in the proteasomal $\alpha 5$ subunit of yeast cells grown to the stationary phase in glucose-containing medium. Innovation: We demonstrate a redox post-translational regulatory mechanism controlling 20SPT activity. Conclusion: S-glutathiolation is a posttranslational modification that triggers gate opening and thereby activates the proteolytic activities of free 20SPT. This process appears to be an important regulatory mechanism to intensify the removal of oxidized or unstructured proteins in stressful situations by a process independent of ubiquitination and ATP consumption. Antioxid. Redox Signal. 16, 1183-1194.
\end{abstract}

\section{Introduction}

T HE 26S PROTEASOMAL COMPLEX is responsible for the degradation of ubiquitin-tagged proteins in eukaryotic cells $(10,26)$. Although only the $20 \mathrm{~S}$ proteasome core (20SPT) capped with the 19S regulatory particle (namely the 26S proteasome) is able to recognize ubiquitylated substrates, $20 \%$ to $30 \%$ of the total proteasome in mammalian and yeast cells lack regulatory particles $(2,48)$. Alternatively, free 20SPT operates in a ubiquitin- and ATP-independent manner to degrade unstructured substrates, including oxidized proteins $(1,25,45)$. Recent work indicated that the 20SPT can cleave $>20 \%$ of intracellular proteins, initiating the polypeptide processing in disordered regions, including internal domains $(5,33)$.

Because few repair systems for protein damage are known (e.g., methionine sulfoxide reductase), it is widely accepted that proteolysis is the cellular protective mechanism against

\section{Innovation}

The 20SPT is responsible for the degradation of oxidized and unstructured proteins. In the present work, we show that 20SPT S-glutathiolation increases the degradation of oxidatively modified proteins by promoting gate opening. 20SPT S-glutathiolation would take place via the oxidation of Cys residues to sulfenic acid species followed by glutathiolation. Thus, a more oxidative environment would be responsible for both an increased protein oxidation and a modification of the redox status of the proteasome contributing to the removal of oxidized proteins before their aggregation without ATP consumption because the mechanism proposed precludes the protein ubiquitylation process. The present results show an important mechanism for coping with stressful conditions to avoid protein aggregation.

\footnotetext{
${ }^{1}$ Laboratório de Bioquímica e Biofísica, Instituto Butantan, São Paulo, Brasil.

${ }^{2}$ Departamento de Genética e Biologia Evolutiva, Instituto de Biociências, Universidade de São Paulo, Brasil.

${ }^{3}$ Instituto de Química, Universidade Estadual de Campinas, Brasil.

${ }^{4}$ Departamento de Bioquímica, Instituto de Química, Universidade de São Paulo, Brasil.

${ }^{5}$ Instituto de Física, Universidade de São Paulo, Brasil.

${ }^{6}$ Laboratório Especial de Toxinologia Aplicada, Instituto Butantan, Brasil.
} 
metabolic protein damage, and the 20SPT is the preferential protease responsible for the removal of such proteins (24). Although it is still under discussion, convincing evidence has suggested that oxidized proteins are degraded in a ubiquitinindependent manner $(1,25,45)$. The mechanism by which oxidized proteins enter the 20SPT catalytic channel is not currently understood. Both higher hydrophobicity and loss of secondary structure were investigated and appear to underlie the process $(5,19,39)$. Notably, many components of the ubiquitin-proteasome system are highly sensitive to oxidative stress, implying an inhibition of protein ubiquitylation $(12,30)$ or an uncoupling of the $26 \mathrm{~S}$ complex $(24,52)$. Although the autophagy-lysosome system can play an important role in the prevention of protein aggregation (11), no convincing data have yet revealed its role in the removal of mildly oxidized proteins. Altogether, the knowledge accumulated to date is in agreement with the hypothesis that the 20SPT is able to remove oxidized proteins.

Because the 20SPT lacks regulatory units, it is unclear how its proteolytic activity is regulated. Most likely, gating regulation and substrate interaction with the $20 S$ core particle would underlie the entrance of substrates into the 20SPT. However, the mechanisms that regulate the gating of the free 20SPT pool are still elusive. Furthermore, there has been no systematic study of the conformational state of the free 20SPT pool in any cellular model. The 20SPT is composed of four heptameric rings $\left(\alpha_{7} \beta_{7} \beta_{7} \alpha_{7}\right)$ arranged in a barrel-like configuration, and the $\alpha$-rings control substrate entrance via a dynamic gating process (42). As previously demonstrated, the closed conformation of the 20SPT is maintained by a lattice formed by interactions among the $\mathrm{N}$-terminal tails of the $\alpha$ subunits $(4,22)$. Deletion of the $\alpha 3 \mathrm{~N}$-terminal domain increased the proteasomal peptidase activity and promoted the opening of the 20SPT gate (22), whereas deletion of both the $\alpha 3$ and $\alpha 7 \mathrm{~N}$-terminal domains was necessary to increase the 20SPT proteolytic activity (4). The opening of the eukaryotic 20SPT gate can occur concomitant with its coupling to the $19 \mathrm{~S}$ regulatory particle $(28,49)$ in a process dependent on specific activators (e.g., yeast Blm10) (12) and on the presence of polyubiquitylated substrates (40).

Our hypothesis is that post-translational modifications, including S-glutathiolation, could also control the activity of the free 20SPT pool by regulating the gating process in a manner that is independent of the 195 regulatory particle. The addition of glutathione moieties to proteasomal cysteine (Cys) residues primarily during oxidative challenges has been described in diverse eukaryotic organisms from yeast to plants and mammals $(14-16,35,46)$. This post-translational modification of the 20SPT affects its peptidase activities $(15,46)$ and is reversed by thiol-disulfide oxido-reductases (46). Although S-glutathiolation appears to be a widespread metabolic modification of the 20SPT, neither the identification of the subunits and Cys residues susceptible to S-glutathiolation nor its structural and functional meaning have been elucidated thus far, which is due, in part, to the large number of Cys residues present in this protein complex. Here, we report that 20SPT within cells is under redox regulation by glutathione that affects gate opening and the degradation of oxidized or unstructured proteins. During this process, the 20SPT purified from yeast cells grown to the stationary phase contains 2 out of the 28 analyzed Cys residues modified by a glutathione moiety.

\section{Results}

\section{Proteolysis rates are increased when the 20SPT is S-glutathiolated}

In a previous work, we showed that the 20SPT isolated from yeast cells grown to stationary phase in a glucosecontaining medium was S-glutathiolated (46). This posttranslational modification alters the proteasomal site-specific activities (peptidase activity) $(14,15,46)$. In the present work, we tested the proteolytic ability of 20SPT in different redox forms: the S-glutathiolated form was obtained from cells grown in YPD medium (referred to as $\mathrm{NPT}-\mathrm{SG}$ ), and the reduced form was obtained by treatment of the nPT-SG samples with $20 \mathrm{mM}$ dithiothreitol (DTT) (referred to as PT-SH). We conducted a set of experiments in vitro with the $\mathrm{nPT}-\mathrm{SG}$ as a model of physiologically S-glutathiolated 20SPT, and we also used similar preparations of PT-SH. Both cores were incubated with proteins known to be degraded by the 20SPT, such as oxidized bovine serum albumin (BSA $\mathrm{ox})$, casein, and glutaredoxin 2 (Grx2). Grx2 was selected because it is either degraded by the 20SPT or poly-ubiquitylated inside yeast cells (46). Moreover, the ability of Grx2 to deglutathiolate the 20SPT concomitant with its degradation has been previously demonstrated (46).

All proteins tested were degraded more extensively by the nPT-SG core than by the PT-SH core (Fig. 1A-C). To quantify the peptide fragments generated by both redox forms, the 20SPT preparations were incubated with either $\mathrm{BSA}_{\text {ox }}$ derivatized with dinitrophenylhydrazine $\left(\mathrm{BSA}_{\mathrm{ox}}-\mathrm{DNPH}\right)$ or fluorescein isothiocyanate (FITC)-modified casein (casein-FITC). The peptides derived from $\mathrm{BSA}_{\mathrm{ox}}$-DNPH refer exclusively to the oxidized fragments generated by hydrolysis. The nPT-SG species produced at least twice as many peptides from each substrate (Fig. 2A and B), confirming the proteolysis rate observed by sodium dodecyl sulfate polyacrylamide gel electrophoresis (SDS-PAGE). Control experiments were conducted by incubating proteins known to be resistant to degradation by the 20SPT (Supplementary Fig. S1; Supplementary Data are available online at www.liebertonline.com/ars).

Here, we show that the proteolytic rate for the degradation of these proteins (oxidized, unstructured, and oxidoreductases) increases when acted upon by the S-glutathiolated form of 20SPT (nPT-SG). Because both processes are dependent on the loss of intracellular reductive ability, it is likely that the intracellular pool of oxidized proteins increases concomitantly with proteasomal S-glutathiolation (15). This conclusion is in agreement with the observation that the Sglutathiolated 20SPT more efficiently degraded oxidized proteins (Figs. 1 and 2). We hypothesized here that the redox control of gating is the mechanism that underlies proteolysis by glutathiolated 20SPT. The nPT-SG would prevail on its open-gate conformation and would facilitate the access of protein substrates into the inner catalytic chamber, thereby increasing proteolytic rates.

\section{S-glutathiolation modifies proteasomal gating conformation}

To test the hypothesis raised above, we used transmission electron microscopy (TEM) to investigate whether proteasomal gating is modified by thiolation. A high frequency $(75 \% \pm 5 \%)$ of open structures was observed in the nPT-SG 
FIG. 1. Protein degradation by redox-modified $20 S$ catalytic unit dodecyl sulfate polyacrylamide gel electrophoresis (SDS-PAGE) of (A) oxidized bovine serum albumin $\left(20 \mu \mathrm{g} ; \mathrm{BSA}_{\mathrm{ox}}\right),(\mathbf{B})$ casein $(20 \mu \mathrm{g})$, and (C) glutaredoxin $2(15 \mu \mathrm{g}$; Grx2) after incubation for 120, 15, and $60 \mathrm{~min}$, respectively, with natively S-glutathiolated $20 S$ proteasome (5 $\mathrm{g}$; nPT-SG) and dithiothreitol (DTT)-treated proteasome ( $5 \mu \mathrm{g} ;$ PT-SH). After this incubation, the samples were filtered through YM-100 microfilters (Millipore) to remove the 20SPT, and the filtrates were used to load the gels. To test the integrity of the preparations, $0.0125 \%$ SDScontaining buffer (+SDS) was utilized as a positive control. BSA was oxidized in the presence of $5 \mathrm{mM}$ $\mathrm{H}_{2} \mathrm{O}_{2}$ and $100 \mu \mathrm{M}$ diethylene triamine pentaacetic acid (DTPA) for 30 minutes at room temperature, and the remaining $\mathrm{H}_{2} \mathrm{O}_{2}$ was removed by cycles of filtration and redilution through YM-10 microfilters (Millipore). All incubations dard proteins not incubated with 20SPT; MW, molecular weight standard. of the proteasome (20SPT) preparations. Representative sodium were performed at $37^{\circ} \mathrm{C}$. St, stan-
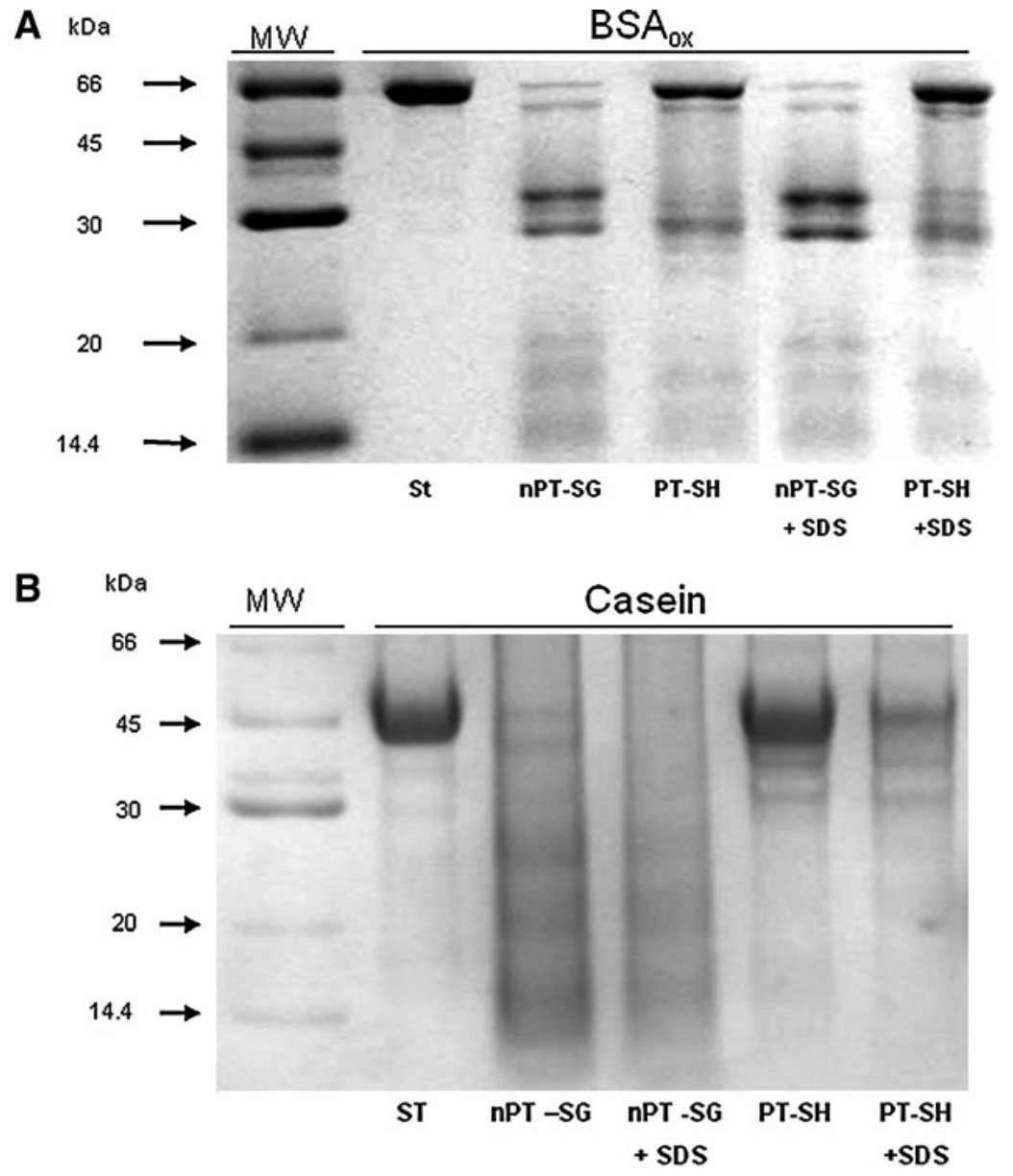

C

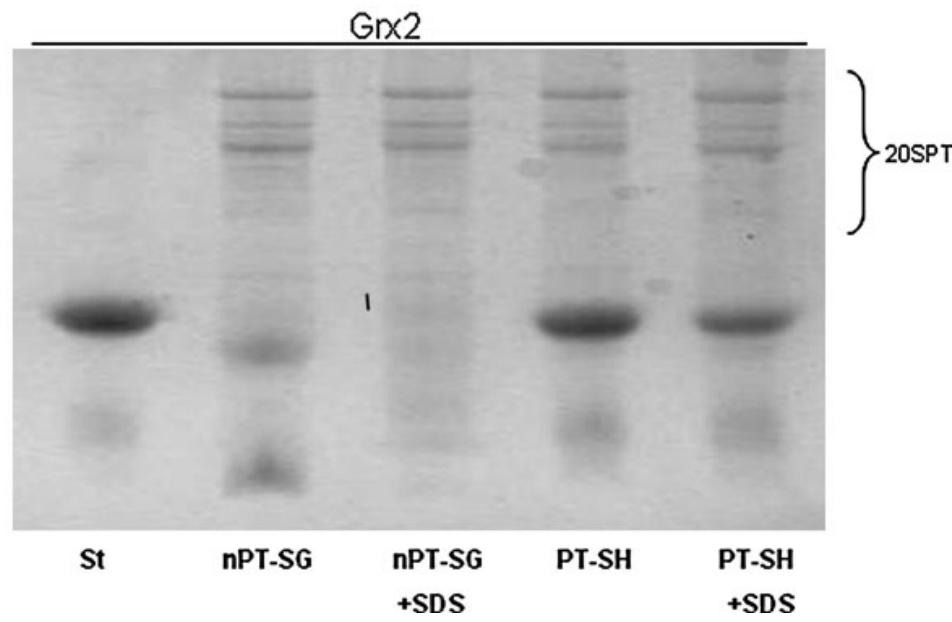

samples (Fig. 3A and Supplementary Fig. S2A), whereas after treatment with DTT $(20 \mathrm{mM})$, the frequency of closed particles predominated and represented approximately $90 \% \pm 10 \%$ of the total complexes (Fig. 3B and Supplementary Fig. S2B). Our results are in agreement with reports in the literature that demonstrate the dynamic state of the proteasomal gate $(36,41,47)$.

As a complementary and independent assessment of the overall dimensions of the proteasome, small-angle X-ray scattering (SAXS) experiments were performed. According there is a significant three-dimensional (3D) structural shift between both redox forms of the 20SPT, which is in agreement with the TEM data already discussed. For both 20SPT redox forms, the SAXS data indicated a cylindrical shape of the particles with an internal hole. The outer diameter decreased from $106 \AA$ (nPT-SG) to $72 \AA$ when identical preparations were treated with DTT (PT-SH). to the results obtained (Table 1 and Supplementary Data), 


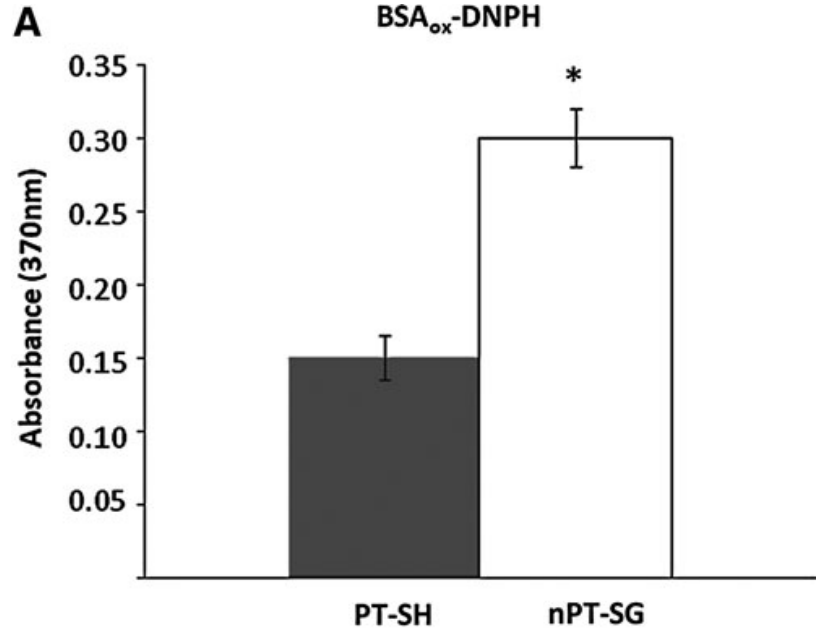

B Casein-FITC

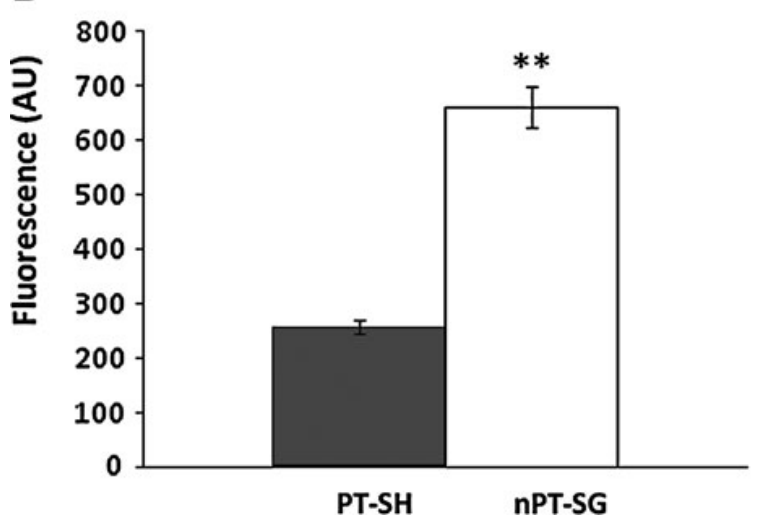

FIG. 2. Quantitative protein degradation by redox-modified 20SPT preparations. (A) $\mathrm{BSA}_{\mathrm{ox}}$ that had reacted with dinitrophenylhydrazine (DNPH), a carbonyl protein reactant (31), was incubated with the 20SPT preparations for $60 \mathrm{~min}$ followed by the addition of $20 \%$ trichloroacetic acid. The supernatant was retained for spectrometric measurement at $370 \mathrm{~nm}$. (B) Fluorescein isothiocyanate (FITC)-modified casein (casein-FITC) was incubated with the proteasomal preparations for $15 \mathrm{~min}$ followed by the addition of $20 \%$ trichloroacetic acid. The supernatant was sampled for fluorometric determination (excitation, $492 \mathrm{~nm}$; emission, $515 \mathrm{~nm}$ ). Both the caseinFITC and DNPH-treated BSA $_{\text {ox }}$ samples were processed using the same conditions in the absence of the proteasome as controls. The results shown represent the mean \pm SD and are expressed as arbitrary units of absorbance (hydrazone adducts) or fluorescence (FITC). ${ }^{*} p<0.000021 ;{ }^{* *} p<0.000003$.

Remarkably, the inner diameter was almost completely closed in the PT-SH samples (Table 1), confirming the data visualized by TEM (Fig. 3B). The shift from the open to the closed conformation was previously demonstrated to be accompanied by slight changes in the outer diameter and length (37). The proteasomal lengths and diameters obtained by SAXS are in agreement with data in the literature (Supplementary Table S1). However, the inner diameter measured in the present work ( $80 \AA$; nPT-SG) is higher than that determined by the few crystallographic studies that have been performed or evaluated by TEM (Supplementary Table S1). A comparative revision of the 20SPT dimensions is presented in the Supplementary Data section (Supplementary Table S1).

\section{Only Cys residues of the $\alpha$ subunits were observed to be modified by glutathione}

Because S-glutathiolation strongly affects both the ability of the 20SPT to degrade oxidized/unstructured proteins and its gate conformation, it was necessary to identify the Cys residues that were post-translationally modified in both nPT-SG and PT-SH. Therefore, we initially isolated and characterized the 20SPT subunits by two-dimensional electrophoresis (2DE) coupled to MALDI-TOF fingerprinting (Supplementary Fig. S3, Supplementary Table S2). Next, the Cys-containing 20SPT subunits were digested with trypsin and prepared for liquid chromatography-tandem mass spectrometry (LC-MS/ MS) analysis. Two S-glutathiolated Cys residues (Cys76 and Cys221) in the $\alpha 5$ subunit were identified in the NPT-SG by tandem mass spectrometry analysis. To better characterize all of the Cys residues that are potentially prone to Sglutathiolation, the purified nPT-SG preparations were treated in vitro with $10 \mathrm{mM}$ glutathione (GSH). In this series of experiments, we identified two other subunits ( $\alpha 6$ and $\alpha 7$ ) in addition to the $\alpha 5$ subunit and a total of seven GSH-modified Cys residues (+305.1 Da) among the 35 Cys residues present in mature yeast 20SPT (Table 2; Fig. 4A). The samples that were reduced by DTT (PT-SH) were subjected to LC-MS/MS analysis as a control (Fig. 4B). The latter preparations did not present any glutathione-modified Cys residues. We cannot discard the possibility that the $\beta$ subunits were also modified by S-glutathiolation because we did not succeed in identifying seven of the Cys-containing fragments in the $\beta$ subunits among the 20 predicted. Nevertheless, all of the Cyscontaining fragments in the $\alpha$ subunits were identified (Supplementary Table S3). This 2-DE/mass spectrometry analysis was employed at least five times with reproducible results.

As expected from the heterogeneous proteasome population (nPT-SG preparations), the Cys residues were observed in different oxidative states as follows: reduced (-SH, which were modified by iodoacetamide), modified via S-glutathiolation or hyper-oxidized to sulfinic acid $\left(\mathrm{Cys}-\mathrm{SO}_{2} \mathrm{H}\right)$ (Supplementary Table S3). Remarkably, Cys- $\mathrm{SO}_{2} \mathrm{H}$ was detected in all of the Cys residues (except Cys66 from the $\alpha 6$ subunit) prone to S-glutathiolation (Supplementary Table S3), indicating that the formation of Cys sulfenic acid (Cys-SOH) is a common intermediate in both processes (hyper-oxidation and Sglutathiolation). In fact, we have previously shown that 20SPT S-glutathiolation occurs via a Cys-SOH intermediate (15). It is likely that the thiolate form of the Cys-sulfur atom $\left(\mathrm{RS}^{-}\right)$would be the most prone to oxidation (53) to sulfenic acid because this anion is a stronger nucleophile than its protonated counterpart. A low $\mathrm{pK}_{\mathrm{a}}$ of the thiol group and solvent accessibility are important factors for increasing the thiol protein reactivity.

Given the location of the S-glutathiolated Cys residues in the 3D structure of the 20SPT, Cys221 from the $\alpha 5$ subunit is the only modified residue whose thiol group is highly accessible to the solvent (Fig. 5A; Supplementary Fig. S 4A and B). Furthermore, the environment around Cys221 allows for the docking of a GSH molecule (Fig. 4B and Supplementary Fig. S4C) that fits very well into the proteasomal bulk where GSH-charged groups (both $\mathrm{N}$ - and C-terminal carboxyl groups and the N-terminal amine) can establish important 
FIG. 3. 20S proteasomal gating control is dependent on the cysteine (Cys) redox state. (A) Representative images obtained by transmission electron microscopy of nPT-SG in the open conformation. (B) nPT-SG samples analyzed immediately after treatment with $20 \mathrm{mM}$ DTT for $30 \mathrm{~min}$ followed by a washing procedure to eliminate DTT, as described in the Materials and Methods section. The squares were amplified as shown on the right. The combined conformations (open and closed) were observed in both 20SPT preparations (nPT-SG and PT-SH), as shown in Supplementary Fig. S1A and B (Supplementary Data).
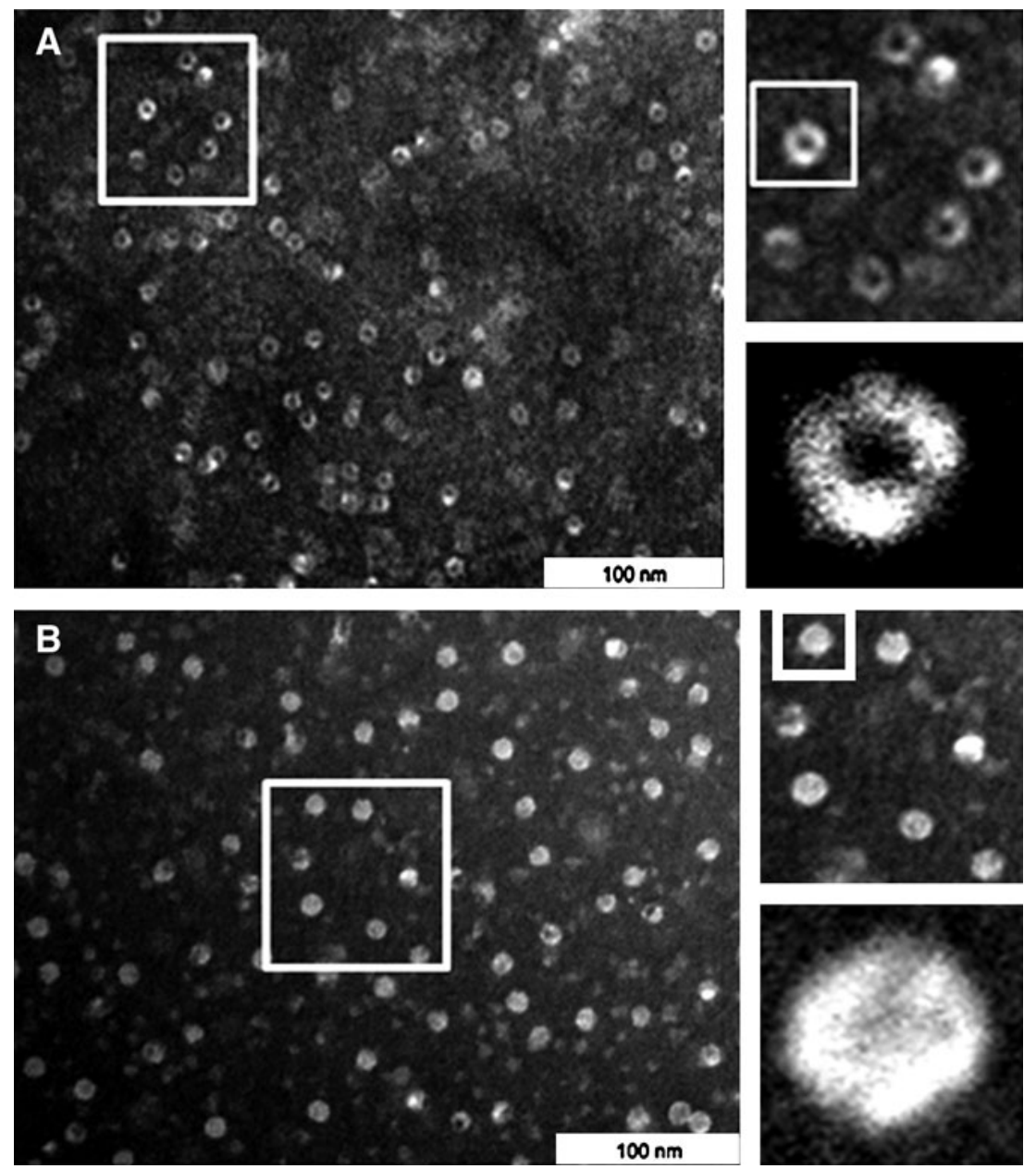

saline interactions with charged groups of the side chains of proteasomal residues (E197, Q225, K229, and K235; Fig. 5B) In the case of Cys76, the other natively S-glutathiolated residue, no docking was obtained, likely because the thiol group is not located on the protein surface. It is probable that the Sglutathiolation of Cys76 is dependent on structural changes that allow the reaction of GSH with the thiol group to occur. Remarkably, Cys76 is fully conserved among the 20SPT $\alpha 5$ subunits from yeast, plants and mammals (Supplementary Fig. S5).

\section{S-glutathiolation promotes the allosteric modification of site-specific proteasomal activity}

The increased degradation of proteins by nPT-SG may appear contradictory to our previous finding that Sglutathiolation of the 20SPT partially inhibited the chymotrypsinlike (ChT-L) and post-acidic proteasomal activities, which were measured using fluorogenic peptides $(15,46)$ (see Supplementary Table S4). Our hypothesis is that, in addition to affecting gating, S-glutathiolation also promotes an allosteric modification of the proteasomal catalytic sites. In fact, according to SAXS analysis (Table 1), the 20SPT conformation experienced changes not only in its outer and inner diameters but also in its longitudinal length depending on its redox state. To address this hypothesis, we performed experiments with the mutated 20SPT lacking the $\mathrm{N}$-terminal sequences of its $\alpha 3$ and $\alpha 7$ subunits. As reported (3), this mutated form of the 20SPT is permanently in its open conformation and is highly active compared with the wild-type 20SPT. These results were reproduced in our lab (not shown). We then performed a series of experiments with purified preparations of the mutated $(\Delta \mathrm{N} \alpha 3 \alpha 7)$ 20SPT to evaluate whether thiol reactants would modify its activity, as had been observed in the case of the wild-type 20SPT (15). Either dimedone (sulfenic acid reactant), 7-chloro-4-nitrobenzo-2-oxa-1,3-diazole (NBD; sulfhydryl and sulfenic acid reactant), or oxidized glutathione (GSSG; sulfhydryl reactant) promoted the inhibition of the ChT-L $\Delta \mathrm{N} \alpha 3 \alpha 7$ 20SPT activity (Table 3), which could not be explained by changes in the diameter of the 20SPT gate but could be related to changes in the length of this core particle (Supplementary Table S1). In the context of this work, emphasis should be placed on the conditions that initially resulted in the 20SPT-Cys-SOH form that is equivalent to that formed by the oxidation of the $\Delta \mathrm{N} \alpha 3 \alpha 7$ 20SPT with $5 \mathrm{mM} \mathrm{H}_{2} \mathrm{O}_{2}$ in the presence of diethylene triamine pentaacetic acid (DTPA; to avoid unspecific oxidation by contaminant metals) followed by incubation at increasing GSH concentrations. The ChT-L $\triangle \mathrm{N} \alpha 3 \alpha 720 \mathrm{SPT}$ activity was inhibited in a dose-dependent manner by GSH (Table 3). Next, we performed SAXS analyses of the $\Delta \mathrm{N} \alpha 3 \alpha 7$ 20SPT preparations to evaluate whether treatment with $1 \mathrm{mM}$ GSH modifies the proteasome conformation. No alteration in either the external or internal diameters was detected by comparing samples incubated with GSH or DTT, 
Table 1. Proteasomal Surface Dimensions Obtained From Small-Angle X-Ray Scattering Measurements

\begin{tabular}{lcc}
\hline Parameters & $n P T-S G$ & $P T-S H$ \\
\hline Outer diameter $(\AA)$ & $106 \pm 4$ & $72 \pm 4$ \\
Pore diameter $(\AA)$ & $78 \pm 4$ & 0 to 10 \\
$\sigma(\AA)$ & 5 & 5 \\
Length L $(\AA)$ & $188 \pm 20$ & $210 \pm 40$ \\
$\chi^{2}$ & 2.5 & 3.5 \\
\hline
\end{tabular}

although the maximum length of the $\Delta \mathrm{N} \alpha 3 \alpha 7$ 20SPT was $210 \mathrm{~nm}$ in the sample incubated with GSH and $230 \mathrm{~nm}$ in the absence of GSH (Supplementary Table S1). These results indicated that partial inhibition of the ChT-L peptidase activity is most likely related to an allosteric phenomenon triggered by Sglutathiolation, which involves changes in the length of 20SPT that are distinct from the gating.

\section{Discussion}

Collectively, the present results demonstrate that the S-glutathiolated 20SPT exhibits higher degradation rates of oxidized and partially unstructured proteins, most likely because of its gate opening. Based on our results, we hypothesize that the opening of the catalytic chamber, which is triggered by the thiolation of the proteasomal $\alpha 5$ subunit, would facilitate the ability of cells to cope with misfolded proteins without requiring ATP. It is likely that the 20SPT plays a prominent role in the response to oxidative stress because various reports have demonstrated that ATP has no stimulating effect on the degradation of oxidized proteins in cell lysates (44). Accordingly, Davies and colleagues (45) concluded that oxidized proteins are degraded by the $20 \mathrm{~S}$ proteasome in a manner independent of both the 195 regulator and, consequently, ubiquitin by demonstrating that the disruption of the ubiquitylation system did not impair the degradation of oxidized proteins.

According to some reports $(10,22,26)$, the so-called latent form of the free 20SPT is closed. However, in reports de- scribing the gating of the 20SPT (yeast and human 20SPT), a mixed pool of open and closed conformations is observed (2, $21,29,36-38)$. Notably, in the protocols described in the literature, DTT is present in the purification procedure at low concentrations $(0.1-2 \mathrm{mM})$, which would not remove the glutathionyl moiety from the 20SPT. Among the DTT concentrations used in our experiments (not shown), a minimum of $20 \mathrm{mM}$ was necessary for alteration of the gating (Fig. 3B, Table 1) to occur concomitantly with the disappearance of the glutathione-modified Cys residues (Fig 4B). As previously demonstrated, the reduction of the 20SPT inside cells may be accomplished by oxidoreductases (46).

Glutathiolation is emerging as a relevant post-translational modification that is involved in redox regulation. In several proteins under redox control by glutathiolation, only one or very few Cys residues are involved (34). In the case of the redox process mediated by peroxides, it is also expected that few Cys residues exhibit high reactivity toward this oxidant (53). Once reactive protein thiols are oxidized to sulfenic acid, they can more easily undergo further reactions, such as hyperoxidation to sulfinic or sulfonic acids and S-glutathiolation and the formation of intra- and interprotein disulfides or sulfenylamide derivatives (53). Notably, depending on the thiol location in the protein ( $\mathrm{pK}_{\mathrm{a}}$; solvent accessibility) and the cellular compartment of a given protein, the peroxidesensitive thiol targets may be directly oxidized without disruption to the overall redox homeostasis. Therefore, the finding that only 2 of the 28 Cys residues detected in the 20SPT were S-glutathiolated indicates that this post-translational modification may represent a redox signaling process. In fact, it appears that there is a microenvironment appropriate for GSH binding in the vicinity of Cys221 from the $\alpha 5$ subunit (Fig. 5B). The other glutathiolated Cys residue (Cys76) is fully conserved among all of the $\alpha 5$ subunits analyzed (Supplementary Fig. S5), suggesting a prominent role for this amino acid. Additionally, Cys42 from the $\alpha 7$ subunit (S-glutathiolated in vitro) is highly conserved (Supplementary Fig. S5).

Interestingly, the activity and gating of the vascular $\mathrm{K}_{\mathrm{ATP}}$ channel are also modulated by the S-glutathiolation of a single

Table 2. 20S Proteasome S-Glutathiolated Cysteine Residues

\begin{tabular}{|c|c|c|c|c|c|}
\hline $\begin{array}{l}\text { Subunits - } \\
\text { position }\end{array}$ & Cys-SG & Peptide sequence & $\begin{array}{l}\text { Monoisotopic ion } \\
{[M+H]+G S H}\end{array}$ & $\begin{array}{c}\mathrm{m} / \mathrm{z} \text { ratio } \\
\text { detected }\end{array}$ & $\begin{array}{l}\text { Error } \\
(\text { ppm })\end{array}$ \\
\hline \multicolumn{6}{|l|}{ PT-SG } \\
\hline \multicolumn{6}{|l|}{$\alpha 5$} \\
\hline $73-86$ & Cys76 & R.HIGCAMSGLTADAR.S & 1707.728 & 569.914 & 17.5 \\
\hline $94-122$ & Cys117 & R.TAAVTHNLYYDEDINVESLTQSVCDLALR.F & 3558.638 & 890.415 & 11.2 \\
\hline $212-224$ & Cys221 & K.LDENNAQLSCITK.Q & 1753.778 & 585.264 & 11.4 \\
\hline \multicolumn{6}{|l|}{$\alpha 6$} \\
\hline $66-82$ & Cys66 & K.CDEHMGLSLAGLAPDAR.V & 2060.888 & 687.634 & 9.7 \\
\hline \multicolumn{6}{|c|}{ 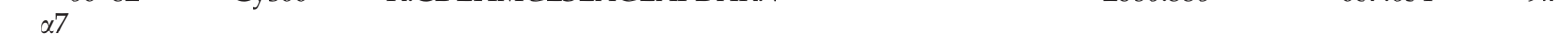 } \\
\hline $42-52$ & Cys42 & K.CNDGVVFAVEK.L & 1485.638 & 743.322 & 6.7 \\
\hline $73-86$ & Cys76 & R.HIGCVYSGLIPDGR.H & 1791.818 & 597.944 & 11.1 \\
\hline \multirow{2}{*}{\multicolumn{6}{|c|}{$\begin{array}{c}\text { nPT-SG } \\
\alpha 5\end{array}$}} \\
\hline & & & & & \\
\hline $73-86$ & Cys76 & R.HIGCAMSGLTADAR.S & 1707.81 & 569.94 & 52.7 \\
\hline $206-224$ & Cys221 & K.QVMEEKLDENNAQLSCITK.Q & 2513.10 & 1257.62 & 35.8 \\
\hline
\end{tabular}

The 20SPT preparations were treated with $10 \mathrm{mM}$ GSH (PT-SG) or were natively S-glutathiolated (nPT-SG). All subunits containing Cys residues identified on the two-dimensional electrophoresis gel coupled to MS-fingerprinting were digested with trypsin followed by an LC-Q-ToF-MS analysis.

GSH, glutathione; PT-SG, in vitro S-glutathiolated 20 s proteasome. 
A

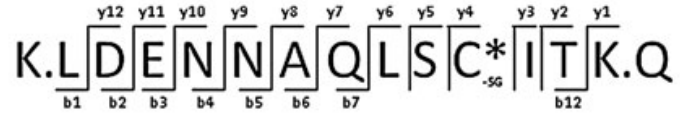

FIG. 4. Representative spectra of the thiol-modified proteasomal Cys residues obtained by LC-ESI-MS/ MS. LC-ESI-Q-TOF (Waters Synapt HDMS) analysis of the tryptic peptide from the 20SPT $\alpha 5$ subunit containing Cys221. (A) MS/MS spectrum of a triply charged ion $[\mathrm{M}+3 \mathrm{H}]^{3+}$ with an $\mathrm{m} / z$ ratio of 585.28 containing a glutathione moiety $(+305.1)$ attached to the Cys residue. The monoisotopic mass of the deprotonated peptide (LDENNAQLSCITK) is equal to 1752.82 Da. (B) MS/MS spectrum corresponding to the same peptide shown in A from DTT-treated samples. The doubly charged ion $[\mathrm{M}+2 \mathrm{H}]^{2+}$ possesses an $\mathrm{m} / \mathrm{z}$ ratio of 724.84 and a monoisotopic mass of 1447.67 Da, indicating the reduced form of the Cys residue. The respective fragmentation series is shown above each spectrum.

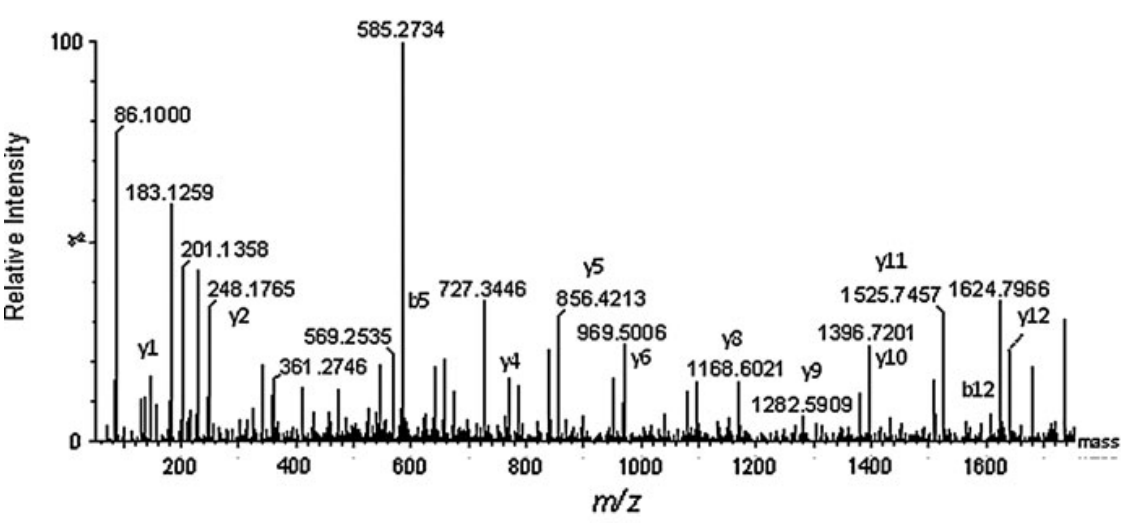

B
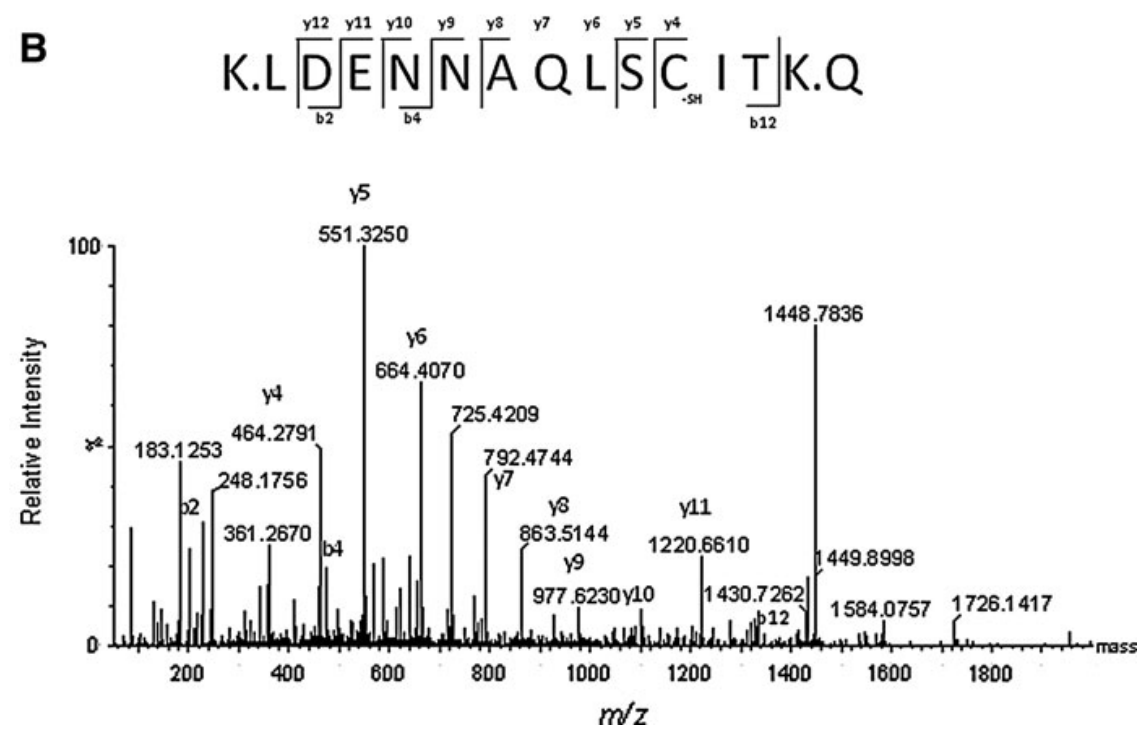

Cys residue (Cys176 residue) within the Kir6.1 subunit (54). In this case, glutathiolation stabilizes the gate in its closed conformation.

We report for the first time a proteasomal post-translational modification that modifies the gate opening of the 20SPT, thereby regulating the ability of the 20SPT to degrade target proteins. Our results suggest a need to reevaluate the fundamental aspects of the currently favored models of the regulation of proteasomal gating based on the destabilization of the $\mathrm{N}$-termini of the $\alpha 3$ and $\alpha 7$ subunits $(3,4,22)$. The latter model summarizes the important dynamics of the $\alpha$ subunits that contribute to gating control upon assembly of the $26 \mathrm{~S}$ proteasome, but it does not explain the mechanism that triggers such dynamics of the free 20SPT pool. The mechanism described here was shown to be closely associated with the intracellular redox status because cells growing in a less oxidative environment possess proteasomes with low levels of Sglutathiolation (46), which corresponds to a population of core particles in the reduced state and with closed gates. The present model agrees with the idea that during the oxidant- mediated damage of proteins, degradation may be facilitated inside cells to avoid energy consumption. The mechanism by which oxidized proteins interact with the 20SPT particle for degradation is unknown. A loss of secondary structure and the consequent increase in the exposure of hydrophobic patches has been claimed as the phenomena underlying this process $(5,19,39,44)$. We propose that the redox modification of the 20SPT under oxidative conditions would facilitate the proteolytic processing of unstructured proteins, including oxidized proteins. The critical function of the proteolytic systems in maintaining a continuous turnover of all intracellular proteins, including those that are still functional, is necessary to prevent the accumulation of intracellular damage and its associated consequences. This function represents an important aspect of protein quality control. Limiting the half-life of the cellular proteins reduces their chances of damage and avoids their risk for aggregation.

The proteasome plays a very important role in the clearance of the majority of proteins implicated in neurodegenerative processes (43). Because intracellular inclusions that are 
A

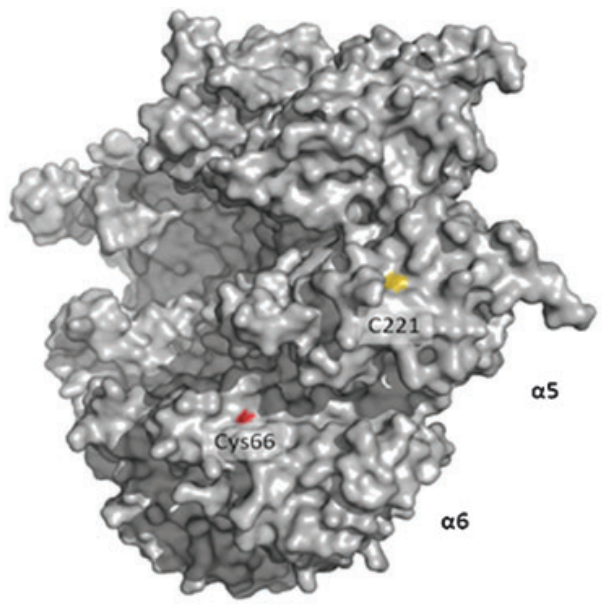

B

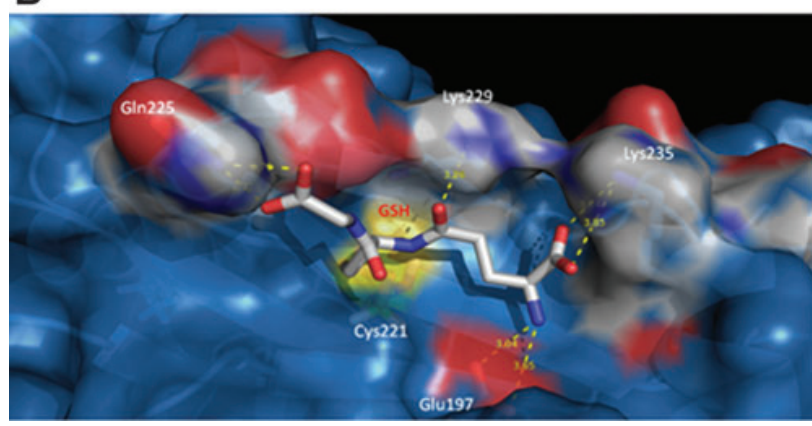

FIG. 5. Location of Cys221 in the $\alpha 5$ subunit in the 3D proteasomal structure. (A) Surface structure of the $\alpha$-ring highlighting the solvent-accessible sulfur atom (yellow) of Cys221 from the $\alpha 5$ subunit and the surface oxygen (red) from the Cys66 residue of the $\alpha 6$ subunit. (B) Modeling of glutathione docking onto Cys221 of the $\alpha 5$ subunit was performed by Gold 4.1-Protein-Ligand Docking (Cambridge Crystallographic Data Centre). The proteasome is shown by a surface representation, and the glutathione is represented by sticks. The proteasomal residues interacting with the GSH-charged groups are highlighted in white in the surface representation and are depicted as blue sticks underneath. The sulfur atoms are depicted in yellow. The distances $(\AA)$ between the GSH-charged groups and the lateral chains of the proteasomal amino acids are shown. The graphical images were generated using Pymol software (DeLano Scientific).

derived from protein aggregation and associated with neurodegenerative diseases are rich in ubiquitylated proteins, it is assumed that ubiquitin-proteasome system (UPS) impairment is associated with the etiology of these pathologies $(6,11$, 43). Thus, UPS has been investigated extensively in many neurodegenerative diseases. In fact, there are data suggesting that the mono-ubiquitylation of protein aggregates is an important signal to remove aggregates via autophagy $(18,27)$. However, processes favoring the ubiquitin-independent removal of oxidized or unstructured proteins that are prone to aggregation appear to also be an immediate and important mechanism to avoid neurotoxicity. In fact, the 20SPT directly interacts with the prion protein (8), soluble oligomers, and insoluble filaments of $\alpha$-synuclein or amyloid-A $\beta$ peptide aggregates $(32,55)$. Additionally, monomeric $\alpha$-synuclein
Table 3. ChT-L Activity of Purified Preparations OF THE $\Delta \mathrm{N} \alpha 3 \alpha 7$ 20SPT AfTER TREATMENT With SulfHydryl Reactants

\begin{tabular}{ll}
\hline Control & $100 \pm 5$ \\
Dimedone $(\mathrm{mM})$ & \\
10 & $85 \pm 4.5$ \\
20 & $60 \pm 5$ \\
NBD $(\mu \mathrm{M})$ & \\
50 & $65 \pm 6$ \\
100 & $49 \pm 5$ \\
GSSG $(\mathrm{mM})$ & \\
5 & $80 \pm 6.5$ \\
10 & $60 \pm 4$ \\
GSH $(\mathrm{mM})^{\mathrm{a}}$ & \\
1 & $91 \pm 5$ \\
2.5 & $79 \pm 5.5$ \\
5 & $40 \pm 4$ \\
\hline
\end{tabular}

The $\Delta \mathrm{N} \alpha 3 \alpha 7$ 20SPT was purified from cells grown to stationary phase in YPD medium. The assays were performed with $10 \mu \mathrm{g}$ 20SPT pre-incubated with the reactants for $10 \mathrm{~min}$ followed by the addition of $65 \mu \mathrm{M}$ succinyl-Leu-Leu-Val-Tyr-MCA. The results are expressed as a percentage of the control samples, which are set at 100 .

${ }^{\text {a The purified }} \Delta \mathrm{N} \alpha 3 \alpha 720 \mathrm{SPT}$ was oxidized with $5 \mathrm{mM} \mathrm{H}_{2} \mathrm{O}_{2}$ in the presence of $100 \mu \mathrm{M}$ DTPA. After $\mathrm{H}_{2} \mathrm{O}_{2}$ washing, the oxidized samples were reacted with GSH at increasing concentrations, as shown. In all experiments, the reactants were removed by cycles of filtration and re-dilution prior to the next step.

NBD， 7-chloro-4-nitrobenzo-2-oxa-1,3-diazole; GSSG, oxidized glutathione.

is easily degraded by the $20 \mathrm{~S}$ proteasome in a ubiquitinindependent manner $(33,50)$. Therefore, the redox regulation process described here represents an important aspect of protein quality control.

Proteasomal S-glutathiolation is a reversible and protective mechanism that allows for the removal of unstructured and oxidatively damaged proteins. Because either hyperoxidation or complexation to metals of proteasomal Cys residues would preclude S-glutathiolation and, thus, gate opening, one would predict deleterious consequences from the accumulation of proteins prone to aggregation in a highly oxidative environment. Accordingly, irreversible proteasome oxidation (9) and metal accumulation (17) are described in the brain of Alzheimer's patients together to proteasome impairment.

According to the present results, the increased proteolysis rates due to proteasomal S-glutathiolation are primarily dependent on the 20SPT gate opening despite the partial inhibition of site-specific activity. According to another line of investigation in our laboratory, the peptide fragments originating from degradation of identical proteins differ in their cleavage sites depending on the proteasomal redox status, including the generation of immune-competent fragments (unpublished). Similar to the case of the immuno- and thymoproteasomes in their specific contexts, the redox modification of the standard proteasome might play an important role in the regulation of cell redox signaling.

\section{Materials and Methods}

\section{Materials}

Bovine serum albumin, casein, casein-FITC, cytochrome c, DTPA, dimedone, DTT, GSH, and NBD were purchased from Sigma-Aldrich (St. Louis, MO). The fluorogenic substrate succinyl-Leu-Leu-Val-Tyr-MCA was purchased from 
Calbiochem (Merck, Darmstadt, Germany). The molecular weight markers for SDS-PAGE and ATP were purchased from GE Biosciences (GE Healthcare Europe, Glattbrugg, Switzerland). The Bradford protein assay reagent was purchased from Bio-Rad (Hercules, CA).

\section{Yeast strain and growth}

The Saccharomyces cerevisiae RJD1144/JD 122 (MATa his3(200 leu2-3,112, lys2-801 trp1(63 ura3-52 PRE1 ${ }^{\mathrm{FH}}$ ::Ylplac211 URA3) strain, derived from the JD47-13C strain, was kindly donated by Dr. Raymond Deshaies (Division of Biology, Caltech, Pasadena, CA). The RJD1144 strain contained the 20S proteasome PRE1 gene modified with the FLAG peptide and a poly-histidine tail sequence (51). The cells were cultured in YPD medium containing $4 \%$ glucose (referred to as YPD) at $30^{\circ} \mathrm{C}$ with reciprocal shaking and harvested after $60 \mathrm{~h}$ of incubation. The SUB556 strain, derived from SUB62, was kindly donated by Dr. Michael $\mathrm{H}$. Glickman (Department of Biology, Technion-Israel Institute of Technology, Haifa, Israel). The 20SPT from the SUB556 strain contains $\mathrm{N}$-terminal deletions in both the $\alpha 3$ and $\alpha 7$ subunits (3).

\section{Extraction and purification of the 20S proteasome}

The 20SPT from the RJD1144 strain was purified by nickel affinity chromatography with a continuous gradient of imidazole using high performance liquid chromatography (Akta Purifier, GE Healthcare). Neither DTT nor any other thiol reductant was utilized in any step of the entire purification procedure, which differs from nearly all other protocols described in the literature to date. The final preparations were passed through a PD10-desalting column according to the manufacturer's protocol (GE Biosciences). The untagged 20SPT from the RJD1144 strain and the $\Delta \mathrm{N} \alpha 3 \alpha 7$ 20SPT from the SUB556 strain were purified by conventional chromatography (14). The untagged 20SPT was utilized as a control relative to the tagged sample.

\section{Reduction and S-glutathiolation of the 20 S proteasome}

When specified, the preparations of the purified 20SPT (1 mg) extracted from cells grown in YPD-rich medium were incubated overnight at $4^{\circ} \mathrm{C}$ with $300 \mathrm{mM}$ DTT. Following this incubation, the proteasome preparations were passed through a PD10-desalting column according to the manufacturer's protocol (GE Biosciences) to remove the DTT, imidazole, and $\mathrm{NaCl}$. The eluted protein fractions were tested for the presence of DTT via the reaction with $75 \mu \mathrm{M} 5,5^{\prime}$-dithiobis(2-nitrobenzoic acid)(DTNB; also known as Ellman's reagent). Only protein fractions in which no DTT was detected were selected for further procedures. These preparations are herein referred to as the DTT-reduced 20SPT (PT-SH). To obtain the in vitro S-glutathiolated protein (PT-SG), aliquots of the native 20SPT (nPT-SG) were incubated at room temperature for $20 \mathrm{~min}$ in the presence of $10 \mathrm{mM} \mathrm{GSH}$ in $50 \mathrm{mM}$ Tris buffer, $\mathrm{pH}$ 7.5. Following the incubation, GSH was removed by cycles of centrifugation and rediluted through YM-100 microfilters. After the determination of the protein concentration, aliquots of the PT-SH and PT-SG preparations were selected for additional assays.

\section{PAGE analysis of proteins}

SDS-PAGE was performed as previously described (7). After incubation at the indicated conditions (Fig. 1), the protein preparations were mixed with gel loading buffer $(100 \mathrm{mM}$ Tris-HCl [pH 6.8], $10 \%$ glycerol, $2 \%$ SDS, and $0.02 \%$ bromophenol blue) and applied to the gel.

\section{Liquid chromatography-quadrupole-time of flight mass- spectrometry identification of S-glutathiolated cysteinyl residues}

The trypsin-digested products were analyzed by LC-MS/ MS in a Synapt HDMS instrument (Waters, Millford, MA) coupled online to a nanoAcquity ultra performance liquid chromatography system. The digests were loaded and desalted using a $180-\mu \mathrm{m} \times 20-\mathrm{mm}$ Waters Symmetry C18 column. After the desalting step, the samples were directed to a $100-\mu \mathrm{m} \times 100-\mathrm{mm}$ Waters BEH130 C18 column at a flow rate of $1.0 \mu \mathrm{L} / \mathrm{min}$. Mobile phases A and B consisted of $0.1 \%$ for$\mathrm{mic}$ acid/water and $0.1 \%$ formic acid/acetonitrile, respectively. The gradient conditions used were as follows: at $0 \mathrm{~min}$ the concentration of $\mathrm{B}$ started at $3 \%$ and increased linearly to $30 \%$ in $20 \mathrm{~min}$; the concentration of B then increased up to $70 \%$ in $40 \mathrm{~min}$ and remained at this level until $50 \mathrm{~min}$; finally, in the next minute, the concentration decreased to $3 \%$. The typical operating conditions of the mass spectrometer in the data-dependent analysis experiments were as follows: capillary voltage, $3.0 \mathrm{kV}$; cone voltage, $40 \mathrm{~V}$; power supply temperature, $100^{\circ} \mathrm{C}$; and collision energy, 6 and $4 \mathrm{eV}$ in the Trap and Transfer in the MS mode. The collision energy was selected as a function of the precursor charge and the $\mathrm{m} / \mathrm{z}$ value. The instrument was externally calibrated using phosphoric acid oligomers over an $\mathrm{m} / \mathrm{z}$ range of 100 to 3000 .

\section{Negative staining of the 20SPT particles by TEM}

Drops $(12 \mu \mathrm{L})$ of the purified 20SPT preparations $(0.5 \mu \mathrm{g} /$ $\mu \mathrm{L}$ ) were applied onto carbon-coated 400 mesh copper grids. After $1 \mathrm{~min}$ the excess liquid was blotted with a tissue paper, leaving a small amount of residual fluid. Negative staining was performed with $12 \mu \mathrm{L}$ of $2 \%$ phosphotungstic acid, $\mathrm{pH}$ 7.2 , for $10 \mathrm{~s}$ and then the samples were blotted dry. The grids were examined in an LEO 906E transmission electron microscope (Zeiss, Germany) at an acceleration voltage of $100 \mathrm{kV}$. The images were acquired using a CCD camera MegaView III in conjunction with the iTEM - Universal TEM Imaging Platform software (Olympus Soft Imaging Solutions $\mathrm{GmbH}$, Germany). Our protocol did not consider the side-on view of the 20SPT; thus, we did not utilize a vacuum to prepare the grids (Dr. Edward Morris, personal communication). A quantitative analysis was manually performed by counting the frequency of open or closed structures from identical proteasomal populations. The possibility of saturated images was excluded because the microscope was operated under similar light conditions and also because many of the images obtained showed both closed and open conformations together, as shown in Supplementary Fig. S2A and B.

\section{Small-angle $X$-ray scattering}

The SAXS experiments were performed using Bruker Nanostar ${ }^{\mathrm{TM}}$ equipment (Karlsruhe, Germany). The data were collected at room temperature using samples of the 
nPT-SG, PT-SH (both at $2.2 \mathrm{mg} / \mathrm{mL}$ ), and $\Delta \mathrm{N} \alpha 3 \alpha 720 \mathrm{SPT}$ $(0.7-1 \mathrm{mg} / \mathrm{mL})$ resuspended in $20 \mathrm{mM}$ Tris $/ \mathrm{HCl}, \mathrm{pH} 7.5$, buffer. The measurements were obtained using samples placed in reusable quartz capillaries glued on stainless steel cases, which allowed for the measurement of both the samples and the background under the same conditions. Several 1-h frames were taken to enable the monitoring of the sample stability. The data treatment, background subtraction and frame average were performed using the SUPERSAXS program package (Oliveira and Pedersen, unpublished). The complete methodology and data analysis are described in Supplementary Data.

\section{GRID methodology}

The GRID methodology (20) was utilized for the docking analysis of the glutathione (GS-) that was covalently attached to Cys residues of the proteasome. The 3D structure of the yeast 20SPT was obtained from the PDB file 1RYP (resolution: $2.4 \AA$ ) (23). The side chains of the glutathione and proteasomal residues were placed in their lowest energy positions, and their energies were minimized using the Tripos force field with Pullman charges and conjugate gradient minimization, keeping all other protein residues rigid. The modeling of glutathione docking was performed on Gold-Protein-Ligand Docking (Cambridge Crystallographic Data Center), and all graphical images were generated using Pymol software (DeLano Scientific).

\section{Acknowledgments}

We thank Dr. Kelvin J.A. Davies and Dr. Ohara Augusto for their critical reading of the present work. We are grateful to Dr. Alberto Malvezzi and Dr. Sylvia Carneiro who helped with the structural modeling and the electron microscopy studies, respectively. We thank Adrian Hand for technical support. This work was supported by Fundação de Amparo a Pesquisa do Estado de São Paulo (FAPESP, Grants 08/06731-9 and 07/58147-6) and Instituto Nacional de Ciência, Tecnologia e Inovação de Processos Redox em Biomedicina (Redoxome, CNPq, FAPESP, CAPES).

\section{Author Disclosure Statement}

The authors declare no conflict of interest.

\section{References}

1. Asher G, Reuven N, and Shaul Y. 20S proteasomes and protein degradation "by default". Bioessays 28: 844-849, 2006.

2. Babbitt SE, Kiss A, Deffenbaugh AE, Chang YH, Bailly E, Erdjument-Bromage $\mathrm{H}$, Tempst P, Buranda T, Sklar LA, Baumler J, Gogol E, and Skowyra D. ATP hydrolysisdependent disassembly of the $26 \mathrm{~S}$ proteasome is part of the catalytic cycle. Cell 121: 553-565, 2005.

3. Bajorek M, Finley D, and Glickman MH. Proteasome disassembly and downregulation is correlated with viability during stationary phase. Curr Biol 13: 1140-1144, 2003.

4. Bajorek M, and Glickman MH. Keepers at the final gates: regulatory complexes and gating of the proteasome channel. Cell Mol Life Sci 61: 1579-1588, 2004.

5. Baugh JM, Viktorova EG, and Pilipenko EV. Proteasomes can degrade a significant proportion of cellular proteins independent of ubiquitination. J Mol Biol 386: 814-827, 2009.
6. Bingol B, and Sheng M. Deconstruction for reconstruction: the role of proteolysis in neural plasticity and disease. Neuron 69: 22-32, 2011.

7. Bollag DM, and Edelstein SJ. Protein Methods. New York: Wiley-Liss, 1991.

8. Cecarini V, Bonfili L, Cuccioloni M, Mozzicafreddo M, Angeletti M, and Eleuteri AM. The relationship between the 20S proteasomes and prion-mediated neurodegenerations: potential therapeutic opportunities. Apoptosis 15: 1322-1335, 2010.

9. Cecarini V, Ding Q, and Keller JN. Oxidative inactivation of the proteasome in Alzheimer's disease. Free Radic Res 41: 673-680, 2007.

10. Coux O, Tanaka K, and Goldberg AL. Structure and functions of the 20S and 26S proteasomes. Annu Rev Biochem 65: 801-847, 1996.

11. Cuervo AM, Wong ES, and Martinez-Vicente M. Protein degradation, aggregation, and misfolding. Mov Disord 25 Suppl 1: S49-54, 2010.

12. Cunha FM, Demasi M, and Kowaltowski AJ. Aging and calorie restriction modulate yeast redox state, oxidized protein removal, and the ubiquitin-proteasome system. Free Radic Biol Med 51:664-670, 2011.

13. Dange T, Smith D, Noy T, Rommel PC, Jurzitza L, Legendre A, Finley D, Goldberg AL, and Schmidt M. Blm10 promotes proteasomal substrate turnover by an active gating mechanism. J Biol Chem, 2011 [Epub ahead of print].

14. Demasi M, Shringarpure R, and Davies KJ. Glutathiolation of the proteasome is enhanced by proteolytic inhibitors. Arch Biochem Biophys 389: 254-263, 2001.

15. Demasi M, Silva GM, and Netto LE. 20 S proteasome from Saccharomyces cerevisiae is responsive to redox modifications and is S-glutathionylated. J Biol Chem 278: 679-685, 2003.

16. Dixon DP, Skipsey M, Grundy NM, and Edwards R. Stressinduced protein S-glutathionylation in Arabidopsis. Plant Physiol 138: 2233-2244, 2005.

17. Duce JA, and Bush AI. Biological metals and Alzheimer's disease: implications for therapeutics and diagnostics. Prog Neurobiol 92: 1-18, 2010.

18. Engelender S. Ubiquitination of alpha-synuclein and autophagy in Parkinson's disease. Autophagy 4: 372-374, 2008.

19. Ferrington DA, Sun H, Murray KK, Costa J, Williams TD, Bigelow DJ, and Squier TC. Selective degradation of oxidized calmodulin by the $20 \mathrm{~S}$ proteasome. J Biol Chem 276: 937-943, 2001.

20. Goodford PJ. A computational procedure for determining energetically favorable binding sites on biologically important macromolecules. J Med Chem 28: 849-857, 1985.

21. Gregori L, Hainfeld JF, Simon MN, and Goldgaber D. Binding of amyloid beta protein to the $20 \mathrm{~S}$ proteasome. J Biol Chem 272: 58-62, 1997.

22. Groll M, Bajorek M, Kohler A, Moroder L, Rubin DM, Huber R, Glickman MH, and Finley D. A gated channel into the proteasome core particle. Nat Struct Biol 7: 1062-1067, 2000.

23. Groll M, Ditzel L, Lowe J, Stock D, Bochtler M, Bartunik HD, and Huber R. Structure of 20S proteasome from yeast at 2.4 A resolution. Nature 386: 463-471, 1997.

24. Grune T, Catalgol B, Licht A, Ermak G, Pickering AM, Ngo JK, and Davies KJA. HSP70 mediates dissociation and reassociation of the $26 \mathrm{~S}$ proteasome during adaptation to oxidative stress. Free Rad Biol Med 51:1355-1364, 2011.

25. Inai $Y$ and Nishikimi M. Increased degradation of oxidized proteins in yeast defective in $26 \mathrm{~S}$ proteasome assembly. Arch Biochem Biophys 404: 279-284, 2002. 
26. Jung T, Catalgol B, and Grune T. The proteasomal system. Mol Aspects Med 30: 191-296, 2009.

27. Kirkin V, McEwan DG, Novak I, and Dikic I. A role for ubiquitin in selective autophagy. Mol Cell 34: 259-269, 2009.

28. Köhler A, Cascio P, Leggett DS, Woo KM, Goldberg AL, and Finley D. The axial channel of the proteasome core particle is gated by the Rpt2 ATPase and controls both substrate entry and product release. Mol Cell 7:1143-1152, 2001.

29. Kopp F, Hendil KB, Dahlmann B, Kristensen P, Sobek A, and Uerkvitz W. Subunit arrangement in the human 20S proteasome. Proc Natl Acad Sci U S A 94: 2939-2944, 1997.

30. Kriegenburg F, Poulsen EG, Koch A, Kruger E, and Hartmann-Petersen R. Redox control of the ubiquitinproteasome system: from molecular mechanisms to functional significance. Antiox Redox Signal 15: 2265-2299, 2011.

31. Levine RL, Williams JA, Stadtman ER, and Shacter E. Carbonyl assays for determination of oxidatively modified proteins. Methods Enzymol 233: 346-357, 1994

32. Lindersson E, Beedholm R, Hojrup P, Moos T, Gai W, Hendil $\mathrm{KB}$, and Jensen $\mathrm{PH}$. Proteasomal inhibition by alpha-synuclein filaments and oligomers. J Biol Chem 279: 12924-12934, 2004.

33. Liu CW, Corboy MJ, DeMartino GN, and Thomas PJ. Endoproteolytic activity of the proteasome. Science 299: 408411, 2003.

34. Mieyal JJ, Gallogly MM, Qanungo S, Sabens EA, and Shelton MD. Molecular mechanisms and clinical implications of reversible protein S-glutathionylation. Antioxid Redox Signal 10: 1941-1988, 2008.

35. Niture SK, Velu CS, Bailey NI, and Srivenugopal KS. Sthiolation mimicry: quantitative and kinetic analysis of redox status of protein cysteines by glutathione-affinity chromatography. Arch Biochem Biophys 444: 174-184, 2005.

36. Osmulski PA and Gaczynska M. Atomic force microscopy reveals two conformations of the $20 \mathrm{~S}$ proteasome from fission yeast. J Biol Chem 275: 13171-13174, 2000.

37. Osmulski PA and Gaczynska M. Nanoenzymology of the $20 S$ proteasome: proteasomal actions are controlled by the allosteric transition. Biochemistry 41: 7047-7053, 2002.

38. Osmulski PA, Hochstrasser M, and Gaczynska M. A tetrahedral transition state at the active sites of the 20S proteasome is coupled to opening of the alpha-ring channel. Structure 17: 1137-1147, 2009.

39. Pacifici RE, Kono Y, and Davies KJ. Hydrophobicity as the signal for selective degradation of hydroxyl radical-modified hemoglobin by the multicatalytic proteinase complex, proteasome. J Biol Chem 268: 15405-15411, 1993.

40. Peth A, Besche HC, and Goldberg AL. Ubiquitinated proteins activate the proteasome by binding to Usp14/Ubp6, which causes 20S gate opening. Mol Cell 36:794-804, 2009.

41. Rabl J, Smith DM, Yu Y, Chang SC, Goldberg AL, and Cheng Y. Mechanism of gate opening in the 20S proteasome by the proteasomal ATPases. Mol Cell 30: 360-368, 2008.

42. Religa TL, Sprangers R, and Kay LE. Dynamic regulation of archaeal proteasome gate opening as studied by TROSY NMR. Science 328: 98-102, 2010.

43. Rogers N, Paine S, Bedford L, and Layfield R. Review: the ubiquitin-proteasome system: contributions to cell death or survival in neurodegeneration. Neuropathol Appl Neurobiol 36: 113-124, 2010

44. Shang F and Taylor A. Ubiquitin-proteasome pathway and cellular responses to oxidative stress. Free Radic Biol Med 51: 5-16, 2011.
45. Shringarpure R, Grune T, Mehlhase J, and Davies KJ. Ubiquitin conjugation is not required for the degradation of oxidized proteins by proteasome. J Biol Chem 278: 311-318, 2003.

46. Silva GM, Netto LE, Discola KF, Piassa-Filho GM, Pimenta DC, Barcena JA, and Demasi M. Role of glutaredoxin 2 and cytosolic thioredoxins in cysteinyl-based redox modification of the 20 S proteasome. FEBS J 275: 2942-2955, 2008.

47. Smith DM, Chang SC, Park S, Finley D, Cheng Y, and Goldberg AL. Docking of the proteasomal ATPases' carboxyl termini in the $20 \mathrm{~S}$ proteasome's alpha ring opens the gate for substrate entry. Mol Cell 27: 731-744, 2007.

48. Tanahashi N, Murakami Y, Minami Y, Shimbara N, Hendi $\mathrm{KB}$, and Tanaka K. Hybrid proteasomes. Induction by interferon-gamma and contribution to ATP-dependent proteolysis. J Biol Chem 275: 14336-14345, 2000.

49. Tian G, Park S, Lee MJ, Huck B, McAllister F, Hill CP, Gygi $\mathrm{SP}$, and Finley D. An asymmetric interface between the regulatory and core particles of the proteasome. Nat Struct Mol Biol 18: 1259-1267, 2011.

50. Tofaris GK, Layfield R, and Spillantini MG. alpha-synuclein metabolism and aggregation is linked to ubiquitinindependent degradation by the proteasome. FEBS Lett 509: 22-26, 2001.

51. Verma R, Chen S, Feldman R, Schieltz D, Yates J, Dohmen J, and Deshaies RJ. Proteasomal proteomics: identification of nucleotide-sensitive proteasome-interacting proteins by mass spectrometric analysis of affinity-purified proteasomes. Mol Biol Cell 11: 3425-3439, 2000.

52. Wang X, Yen J, Kaiser P, and Huang L. Regulation of the $26 \mathrm{~S}$ proteasome complex during oxidative stress. Sci Signal 3: ra88-98, 2010.

53. Winterbourn CC and Hampton MB. Thiol chemistry and specificity in redox signaling. Free Radic Biol Med 45: 549-561, 2008

54. Yang Y, Shi W, Chen X, Cui N, Konduru AS, Shi Y, Trower TC, Zhang S, and Jiang C. Molecular basis and structural insight of vascular K(ATP) channel gating by S-glutathionylation. J Biol Chem 286: 9298-9307, 2011.

55. Zhao X and Yang J. Amyloid-beta peptide is a substrate of the human $20 S$ proteasome. ACS Chem Neurosci 1: 655-660, 2010.

Address correspondence to: Dr. Marilene Demasi Instituto Butantan

Laboratório de Bioquímica e Biofísica Avenida Vital Brasil, 1500 São Paulo, SP, CEP: 05503-001

Brasil

E-mail: marimasi@butantan.gov.br

Dr. Luis E.S. Netto

Instituto de Biociencias

Universidade de São Paulo

Rua do Matao, 277

05508-090

Sao Paulo-SP

Brasil

E-mail: nettoles@ib.usp.br

Date of first submission to ARS Central, August 2, 2011; date of final revised submission, January 4, 2012; date of acceptance, January 4, 2012 


$\begin{aligned} & \text { Abbreviations Used } \\ & 2-\mathrm{DE}= \text { two-dimensional electrophoresis } \\ & 3 \mathrm{D}==\text { three-dimensional } \\ & 20 \mathrm{SPT}=20 \mathrm{~S} \text { catalytic unit of the proteasome } \\ & \Delta \mathrm{N} \alpha 3 \alpha 7 \mathrm{SPPT}= \text { 20SPT purified from the SUB556 strain } \\ & \mathrm{BSA}_{\mathrm{ox}}=\text { oxidized bovine serum albumin } \\ & \mathrm{ChT}-\mathrm{L}=\text { chymotrypsin-like } \\ & \mathrm{Cys}=\text { cysteine } \\ & \mathrm{Cys}-\mathrm{SOH}=\text { cysteine sulfenic acid } \\ & \mathrm{Cys}-\mathrm{SO}_{2} \mathrm{H}=\text { cysteine sulfinic acid } \\ & \mathrm{DNPH}=\text { dinitrophenylhydrazine } \\ & \mathrm{DTPA}=\text { diethylene triamine pentaacetic acid } \\ & \mathrm{DTT}=\text { dithiothreitol } \\ & \mathrm{FITC}=\text { fluorescein isothiocyanate } \\ & \mathrm{Gr} 2 \mathrm{x}=\text { glutaredoxin } 2 \\ & \mathrm{GSH}=\text { reduced glutathione }\end{aligned}$

GSSG $=$ oxidized glutathione

LC-MS/MS = liquid chromatography-tandem mass spectrometry

LC-Q-ToF-MS = liquid chromatography-quadrupole-time of flight-mass spectrometry

$\mathrm{NBD}=$ 7-chloro-4-nitrobenzo-2-oxa-1,3-diazole $\mathrm{nPT}-\mathrm{SG}=$ natively S-glutathiolated $20 \mathrm{~S}$ proteasome purified from yeast grown in YPD medium to stationary phase

PAGE $=$ polyacrylamide gel electrophoresis PT-SH $=$ DTT-reduced 20 S proteasome

PT-SG $=$ in vitro S-glutathiolated $20 \mathrm{~S}$ proteasome

SAXS $=$ small-angle $X$-ray scattering

$\mathrm{SDS}=$ sodium dodecyl sulfate

TEM $=$ transmission electron microscopy

UPS $=$ ubiquitin-proteasome system 


\section{A.2 Redox regulation of the proteasome via S-glutathionylation}

\section{Regulação redox do proteassomo via S-Gluatationilação}

O proteassomo é uma protease intracelular multmérica e multicatalítica, responsável pela degradação de proteínas envolvidas no controle do ciclo celular, vários processos de sinalização, apresentação de antígenos e, controle da síntese de proteínas. A parte central do complexo catalítico do proteassomo é chamado de 20S, no núcleo da partícula. Em sua maioria são flanqueados em um ou ambos os lados por unidades regulatórias. A mais comum entre estas unidades é a unidade regulatória 19S. Quando acoplado à unidade 19S, o complexo é denominado o proteassomo 26S, assimétrico ou simétrico, dependendo se um ou ambos os lados são acoplados à unidade 19S, respectivamente. O proteassomo $26 \mathrm{~S}$ reconhece substratos poli-ubiquitinados marcados para proteólise. Proteínas marcadas interagem com a unidade 19S onde elas são desubiquitinadas, desenoveladas, e translocadas para a câmara catalítica 20S para a degradação. O proteassomo 26S é responsável pela degradação de proteínas envolvidas na regulação do ciclo celular, apresentação de antígenos e, controle da síntese de proteínas. Alternativamente, o proteassomo também é ativo quando dissociado das unidades regulatórias. Este pool de proteassomo 20 S livre é descrito desde em células de levedura até em células de mamífero. O proteassomo 20S livre degrada proteínas por um processo independente de poli-ubiquitinação e consumo de ATP. Proteínas oxidativamente modificadas e outros substratos são degradados desta maneira. O proteassomo 20S é composto de dois heptâmeros centrais (anéis- $\beta$ ), onde os sítios catalíticos estão localizados nos dois heptameros externos (anéis- $\alpha$ ) que são responsáveis pela ativação do proteassomo. Porque o proteassomo 20S não precisa de unidades regulatórias, não é claro quais os mecanismos que regulam as alterações induzidas pela 
ativação nos anéis- $\alpha$ entre formas abertas e fechadas. Na presente revisão, discutimos a modulação da ativação do proteassomo 20S através de um mecanismo redox, ou seja, S-glutathionilação de resíduos de cisteína localizados nos anéis- $\alpha$, e a conseqüência desta modificação pós-traducional na função do proteassomo 20S. 
Review Article

\title{
Redox regulation of the proteasome via S-glutathionylation
}

\author{
Marilene Demasi ${ }^{\mathrm{a}, *}$, Luis E.S. Netto ${ }^{\mathrm{b}}$, Gustavo M. Silva ${ }^{\mathrm{a}, \mathrm{b}, 1}$, Adrian Hand ${ }^{\mathrm{a}}$, \\ Cristiano L.P. de Oliveira ${ }^{c}$, Renata N. Bicev ${ }^{c}$, Fabio Gozzo ${ }^{d}$, Mario H. Barros ${ }^{e}$, \\ Janaina M.M. Leme ${ }^{\mathrm{a}, \mathrm{b}}$, Erina Ohara ${ }^{\mathrm{a}}$ \\ a Laboratório de Bioquímica e Biofísica, Instituto Butantan, São Paulo, SP, Brazil \\ ${ }^{\mathrm{b}}$ Departamento de Genética e Biologia Evolutiva, IB-Universidade de São Paulo, São Paulo, SP, Brazil \\ ${ }^{\mathrm{c}}$ Departamento de Física Experimental, IF-Universidade de São Paulo, São Paulo, SP, Brazil \\ d Instituto de Ouímica, UNICAMP, Campinas, SP, Brazil \\ e Departamento de Microbiologia, ICB-Universidade de São Paulo, São Paulo, SP, Brazil
}

\section{A R T I C L E I N F O}

\section{Article history:}

Received 30 October 2013

Received in revised form

4 December 2013

Accepted 5 December 2013

Available online 14 December 2013

\section{Keywords:}

Proteasome

$S$-glutathionylation

Oxidized proteins

Proteasomal gating

Redox regulation

\begin{abstract}
A B S T R A C T
The proteasome is a multimeric and multicatalytic intracellular protease responsible for the degradation of proteins involved in cell cycle control, various signaling processes, antigen presentation, and control of protein synthesis. The central catalytic complex of the proteasome is called the $20 \mathrm{~S}$ core particle. The majority of these are flanked on one or both sides by regulatory units. Most common among these units is the 19S regulatory unit. When coupled to the 19S unit, the complex is termed the asymmetric or symmetric 26S proteasome depending on whether one or both sides are coupled to the $19 \mathrm{~S}$ unit, respectively. The $26 \mathrm{~S}$ proteasome recognizes polyubiquitinylated substrates targeted for proteolysis. Targeted proteins interact with the 19S unit where they are deubiquitinylated, unfolded, and translocated to the 20S catalytic chamber for degradation. The 26S proteasome is responsible for the degradation of major proteins involved in the regulation of the cellular cycle, antigen presentation and control of protein synthesis. Alternatively, the proteasome is also active when dissociated from regulatory units. This free pool of $20 \mathrm{~S}$ proteasome is described in yeast to mammalian cells. The free $20 \mathrm{~S}$ proteasome degrades proteins by a process independent of poly-ubiquitinylation and ATP consumption. Oxidatively modified proteins and other substrates are degraded in this manner. The $20 \mathrm{~S}$ proteasome comprises two central heptamers ( $\beta$-rings) where the catalytic sites are located and two external heptamers ( $\alpha$-rings) that are responsible for proteasomal gating. Because the $20 \mathrm{~S}$ proteasome lacks regulatory units, it is unclear what mechanisms regulate the gating of $\alpha$-rings between open and closed forms. In the present review, we discuss $20 \mathrm{~S}$ proteasomal gating modulation through a redox mechanism, namely, S-glutathionylation of cysteine residues located in the $\alpha$-rings, and the consequence of this post-translational modification on $20 \mathrm{~S}$ proteasomal function. (c) 2013 The Authors. Published by Elsevier B.V. All rights reserved.
\end{abstract}

\section{Contents}

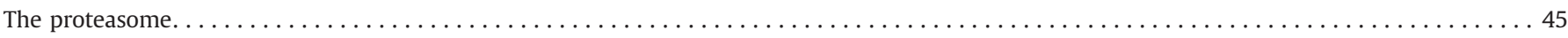

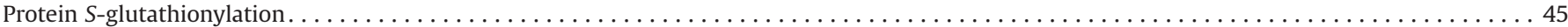

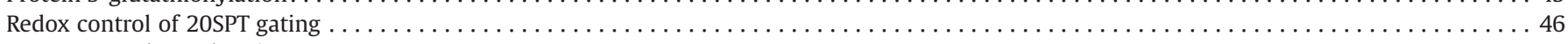

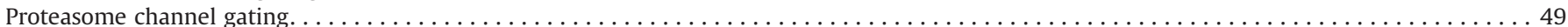

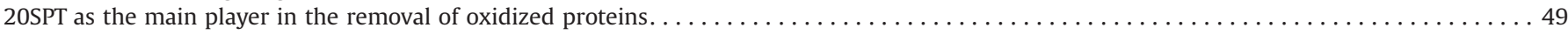

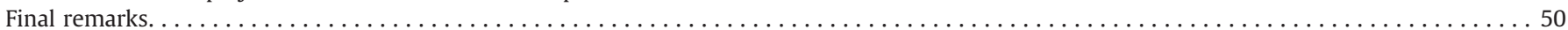

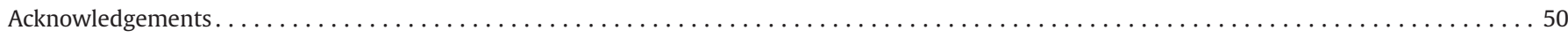

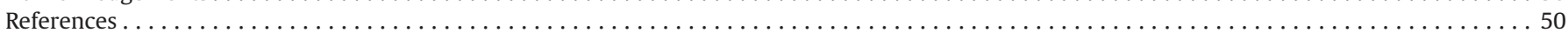

Abbreviations: GSH, reduced glutathione; GSSG, oxidized glutathione; ROS, reactive oxygen species; SAXS, small angle X-rays scattering; 20SPT, 20S proteasome core particle; 26SPT, 26S proteasome; TEM, transmission electron microscopy

in This is an open-access article distributed under the terms of the Creative Commons Attribution-NonCommercial-No Derivative Works License, which permits noncommercial use, distribution, and reproduction in any medium, provided the original author and source are credited.

* Corresponding author. Tel.: +55 1126279745 .

E-mail address: marilene.demasi@butantan.gov.br (M. Demasi).

${ }^{1}$ Present address: Center for Genomics and Systems Biology, New York University, New York, USA. 


\section{The proteasome}

The proteasome is a ubiquitous, intracellular, multimeric, and multicatalytic protease responsible for the degradation of intracellular proteins [1]. It is composed of a central unit called 20SPT. This unit is most often flanked on one or both sides by regulatory units such as 19S, 11S, and/or PA200. The most abundant regulatory complex is the $19 \mathrm{~S}$ unit, which recognizes poly-ubiquitinylated proteins. When coupled to the $19 \mathrm{~S}$ unit, the proteasome is termed 26SPT. The 26SPT is responsible for quality control of protein synthesis and the degradation of proteins involved in major metabolic pathways related to cell cycle regulation, antigen presentation, and most signaling processes. The poly-ubiquitinylated proteins bind to specific subunits of the $19 \mathrm{~S}$ complex, are deubiquitinylated by enzymes present in the $19 \mathrm{~S}$ unit, are unfolded, and are translocated to the catalytic chamber through the ATPase activity of a hexameric ring located in the base of the 19S unit. The 20SPT comprises two $\alpha$ and two $\beta$ heptameric rings. The internal $\beta$ rings are responsible for catalysis, while the peripheral $\alpha$ rings are responsible for the gating of the 20SPT.

Because 20S proteasome free pool lacks regulatory units, the regulation of the gating mechanism between open and closed forms is unclear. We have presented evidence that S-glutathionylation of cysteine residues located in the $\alpha$-rings may represent a redox post-translational regulation of the 20 s proteasome.

\section{Protein S-glutathionylation}

The term S-glutathionylation was adopted in this review by taking into account the conclusive criticism on the alternative nomenclature (S-glutathiolation), as discussed by Mieyal \& Chock [2].

$S$-glutathionylation is the formation of mixed disulfides between glutathione and cysteine residues of proteins. Originally described as a result of oxidative stress [3], S-glutathionylation was later recognized as a post-translational modification that can play major regulatory functions [3-6]. In the last 10 years, the investigation on protein $S$-glutathionylation was intensified because of the increased understanding on ROS and NO derived species role in signal transduction and most likely by the reversibility of protein S-glutathionylation. Either protein thiols or glutathione (GSH) can be activated by oxidants to further react with other sulfhydryls. Therefore, protein S-glutathionylation might transduce redox signals generated by ROS and NO derived species $[7,8]$. Because the intracellular environment is highly reducing, except in some organelles, such as the endoplasmic reticulum, very few protein thiols are prone to be $S$-glutathionylated. Therefore, it is arguable that $S$-glutathionylation occurs in a site- and protein-specific manner. The global susceptibility and site-specific specificity of proteins for $S$-glutathionylation is dependent on the reactivity of their thiol groups. Two relevant factors in protein susceptibility for $S$-glutathionylation may be thiol steric accessibility and thiol $\mathrm{p} K_{a}$; these factors depend upon protein folding and vicinity to side chains of basic amino acids, respectively. The specificity of protein $S$-glutathionylation remains an active field of research $[5,6,9]$. The chemical mechanisms of protein $S$-glutathionylation proposed to date $[5,10]$ are based on either thiol protein or GSH pool redox modifications (Fig. 1). These reactions may be triggered through ROS or NO derived species. The most cited and explored mechanisms of protein S-glutathionylation are based on either thiol-disulfide exchange through protein thiolate and glutathione disulfide (GSSG) or the reaction between an oxidized thiol to sulfenic acid with the reduced form of GSH.

Data obtained by new methodologies based on encoded fluorescent protein-glutaredoxin conjugates indicated that intracellular GSH/GSSG ratios could be two orders magnitude higher compared to those previously described $[11,12]$. Cells most likely can maintain such highly reducing intracellular conditions through elimination of excess GSSG by either extrusion [13] or vacuole uptake [12]. A GSH/

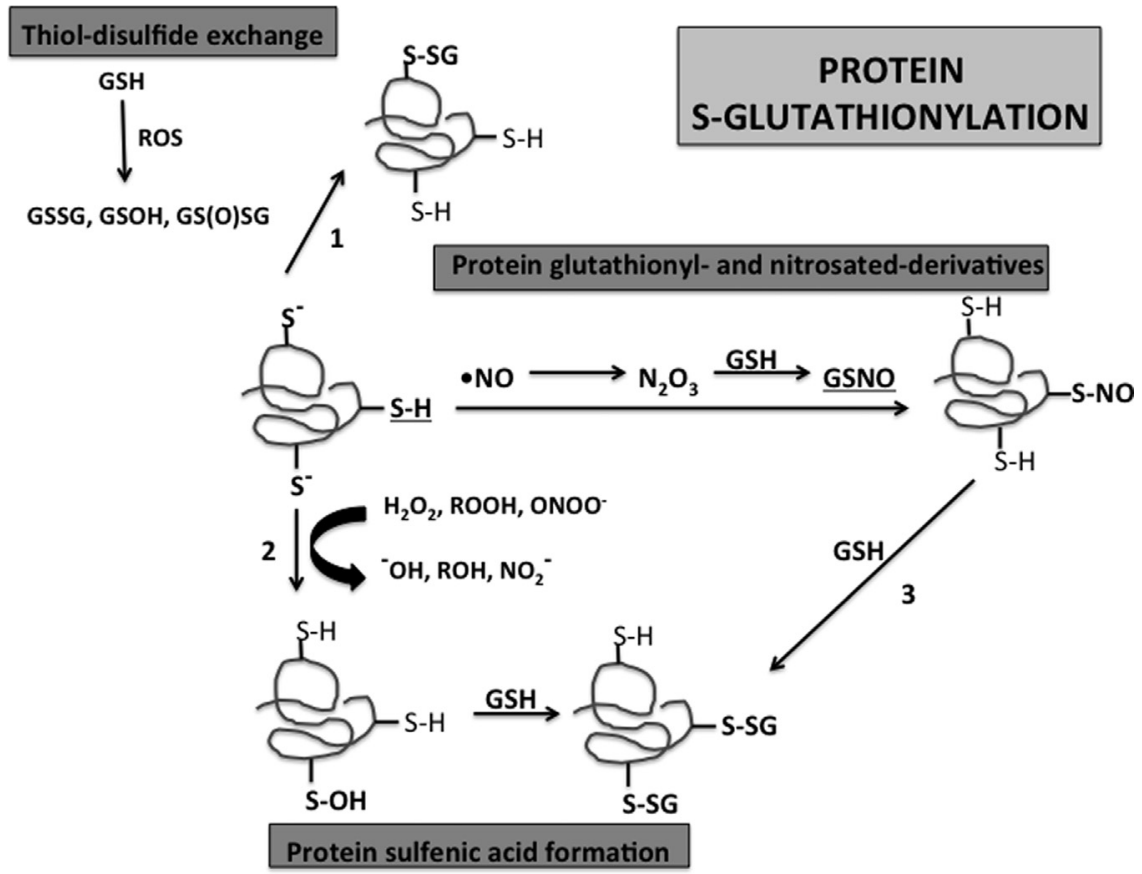

Fig. 1. Major mechanisms of protein $S$-glutathionylation. Route $\mathbf{1}$ describes the classical mechanism of protein $S$-glutathionylation. This mechanism causes modification through thiol-disulfide exchange. Formation of adduct may be triggered by an increased GSSG pool mediated by intensified ROS formation or the oxidized glutathione species GSOH and GS(O)SG. Route 2 describes mechanisms based on protein sulfenic acid formation through reaction with peroxides or peroxynitrite followed by reaction with GSH. Other physiological oxidants, e.g., hypochlorous acid or chloramine derivatives can also oxidize thiol groups to the sulfenic form [15]. Route $\mathbf{3}$ describes mechanisms based on nitrosylated protein or gluathionyl derivatives that are formed through reaction with intermediates of NO radical metabolism. 
GSSG in the range of 10,000 would suggest that S-glutathionylation through thiol-disulfide exchange is highly specific to selected proteins or even improbable. However, investigation on the unintended consequences on cell biology of adding a genetically encoded fluorescent probe is required. Indeed, expression of some of these probes in fibroblasts resulted in the appearance of a dimer form that exhibited an intermediate excitation fluorescence spectrum between those of oxidized and reduced monomers [14].

Other mechanisms of protein S-glutathionylation are based on protein thiol activation by oxidants such as hydrogen peroxide, peroxynitrite, and others through formation of sulfenic acid (P-SOH; [15]), followed by reaction with GSH (Scheme 1, reaction 2; [16]). However, proteins such as peroxiredoxins and glutathione peroxidases are one million times more reactive towards hydroperoxides than other thiol-proteins, such as protein tyrosine phosphatases $[17,18]$. Therefore, peroxiredoxins and glutathione peroxidases are the most probable biological sensors of hydroperoxides. These proteins would then have to transmit peroxide binding signals to other redox players, such as thioredoxin $[19,20]$. However, the mechanisms that connect thiol oxidation by hydroperoxides to protein $S$-glutathionylation are still elusive.

Many examples of substrates undergoing S-glutathionylation by other specific mechanisms have already been reported [21]; however, this is not the focus of present review. Because nonenzymatic thiol-disulfide reactions are slow $[17,22]$, a challenge is the identification of proteins that add and remove the glutathione moiety. Indeed, some candidates for protein S-glutathionylation, such as glutathione-S-transferase [23] or alternative enzymeassisted thiol-disulfide exchange [8], have been proposed. Regarding the reversal of protein $S$-glutathionylation, glutaredoxins (Grxs) are frequently considered as oxidoreductases that catalyze the reduction of protein mixed disulfides. These proposed pathways strengthen the notion that protein $S$-glutathionylation is either a regulatory post-translational modification and/or a protective mechanism of thiol homeostasis [4,24]. We have accumulated evidence that protein $S$-glutathionylation is a posttranslational modification that regulates $20 \mathrm{~S}$ proteasome activity, as will be discussed below.

\section{Redox control of 20SPT gating}

The first observation of 20SPT redox modification through Sglutathionylation was in preparations of the human proteasome incubated with increasing concentrations of both redox forms of glutathione [25]. In those studies, the peptidolytic chymotrypsinlike (ChT-L) proteasomal activity was shown to be modulated by both glutathione redox forms: micromolar concentrations activated the ChT-L activity and millimolar concentrations inhibited it. Interestingly, it was also observed that inhibition of the 20SPT by irreversible inhibitors increased the incorporation of $\mathrm{G}\left[{ }^{35} \mathrm{~S}\right] \mathrm{H}$ into purified human 20SPT preparations. Initially, the thiol-disulfide exchange mechanism for $S$-glutathionylation (reactions 1 and 2, Scheme 1) was considered because the human 20SPT possesses two S-S bonds. However, it is also possible that GSH reacted with oxidized proteasomal thiol groups (reaction 3), not predicted at that time.

\section{(1) $20 S P T-S H+G S S G \longrightarrow 20 S P T-S S G+G S H$}

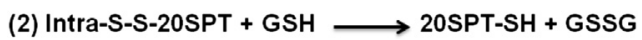

(3) 20SPT-SOH + GSH $\longrightarrow$ 20SPT-SSG

Scheme 1. Proposed mechanisms for the $S$-glutathionylation of mammalian and yeast 20SPT
Further studies with preparations of 20SPT purified from Saccharomyces cerevisiae demonstrated inhibition of the ChT-L activity only after proteasomal incubation with millimolar concentrations of GSH. A pathway involving the oxidation of proteasomal thiol groups to sulfenic acid by hydrogen peroxide followed by reaction with GSH to form $S$-glutathionylated proteasomes was supported by data from these studies (Scheme 1, reaction 3; [26]). An increased pool of $S$-glutathionylated 20SPT was observed in yeast cells incubated with $\mathrm{H}_{2} \mathrm{O}_{2}$ [26], unraveling the notion of proteasomal S-glutathionylation as a post-translational regulatory mechanism.

20SPT S-glutathionylation is a widespread post-translational modification that has been corroborated through proteomic approaches in various species including plants and mammals [27-29].

$S$-glutathionylated 20SPT from S. cerevisiae was recently investigated by two-dimensional electrophoretic separation of the 14 proteosomal subunits followed by LC-Q-ToF-MS analysis [30]. Two Cys residues of the $\alpha 5$-subunit were found to be $S$-glutathionylated in the 20SPT preparations purified from yeast cells grown to stationary phase in fermentative medium (glucose as the carbon source). When the same proteasome preparations were incubated in vitro in the presence of GSH, four additional S-glutathionylated Cys residues were observed: one each in subunits $\alpha 5$ and $\alpha 6$ and two in subunit $\alpha 7$. Remarkably, five out of the six Cys residues prone to $S$-glutathionylation were also found through LC-Q-ToFMS analyses either in the reduced or hyperoxidized sulfinic acid form, evidencing their susceptibility towards oxidation. Additionally, these findings suggested that $S$-glutathionylation occurs after oxidation of Cys residues to the sulfenic form followed by reaction with reduced glutathione (Scheme 1, reaction 3). Two of these Cys residues ( $\alpha 5-\mathrm{C} 76$ and $\alpha 7-\mathrm{C} 42)$ are highly conserved, from $S$. cerevisiae to humans.

Large-scale structural movements were verified through small angle X-ray scattering (SAXS) experiments that compared yeast proteasomal preparations where both Cys residues in the $\alpha 5$ subunit were S-glutathionylated or unmodified (Fig. 2 and Ref. [30]. A profound structural re-modeling was observed during transition of the $S$-glutathionylated to the DTT-reduced 20SPT form. When S-glutathionylated, the 20SPT is in the open gate conformation whereas after treatment with sulfhydryl reductants, such as DTT, its gate is closed. These results were confirmed by TEM evaluation of the same 20SPT preparations (Fig. 3 and Ref. [30].

Unpublished findings from our group involving yeast strains harboring either the $\alpha 5-\mathrm{C} 76 \mathrm{~S}$ or the $\alpha 5-\mathrm{C} 221 \mathrm{~S}$ mutations have revealed that the conserved $\alpha 5-\mathrm{C} 76$ residue is directly involved in gating regulation, as the closed conformation is prevalent in 20SPT preparations from the $\alpha 5$-C76S strain. However, over $90 \%$ of 20 SPT are in the open conformation in the $\alpha 5-\mathrm{C} 221 \mathrm{~A}$ strain. It seems that $\alpha 5-\mathrm{C} 221$, the only Cys residue located on the surface of the yeast 20SPT [30], is responsible for negative regulation of the gating mechanism. This residue most likely functions as a firsthand sensor of loss of the intracellular reducing ability regarding proteasomal functionality.

Growing yeast in either fermentative or respiratory media using glucose or glycerol/ethanol, respectively, promotes different intracellular redox conditions [31]. Glucose represses genes related to mitochondrial biogenesis and antioxidant defenses, while growth under respiratory conditions increases the expression of genes related to antioxidant defenses despite an increased production of ROS. Purified 20SPT from yeast cells grown in either fermentative or respiratory media was analyzed by SDS-PAGE followed by immunoblotting with anti-GSH antibody. The results of this experiment indicated that 20SPT in cells grown in glucose-rich medium were preferentially $S$-glutathionylated [32]. The labeling of the $\alpha 5$-subunit in proteasome preparations from cells grown in glucose, but not of those grown in glycerol/ethanol, was confirmed by the separation of the 20SPT subunits by 2D electrophoresis followed by anti-GSH 
A
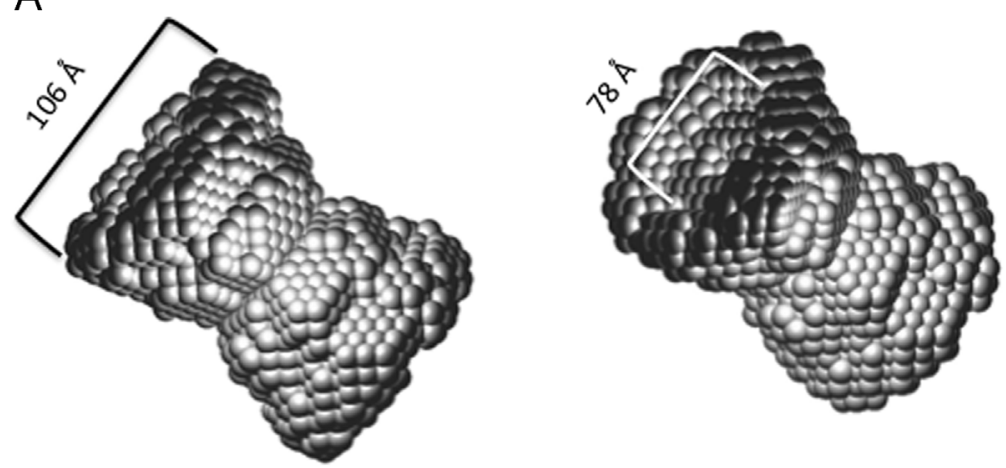

$188 \AA$
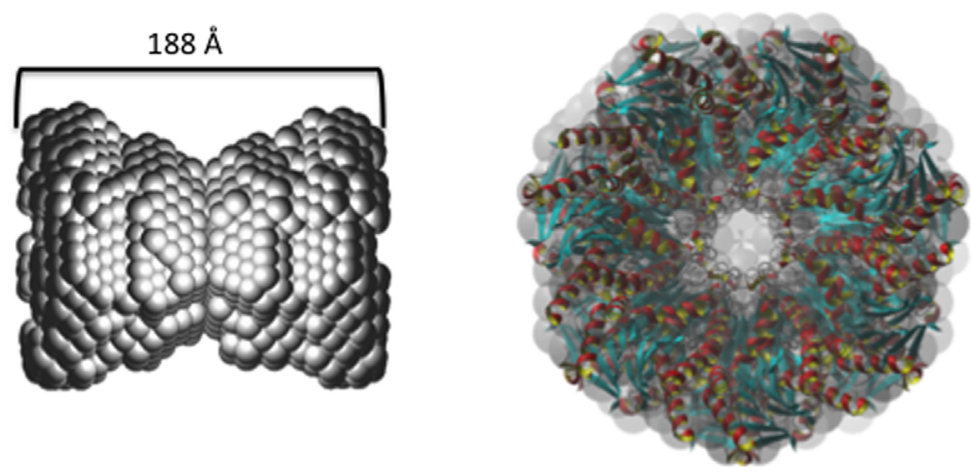

B
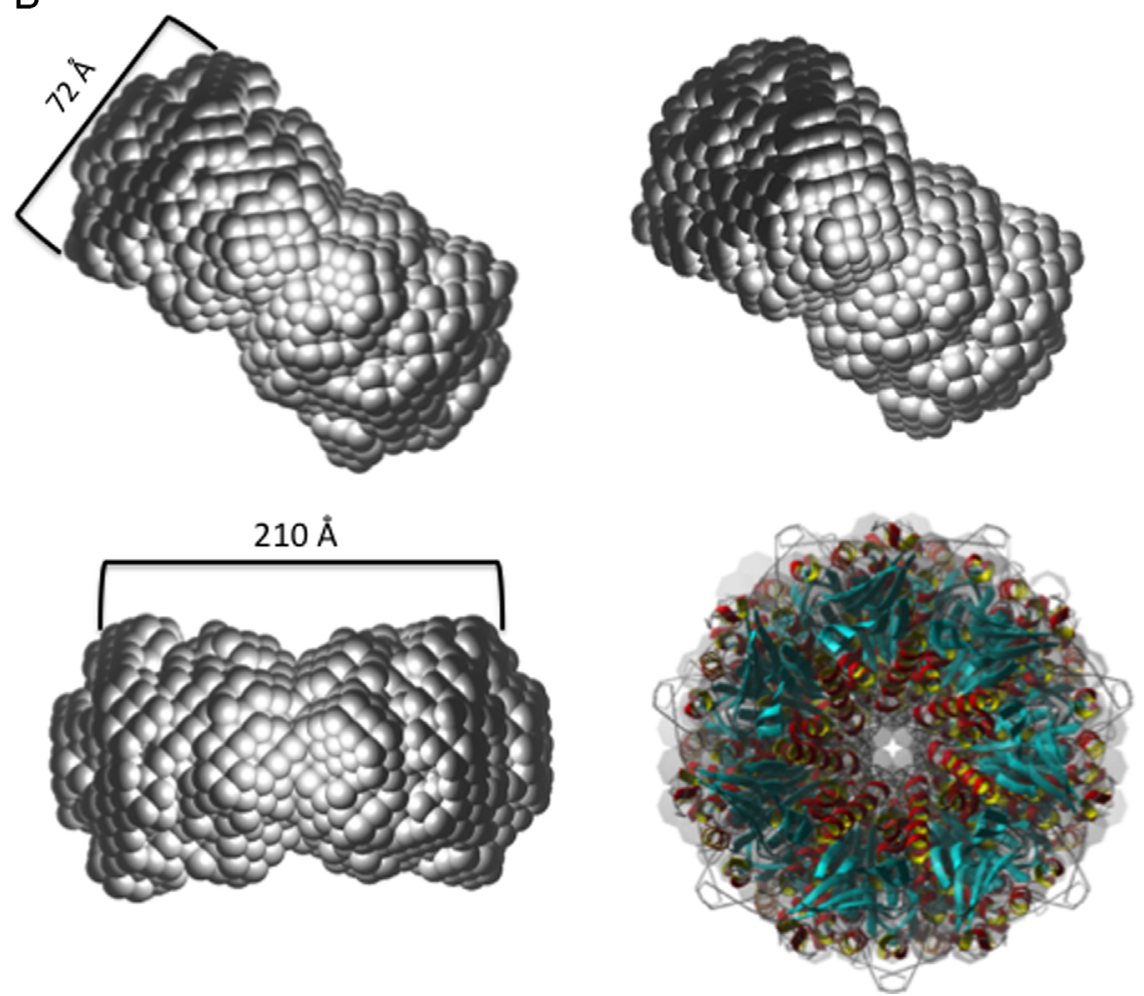

Fig. 2. Modeling of the 20SPT redox forms according to SAXS analyzes. (A) Top (left) and front (right) views of the 20SPT purified from yeast cells grown under conditions that promote fermentation; (B) same preparations after treatment with DTT. Internal and external diameters of the catalytic chamber (upper models) and the length of the 20SPT (botton left models) in both redox conditions were obtained through SAXS measurements [30]. Modeling of S-glutathionylated 20SPT (A) indicated a decreased length and a concave surface. The opposite conformation was deduced from DTT-treated 20SPT (B). Colored models are alternative modelings highlighting the gate conformation.

immunoblotting (Demasi et al., unpublished). By comparing both preparations through TEM, $85 \%$ of the 20SPT purified from cells grown in glycerol/ethanol were in the closed conformation compared with $30 \%$ of the 20SPT from cells grown in glucose. Taken together, these results indicate $S$-glutathionylation of the $\alpha 5$-Cys residues depends on intracellular redox conditions.

Variable diameters of the open 20SPT gate were observed by TEM analysis of wild-type 20SPT extracted from yeast cells grown in 
A

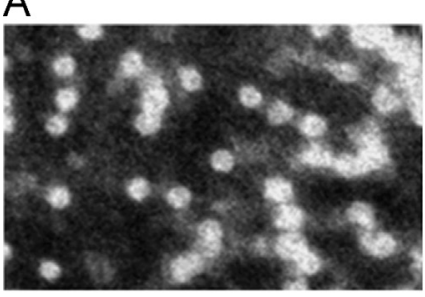

B

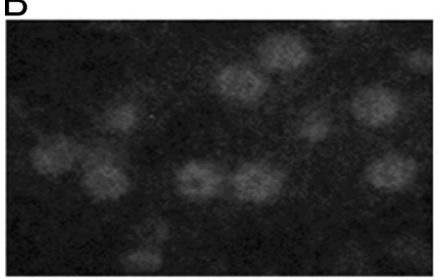

C

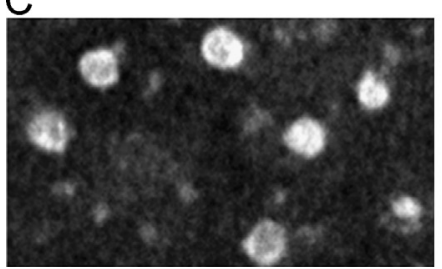

$\mathrm{D}$

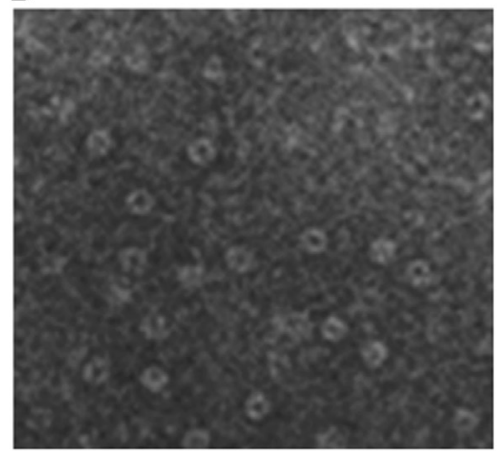

$\mathrm{E}$

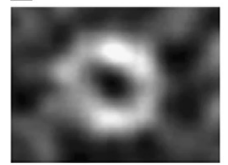

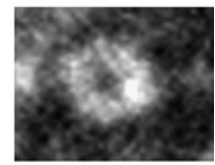

Fig. 3. TEM images of the yeast 20SPT top view. (A)-(C) are panels representative of the closed conformation of 20SPT purified from (A) cells grown in respiratory medium where the closed conformation prevails (Demasi et al., unpublished); (B) strains carrying the $\alpha 5-\mathrm{C} 76 \mathrm{~S}$ mutation and, (C) cells grown in fermentative conditions after treatment with DTT that reduces S-glutathionylated or oxidized Cys residues to the sulfenic acid. (D) and (E) are images representative of the 20SPT open conformation: (D) preparations obtained from strains carrying the mutated $\alpha 5$-C221S 20SPT; (E) image of the 20SPT obtained from the $\alpha 5$-C221S strain (left) and wild type 20SPT from cells grown in fermentative glucose-rich (middle) and -synthetic media (right).

\section{REGULATION OF PROTEASOME GATING VIA S-GLUTATHIONYLATION}
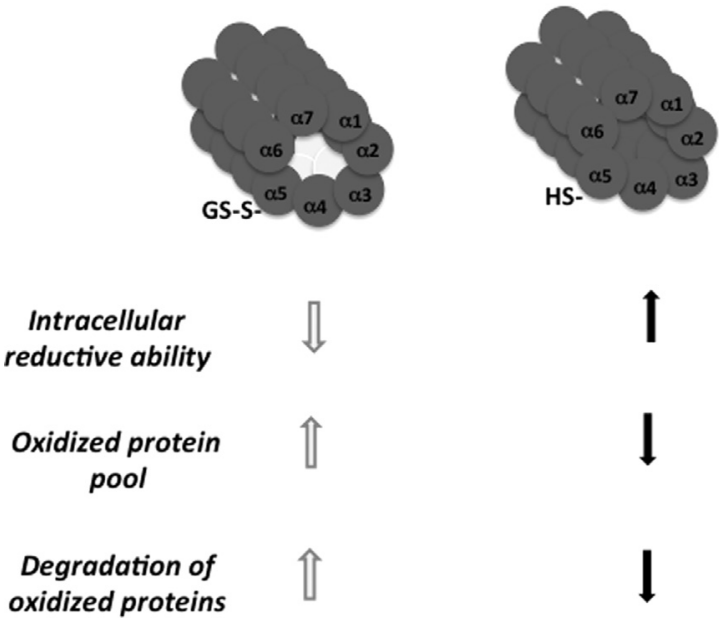

Fig. 4. The regulation of the 20SPT S-glutathionylation inside cells and the degradation of oxidized proteins. According to our hypothesis, when cells go through an oxidative imbalance, which results in the loss of their reducing ability, the pool of oxidized proteins increases and free 20SPT is S-glutathionylated. This modification of the 20SPT allows gate opening which increases the degradation of oxidized proteins (left). Opposite conditions are likely when cells possess increased reducing ability (right).

glucose-rich, synthetic, or glycerol/ethanol media or $\alpha 5$-C221S and $\alpha 5-C 76 S$ mutants extracted from yeast cells grown in glucose-rich medium (Fig. 3E; unpublished results). Most likely, gate opening is a stepwise process starting with oxidation of specific sulfhydryl groups followed by $S$-glutathionylation of a few Cys residues. It seems that the maximum diameter of the open conformation is achieved when the $\alpha 5$-Cys76 residue is S-glutathionylated. Analysis of 20SPT dimensions by SAXS is underway by our group to confirm these results.

S-glutathionylation of $\alpha 5-\mathrm{C} 221$ and -C76 residues as observed in extracts from yeast cells grown to stationary phase in glucoserich medium, degraded oxidized proteins at an increased rate [30]. Decreased protein degradation was observed in 20SPT preparations obtained by treatment with sulfhydryl reductants (DTT or TCEP). Moreover, yeast cells presented a decreased pool of oxidized proteins, a decreased ratio of $20 \mathrm{~S}$ to $19 \mathrm{~S}$ complexes and increased pool of the 20SPT in open configuration when grown in medium that triggers fermentative metabolism. Opposite results were observed in cells presenting increased reductive ability, such as those grown in respiratory conditions (Demasi et al., unpublished).

The data obtained thus far supports the hypothesis that 20SPT $S$-glutathionylation is a post-translational modification that modulates proteasome activity toward oxidized proteins. The gate opening of the free 20SPT pool would increase the degradation of oxidized proteins when cells transiently lose their reductive ability (Fig. 4).

The deglutathionylation of the yeast 20SPT was investigated in vitro with the yeast recombinant oxidoreductases Grx2, Trx1 and Trx2 as potential deglutathionylating enzymes [32]. These three enzymes were equally competent for 20SPT deglutathionylation, as identical molar ratios of 20SPT:oxidoreductases produced similar results. However, these enzymes are easily degraded in vitro by the 20SPT. Because the substrate moieties of the oxidoreductases are located on the external proteasomal surface ( $\alpha 5-\mathrm{C} 221)$, in the $\alpha$-pocket ( $\alpha 5-\mathrm{C} 76)$, and out of the catalytic chamber (internal $\beta$-rings), their activity as proteasomal deglutathionylating enzymes is reliable. However, the physiological meaning of their role in the regulation of 20SPT redox modulation needs further investigation. 
The 19S regulatory unit was also shown to go through redox modification via $S$-glutathionylation. The $S$-glutathionylation of the Rpn1 and Rpn2 subunits of the 19S regulatory complex was shown to induce the loss of ChT-L proteasomal catalytic activity in mammalian cells [33]. Interestingly, oxidoreductases associate with the 19S complex in both fission yeast Schizosaccharomyces pombe (Txl1) and mammalian (Txnl1) cells; however, this process is not yet well understood [34,35]. It is unclear whether these proteins function as disulfide reductants of proteasomal substrates, of the proteasome itself, or of proteasomal co-factors.

\section{Proteasome channel gating}

The relationship between 20SPT channel gating and the coupling of regulatory units $19 \mathrm{~S}, 11 \mathrm{~S}$ and the PA200 has been extensively studied [36-38]. Of the regulatory units, the $19 \mathrm{~S}$ is most abundant. Binding of this unit to the $20 \mathrm{~S}$ core particle results in gate opening and substrate degradation. Proteolysis is a coordinate process involving binding of the poly-ubiquitinylated substrate, deubiquitinylation by 195 activity and binding of ATP to the 19S ATPase hexameric ring. Gating is dependent on the coupling of both units (20S and 19S) and on binding of ATP to the hexameric ring located in the base of the $19 \mathrm{~S}$ unit. However, stabilization of the 20SPT open conformation and substrate unfolding and translocation are dependent on the poly-ubiquitinylated substrate binding to the $19 S$ unit and ATP hydrolysis, respectively. The 195 regulatory particle and 20SPT interact through the 19S ATPase hexameric ring and the 20SPT $\alpha$-heptameric ring. A perfect fitting between these rings is impossible because of their diverse symmetries. The $19 \mathrm{~S}$ unit undergoes conformational changes depending on the nucleotide state of its ATPase subunits allowing interaction with the 20SPT $\alpha$-ring [38]. Pockets between $\alpha$-subunits on the 20SPT participate in interactions between 19S and 20SPT.

In the closed 20SPT conformation, the N-termini of the $\alpha$ subunits form an intricate lattice of interactions that block access to the catalytic chamber through the so called $\alpha$-annulus, located just below the surface of the $\alpha$-heptameric ring. This conformation supposedly maintains a fixed opening of 13-20 A allowing the entrance of only small peptides [39]. The N-terminal of the $\alpha 3$ subunit of yeast proteasome was shown to be essential for the closed conformation as it causes the stabilization of the neighboring tails of the $\alpha$-ring. Deletion of the $\alpha 3 \mathrm{~N}$-terminal causes gate opening as deduced from its activation whereas deletion of the N-termini of both $\alpha 3$ and $\alpha 7$ was shown to promote permanent open conformation of the 20SPT [40]. It has been shown that $\alpha 3$-subunit knockout yeast strains incubated in high levels of the pro-oxidant cadmium induced the formation of an alternative $\alpha$-ring structure composed of a double $\alpha 4$-subunit [41]. Remarkably, these mutated strains grew more robustly than the wild type in the presence of cadmium, suggesting that the alternative conformation provides a selective advantage under oxidative stress. A possible explanation for this phenotype might be that the absence of the $\alpha 3$-subunit facilitates formation of the 20SPT open conformation.

Some treatments such as exposure to minute amounts of detergents, hydrophobic peptides, and medium at low ionic strength promote disordering of the blocking $\alpha$-N-termini allowing substrate entry [42].

Interestingly, 20SPT represents $20-30 \%$ of the total proteasome pool in mammal and yeast cells [43-46]. However, there is no systematic study addressing the gate conformation of the free physiological 20SPT pool. As will be discussed below, the free 20SPT pool is likely crucial for the degradation of oxidized proteins.

\section{SPT as the main player in the removal of oxidized proteins}

Proteins can oxidize by ROS and NO derived species through a variety of pathways [47]. Oxidative protein damage results in chemical modification of the side chain of amino acid residues [48]. Proteins are poorly repaired in comparison to other macromolecules. Only the sulfur-containing amino acids Met and Cys can be reduced from sulfoxide and some oxidized forms, respectively. Since the middle 1980s, protein degradation has been proposed as the main mechanism of cells to cope with oxidative modification $[49,50]$. This mechanism was first observed in the ATP-independent degradation of oxidatively damaged proteins in extracts of red blood cells, whereas the non-oxidized forms of the model proteins were not degraded under same conditions [49]. Moreover, the degradation of mildly oxidized proteins by 20SPT was extensively investigated in vitro [51]. Since that time, the 20SPT has been proposed to be the preferential system to degrade oxidized proteins. The degradation of oxidized proteins was demonstrated in mammal and yeast cellular models to be independent of polyubiquitinylation. These results precluded degradation by the 26SPT pool [52-54].

Indeed, the most important data to date linking degradation of oxidized proteins to a free pool of 20SPT inside cells is indirect: uncoupling between the $19 \mathrm{~S}$ and $20 \mathrm{~S}$ particles during oxidative stress [54-56], transient inactivation of enzymes involved in the ubiquitylation and deubiquitylation of proteins [57-59], higher susceptibility of the $19 \mathrm{~S}$ to oxidation as compared to the $20 \mathrm{~S}$ $[55,60]$, and no preference for the ubiquitinylation of oxidized proteins [61]. In addition, 26SPT decoupling was shown to be dependent on the proteasome-interacting protein Ecm29 in budding yeast [54]. Strains lacking this protein are more sensitive to oxidative stress. Their recovery from it is also delayed. In mammalian cells, a similar mechanism of decoupling under oxidative challenge was described as being mediated by HSP70 [56]. These data suggest that when cells experience oxidative imbalances, there is an adaptive response to increase the pool of free 20SPT.

An important criticism against degradation of oxidized proteins by free 20SPT is that the closed gate does not support the entrance of folded proteins [42]. However, it is known that oxidized proteins interact with the 20SPT through hydrophobic patches exposed on the protein surface due to partial unfolding upon oxidation [62-64]. It is thought that proteasomal interaction with the hydrophobic protein surface would trigger 20SPT gating [1]. This mechanism is supported by the observation that proteasome opening is triggered by the C-terminal hydrophobic motif HbYX (hydrophobic residue, conserved penultimate tyrosine and a variable C-terminal residue) of three 19S ATPase subunits that interact with the $\alpha$-subunits of the 20SPT [65]. Notably, peptides containing the motif trigger proteasomal opening independent of 195 unit coupling. Many other reports in the literature show increased peptidolytic proteasomal activity upon incubation with hydrophobic compounds, suggesting that hydrophobic interactions activate the 20SPT. Some structured proteins can be degraded independently by the 20SPT, supposedly through hydrophobic interactions $[64,66]$.

Indeed, there is no extant systematic study reporting the gate conformation of the free 20SPT pool. It is currently assumed that free 20SPT would be in a latent form, which usually means the closed conformation, allowing the entrance of only peptides [67]. The most conclusive data supporting this assumption are related to crystallographic studies of the yeast and mammal 20SPT $[68,69]$. However, the presence of inhibitors, the yeast growth conditions, and the addition of thiol reductants in the extraction buffers utilized for proteasomal purification make it impossible to infer the conformation of the $20 \mathrm{~S}$ proteasomal gate in vivo. 
A major question to be addressed regarding preferential degradation of oxidized proteins inside cells is whether such proteins are ubiquitinylated and are therefore subject to 26SPT proteolysis. Related to this question is whether proteolysis by free 20SPT, which bypasses ubiquitinylation, is kinetically favored. During oxidative stress, proteins already ubiquitinylated or being ubiquitinylated that are also being oxidized may be reliably degraded after 26SPT recognition. In addition, mild oxidation of specific proteins may augment their ubiquitinylation because oxidationinduced conformational changes might expose specific ubiquitinylation targets, as predicted by the $\mathrm{N}$-end rule $[70,71]$. The energy and time costs of degrading ubiquitinylated substrates by the $26 \mathrm{~S}$ proteasome was recently explored [72], showing it to be dependent on protein length and how tightly the protein is folded among other variables involving 26S proteasomal properties and the ubiquitinylation process. By comparing two substrates differing in length and folding, these authors demonstrated that the molar ratio between ATP consumption and protein substrate could vary from 50 to 160 . The time course for degradation increased proportionally with increased protein length. According to these data, degradation of ubiquitinylated substrates is a process that consumes large amounts of energy.

The notion that oxidized proteins might promptly interact with the free 20SPT pool is attractive, as the process is most likely kinetically favored. The rate-limiting step of the preferential degradation of oxidized proteins by the 20SPT free pool would be the availability of active 20SPT. Strengthening this hypothesis are the observations that 20SPT uncouples from the 19S regulatory particle during oxidative stress $[54,56]$ and that $S$-glutathionylation stabilizes the 20SPT active open conformation [30]. Therefore, more accurate approaches are needed to measure the kinetics of degradation of oxidized proteins inside cells.

\section{Final remarks}

This review presents data regarding $S$-glutathionylation as a potential regulatory mechanism for 20SPT [2]. Four main observations supporting this notion were reviewed: (1) modification of specific Cys residues under physiological conditions (high GSH/ GSSG ratio); (2) conformational changes of the modified protein; (3) reversibility of the reaction; and (4) concomitant change of the physiological response, e.g., the increased degradation of oxidized proteins. Therefore, we hypothesize that 20SPT S-glutathionylation plays a regulatory role that allows cells to cope with increased oxidative stress (Fig. 4).

There are few studies on proteasomal S-glutathionylation resulting in structural and functional modifications, and thus many questions remain unaddressed. One important question is whether S-glutathionylation would trigger $26 \mathrm{~S}$ uncoupling per se during oxidative stress. Additionally, two open questions are why and how oxidized proteins interact with 20SPT. Peptide fragments generated by both redox forms of 20SPT are also predicted to differ, as the peptidolytic activities of both forms differ $[25,26]$. Finally, additional unresolved questions are whether S-glutathionylation is enzymatically regulated and whether oxidized protein degradation through the free S-glutathionylated 20SPT presents a kinetic advantage over degradation via 26SPT.

It is noteworthy that the number of Cys residues in the proteasome core particle evolved from 32 in yeast to 54 in human. No disulfide bond is present in yeast 20SPT but there are two in human 20SPT. As demonstrated previously, the ChT-L activity of the human 20SPT is modulated by both glutathione redox states and at a broad glutathione concentration range [25]. This observation contrasts with yeast 20SPT which is modulated only by the reduced glutathione form. Whether the increased number of Cys residues in the mammal proteasome would be a functional evolutionary advantage is an intriguing open question.

\section{Acknowledgements}

I am grateful to the authors for their important contributions to the work described here. The studies by our group cited in the present review were supported by FAPESP (Fundação de Amparo a Pesquisa do Estado de São Paulo), the Instituto Nacional de Ciência, Tecnologia e Inovação de Processos Redox em BioMedicina (Redoxome; CNPq, FAPESP, CAPES), and the Conselho Nacional de Ciência e Tecnologia (CNPq).

\section{References}

[1] T. Jung, T. Grune, The proteasome and the degradation of oxidized proteins: Part I-Structure of proteasomes, Redox Biol. 1 (2013) 178-182.

[2] J.J. Mieyal, P.B. Chock, Posttranslational modification of cysteine in redox signaling and oxidative stress: focus on s-glutathionylation, Antioxid. Redox Signal. 16 (2012) 471-475.

[3] D.M. Ziegler, Role of reversible oxidation-reduction of enzyme thiolsdisulfides in metabolic regulation, Annu. Rev. Biochem. 54 (1985) 305-329.

[4] M.M. Gallogly, J.J. Mieyal, Mechanisms of reversible protein glutathionylation in redox signaling and oxidative stress, Curr. Opin. Pharmacol. 7 (2007) 381-391.

[5] I. Dalle-Donne, R. Rossi, G. Colombo, D. Giustarini, A. Milzani, Protein Sglutathionylation: a regulatory device from bacteria to humans, Trends Biochem. Sci. 34 (2009) 85-96.

[6] B.G. Hill, A. Bhatnagar, Protein S-glutathiolation: redox-sensitive regulation of protein function, J. Mol. Cell. Cardiol. 52 (2012) 559-567.

[7] P. Klatt, S. Lamas, Regulation of protein function by S-glutathiolation in response to oxidative and nitrosative stress, Eur. J. Biochem. 267 (2000) 4928-4944.

[8] M. Gutscher, M.C. Sobotta, G.H. Wabnitz, S. Ballikaya, A.J. Meyer, Y. Samstag, T.P. Dick, Proximity-based protein thiol oxidation by $\mathrm{H}_{2} \mathrm{O}_{2}$-scavenging peroxidases, J. Biol. Chem. 284 (2009) 31532-31540.

[9] A. Malvezzi, P.M. Higa, A. T-do Amaral, G.M. Silva, F.C. Gozzo, E.S. Ferro, L.M. Castro, L. de Rezende, G. Monteiro, M. Demasi, The cysteine-rich protein thimet oligopeptidase as a model of the structural requirements for S-glutathiolation and oxidative oligomerization, PLoS One 7 (2012) e39408.

[10] A. Martínez-Ruiz, S. Cadenas, S. Lamas, Nitric oxide signaling: classical, less classical, and nonclassical mechanisms, Free Radic. Biol. Med. 51 (2011) 17-29.

[11] H. Østergaard, C. Tachibana, J.R. Winther, Monitoring disulfide bond formation in the eukaryotic cytosol, J. Cell Biol. 166 (2004) 337-345.

[12] B. Morgan, D. Ezerina, T.N. Amoako, J. Riemer, M. Seedorf, T.P. Dick, Multiple glutathione disulfide removal pathways mediate cytosolic redox homeostasis, Nat. Chem. Biol. 9 (2013) 119-125.

[13] N. Le Moan, G. Clement, S. Le Maout, F. Tacnet, M.B. Toledano, The Saccharomyces cerevisiae proteome of oxidized protein thiols: contrasted functions for the thioredoxin and glutathione pathways, J. Biol. Chem. 81 (2006) 10420-10430.

[14] D.D. Sarkar, S.K. Edwards, J.A. Mauser, A.M. Suarez, M.A. Serowoky, N.L. Hudok, P.L. Hudok, M. Nuñez, C.S. Weber, R.M. Lynch, O. Miyashita, T.S. Tsao, Increased redox-sensitive green fluorescent protein reduction potential in the endoplasmic reticulum following glutathione-mediated dimerization, Biochemistry 52 (2013) 3332-3345.

[15] Gupta V., Carroll K.S. Sulfenic acid chemistry, detection and cellular lifetime. Biochim. Biophys. Acta doi:pii: S0304-4165(13)00244-4. 10.1016/j.bbagen. 2013.05.040

[16] D. Pimentel, D.J. Haeussler, R. Matsui, J.R. Burgoyne, R.A. Cohen, M.M. Bachschmid, Regulation of cell physiology and pathology by protein $S$-glutathionylation: lessons learned from the cardiovascular system, Antioxid. Redox Signal. 16 (2012) 524-542.

[17] C.C. Winterbourn, M.B. Hampton, Thiol chemistry and specificity in redox signaling, Free Radic. Biol. Med. 45 (2008) 549-561.

[18] L. Flohé, The fairytale of the GSSG/GSH redox potential, Biochim. Biophys. Acta 3139-42 (1830) 2013.

[19] C.A. Tairum Jr, MA de Oliveira, BB Horta, FJ Zara, LE. Netto, Disulfide biochemistry in 2-cys peroxiredoxin: requirement of Glu50 and $\operatorname{Arg} 146$ for the reduction of yeast Tsa1 by thioredoxin, J. Mol. Biol. 424 (2012) 28-41.

[20] A.M. Day, J.D. Brown, S.R. Taylor, J.D. Rand, B.A. Morgan, E.A. Veal, Inactivation of a peroxiredoxin by hydrogen peroxide is critical for thioredoxin-mediated repair of oxidized proteins and cell survival, Mol. Cell 45 (2012) 398-408.

[21] C.L. Grek, J. Zhang, Y. Manevich, D.M. Townsend, K.D. Tew, Causes and consequences of cysteine s-glutathionylation, J. Biol. Chem. 288 (2013) 26497-26504.

[22] M. Kemp, Y.M. Go, D.P. Jones, Non equilibrium thermodynamics of thiol/ disulfide redox systems: a perspective on redox systems biology, Free Radic. Biol. Med. 44 (2008) 921-937. 
[23] D.M. Townsend, Y. Manevich, L. He, S. Hutchens, C.J. Pazoles, K.D. Tew, Novel role for glutathione $S$-transferase pi. Regulator of protein S-Glutathionylation following oxidative and nitrosative stress, J. Biol. Chem. 284 (2009) 436-445.

[24] E.M. Allen, J.J. Mieyal, Protein-thiol oxidation and cell death: regulatory role of glutaredoxins, Antioxid. Redox Signal. 17 (2012) 1748-1763.

[25] M. Demasi, R. Shringarpure, K.J. Davies, Glutathiolation of the proteasome is enhanced by proteolytic inhibitors, Arch. Biochem. Biophys. 389 (2001) 254-263.

[26] M. Demasi, G.M. Silva, L.E. Netto, 20 S proteasome from Saccharomyces cerevisiae is responsive to redox modifications and is S-glutathionylated, J. Biol. Chem. 278 (2003) 679-685.

[27] D.P. Dixon, M. Skipsey, N.M. Grundy, R. Edwards, Stress-induced protein S-glutathionylation in Arabidopsis, Plant Physiol. 138 (2005) 2233-2244.

[28] S.K. Niture, C.S. Velu, N.I. Bailey, K.S. Srivenugopal, S-thiolation mimicry: quantitative and kinetic analysis of redox status of protein cysteines by glutathione-affinity chromatography, Arch. Biochem. Biophys. 444 (2005) 174-184.

[29] C. Zong, G.W. Young, Y. Wang, H. Lu, N. Deng, O. Drews, P. Ping, Twodimensional electrophoresis- based characterization of post-translational modifications of mammalian 20S proteasome complexes, Proteomics 8 (2008) 5025-5037.

[30] G.M. Silva, L.E. Netto, V. Simões, L.F. Santos, F.C. Gozzo, M.A. Demasi, C.L. Oliveira, R.N. Bicev, C.F. Klitzke, M.C. Sogayar, M. Demasi, Redox control of 20S proteasome gating, Antioxid. Redox Signal. 16 (2012) 1183-1194.

[31] D.J. Jamieson, Oxidative stress responses of the yeast Saccharomyces cerevisiae, Yeast 14 (1998) 1511-1527.

[32] G.M. Silva, L.E. Netto, K.F. Discola, G.M. Piassa-Filho, D.C. Pimenta, J.A. Bárcena, M. Demasi, Role of glutaredoxin 2 and cytosolic thioredoxins in cysteinylbased redox modification of the 20 S proteasome, FEBS J. 275 (2008) $2942-2955$.

[33] J.W. Zmijewski, S. Banerjee, E. Abraham, S-glutathionylation of the Rpn2 regulatory subunit inhibits $26 \mathrm{~S}$ protea- somal function, J. Biol. Chem. 284 (2009) 22213-22221.

[34] K.M. Andersen, L. Madsen, S. Prag, A.H. Johnsen, C.A. Semple, K.B. Hendil, R. Hartmann-Petersen, Thioredoxin Txnl1/TRP32 is a redox-active cofactor of the 26 S proteasome, J. Biol. Chem. 284 (2009) 15246-15254.

[35] K.M. Andersen, C. Jensen, F. Kriegenburg, A-MB Lauridsen, C. Gordon, R. Hartmann-Petersen, Txl1 and Txc1 are co-factors of the 26S proteasome in fission yeast, Antioxid. Redox Signal. 14 (2011) 1601-1608.

[36] X. Li, G.N. Demartino, Variably modulated gating of the $26 \mathrm{~S}$ proteasome by ATP and polyubiquitin, Biochem. J. 421 (2009) 397-404.

[37] S. Bar-Nun, M.H. Glickman, Proteasomal AAA-ATPases: structure and function, Biochim. Biophys. Acta 67-82 (1823) 2012.

[38] P. Sledź, F. Förster, W.J. Baumeister, Allosteric effects in the regulation of $26 \mathrm{~S}$ proteasome activities, Mol. Biol. 425 (2013) 1415-1423.

[39] B.M. Stadtmueller, C.P. Hill, Proteasome activators, Mol. Cell. 41 (2011) 8-19.

[40] M. Groll, M. Bajorek, A. Köhler, L. Moroder, D.M. Rubin, R. Huber, M.H. Glickman, D. Finley, A gated channel into the proteasome core particle, Nat. Struct. Biol. 7 (2000) 1062-1067.

[41] A.R. Kusmierczyk, M.J. Kunjappu, M. Funakoshi, M. Hochstrasser, A multimeric assembly factor controls the formation of alternative $20 \mathrm{~S}$ proteasomes, Nat. Struct. Mol. Biol. 153 (2008) 237-244.

[42] M. Bajorek, M.H. Glickman, Keepers at the final gates: regulatory complexes and gating of the proteasome channel, Cell. Mol. Life Sci. 61 (2004) 1579-1588.

[43] T. Shibatani, E.J. Carlson, F. Larabee, A.L. McCormack, K. Fruh, W.R. Skach, Global organization and function of mammalian cytosolic proteasome pools: implications for PA28 and 19S regulatory complexes, Mol. Biol. Cell 17 (2006) 4962-4971.

[44] S.E. Babbitt, A. Kiss, A.E. Deffenbaugh, Y.H. Chang, E. Bailly, H. ErdjumentBromage, P. Tempst, T. Buranda, L.A. Sklar, J. Baumler, E. Gogol, D. Skowyra, ATP hydrolysis-dependent disassembly of the $26 \mathrm{~S}$ proteasome is part of the catalytic cycle, Cell 121 (2005) 553-565.

[45] N. Tanahashi, Y. Murakami, Y. Minami, N. Shimbara, K.B. Hendil, K. Tanaka, Hybrid proteasomes. Induction by interferon-gamma and contribution to ATPdependent proteolysis, J. Biol. Chem. 275 (2000) 14336-14345.

[46] K.B. Hendil, S. Khan, K. Tanaka, Simultaneous binding of PA28 and PA700 activators to 20 S proteasomes, Biochem. J. 332 (1998) 749-754.

[47] Höhn A., König J., Grune T. Protein oxidation in aging and the removal of oxidized proteins. J. Proteomics doi:pii: S1874-3919(13)00021-3. 10.1016/j. jprot.2013.01.004.
[48] E.R. Stadtman, Protein oxidation and aging, Free Radic. Res. 40 (2006) $1250-1258$.

[49] K.J. Davies, A.L. Goldberg, Proteins damaged by oxygen radicals are rapidly degraded in extracts of red blood cells, J. Biol. Chem. 262 (1987) 8227-8234.

[50] K.J. Davies, M.E. Delsignore, Protein damage and degradation by oxygen radicals. III. Modification of secondary and tertiary structure, J. Biol. Chem. 262 (1987) 9908-9913.

[51] K.J. Davies, Protein damage and degradation by oxygen radicals. I. general aspects, J. Biol. Chem. 262 (1987) 9895-9901.

[52] Y. Inai, M. Nishikimi, Increased degradation of oxidized proteins in yeast defective in 26 S proteasome assembly, Arch. Biochem. Biophys. 404 (2002) 279-284.

[53] R. Shringarpure, T. Grune, J. Mehlhase, K.J. Davies, Ubiquitin conjugation is not required for the degradation of oxidized proteins by proteasome, J. Biol. Chem. 278 (2003) 311-318.

[54] X. Wang, J. Yen, P. Kaiser, L. Huang, Regulation of the 26 S proteasome complex during oxidative stress, Sci. Signaling 3 (2010). (ra88).

[55] T. Reinheckel, O. Ullrich, N. Sitte, T. Grune, Differential impairment of $20 \mathrm{~S}$ and 265 proteasome activities in human hematopoietic K562 cells during oxidative stress, Arch. Biochem. Biophys. 377 (2000) 65-68.

[56] T. Grune, B. Catalgol, A. Licht, G. Ermak, A.M. Pickering, J.K. Ngo, K.J. Davies, HSP70 mediates dissociation and reassociation of the 26S proteasome during adaptation to oxidative stress, Free Radic. Biol. Med. 51 (2011) 1355-1364.

[57] J. Jahngen-Hodge, M.S. Obin, X. Gong, F. Shang, T.R. Nowell Jr, J. Gong, H. Abasi, J. Blumberg, A. Taylor, Regulation of ubiquitin-conjugating enzymes by glutathione following oxidative stress, J. Biol. Chem. 272 (1997) 28218-28226.

[58] M. Obin, F. Shang, X. Gong, G. Handelman, J. Blumberg, A. Taylor, Redox regulation of ubiquitin-conjugating enzymes: mechanistic insights using the thiol-specific oxidant diamide, FASEB J. 12 (1998) 561-569.

[59] F.M. da Cunha, M. Demasi, A.J. Kowaltowski, Aging and calorie restriction modulate yeast redox state, oxidized protein removal, and the ubiquitinproteasome system, Free Radic. Biol. Med. 51 (2011) 664-670.

[60] T. Reinheckel, N. Sitte, O. Ullrich, U. Kuckelkorn, KJ. Davies, T. Grune, Comparative resistance of the $20 \mathrm{~S}$ and $26 \mathrm{~S}$ proteasome to oxidative stress, Biochem. J. 335 (1998) 637-642.

[61] M. Kästle, S. Reeg, A. Rogowska-Wrzesinska, T. Grune, Chaperones, but not oxidized proteins, are ubiquitinated after oxidative stress, Free Radic. Biol. Med. 53 (2012) 1468-1477.

[62] R.E. Pacifici, Y. Kono, K.J. Davies, Hydrophobicity as the signal for selective degradation of hydroxyl radical-modified hemoglobin by the multicatalytic proteinase complex, proteasome, J. Biol. Chem. 268 (1993) 15405-15411.

[63] D.A. Ferrington, H. Sun, K.K. Murray, J. Costa, T.D. Williams, D.J. Bigelow, T.C. Squier, Selective degradation of oxidized calmodulin by the $20 \mathrm{~S}$ proteasome, J. Biol. Chem. 276 (2001) 937-943.

[64] J.M. Baugh, E.G. Viktorova, E.V. Pilipenko, Proteasomes can degrade a significant proportion of cellular proteins independent of ubiquitination, J. Mol. Biol. 386 (2009) 814-827.

[65] D.M. Smith, S.C. Chang, S. Park, D. Finley, Y. Cheng, A.L. Goldberg Docking of the proteasomal ATPases' carboxyl termini in the 20S proteasome's $\alpha$ ring opens the gate for substrate entry, Mol. Cell. 27 (2007) 731-744.

[66] C.W. Liu, M.J. Corboy, G.N. De Martino, P.J. Thomas, Endoproteolytic activity of the proteasome, Science 299 (2003) 408-411.

[67] E. Kish-Trier, C.P. Hill, Structural biology of the proteasome, Annu. Rev. Biophys. 42 (2013) 29-49.

[68] M. Groll, L. Ditzel, J. Löwe, D. Stock, M. Bochtler, H.D. Bartunik, R. Huber, Structure of 20S proteasome from yeast at 2.4A resolution, Nature 386 (1997) 463-471.

[69] M. Unno, T. Mizushima, Y. Morimoto, Y. Tomisugi, K. Tanaka, N. Yasuoka, T. Tsukihara, The structure of the mammalian $20 \mathrm{~S}$ proteasome at $2.75 \mathrm{~A}$ resolution, Structure 10 (2002) 609-618.

[70] A. Varshavsky, The N-end rule pathway and regulation by proteolysis, Protein Sci. 20 (2011) 1298-1345.

[71] T. Tasaki, S.M. Sriram, K.S. Park, Y.T. Kwon, The N-end Rule Pathway 81 (2012) 261-289.

[72] A. Peth, J.A. Nathan, A.L. Godberg, The ATP Costs and Time Required to Degrade Ubiquitinated Proteins by the 26S Proteasome, J. Biol. Chem. (2013). (Epub ahead of print) 
A.3. 20S proteasome activity is modified via S-glutathionylation based on intracellular redox status of

the yeast Saccharomyces cerevisiae: Implications for the degradation of oxidized proteins

A.3 20 S proteasome activity is modified via S-glutathionylation ba-

sed on intracellular redox status of the yeast Saccharomyces

cerevisiae: Implications for the degradation of oxidized proteins

\author{
Atividade do proteassomo 20S é modificada via S-glutathionilação com base \\ no estado redox intracelular de levedura Saccharomyces cerevisiae: \\ Implicações para a degradação de proteínas oxidadas
}

A S-glutathionilação da proteína é uma modificação pós-traducional que controla muitas vias celulares. Recentemente, demonstrou-se que a subunidade $\alpha 5$ do proteassomo 20S é S-glutationilizada em células de levedura crescidas na fase estacionária em meio rico em glicose, estimulando a abertura da passagem do núcleo do $20 \mathrm{~S}$ e aumentando a degradação de proteínas oxidadas. No presente estudo, nós avaliamos a correlação entre S-glutathionilação do proteossomo e o estado redox intracelular. O estado redox foi controlado pelo crescimento de células de levedura em fontes de carbono distintas que induziram metabolismo respiratório (glicerol / etanol) ou fermentativo (glicose). As células cultivadas em glicerol / etanol exibem poder de redução superior quando em comparação com células crescidas em glicose. Quando purificado a partir de células crescidas em glicose, a subunidade $\alpha 5$ do proteassomo 20S exibiu uma intensa marcação anti-glutationa. A maior frequência da abertura da câmera catalítica foi observado nas preparações Sglutathioniladas como demonstrado por microscopia eletrônica de transmissão. Portanto, as células crescidas em glicose indicou uma maior capacidade para degradar proteínas oxidadas. Os resultados do presente estudo sugerem que a S-glutationilação do proteassomo 20S é uma resposta adaptativa relevante para o stress oxidativo, que é capaz de perceber 
o ambiente redox intracelular, que conduz para a remoção de proteínas oxidadas por meio de um processo que não é dependente de ubiquitinação e consumo de ATP 


\title{
20S proteasome activity is modified via S-glutathionylation based on intracellular redox status of the yeast Saccharomyces cerevisiae: Implications for the degradation of oxidized proteins
}

\author{
Marilene Demasi $^{\mathrm{a}, *}$, Adrian Hand ${ }^{\mathrm{a}}$, Erina Ohara ${ }^{a}$, Cristiano L.P. Oliveira ${ }^{\mathrm{b}}$, Renata N. Bicev ${ }^{\mathrm{b}}$, \\ Clelia A. Bertoncini ${ }^{c}$, Luis E.S. Netto ${ }^{d}$ \\ ${ }^{a}$ Laboratório de Bioquímica e Biofisica, Instituto Butantan, Brazil \\ ${ }^{\mathrm{b}}$ Instituto de Física, Universidade de São Paulo, Brazil \\ ${ }^{\mathrm{c}}$ Universidade Federal de São Paulo, Brazil \\ ${ }^{\mathrm{d}}$ Departamento de Genética e Biologia Evolutiva, Instituto de Biociências, Universidade de São Paulo, Brazil
}

\section{A R T I C L E I N F O}

\section{Article history:}

Received 23 December 2013

and in revised form 11 April 2014

Available online $\mathrm{xxxx}$

\section{Keywords:}

20S proteasome

S-glutathionylation

S. cerevisiae

Redox modulation

Oxidized proteins

Proteolysis

\begin{abstract}
A B S T R A C T
Protein S-glutathionylation is a post-translational modification that controls many cellular pathways. Recently, we demonstrated that the $\alpha 5$-subunit of the 20S proteasome is S-glutathionylated in yeast cells grown to the stationary phase in rich medium containing glucose, stimulating $20 \mathrm{~S}$ core gate opening and increasing the degradation of oxidized proteins. In the present study, we evaluated the correlation between proteasomal S-glutathionylation and the intracellular redox status. The redox status was controlled by growing yeast cells in distinct carbon sources which induced respiratory (glycerol/ethanol) or fermentative (glucose) metabolism. Cells grown under glycerol/ethanol displayed higher reductive power when compared to cells grown under glucose. When purified from cells grown in glucose, 20S proteasome $\alpha 5$-subunit exhibited an intense anti-glutathione labeling. A higher frequency of the open catalytic chamber gate was observed in the S-glutathionylated preparations as demonstrated by transmission electron microscopy. Therefore, cells that had been grown in glucose displayed an increased ability to degrade oxidized proteins. The results of the present study suggest that $20 \mathrm{~S}$ proteasomal S-glutathionylation is a relevant adaptive response to oxidative stress that is capable to sense the intracellular redox environment, leading to the removal of oxidized proteins via a process that is not dependent upon ubiquitylation and ATP consumption.
\end{abstract}

(c) 2014 Elsevier Inc. All rights reserved.

\section{Introduction}

The proteasome is the main nuclear and cytosolic proteolytic system that degrades intracellular proteins, and it exists in distinct forms. The $26 \mathrm{~S}$ proteasome degrades proteins that have been modified by a poly-ubiquitin chain and that are involved in major cellular functions related to signaling, cell cycle regulation and homeostasis. The $26 \mathrm{~S}$ proteasome is composed of a catalytic unit, termed the $20 \mathrm{~S}$ proteasome $(20 \mathrm{~S}){ }^{1}$ and the $19 \mathrm{~S}$ regulatory unit,

\footnotetext{
* Corresponding author. Address: Laboratório de Bioquímica e Biofísica, Instituto Butantan, Avenida Vital Brasil, 1500, São Paulo, SP CEP 05503-001, Brazil. Fax: +55 $1137267222 \times 2018$.

E-mail address: marimasi@butantan.gov.br (M. Demasi).

1 Abbreviations used: BSA, bovine serum albumin; 2-DE PAGE, two-dimensional poly-acrylamide gel electrophoresis; DNPH, 2,4-dinitrophenylhydrazine; DTT, dithiothreitol; Glu, yeast cells grown in glucose-synthetic medium; Gly, yeast cells grown in glycerol/ethanol-synthetic medium; GR, glutathione reductase; Grx2, recombinant glutaredoxin 2; GSH, glutathione; GSSG, oxidized glutathione; HRP, horse radish peroxidase; OD, optical density; 20S, 20S proteasome; 26S, 26S proteasome; TEM, transmission electron microscopy; Trr, thioredoxin reductase; Trx, thioredoxin.
}

which is coupled to one or both sides of the 20S. The proteasome also exists in a form that is devoid of regulatory subunits, which is termed the free 20S. In mammalian and yeast cells, the $20 \mathrm{~S}$ accounts for one-third of the total proteasome [1-3]. The degradation of oxidatively modified proteins is considered to be one of the major roles of the 20S [4-6], which is of importance because few repair systems for oxidatively modified amino acid residues exist. The relevance of 20S-mediated degradation of oxidized proteins has been demonstrated in various cellular models to be a ubiquitinand ATP-independent process [7-10].

The $20 \mathrm{~S}$ is cylindrical in shape and is composed of four heptameric rings that are ordered as follows: $\alpha_{7} \beta_{7} \beta_{7} \alpha_{7}$. The outer $\alpha$ rings are responsible for proteasome gating, and the two $\beta$ rings contain three catalytic sites disposed in the $\beta 1,2$ and 5 subunits, summarizing six active sites in both $\beta$-heptamers. The opening of the $20 \mathrm{~S}$ gate is favored by coupling of the 19S unit, or alternatively, by other activators, such as the $11 \mathrm{~S}$ and PA200 [11]. The binding of poly-ubiquitylated substrates to the $19 \mathrm{~S}$ regulatory unit promotes 
gate opening, as previously demonstrated by the increased peptidolytic activity of the $20 \mathrm{~S}$ [12]. In addition, ATP binding to the ATPase hexameric ring, located in the base of the 19S unit, independent of ATP hydrolysis, is important for gate opening [13].

All of the free $20 \mathrm{~S}$ core particles within the cells were previously assumed to be in the closed gating conformation, although evidence has indicated that oxidized and disordered proteins can be degraded by the $20 \mathrm{~S}$ proteasome in vitro and in vivo $[7,14]$. We recently demonstrated that S-glutathionylation of the $20 \mathrm{~S}$ proteasomal $\alpha$-subunits promotes gate opening in a 19S-independent manner, increasing the degradation of oxidized proteins [15].

Cysteinyl-redox modification is a widespread enzymatic and regulatory mechanism that is coupled to intracellular redox signaling [16,17]. Protein S-glutathionylation is among these modifications and is related to many regulatory pathways, ranging from gene expression to the modification of transcription factors to enzymatic modulation [18-20].

Our present hypothesis is that the post-translational modification of the 20S via S-glutathionylation may play an antioxidant role, controlling oxidized protein levels inside the cells. Accordingly, we observed that the regulation of the $20 \mathrm{~S}$ by S-glutathionylation is correlated with the intracellular redox state. Therefore, in the present study, we evaluated the correlation between the intracellular redox status, proteasomal S-glutathionylation and the removal of oxidized proteins.

\section{Materials and methods}

Materials

Reagents were obtained from the following sources: anti-DNP antibody, azo-modified Bovine Serum Albumin (azo-BSA), dithiothreitol (DTT), $\mathrm{H}_{2} \mathrm{O}_{2}$, reduced glutathione (GSH) and yeast glutathione reductase from Sigma; anti-20S (subunits $\beta 1$ and $\beta 7$ ), anti-ubiquitin and anti-19S (Rpt4 subunit) antibodies from Merck; the molecular weight markers for SDS-PAGE from GE Healthcare; anti-actin and anti-ubiquitin antibodies from Santa Cruz Biotechnology, Inc.; anti-glutathione antibody from Arbor Assay; antiactin antibody from ICM; the Bradford protein assay reagent from Bio-Rad; Amplex Red from Molecular Probes; and horse-radish peroxidase (HRP) from Pierce. Anti-Grx2, anti-Trr1 and anti-Trx3 antibodies were generated in the Instituto Butantan via rabbit immunization with yeast recombinant proteins, as previously described [21].

\section{Yeast strain and growth}

The Saccharomyces cerevisiae RJD1144 strain (MATa his3 $\Delta 200$ leu2-3,112, lys2-801 trp1 $\Delta 63$ ura3-52 PRE1 ${ }^{\mathrm{FH}}::$ :Ylplac211 URA3), which was derived from JD47-13C, was kindly donated by Dr. Raymond Deshaies, Division of Biology, Caltech, Pasadena, CA. This strain contains a 20S Pre1 subunit that is tagged with a flag peptide sequence and a polyhistidine tail [22]. The cells were diluted to an $\mathrm{OD}_{600}$ of 0.1 , cultured in synthetic medium containing either $2 \%$ glucose (Glu) or $2 \%$ glycerol plus $2 \%$ ethanol (Gly) at $30^{\circ} \mathrm{C}$ with reciprocal shaking and harvested after a $48 \mathrm{~h}$ incubation. Growth to the stationary phase was monitored using a growth curve (Suppl. Data, Fig. S1).

\section{Extraction and purification of the 20S proteasome}

The 20S was purified using either affinity chromatography through a continuous gradient of imidazole in an HPLC system (Äkta Purifier GE Healthcare) or immunoprecipitation with the
ANTI-FLAG ${ }^{\circledR}$ M2 Affinity Gel Freezer-safe (Sigma), as previously described [23].

Intracellular measurements of total and oxidized glutathione, oxygen consumption, and $\mathrm{H}_{2} \mathrm{O}_{2}$ removal

Intracellular GSH and GSSG extraction and determination were performed as previously described [23]. Oxygen consumption was measured using a Clark-type electrode in a glass cuvette that was equipped with magnetic stirring, as described by Monteiro et al. [24]. To evaluate the total $\mathrm{H}_{2} \mathrm{O}_{2}$ removal activity, 5-1000 $\mu \mathrm{g}$ of the protein extracts of freshly lysed yeast cells were incubated with $0.1 \mathrm{M}$ phosphate buffer at $\mathrm{pH} 7.0$ for $3 \mathrm{~min}$ at $37{ }^{\circ} \mathrm{C}$ in the presence of $2 \mathrm{mM} \mathrm{H}_{2} \mathrm{O}_{2}$. A $2.5 \mu \mathrm{l}$ aliquot was collected and diluted into $200 \mu \mathrm{l}$ of buffer containing $50 \mu \mathrm{M}$ Amplex Red and $1.0 \mathrm{U} / \mathrm{ml}$ of horseradish peroxidase (HRP). Fluorescence emission was recorded at $587 \mathrm{~nm}$ (excitation at $563 \mathrm{~nm})$.

\section{Two-dimensional gel electrophoresis (2-D PAGE)}

Purified 20S preparations $(50 \mu \mathrm{g})$ were subjected to 2-D PAGE to separate the $20 \mathrm{~S}$ subunits. The first dimension was carried out on $7 \mathrm{~cm}$ IPG strips on a 4-7 pH gradient, as specified in the legends of the figures. After strip rehydration for $16 \mathrm{~h}$ at room temperature, IEF was conducted in gradient mode on an IPGphor 3 IEF system (GE Healthcare) according to the manufacturer's recommendations. The second dimension was performed on a 12.5\% SDS-PAGE, and the protein spots were visualized using Coomassie Brilliant Blue R-250 staining. The proteasomal subunits were identified using Maldi-TOF-MS fingerprinting, as described by Silva et al. [15]. When specified, the subunits that had been separated using 2-D PAGE electrophoresis were transferred to nitrocellulose membranes for anti-GSH labeling.

\section{Immunoblotting}

Immunoblotting was performed as outlined in the protocol that was enclosed in the ECL ${ }^{\mathrm{TM}}$ Western Blotting System packaging (GE Healthcare). After being labeled with the primary antibody, the membranes were incubated with horseradish peroxidaseconjugated secondary antibodies and the protein signals were detected using Enhanced Chemiluminescence Western Blotting Detection Reagents (GE Healthcare). The band intensities were quantified using the Histogram tool of the AdobePhotoshop software version 6.0. The dilutions of the primary antibodies were as follows: Anti-GSH, 1:500; anti-Actin, 1:750; anti-DNP, 1:5000; anti-20S, 1:1000; anti-19S, 1:1000; anti-Ub, 1:200; Anti-Trr1, 1:2000; anti-Trx3, 1:2000; and anti-Grx2, 1:1500.

\section{Proteolysis determination}

Total extracts of cells that had been grown in glucose and glycerol/ethanol-containing media were utilized to evaluate the degradation of the azo-BSA ${ }_{\text {ox }}$ derivative, as follows: Total extract ( $200 \mu \mathrm{g}$ of total protein) was incubated for $2 \mathrm{~h}$ at $37^{\circ} \mathrm{C}$, followed by protein precipitation with $20 \%$ TCA and centrifugation. The supernatants were collected for absorbance measurements at $412 \mathrm{~nm}$. When specified, $1 \mathrm{mg}$ of the total cellular extracts was utilized to immunoprecipitate the 20 S using anti-FLAG Sepharose resin [23]. After a 2-h incubation, the resin was washed 3 times with standard buffer containing $150 \mathrm{mM} \mathrm{NaCl}$. After washing, the samples were resuspended in standard buffer and incubated in the presence of azo-BSA $A_{\text {ox }}$ for $2 \mathrm{~h}$ at $37^{\circ} \mathrm{C}$ followed by centrifugation, and the supernatants were collected for absorbance determinations. The cell extracts were also assayed after immune-depletion of the $20 \mathrm{~S}$ and are representative of the cellular hydrolytic ability in the 
absence of the 20S. Azo-BSA was oxidized by incubation of the azo-modified BSA in the presence of $5 \mathrm{mM} \mathrm{H}_{2} \mathrm{O}_{2}$ for $30 \mathrm{~min}$ at room temperature and the remaining $\mathrm{H}_{2} \mathrm{O}_{2}$ was removed by cycles of filtration and redilution through YM-10 micro-filters (Millipore).

\section{Negative staining of the 20S particles using TEM}

TEM quantitative analyses of the purified 20S preparations were manually performed by counting the frequencies of the open or closed structures from proteasomal populations that were obtained from two independent preparations of both growth conditions in glucose- and glycerol/ethanol-containing media. The counting was performed on 100 panels (50-60 core particles in each panel) from each preparation. The possibility of saturated images was excluded because the microscope was operated under similar light conditions and many of the images that were obtained contained both the closed and open conformations.

\section{Results}

20 S proteasome S-glutathionylation is determined by yeast cell growth conditions

In the present work, $S$. cerevisiae cells were grown to the stationary phase in the presence of two different carbon sources, glucose (Glu) and glycerol/ethanol (Gly), to obtain distinct intracellular redox conditions. In the presence of glucose (Glu), fermentative conditions were achieved, with the repression of the expression of antioxidant defense-related genes via catabolite repression [25-27]. In contrast, cells grown in the presence of glycerol/ethanol (Gly) consumed higher levels of $\mathrm{O}_{2}$ via the mitochondrial respiratory chain, which was accompanied by the increased production of reactive oxygen species, but also with increased antioxidant defense activity. Therefore, the conditions of growth in the presence of glucose or glycerol/ethanol adopted in the present work do not represent same steps of stationary phase (Suppl. Data Fig. S1) but they are representative of diverse intracellular redox conditions, as shown below.

The 20S was isolated from these cells and subjected to 2-D PAGE followed by an immunoblot analysis with anti-GSH antibody. Fig. $1 \mathrm{~A}$ and $\mathrm{B}$ represent the 2-DE pattern of the $20 \mathrm{~S}$ stained by Coomassie Blue, whose subunits were previously identified using Maldi-TOF analysis [15, Suppl. Data Fig.S2]. The anti-GSH immunoblotting revealed intense labeling of the $\alpha 5$ subunit of the $20 \mathrm{~S}$ that was purified from cells grown in glucose-containing medium (Fig. 1C). Remarkably, distinct labeling was detected in $20 \mathrm{~S}$ preparations from cells grown in glycerol/ethanol (Fig. 1D). Later preparations displayed discrete labeling probably of $\alpha 1$ or of $\beta 7$ subunits, which were not detected in the $20 \mathrm{~S}$ that had been extracted from cells grown either in synthetic medium containing glucose (Fig. 1C) or YPD [15]. Both preparations were incubated with glutaredoxin 2 (Grx2). As previously described [21], this oxidoreductase provoked deglutathionylation of the 20S, as revealed using 2-D PAGE followed by anti-GSH immunolabeling (Fig. 1E and F). As expected, $\alpha 5$ labeling after Grx2 treatment was significantly decreased (Fig. 1E) when compared to that shown in Fig. 1C, whereas S-glutathionylation seen in Fig. 1E, completely disappeared (Fig. 1F). The $\alpha 5$-subunit S-glutathionylation of proteasome purified from cells grown in synthetic medium containing glucose was also confirmed with an anti-S-glutathionylated a5-C76 antibody (Suppl. Data Fig. S3).

S-glutathionylation of the $\alpha 5$ subunit of the $20 \mathrm{~S}$ is related to gate opening [15]. Therefore, gate status in 20S preparations was analyzed using TEM. In these experiments, we observed that $70 \pm 2 \%$ of the 20 S that was purified from cells that had been grown

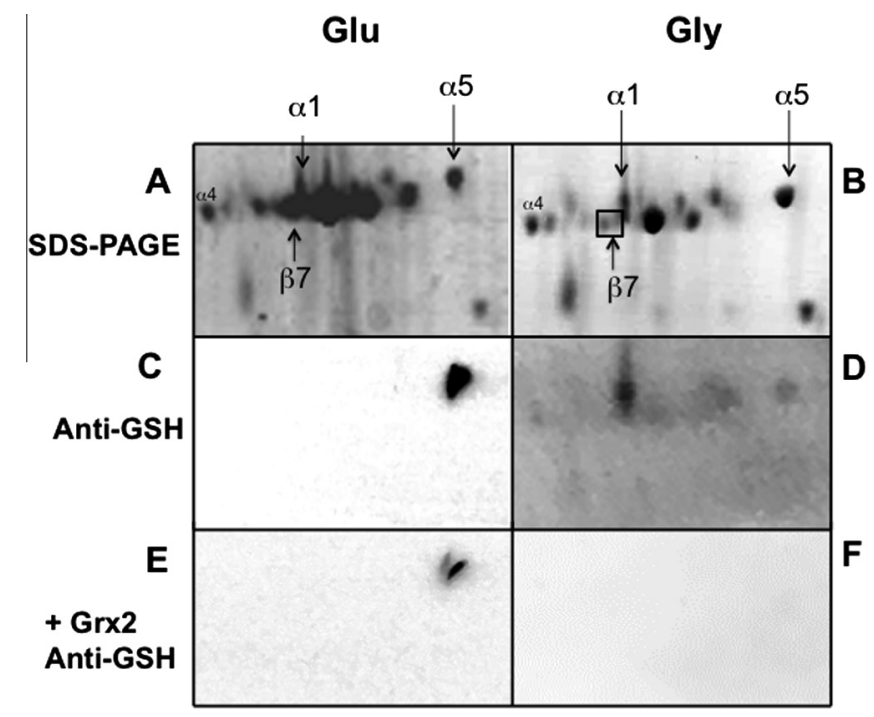

Fig. 1. (A) 20 S proteasomal subunits that were separated by 2-D gel electrophoresis from yeast cells that were grown to the stationary phase using glucose and glycerol/ ethanol as carbon sources. (A and B) show the representative 2-D PAGEs of the 20S $(30 \mu \mathrm{g})$ that was purified from yeast cells that had been grown in glucose $(\mathrm{Glu})$ - and glycerol/ethanol (Gly)-containing media and stained with Coomassie blue. The $\mathrm{pH}$ range was 4-7 from left to right. The subunits, as indicated, were identified using Maldi-Tof analyses (Suppl. Data Fig. S2). ( $C$ and D) represent the results of the western blot analyses of the same $20 \mathrm{~S}$ preparations using the anti-GSH antibody. (E and F) display these same preparations after incubation for 30 min with Grx2 $(60 \mu \mathrm{g})$, as described in the "Experimental procedures" section, prior to anti-GSH labeling. The $\alpha 5$-subunit, as indicated ( $\mathrm{C}$ and $\mathrm{E}$ ), was deduced by superposing membranes and 2D-gels.

in glucose was in the open gate conformation (Fig. 2A) in contrast to $15 \pm 1 \%$ found in cells grown in glycerol/ethanol (Fig. 2B). To demonstrate that the open proteasomal conformation is related to S-glutathionylation-mediated a5 subunit modification, the $20 \mathrm{~S}$ samples obtained from cells grown in glucose were treated with $10 \mathrm{mM}$ DTT, a sulfhydryl-reductant, followed by TEM analyses. The frequency of the open conformation after DTT treatment decreased to $30 \%$, whereas prior to treatment, it had represented $70 \%$ of the total structures examined.

Whether $\alpha 1$ - or $\beta 7$-subunit is S-glutathionylated in 20 S purified from cells grown into glycerol-containing medium is under investigation in our lab. In any case, these posttranslational modifications are most likely not related to gating regulation, as their redox modification were not observed in any preparation of the $20 \mathrm{~S}$ obtained from cells that had been grown in glucose. In these cells, S-glutathionylation of the $\alpha 5$-subunit was clearly related to the increased open gate conformation [15 and present results].

Intracellular reductive ability and oxidative protein damage are dependent upon yeast growth conditions

To correlate the intracellular reductive capability with proteasomal S-glutathionylation and proteasomal gate opening, we examined a series of parameters related to mitochondrial and redox metabolism. Although the total glutathione levels were not found to significantly differ between the two growth conditions, the GSH/GSSG ratio in the cells grown in Gly-containing medium was at least 2-fold the ratio found in cells grown in Glu-containing medium (Table 1), indicating that in the absence of catabolic repression, yeast cells displayed more reductive conditions.

As expected for respiratory conditions, the cells that had been grown in the presence of glycerol/ethanol consumed approximately 4 -fold more oxygen than the cells that had been grown in the presence of glucose (Table 1 ). Moreover, the cellular ability 
Glu

A

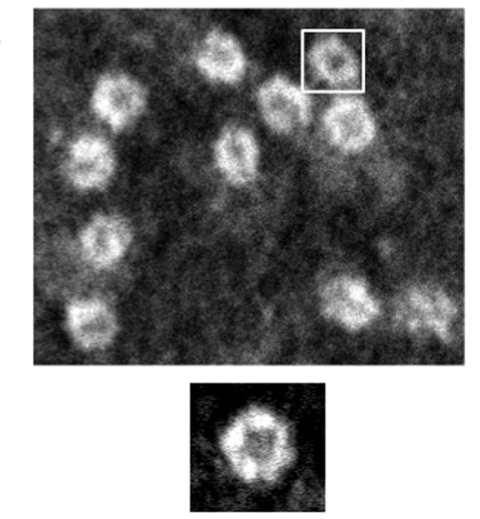

Gly

B
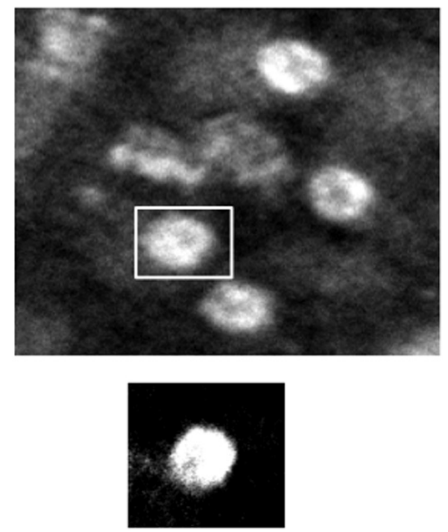

Fig. 2. Transmission electron microscopy (TEM) of 20S preparations that were purified from yeast cells grown to the stationary phase using glucose and glycerol/ethanol as carbon sources. The images shown are representative of the top views of the 20 S purified from yeast cells that had been grown in (A) glucose- and (B) glycerol/ethanolcontaining media. The structures marked by squares are highlighted below each panel.

to remove $\mathrm{H}_{2} \mathrm{O}_{2}$ was found to be approximately 12 -fold higher under these conditions (Table 1 ), in accordance with the higher levels of antioxidant enzymes that were anticipated in the absence of repression by glucose [16].

In addition, we determined the protein levels of distinct enzymatic antioxidant pathways. Cytoplasmic Trr1, which maintains Trxs in the reduced form, and Grx2 concentrations were evaluated (Fig. 3). Based on our previous data, cytosolic Trxs and Grx2 were hypothesized to play important roles in keeping the 20S deglutathionylated [21]. Trx3 was also evaluated because it is representative of mitochondrial metabolism. The increased pool of Trx3, in combination with increased oxygen consumption, could also be considered to be a parameter that is associated with the expected increase in mitochondrial biogenesis and oxidative phosphorylation activity in cells grown in medium containing glycerol/ethanol (Fig. 3 and Table 1). The expression of Grx2 was also measured using RT-PCR and was found to be twofold higher in Gly cells as compared to Glu (Suppl. Data Fig. S4), corroborating the elevated levels of Grx2 that were observed using western blotting (Fig. 3).

Next, the levels of oxidative protein damage were evaluated by measuring the carbonyl protein levels [28] because carbonyl proteins have been described to be substrates for the 20S [5]. A comparatively increased pool of carbonylated proteins was detected in cells grown in Gly-containing medium (Fig. 4A, Anti-DNP), which represented an apparent contrast, given the fact that those cells displayed higher reductive properties (Table 1) and increased levels of antioxidant defense enzymes (Fig. 3). Therefore, we hypothesized that the proteasomal degradation of oxidized proteins would be higher in cells grown in Glu, according to the gate conformation status.

\section{Table 1}

Redox parameters in yeast cells grown using glucose and glycerol/ethanol as carbon sources during the stationary phase. The cells were grown to the stationary phase in synthetic medium containing glucose or glycerol/ethanol, as described in the "Materials and methods" section.

\begin{tabular}{lcc}
\hline & Glucose & Glycerol \\
\hline GSH/GSSG & $40 \pm 7$ & $91.5 \pm 15^{*}$ \\
Total GSH ( $\mu$ moles/g of wet pellet) & $7 \pm 2$ & $9 \pm 1.5$ \\
$\mathrm{H}_{2} \mathrm{O}_{2}$ removal activity (nmoles/ $\mu$ g of cellular & $1.5 \pm 0.05$ & $20 \pm 0.5^{*}$ \\
$\quad$ protein) & $2.5 \pm 0.1$ & $9.5 \pm 0.15^{* *}$ \\
Oxygen consumption ( $\mu$ moles/min) & \\
\hline
\end{tabular}

All results are displayed as the means \pm SD of 3-4 independent experiments. $p<0.00027$.

$p<0.025$.
To establish a correlation with proteasomal S-glutathionylation, the total pool of S-glutathionylated proteins was also evaluated. As depicted in Fig. 4B (Anti-GSH), higher levels of S-glutathionylated proteins were found in the cells grown in Glu, which was in agreement with the $20 \mathrm{~S}$ S-glutathionylation that was observed under the same growth conditions (Fig. 1), as well as with a lower reductive capability (Table 1 ). Notably, the levels of protein carbonylation (Fig. 4A) were not found to be positively correlated with S-glutathionylation. This observation is aligned with our hypothesis that protein S-glutathionylation is associated with the mild loss of intracellular reductive ability, and likely indicates that this process plays a regulatory and protective role, which may mediate the degradation of oxidized proteins by the S-glutathionylated 20S. As demonstrated above (Fig. 3), relevant deglutathionylases were also present in higher amounts in cells grown in Gly, corroborating the decreased levels of S-glutathiolated proteins in such condition (Fig. 4B).

Taken together, these data indicated that intracellular reductive parameters (GSH/GSSG ratio, GRX2 expression, Grx2, Trx3 and Trr1 levels, and the ability to remove $\mathrm{H}_{2} \mathrm{O}_{2}$ ) were found to be inversely correlated with proteasome S-glutathionylation, indicating that when cells are grown in Gly-containing medium, the ability of the $20 \mathrm{~S}$ to degrade oxidized proteins is inhibited (the gate is closed), leading to the accumulation of carbonylated proteins.

\section{Basal conditions for the degradation of poly-ubiquitinylated proteins}

The overall levels of ubiquitinylated proteins, and the concentrations of the 20S and 19S proteasomal units, were also evaluated under both growth conditions. While 20S concentrations were not significantly altered under either condition (Fig. 5, Anti-20S and Suppl. Data Fig. S4), the concentrations of the 19S unit were 35\% higher in the cells that had been grown in the presence of Gly (Fig. 5, Anti-19S). The lower levels of poly-ubiquitinylated proteins (Fig. 5, Anti-ubiquitin) in the cells that had been grown in the presence of Gly were consistent with the higher levels of the 26S, which is capable of degrading such modified polypeptides. However, we cannot rule out the possibility of decreased activity of proteins responsible for the poly-ubiquitinylation process (E1-E3) that would imply on reduced levels of poly-ubiquitinylated proteins. The mRNA levels corresponding to a subunit of the $20 \mathrm{~S}$ (PRE2, the gene encoding the $\beta 5$ catalytic subunit) were also evaluated using RT-PCR. According to these results, PRE2 expression did not significantly vary under either condition (Suppl. Data Fig. S4), though a discrete increase in its expression was observed 


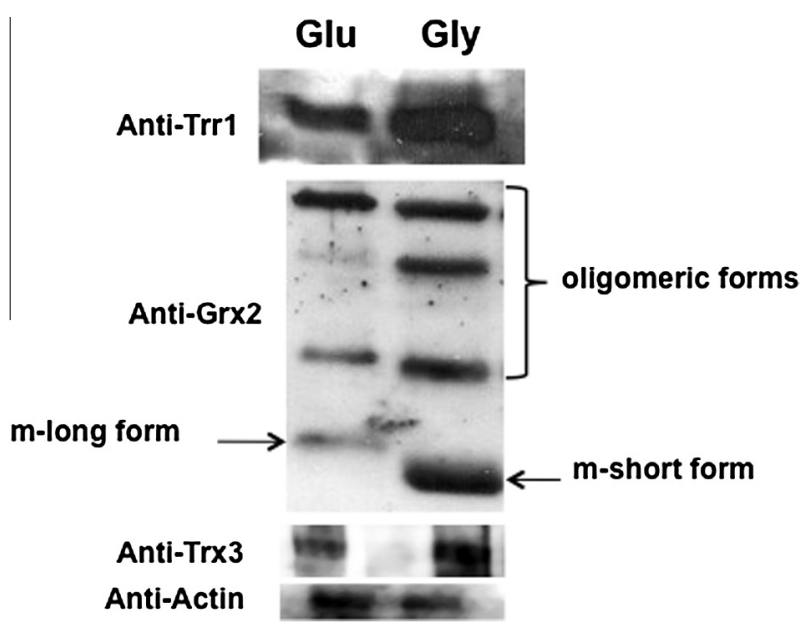

Fig. 3. The oxidoreductase systems of yeast cells grown to the stationary phase using glucose and glycerol/ethanol as carbon sources. Total cellular extracts (20$50 \mu \mathrm{g}$ protein) from cells that had been grown to the stationary phase in glucose(Glu) or glycerol/ethanol-containing media (Gly) were analyzed using immunoblotting. All the results shown were obtained from samples of the same cellular extract and are representative of three independent experiments. Trr1, cytosolic thioredoxin reductase; $\operatorname{Tr} \times 3$, mitochondrial thioredoxin and Grx2, mitochondrial long- and short-forms of glutaredoxin 2 ( $m$-long form and $m$-short form, respectively; [21]). Sample of the anti-actin immunoblotting, utilized as a loading control for the preparations, was taken from the same cellular extract.

\section{A}

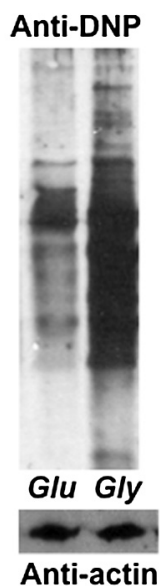

\section{B}

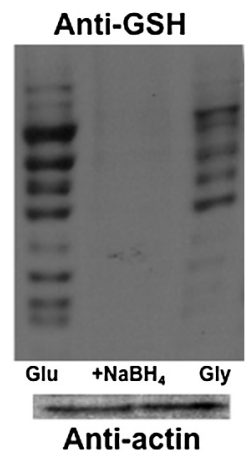

Anti-actin
Fig. 4. Immunoblotting analyses of the carbonylated and S-glutathiolated protein pool of yeast cells grown to the stationary phase using glucose and glycerol/ethanol as carbon sources. (A) Yeast extracts that were obtained from cells that had been grown to the stationary phase in glucose- $(\mathrm{Glu})$ or glycerol/ethanol-containing media (Gly) were reacted with $5 \mathrm{mM}$ DNPH. After $\mathrm{pH}$ neutralization, the samples $(20 \mu \mathrm{g})$ were subjected to $10 \%$ SDS-PAGE and transferred to a nitrocellulose membrane, followed by blotting against anti-DNP. (B) Extracts $(50 \mu \mathrm{g})$ that were obtained from the same cellular growth conditions that were described above from independent experiments were subjected to $10 \%$ SDS-PAGE and transferred to a nitrocellulose membrane, followed by blotting against anti-GSH. $+\mathrm{NaBH}_{4}$ refers to the samples that were obtained from cells that had been grown in glucose $(\mathrm{Glu})$ and were treated with $1 \mathrm{mM} \mathrm{NaBH}_{4}$. These samples served as a control for anti-GSH specificity. Samples of the anti-actin immunoblottings shown were taken from the same cellular extracts utilized for the anti-DNP and anti-GSH analyses.

in cells grown in the presence of glucose (not statistically significant). The importance of the inter-conversion between proteasomal conformations is still a poorly studied process. Recently, uncoupling between the 20S core particle and the 19S regulatory unit was described [10,29], and the augmented expression of the $20 \mathrm{~S}$ unit [30] was observed to be a cellular adaptation to oxidative stress. Our results indicated that the free $20 \mathrm{~S}$ is prevalent in cells grown in Glu-containing medium, whereas the $26 \mathrm{~S}$ is more abundant in cells grown in Gly-containing medium though these conditions are not related to an acute production of oxidative imbalance. Instead, the conditions assayed in the present work are probably an adaptive response to oxidative stress.

Degradation of oxidized BSA by the 20S redox forms

As previously mentioned, the $20 \mathrm{~S}$ is the primary proteolytic system responsible for the degradation of oxidized proteins [31]. Therefore, we investigated the proteolytic ability of the 20S, which was purified from cells that were grown under both growth conditions, to degrade oxidized proteins. As expected based on our previous results, the proteolysis rates of oxidized albumin $\left(\mathrm{BSA}_{\mathrm{ox}}\right)$ were $55 \%$ higher in the Glu-derived extracts than in the Gly-derived extracts (Table 2, first column). Proteolysis rates were evaluated by incubating the samples with azoBSA $\mathrm{ox}_{\mathrm{ox}}$. To unequivocally attribute these activities to proteasomal particles, the $20 \mathrm{~S}$

A

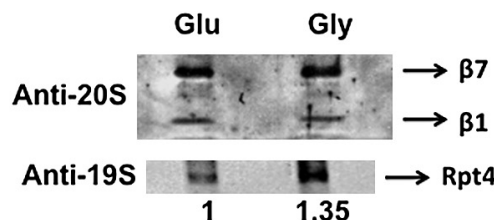

Anti-actin =

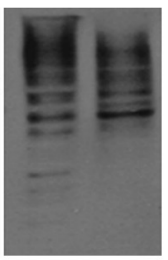

Anti-ubiquitin

B

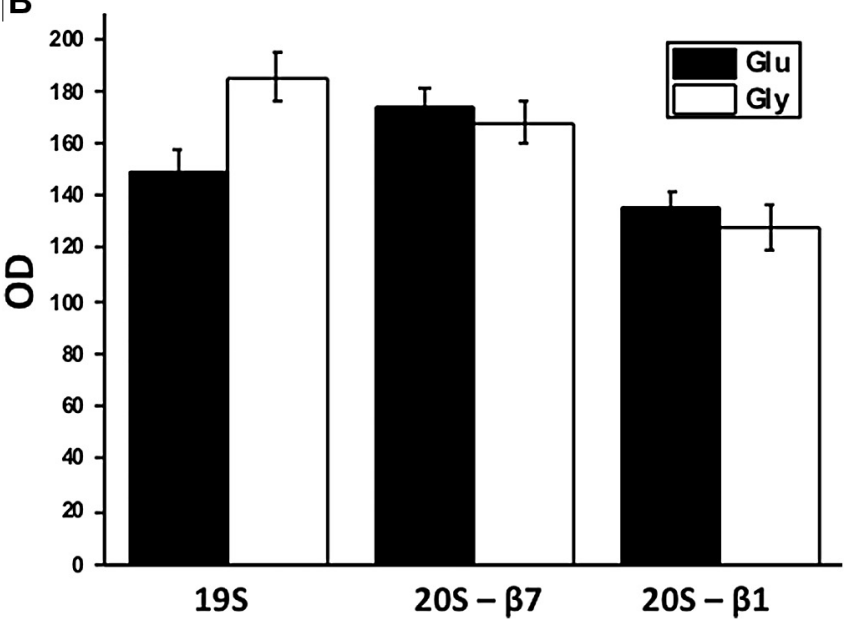

Fig. 5. The levels of the proteasomal subunits (19S and 20S) and the pool of ubiquitylated proteins in yeast cells grown to the stationary phase using glucose and glycerol/ethanol as carbon sources. (A) Yeast extracts (50 $\mu$ g total protein) were obtained from cells that were grown to the stationary phase in glucose- (Glu) or glycerol/ethanol-containing media (Gly) and were immunoblotted, as shown. The proteasomal concentration was determined by immunoblotting against the $\beta 7$ - and $\beta 1-20$ S subunits of the catalytic core, and the Rpt 4 subunit of the19S regulatory particle. The total levels of ubiquitylated proteins were assessed using immunoblotting with anti-Ub. Anti-actin immunoblotting was performed as a loading control and is displayed here. All samples for the immunoblottings shown were taken from the same cellular extracts (B) The values that are shown in the plot are reported as the relative optic density (OD) of the blottings shown in $(A)$ and normalized by the anti-actin immunoblotting. The results are expressed as the means \pm SD of 3 independent experiments. 
Table 2

Proteolytic abilities of yeast cells. Total extracts of cells that had been grown in glucose (Glu)- and glycerol/ethanol (Gly)-containing media were utilized to evaluate the

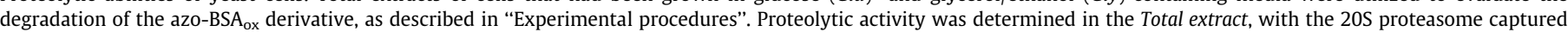
onto anti-FLAG resin (20S) and in the total protein extract of the immune-depleted $20 \mathrm{~S}$ (third column). Therefore, these extracts are representative of the cellular hydrolytic ability in the absence of the 20S. The 20S proteasome was recovered from the anti-FLAG Sepharose resin and was subjected to SDS-PAGE, where it served as a control for the 20S concentration in the hydrolytic assay (Suppl. Data, Fig. 3S).

\begin{tabular}{llcl}
\hline & Total extract $\left(\mathrm{A}_{412} / \mathrm{mg}\right.$ of total protein $)$ & $20 \mathrm{~S}^{1}\left(\mathrm{~A}_{412}\right)$ & Total extract after removal of the 20S $\left(\mathrm{A}_{412} / \mathrm{mg}\right.$ of total protein $)$ \\
\hline Gly & $0.125 \pm 0.010$ & $1.0 \pm 0.1$ & $0.063 \pm 0.005$ \\
Glu & $0.195 \pm 0.015^{*}$ & $3.50 \pm 0.25^{* *}$ & $0.065 \pm 0.010$ \\
\hline
\end{tabular}

The results are expressed as the means \pm SD of three independent experiments.

1 The results were calculated by setting the determined minor absorbance (Gly samples) to 1 after considering the total $20 \mathrm{~S}$ levels in both samples to be identical, as shown in Suppl. Data (Fig. 3S).

$p<0.003$ (ANOVA).

$p<0.000043$ (ANOVA)

was immobilized on anti-FLAG Sepharose resin. Again, the proteolysis rates were increased in anti-FLAG 20S-isolated preparations $(3.5 \times)$ from cells that had been grown in the presence of Glu in comparison with similar preparations that were grown in the presence of Gly (Table 2, second column). Finally, the proteolytic activities in the proteasome immune-depleted extracts were determined to test their ability to degrade oxidized $\mathrm{BSA}_{\mathrm{ox}}$ (Table 2, third column). As predicted, the proteolysis rates did not differ between the samples. These results unequivocally indicated that higher rates of protein degradation by the $20 \mathrm{~S}$ core particle occurred when the cells were grown in Glu-containing medium, which was likely the result of $\alpha 5$-subunit S-glutathionylation and gate opening.

\section{Discussion}

The yeast cell is an interesting model for performing redox metabolism studies because its intracellular redox state can be manipulated according to the growth phase and the carbon source. Glucose is thought to repress the expression of many genes related to mitochondrial biogenesis and antioxidant defenses [32]. Thus, the yeast cell represents an important physiological model for the investigation of signaling and regulation by redox mechanisms.

Small number of Cys residues of the 20S is redox modulated inside cells [15]. Indeed, S-glutathionylation of two Cys residues on the $\alpha 5$ subunit correlates with the opening of the catalytic chamber, thereby facilitating protein entrance, as evidenced by the increased degradation of oxidized proteins. The results of the present study indicated that the increased breakdown of oxidized proteins in less reductive environments is consistent with the idea of an adaptive response to oxidative stress.

Interestingly, peptidase activities of the $20 \mathrm{~S}$ are decreased when the $20 \mathrm{~S}$ is S-glutathionylated $(21,23,33)$. Accordingly, in the present work we found that the $20 \mathrm{~S}$ chymotrypsin-like activity was 5 -fold increased in $20 \mathrm{~S}$ samples purified from cells grown in glycerol/ethanol medium when compared to samples grown in glucose (Table 2S). This apparently is in contradiction with the fact that S-glutathionylated $20 \mathrm{~S}$ is more active in degrading oxidizing proteins. Same samples when incubated in the presence of Grx2 showed a significant increase $(90 \%)$ in the site-specific hydrolytic activity of the $20 \mathrm{~S}$ extracted from cells grown in glucose whereas same procedure rendered less than $10 \%$ of increased activity of the $20 \mathrm{~S}$ extracted from cells grown in glycerol/ethanol. This was expected since the content of S-glutathionylated 20S was higher in Glu than in Gly condition. We had observed before $[15,21]$ that S-glutathiolation promotes an allosteric effect to the proteasomal catalytic sites that inhibited the peptidase activities, as assessed by fluorogenic peptides. We hypothesize that the site-specific activity modification observed would determine the generation of diverse peptide fragments of same protein depending on proteasomal redox state. The nature of this allosteric effect remains to be identified but it is clearly distinct to the gate conformational effect.

S-glutathionylation is an important post-translational modification that is involved in redox cellular processes. The identification of proteasome S-glutathionylation in other organisms, such as plants, rats and humans [33-35], has provided important evidence of the ubiquitous relevance of this post-translational modification of the 20S. The increased degradation of oxidized proteins that is induced by $20 \mathrm{~S}$ S-glutathionylation may be important in all eukaryotic cells and may play a key role in antioxidant defense. 20S S-glutathionylation may also prevent the formation of insoluble protein aggregates, which is a cytotoxic hallmark of oxidative stress-dependent processes, such as aging and neurodegenerative diseases.

Oxidized proteins have been observed to activate the $20 \mathrm{~S}$ particle in vitro [30]. Indeed, convincing reports in the literature have demonstrated that the proteasomal degradation of oxidized proteins in mammalian cells is not dependent upon ubiquitin conjugation [7-10,29]. Wang and co-workers [10] demonstrated that the decoupling of the $20 \mathrm{~S}$ and its $19 \mathrm{~S}$ regulatory particle occurs in oxidative intracellular environments, favoring the degradation of oxidized proteins that are not poly-ubiquitylated. In agreement with this idea, a decreased ratio of the $19 \mathrm{~S}$ and $20 \mathrm{~S}$ particles were observed (Fig. 5) under glucose-containing medium during which oxidized azoBSA degradation was intensified (Table 2). The mechanism by which oxidized proteins are recognized and interact with the $20 \mathrm{~S}$ particle for degradation is still under investigation. The loss

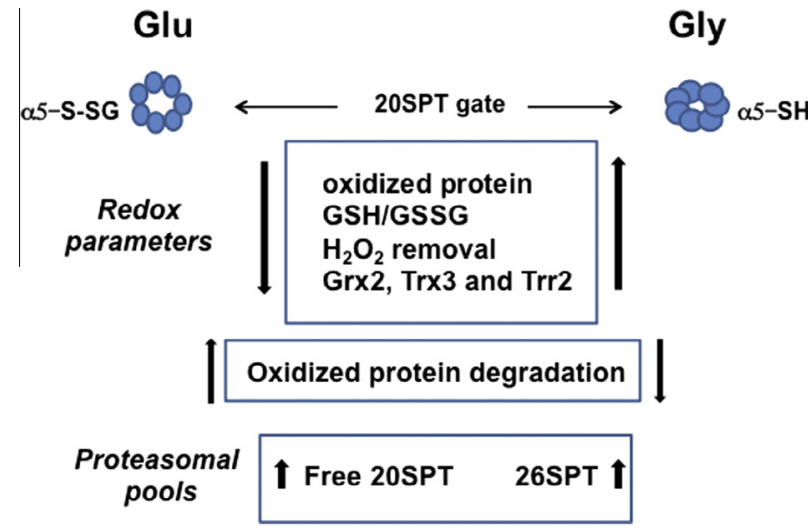

Fig. 6. The intracellular redox state and protein metabolism based on yeast growth conditions. The $\alpha 5$-subunit of the $20 \mathrm{~S}$ from cells that had been grown in the presence of glucose (Glu) was S-glutathionylated and the open conformation was the most prevalent conformation, while the closed form of the $20 \mathrm{~S}$ from cells grown in the presence of glycerol/ethanol (Gly) was the most prevalent conformation. The growth conditions determine the intracellular redox state of the 20S, which in turn modifies the rate of degradation of oxidized and poly-ubiquitinylated proteins. In addition, the proteasomal pools (the free $20 \mathrm{~S}$ and the 26S) are dependent upon the cellular redox state. 
of secondary structure, and thus increased surface hydrophobicity, is assumed to be the starting-point for proteasomal interaction $[14,36,37]$. We hypothesize that increased protein interaction with the $20 \mathrm{~S}$ proteasome via oxidation, together with the opening of the catalytic chamber by proteasomal S-glutathionylation and the disassembly of the $26 \mathrm{~S}$ proteasome, are concerted processes that allow cells to cope with the increased levels of oxidized proteins during the loss of reductive capability. In any case, it is possible that the free $20 \mathrm{~S}$ and the $26 \mathrm{~S}$ interact in a collaborative manner to resolve distinct stressful conditions. The discovery of thioredoxin-like proteins in the $19 \mathrm{~S}$ regulatory unit suggests that $26 \mathrm{~S}$ may also be subject to redox regulation by a still unknown mechanism [38-40]. Our proposal is that 20S and 26S would degrade proteins in distinct redox environments such as the scheme described in Fig. 6.

\section{Acknowledgments}

This work was supported by the Fundação de Amparo a Pesquisa do Estado de São Paulo (FAPESP; Grants 2011/23268-3 and $07 / 58147-6$ ) and the Instituto Nacional de Ciência,Tecnologia e Inovação de Processos Redox em BioMedicina (Redoxome; CNPq, FAPESP, CAPES).

\section{Appendix A. Supplementary data}

Supplementary data associated with this article can be found, in the online version, at http://dx.doi.org/10.1016/j.abb.2014.05.002.

\section{References}

[1] K.B. Hendil, S. Khan, K. Tanaka, Biochem. J. 332 (Pt. 3) (1998) 749-754.

[2] N. Tanahashi, Y. Murakami, Y. Minami, N. Shimbara, K.B. Hendil, K. Tanaka, J. Biol. Chem. 275 (19) (2000) 14336-14345.

[3] S.E. Babbitt, A. Kiss, A.E. Deffenbaugh, Y.H. Chang, E. Bailly, H. ErdjumentBromage, P. Tempst, T. Buranda, L.A. Sklar, J. Baumler, Cell 121 (4) (2005) 553565.

[4] K.J. Davies, A.L. Goldberg, J. Biol. Chem. 262 (17) (1987) 8227-8234.

[5] K.J. Davies, Biochimie 83 (3-4) (2001) 301-310.

6] T. Jung, B. Catalgol, T. Grune, Mol. Aspects Med. 30 (4) (2009) 191-296.

[7] T. Reinheckel, O. Ullrich, N. Sitte, T. Grune, Arch. Biochem. Biophys. 377 (1) (2000) 65-68.

[8] Y. Inai, M. Nishikimi, Arch. Biochem. Biophys. 404 (2) (2002) 279-284.

[9] R. Shringarpure, T. Grune, J. Mehlhase, K.J. Davies, J. Biol. Chem. 278 (1) (2003) $311-318$.
[10] X. Wang, J. Yen, P. Kaiser, L. Huang, Sci. Signal. 3 (151) (2010). ra88.

[11] S. Bar-Nun, M.H. Glickman, Biochim. Biophys. Acta 1823 (1) (2012) 67-82.

[12] D. Besh-Otschir, A. Helfrich, C. Enenkel, G. Consiglieri, M. Seeger, H.G. Holzhütter, B. Dahlmann, P.M. Kloetzel, Nat. Struct. Mol. Biol. 16 (2) (2009) 219-225.

[13] X. Li, G.N. Demartino, Biochem. J. 421 (3) (2009) 397-404.

[14] J.M. Baugh, E.G. Viktorova, E.V. Pilipenko, J. Mol. Biol. 386 (3) (2009) 814-827.

[15] G.M. Silva, L.E. Netto, V. Simões, L.F. Santos, F.C. Gozzo, M.A. Demasi, C.L. Oliveira, R.N. Bicev, C.F. Klitzke, M.C. Sogayar, M. Demasi, Antioxid. Redox Signal. 16 (11) (2012) 1183-1194.

[16] L.E. Netto, M.A. de Oliveira, G. Monteiro, A.P. Demasi, J.R. Cussiol, K.F. Discola, M. Demasi, G.M. Silva, S.V. Alves, V.G. Faria, B.B. Horta, Comp. Biochem. Physiol. C Toxicol. Pharmacol. 146 (1-2) (2007) 180-193.

[17] N. Brandes, S. Schmitt, U. Jakob, Antioxid. Redox Signal. 11 (5) (2009) 9971014.

[18] M.M. Gallogly, J.J. Mieyal, Curr. Opin. Pharmacol. 7 (4) (2007) 381-391.

[19] I. Dalle-Donne, R. Rossi, G. Colombo, D. Giustarini, A. Milzani, Trends Biochem. Sci. 34 (2) (2009) 85-96.

[20] B.G. Hill, A. Bhatnagar, J. Mol. Cell. Cardiol. 52 (3) (2012) 559-567.

[21] G.M. Silva, L.E. Netto, K.F. Discola, G.M. Piassa-Filho, D.C. Pimenta, J.A. Barcena, M. Demasi, FEBS J. 275 (11) (2008) 2942-2955.

[22] R. Verma, S. Chen, R. Feldman, D. Schieltz, J. Yates, J. Dohmen, R.J. Deshaies, Mol. Biol. Cell 11 (10) (2000) 3425-3439.

[23] M. Demasi, G.M. Silva, L.E. Netto, J. Biol. Chem. 278 (1) (2003) 679-685.

[24] G. Monteiro, A.J. Kowaltowski, M.H. Barros, L.E. Netto, Arch. Biochem. Biophys. 425 (1) (2004) 14-24.

[25] W.A. Wilson, S.A. Hawley, D.G. Hardie, Curr. Biol. 6 (11) (1996) 1426-1434.

[26] J.L. DeRisi, V.R. Iyer, P.O. Brown, Science 278 (5338) (1997) 680-686.

[27] J.M. Gancedo, Microbiol. Mol. Biol. Rev. 62 (2) (1998) 334-361.

[28] R.L. Levine, J.A. Williams, E.R. Stadtman, E. Shacter, Methods Enzymol. 233 (1994) 346-357.

[29] T. Grune, B. Catalgol, A. Licht, G. Ermak, A.M. Pickering, J.K. Ngo, K.J. Davies, Free Radic. Biol. Med. 51 (7) (2011) 1355-1364.

[30] A.M. Pickering, L. Vojtovich, J. Tower, K.J. Davies, Free Radic. Biol. Med. 55 (2013) 109-118.

[31] A. Höhn, J. König, T. Grune, J. Proteomics (2013) [Epub ahead of print].

[32] D.J. Jamieson, Yeast 14 (16) (1998) 1511-1527.

[33] M. Demasi, R. Shringarpure, K.J. Davies, Arch. Biochem. Biophys. 389 (2) (2001) $254-263$.

[34] D.P. Dixon, M. Skipsey, N.M. Grundy, R. Edwards, Plant Physiol. 138 (4) (2005) 2233-2244.

[35] S.K. Niture, C.S. Velu, N.I. Bailey, K.S. Srivenugopal, Arch. Biochem. Biophys. 444 (2) (2005) 174-184.

[36] R.E. Pacifici, Y. Kono, KJ. Davies, J. Biol. Chem. 268 (21) (1993) 15405-15411.

[37] D.A. Ferrington, H. Sun, K.K. Murray, J. Costa, T.D. Williams, D.J. Bigelow, T.C. Squier, J. Biol. Chem. 276 (2) (2001) 937-943.

[38] R.L. Wiseman, K.T. Chin, C.M. Haynes, A. Stanhill, C.F. Xu, A. Roguev, N.J. Krogan, T.A. Neubert, D. Ron, J. Biol. Chem. 284 (22) (2009) 15233-15245.

[39] K.M. Andersen, L. Madsen, S. Prag, A.H. Johnsen, C.A. Semple, K.B. Hendil, R. Hartmann-Petersen, J. Biol. Chem. 284 (22) (2009) 15246-15254.

[40] K.M. Andersen, C. Jensen, F. Kriegenburg, A.M. Lauridsen, C. Gordon, R. Hartmann-Petersen, Antioxid. Redox Signal. 14 (9) (2011) 1601-1608. 